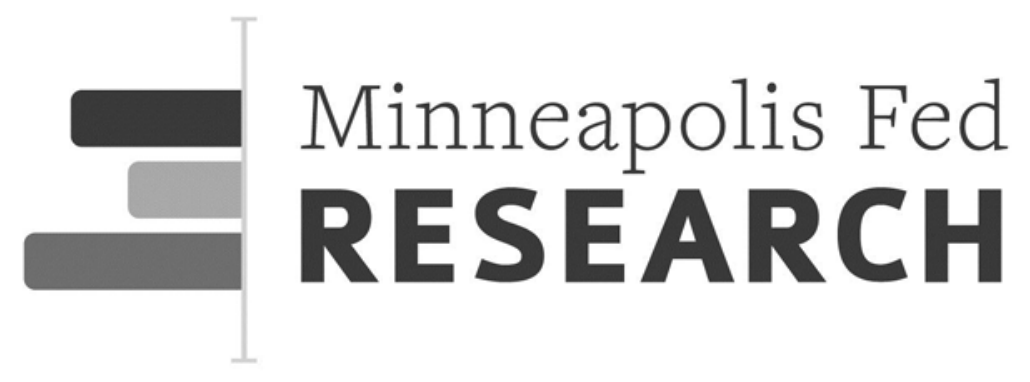

Online Appendix for:

International Evidence on Long-Run Money Demand

Luca Benati

University of Bern

Robert E. Lucas, Jr.

University of Chicago

Juan-Pablo Nicolini

Federal Reserve Bank of Minneapolis

Warren Weber

University of South Carolina, Bank of Canada, and

Federal Reserve Bank of Atlanta

Working Paper 738

February 2017

Keywords: Long-run money demand; Cointegration

JEL classification: E41, C32

The views expressed herein are those of the authors and not necessarily those of the Federal Reserve Bank of Minneapolis or the Federal Reserve System. 


\title{
Online appendix for: International Evidence on Long-Run Money Demand
}

\author{
Luca Benati \\ University of Bern* \\ Robert E. Lucas, Jr. \\ University of Chicago ${ }^{\dagger}$ \\ Juan-Pablo Nicolini \\ Federal Reserve Bank \\ of Minneapolis ${ }^{\ddagger}$ \\ Warren Weber \\ University of South Carolina, Bank of Canada and \\ Federal Reserve Bank of Atlanta ${ }^{\S}$
}

\section{A The Data}

Here follows a detailed description of the data set. Almost all of the data used in this paper are from original sources. Specifically, they are from either $(i)$ original hard copy (books or, in the case of West Germany's $M_{1}$, scanned PDFs of the Bundesbank's Monthly Reports, which are available from the Bundesbank's website), in which case we have entered the data manually into Excel; or $(i i)$ central banks' or national statistical agencies websites (these data are typically available in either Excel or simple text format). The few exceptions to this are discussed below. In those cases, we were not able to find the data we were looking for in original documents, and therefore we took them from either the International Monetary Fund's International Financial Statistics (henceforth, IMF and IFS, respectively) or the World Bank.

*Department of Economics, University of Bern, Schanzeneckstrasse 1, CH-3001, Bern, Switzerland. Email: luca.benati@vwi.unibe.ch

${ }^{\dagger}$ Department of Economics, University of Chicago, 1126 East 59th Street, Chicago, Illinois 60637, United States. Email: relucas@uchicago.edu

${ }^{\ddagger}$ Federal Reserve Bank of Minneapolis, 90 Hennepin Avenue, Minneapolis, MN 55401, United States. Email: juanpa@minneapolisfed.org

$\S$ Email: wew@webereconomics.com 


\section{A.1 Argentina}

With the single exception of an $M_{2}$ series available for the period 1884-1994, which is from the Rolnick-Weber (henceforth, RW) data set, all other series are from the Banco Central de la República Argentina (the central bank, henceforth, Banco Central). Specifically, two series for $M_{1}$ and $M_{3}$, available for the periods 1900-2004 and 18632004, respectively, are from Banco Central's Table 7.1.4 ( "Agregados Monetarios"). A series for a short-term nominal interest rate, available for the period 1821-2004, is from Banco Central's Table 7.1.4 ("Tasas activas"). Interestingly, among all of the countries we consider in this paper, Argentina is the only one that directly provides an estimate of (the inverse of) the velocity of circulation of monetary aggregates. Specifically, Banco Central's Table 7.1.4 provides the ratios between either $M_{1}$ and $M_{3}$ and nominal GDP (" $M_{1} \% \mathrm{PBI"} \mathrm{and} \mathrm{"} M_{3} \% \mathrm{PBI",} \mathrm{respectively;} \mathrm{"PBI"} \mathrm{is} \mathrm{the}$ Spanish acronym for GDP). The two sample periods are the same as for $M_{1}$ and $M_{3}$, respectively. Based on the ratio between $M_{1}$ and GDP, and the series for $M_{1}$, we then reconstructed a nominal GDP series.

\section{A.2 Australia}

An $M_{1}$ series for the period 1900-2014 has been constructed in the following way. An annual series for the period 1900-1973 has been kindly provided by Cathie Close of the Reserve Bank of Australia (henceforth, RBA). A monthly seasonally unadjusted series, available since 1975 , is from the RBA's website (" $M_{1}, \$$ billion, RBA, 42216 "; the series' acronym is DMAM1N), and it has been converted to the annual frequency by taking annual averages (since for the year 1975 the series is available from February, the average for that year has been computed for the period February-December). The missing observation for 1974 has been interpolated as in Bernanke, Gertler, and Watson (1997), using as interpolator series the IMF's IFS series labeled as "Money", which, over the periods of overlapping, closely comoves with both $M_{1}$ series. A 90day nominal interest rate for bank accepted bills and negotiable certificates of deposit is from the RBA's website ("90-day BABs/NCDs, Bank Accepted Bills/Negotiable Certificates of Deposit-90 days, Monthly, Original, Per cent, AFMA, 42156, FIRMMBAB90"). It is available since 1969. A series for nominal GDP, available since 1960, is from the Australian Bureau of Statistics ("Gross domestic product: Current prices; A2304617J; \$ Millions"). An alternative series for nominal GDP, available for the period 1870-2012, is from the website of the Global Price and Income History Group at the University of California at Davis, at: http://gpih.ucdavis.edu/. A series for the three-month discount rate for commercial banks is from Table 51 ("Australian Trading Banks, Interest and Lending Rates") of a publication of historical statistics from the Reserve Bank of Australia. This series is available for the period 1851-1943, but it has several missing observations, and we therefore use it uniquely for the scatterplot in Figure 1, whereas we do not use it for the econometrics. 


\section{A.3 Belgium}

An annual $M_{1}$ series ("Stock monétaire (milliards de francs)"), available for the period 1920-1990, is from the Séries rétrospectives, Statistiques 1920-1990 from Banque Nationale de Belgique (Belgium's central bank, henceforth $B N B$ ), Statistiques Economiques Belges 1980-1990. For the period 1991-1998, $M_{1}$ data are from the BNB's Bulletin Statistique. An annual series for nominal GDP ("Value Added at Market Prices in Current Prices, billion of francs"), available for the years 1920-1939 and 1946-1990 is from Smits, Woltjer, and Ma (2009). An annual series for the BNB's discount rate available for the period 1920-1990 is from the Séries rétrospectives, Statistiques 19201990 from the BNB's Statistiques Economiques Belges 1980-1990. For the period 1991-1998, the discount rate is from several issues of the BNB's Annual Report.

\section{A.4 Bolivia}

Series for nominal GDP, the GDP deflator, the monetary base, $M_{0}, M_{1}$, and a shortterm nominal interest rate, all available for the period 1980-2013, are from the Unidad de Analisis de Politicas Sociales y Economicas (Bolivia's national statistical agency, known as UDAPE for short).

\section{A.5 Brazil}

Series for nominal GDP, $M_{0}, M_{1}$, and GDP deflator inflation, all available for the period 1901-2000, are from IBGE's (the Brazilian Institute of Geography and Statistics) Estatisticas do Seculo $X X$ (Statistics of the XX Century). The URL is http://seculoxx.ibge.gov.br/economicas. A series for nominal GDP for the period 2000-2012 is also from IBGE. Series for $M_{0}$ and $M_{1}$ for the period 2000-2012 are from the Banco Central do Brasil (Brazil's central bank). A series for a short-term nominal interest rate for the period 1974-2012 is from the Banco Central do Brasil. Two series for a nominal government bond yield (period: 1901-1913 and 1929-1959) and the Banco Central do Brasil's discount rate (period: 1948-1989) are both from Homer and Sylla (2005)'s Table 81, pages 629-631.

\section{A.6 Canada}

An annual series for nominal GDP, available since 1870, has been constructed by linking the Urquhart series (available from Statistics Canada, which is Canada's national statistical agency), for the period 1870-1924; series 0380-0515, v96392559 (1.1) from Statistics Canada, for the period 1925-1980; and series 0384-0038, v62787311 (1.2.38) from Statistics Canada, for the period 1981-2013. A series for the GDP deflator available since 1870 is from Statistics Canada (the series' code is 3830027 , v55080518 (1.11)). A short-term interest rate for the period 1871-1907 (specifically, the "Montreal call loan rate") is from Furlong (2001). A series for the official discount rate, 
available since 1926, has been constructed as follows. Since 1934, when the Bank of Canada was created, it is simply the official bank rate ("Taux Officiel d'Escompte") from the Bank of Canada's website. Before that, we use the Advance Rate, which had been set by the Treasury Department for the discounting of bills, from Table 6.1 of Shearer and Clark (1984). To be precise, Shearer and Clark (1984) do not provide the actual time series for the Advance Rate, but rather the dates at which the rate had been changed (starting from August 22, 1914), together with the new value of the rate prevailing starting from that date. Based on this information, we constructed a daily series for the rate starting on January 1, 1915, via a straightforward MATLAB program, and we then converted the series to the annual frequency by taking annual averages. As for the later period, we use a series for the three-month Treasury bill rate, which has been constructed by linking the series from the Historical Statistics of Canada, available for the period 1934-1935, to the series "Treasury Bill Auction - Average Yields - 3 Month, Per cent / en pourcentage" from the Bank of Canada (Canada's central bank). Monthly series for $M_{0}, M_{1}$, and $M_{2}$ starting in January 1872 are from Metcalf, Redish, and Shearer (1996), and they have been extended as follows. As for $M_{0}$, we use the series from Metcalf et al. (1996) until December 1954. Then, starting from January 1955, we use the series labeled as "Monetary base (notes and coins in circulation, chartered bank and other Canadian Payments Association members' deposits with the Bank of Canada) (x 1,000,000)" from Statistics Canada. As for $M_{2}$, we use the series from Metcalf et al. (1996) until December 1967. Then, starting from January 1968, we use the series labeled as "M2 (net) (currency outside banks, chartered bank demand and notice deposits, chartered bank personal term deposits, adjustments to M2 (net), v37198" from Statistics Canada. Finally, as for $M_{1}$, we use the series from Metcalf et al. (1996) until December 1952; after that, we link it via splicing to the series labelled as "Currency and demand deposits, $M_{1}$ (x 1,000,000), v37213" until November 1981 from Statistics Canada; finally, from December 1981 until December 2006, we use the series from Statistics Canada labelled as " $M_{1}$ (net) (currency outside banks, chartered bank demand deposits, adjustments to $M_{1}$ (continuity adjustments and inter-bank demand deposits) (x 1,000,000), v37200". An important point to stress is that over the periods of overlapping, the three series are nearly-identical (up to a scale factor), which justifies their linking. On the other hand, for the period after December 2006, we were not able to find an $M_{1}$ series that could be reliably linked to the one we use for the period December 1981-December 2006 (over the last several decades, Canada's monetary aggregates have undergone a number of redefinitions, which complicates the task of constructing consistent longrun series for either of them). As a result, for the most recent period we have decided to consider another series that we consider in isolation (that is, without linking it to any other $M_{1}$ aggregate). The series is "M1B (gross) (currency outside banks, chartered bank chequable deposits, less inter-bank chequable deposits) (x 1,000,000), v41552787", which is available since January 1967 from Statistics Canada. Finally, we convert the monthly series to the annual frequency by taking simple annual averages. 


\section{A.7 Chile}

Annual series for nominal GDP, the GDP deflator, $M_{1}$, and $M_{2}$ are from Braun-Llona et al. (1998) for the period 1940-1995. As for the period 1996-2012, they are from the Banco Central de Chile, Chile's central bank (specifically, nominal GDP and the GDP deflator are from the Banco Central's Anuarios de Cuentas Nacionales, whereas $M_{1}$ and $M_{2}$ are from Banco Central's Base Monetaria y Agregados Monetarios Privados). A short-term nominal interest rate ("1-day interbank interest rate, financial system average (annual percentage)") from the Banco Central de Chile is available for the period 1940-1995. In order to extend our analysis to the present as much as possible, we therefore also consider, as an alternative measure of the opportunity cost of money, GDP deflator inflation.

\section{A.8 Colombia}

Data for Colombia have been kindly provided by David Perez Reyna. Annual series for nominal GDP, the monetary base, and a short-term nominal interest rate for the period 1905-2003 are from Junguito and Rincón (2007). As for the period 2004-2012, they are from Colombia's Ministerio de Hacienda y Credito Publico. Annual series for the monetary base, $M_{1}$, and $M_{3}$ for the period 1905-2012 are from the Banco de la Republica, Colombia's central bank.

\section{A.9 Denmark}

Long-run data for Denmark have been kindly provided by Kim Abildgren of Danmarks Nationalbank (the Danish Central Bank, henceforth, DNB). A series for nominal GDP (million kroner, current prices) is available for the period 1856-2012. A series for the $D N B$ 's lending rate (percent per annum) is available for the period 1819-2012. A quarterly series for $M_{2}$ is available for the period 1923Q1-2011Q4, and it has been converted to the annual frequency by taking annual averages. An annual series for $M_{1}$ for the period 1875-2012 has been constructed as follows. From the financial balance sheets of the central bank, of the central government, and of private commercial and savings banks (all available for the period 1875-2005), we have extracted three series for central bank currency, Treasury currency, and deposits at private commercial and savings banks. The $M_{1}$ aggregate has been constructed as the simple sum of the three series. Note that the series for deposits at private commercial and savings banks also includes long-term deposits and may therefore not be exactly comparable to the other $M_{1}$ series we use in this paper. Unfortunately, there is no way to eliminate this problem because the financial balance sheets of private commercial and savings banks do not possess an extent of disaggregation sufficient to allow us to uniquely focus on short-term deposits. We have performed two checks on the reliability of the $M_{1}$ aggregate we have constructed. First, we have compared it to the $M_{1}$ series from the OECD's Main Economic Indicators, which is available since 1970. Over the period of 
overlapping, the evolution of the two $M_{1}$ aggregates is very similar. Second, we have compared it to the annual $M_{1}$ series we constructed by taking annual averages of the monthly $M_{1}$ series from the DNB's website ("DNM1KOR"), which is available for the period January 1991-October 2013. Once again, over the period of overlapping, the evolution of the two $M_{1}$ aggregates is very similar, which provides some reassurance on the reliability of our long-run reconstructed series. Finally, we have linked the long-run reconstructed series to the DNB's one (available since 1991) by splicing.

\section{A.10 Finland}

Long-run monthly data for $M_{1}$ for the period January 1866-December 1985 have been generously provided by Tarmo Haavisto. The data come from his Ph.D. dissertation (see Haavisto (1992)) and have been converted to the annual frequency by taking simple annual averages. A series for Bank of Finland's monetary policy rate (labeled as the "Base rate"), available since January 1867, is from Suomen Pankki Finlands Bank, that is, Finland's central bank (henceforth, Suomen Pankki). To be precise, Suomen Pankki does not provide the actual time series for the base rate, but rather the dates at which the rate had been changed (starting from January 1, 1867), together with the new value of the base rate prevailing starting from that date. Based on this information, we constructed a daily series for the base rate starting on January 1, 1867, via a straightforward MATLAB program, and we then converted the series to the annual frequency by taking annual averages. Finally, annual series for nominal GDP, real GDP, and the GDP deflator, available since 1860, are from Finland's Historical Statistics, which are available from the web page of Statistics Finland, which is Finland's national statistical agency. (To be precise, from the homepage of Statistics Finland, look at Home $>$ Statistics $>$ National Accounts $>$ Annual national accounts > Tables.) Specifically, the nominal GDP series is B1GMHT ("Gross domestic product at current prices, 1860-1960, million. mk").

\section{A.11 France}

Annual series for nominal GDP, nominal $M_{1}$, and the short rate are all from SaintMarc (1983). Specifically, the series for nominal GDP is the Toutain Index from Annexe I: Revenu national, Produit Interieur Brut, pages 99-100 of Saint Marc (1983), and it is available for the period 1815-1913. The series for $M_{1}$ is from the table "VitesseRevenu, Vy, et taux de liquidite, TL", pages 74-75 of Saint Marc (1983), and it is available for the period 1807-1913. The series for the short rate is from Section 7, 'Evaluation des taux de l'interet', pages 93-96, of Saint Marc (1983), and it is available for the period 1807-1913. In our analysis, however, we focus on the period 1851-1913 because for the entire period 1820-1851, the short rate had been fixed at $4 \%$. 


\section{A.12 Germany}

\section{A.12.1 Germany under the Gold Standard}

An annual series for nominal GDP for the period 1876-1913 is from the RW data set. An annual series for $M_{1}$ for the period 1876-1923 has been reconstructed based on the disaggregated monetary data reported in the Bundesbank publication Bundesbank (1976), which has been kindly provided by Martin Mandler of the Bundesbank. An annual series for the central bank's monetary policy rate is from the NBER Historical Database. Specifically, the series is the "Official Bank Discount Rate for Germany" (acronym is M13015DEM156NNBR).

\section{A.12.2 West Germany}

Although data for post-WWII Germany are available, in principle, for the entire period 1950-1998, in the empirical work we have decided to only use data for West Germany for the period 1960-1989. The reason is that we are skeptical about the possibility of meaningfully linking the various series for nominal GDP in order to create a single series for the period 1950-1998 because $(i)$ before 1960, GDP data did not include West Berlin and the Saarland, which, in 1960, jointly accounted for about $6 \%$ of overall GDP; and $(i i)$ the reunification of 1990 created discontinuities in both GDP and $M_{1}$ (we thought the problem could be side-stepped by focusing on $M_{1}$ velocity, but in fact this series also seems to exhibit a discontinuity around the time of reunification). Entering into details, an annual series for the Bundesbank's monetary policy rate for the period 1949-1998 has been constructed by taking annual averages of the monthly series "BBK01.SU0112, Diskontsatz der Deutschen Bundesbank / Stand am Monatsende, \% p.a.", which is available from the Bundesbank's website. As for nominal GDP, the original annual series are from Germany's Federal Statistical Office, and they are available for the period 1950-1960 ("Gross domestic product at current prices, Former Territory of the Federal Republic excluding Berlin-West and Saarland"); 1960-1970 ("Gross domestic product at current prices, Former Territory of the Federal Republic"); and 1970-1991 ("Gross domestic product at current prices, Former Territory of the Federal Republic, (results of the revision 2005)"). There is also a fourth series available for reunified Germany, but, as we already mentioned, it cannot be meaningfully linked to the series for the period 1970-1991 because of the discontinuity induced by the 1990 reunification. The second and third series can be linked because the difference between them is uniquely due to changes in the accounting system, rather than to territorial redefinitions. Linking the first and second series, on the other hand, is problematic because, as previously mentioned, before 1960 GDP data did not include West Berlin and the Saarland. Our decision has been to ignore the first GDP series, and therefore to start the sample in 1960, for the following two reasons. First, the dimension of West Berlin and the Saarland was not negligible. The value taken by nominal GDP in 1960 according to the first and second 
series was equal to 146.04 and 154.77 , respectively, a difference equal to $6 \%$. Second, this problem might be ignored if we had good reasons to assume that, during those years, West Berlin and the Saarland's nominal GDP was growing exactly at the same rate as in the rest of Germany. This, however, is pretty much a heroic assumptionespecially for West Berlin. As a result, in the end we just decided to ignore the first series. Finally, turning to $M_{1}$, this turned out to be the single most excruciating piece of data collection in the entire enterprise (it took about one and a half days). German $M_{1}$ data, which are available at the monthly frequency since 1948, can only be recovered from the Bundesbank's original Monthly Reports, which are available in scanned form at the Bundesbank's website. So we did the following. We downloaded the scanned PDFs of the Monthly Reports, and we manually entered the data in Excel, one "chunk" (that is, one Monthly Report) at a time. An important point to notice is that German monetary aggregates are not revised, so that it is indeed possible to link the figures coming from successive issues of the Monthly Report (for example, that is also the case in the United States). With a few exceptions in 1940 and the early 1950 s, each report contains about one year to one year and a half of data. There are a few discontinuities in the series, but other than that, the overlapping portions coming from successive issues are identical (over the entire sample we noticed about four to five exceptions, which means that those months were revised, and in those cases we took the values coming from the most recent Monthly Report). The discontinuities were just level shifts: we checked the log-differences of the two series pertaining to each discontinuity, and they were nearly identical. So in the end we linked the various pieces coming from the different issues of the Monthly Report, thus obtaining a single monthly series for the period up to December 1998. Finally, we converted the series to the annual frequency by taking annual averages.

\section{A.13 Guatemala}

All of the data are from the Banco de Guatemala's website. A series for nominal GDP is available for the period 1950-2012. A series for $M_{1}$ ("M1 Medio CirculanteMillones de quetzales") is available for the period 1980-2014. A series for a nominal short rate ("Interest rate $1 /$ Domestic currency, passive") is available for the period 1980-2013.

\section{A.14 Hong Kong}

An annual series for nominal GDP for the period 1961-2012 is from the Hong Kong Monetary Authority's (henceforth, HKMA) website (the series is labeled as "Nominal GDP, HK\$ million, Table031: GDP and its main expenditure components at current market prices"). An annual series for $M_{1}$ for the period 1985-2014 is from the HKMA's website (the series is labeled as " $M_{1}$, Total,l HK\$"). An annual series for the $M_{1}$ for the period 1982-2014 is from the HKMA's website (the series is labeled as "Overnight 
rate, Table 6.3: Hong Kong Interbank Offered Rates").

\section{A.15 Japan}

Sources for Japanese data are as follows. A monthly series for the Bank of Japan's (henceforth, BoJ) discount rate, available since January 1883, is from the BoJ's longrun historical statistics, which are available at its website (the series is labeled as "BJ'MADR1M: The Basic Discount Rate and Basic Loan Rate"). Annual series for nominal GNP and $M_{1}$ for the period 1885-1940 are from Table 48 of Tamaki (1995). As for the period since 1955, data for nominal GDP and $M_{1}$ are as follows. Series for nominal and real GDP and the GDP deflator are from the Economic and Social Research Institute (henceforth, ESRI), Cabinet Office, Government of Japan. (The key URLs are http://www.stat.go.jp/english/data/chouki/03.htm and http://www.stat.go.jp/english/data/nenkan/1431-03.htm.) An important point to stress here is the following. For the period before 1970, ESRI only provides tables for gross domestic expenditure, rather than gross domestic product. However, over the period of overlapping (that is, 1970-1998), the relevant series coming from Table 3-1 ("Gross Domestic Expenditure (At Current Prices, At Constant Prices, Deflators) - 68SNA, Benchmark year $=1990$ (C.Y.1955-1998, F.Y.1955-1998), Value in billions of yen") and Table 3-3b ("3-3-b Gross Domestic Product Classified by Economic Activities (Medium Industry Group), (At Current Prices, At Constant Prices, Deflators) - 68SNA, Benchmark year $=1990$ (1970-1998), Value in billions of yen") are either numerically identical (in the case of nominal GDP) or numerically identical up to a scale factor (for the other two series). This means that - as should be expected based on just simple economic logic - the series that in Table 3-1 is labeled as "Gross Domestic Expenditure" (Column Y in the Excel spreadsheet 03-01.xls) is, in fact, nominal gross domestic product, and the same holds for its real counterpart and the deflator. As for $M_{1}$, a monthly series for the period January 1955December 2014 was constructed by linking, via splicing, the following thre series from the BoJ's website: MA'MAMS1EN01 ("(discontinued)_M1/Amounts Outstanding at End of Period/(Reference) Money Stock (Based on excluding Foreign Banks in Japan, etc., through March 1999)"); MA'MAMS3EN01 ("(discontinued)_M1/Amounts Outstanding at End of Period /(Reference) Money Stock (from April 1998 to March 2008)"); and MA'MAM1NEM3M1MO ("M1/Amounts Outstanding at End of Period/Money Stock"). An important point to stress is that, over the periods of overlapping, the series are essentially identical (up to a scale factor), which justifies their linking. Finally, the resulting monthly $M_{1}$ series was converted to the annual frequency by taking annual averages. 


\section{A.16 Korea}

A series for $M_{1}$ (" $M_{1}$, Narrow Money, Average, Bil.Won") is available since 1970 from the website of the Central Bank of Korea (henceforth, BOK). A series for nominal GDP ("Gross domestic product, current prices, Bil.Won") is available since 1953, again from the BOK's website. A series for the central bank's discount rate ("Republic of Korea, Interest Rates, Discount Rate, Percent per Annum") is available since 1948 from the IMF's IFS.

\section{A.17 Israel}

Series for nominal and real GDP, available for the period 1950-2013, are from Israel's Central Bureau of Statistics (henceforth, CBS; special thanks to Svetlana Amuchvari of the CBS for help with the data). Specifically, starting from 1995, the data are from Table 17 of the "National Accounts, 1995-2013". For the period 1950-1994, they are from the CBS's Statistical Abstract of Israel (see columns D and J of Table 6.1, "National Income and Expenditure: Resources and Uses of Resources"). The GDP deflator has been computed as the ratio between the two series. An annual CPI inflation series ("Change in Level of Price Indices, Percentages, Annual, average"), available since 1971, is from the CBS website (specifically, the series is from Table 13.1 of Statistical Abstract of Israel). For the period 1966-1975, the series for $M_{1}$ is from Table 4.6, page 120, of Barkai and Liviatan (2007). For the period since April 1981, a monthly $M_{1}$ series is from the Bank of Israel's website (special thanks to Aviel Shpitalnik of the Bank of Israel for help with the data). The series is M1.M ("M1 = Money supply, Monthly (M), NIS, million, Current prices"), and it has been converted to the annual frequency by taking annual averages. A short-term interest rate for the period 1966-1974 is the "Nominal rate of return on MAKAM (3-month bills)" from Table 4.9, page 129, of Barkai and Liviatan (2007). Since 1989 it is the Bank of Israel's "Actual effective rate of interest", from the Bank of Israel's website. For the period 1983-1988, we use the "Discount Rate" from the IMF's IFS. Over the period of overlapping (i.e., since 1989), the Bank of Israel's actual effective rate of interest and the discount rate from the IMF are virtually identical, which justifies their linking.

\section{A.18 Italy}

Series for nominal GDP at current market prices, real GDP in chained 2005 euros, and the implied GDP deflator, all available for the period 1861-2010, are from the sheet "Tab_03' in the Excel spreadsheet 'Data_Na150-1.1.xls", which is available at the Banca d'Italia's website at http://www.bancaditalia.it/statistiche/tematiche/stat-storiche/index.ht The spreadsheet contains the estimates of the Italian National Accounts' aggregates, which are extensively discussed in Baffigi (2011). A series for $M_{0}$, available for the period 1947-1993, respectively, is from the Rolnick-Weber data set. A series for $M_{1}$, 
available for the period 1861-1991, is from the Data Appendix, pp. 49-52, of Fratianni and Spinelli (1997). Series for $M_{1}$ and $M_{2}$, available for the period 1948-1998, are from the table "Componenti della moneta dal 1948 al 1998" of BancadItalia (2013). In our analysis we use the $M_{1}$ series from Fratianni and Spinelli (1997) for the gold standard period, and the one from Banca d'Italia for the post-WWII period (over the period of overlapping, however, the two series are very similar, so that in practice this choice does not entail material implications). Short- and long-term interest rates for the period 1861-1996 are from Muscatelli and Spinelli (2000). A series for the "Tasso Ufficiale di Sconto" - that is, Banca d'Italia's official discount rate -is from the tables "Tassi d'interesse delle principali operazioni della banca centrale" and "Variazione dei tassi ufficiali della Banca d'Italia, 1936-2003" of BancadItalia (2013).

\section{A.19 Mexico}

A monthly interest rates series for the period January 1978 to the present is from the Banco de Mexico's "Indicadores de tasas de interes de Valores Publicos" (Banco de Mexico, henceforth BdM, is Mexico's central bank). It has been converted to the annual frequency by taking annual averages. Two annual interest rates series ("Interest Rate (\%) Commercial loans" and "Interest Rate (\%), Official discount rate", respectively) are from Table 83, pages 639-640, of Homer and Sylla (2005). The first series is available for the periods 1942-1963 and 1978-1989. The second is available for the period 1936-1978. Annual series for $M_{0}, M_{1}$, and $M_{2}$ for the period 1925-2014 are from the Instituto Nacional de Estadistica y Geografia (Mexico's national statistical agency, henceforth INEGI), "Estadisticas Historicas de Mexico, 2014", whereas for the period 1985-2014 they are from the BdM's website. The series from the BdM are available at the monthly frequency, and we converted them to the annual frequency by taking annual averages. Annual series for nominal GDP are from INEGI, "Estadisticas Historicas de Mexico 2014", for the period 1925-1970; from the IMF's IFS for the period 1970-1988; from BdM for the period 1988-2004; and from INEGI for the period 2004-2013. The four series have been linked via splicing. An annual CPI inflation series available since 1949 is from the IMF's IFS ("Mexico, Consumer Prices, All items, Percent Change over Corresponding Period of Previous Year").

\section{A.20 Morocco}

A monthly seasonally unadjusted series for $M_{1}$, available since January 1985, is from the website of Bank Al-Maghrib (the Central Bank of Morocco, henceforth, BAM). The annual series has been computed by taking simple annual averages of the original monthly data. An annual series for nominal GDP, available for the period 19802010, is from the "Comptes Nationaux" (National Accounts) from the website of the High Commission for Planning of Morocco. A series for the minimum rate applied to 
notebook accounts, available since January 1983, is from the website of BAM. BAM sets the interest rate two times a year, on January 1 and on July 1 . The table at the central bank's website reports the values for the interest rate that have been set every January 1 and July 1 starting from 1983. From this information we computed the annual average rates by taking a simple average within the year.

\section{A.21 Netherlands}

A series for the discount rate of De Nederlandsche Bank (the Dutch central bank, henceforth, DNB) for the period 1900-1992 is from Table 65 of Homer and Sylla (2005) until 1989, and from DNB's website after that. Series for nominal and real Net National Income (NNI) and for the NNI deflator for the period 1900-1992 are from Table 1, pages 94-95, of Boeschoten (1992). A series for $M_{2}$, available for the period 1900-1992, is from the Rolnick-Weber data set. A series for $M_{1}$, available since 1864, has been constructed by linking the series from deJong (1967) and one from DNB.

\section{A.22 New Zealand}

A series for $M_{1}$, available since 1934, is from the Reserve Bank of New Zealand (henceforth, RBNZ). A series for nominal GDP in millions of Australian dollars is from Statistics New Zealand. A series for a short-term nominal interest rate starting in 1934 has been constructed in the following way. Homer and Sylla's (2005) Table 79 contains a series for the RBNZ's official discount rate for the period 1934-1989. Since 1999, the RBNZ has been using, as its monetary policy rate, the "Official Cash Rate", which is available from the RBNZ's website. Since these two short-term rates have been used by the RBNZ as its official monetary policy rate for the periods 1934-1989 and 1999 to the present, respectively, they are in fact conceptually the same and can therefore be linked. For the period in between (1990-1998), for which no monetary policy rate is available, we have used the "Overnight Interbank Cash Rate" from the RBNZ. The rationale for doing so is that since 1999, this rate has been very close to the Official Cash Rate, which justifies the linking of the two series.

\section{A.23 Norway}

A series for $M_{1}$, available since 1919, and two series for $M_{0}$ and $M_{2}$, available since 1819, are from the Historical Statistics of Norges Bank (Norway's central bank), which are available at its website. Specifically, all historical statistics for Norway's monetary aggregates are from Klovland (2004). Series for nominal GDP and the GDP deflator; and for real GDP, real private consumption expenditures, and real gross investments (in millions of $2005 \mathrm{NOKs}$ ), all available since 1830, are from Norges Bank's Historical Statistics (for all series, the period 1940-1945 is missing). As for the short-term nominal interest rate, ideally we would have liked to use Norges Bank's 
discount rate. The problem is that, although the discount rate is available (from Norges Bank's website) since 1819, it has missing observations for the period 19871990. As a result, we have resorted to using the Average Deposit Rate (again, from Norges Bank's website), which is available since 1822, has no missing observations, and over the period that is analyzed herein has been quite close to the discount rate.

\section{A.24 Portugal}

An annual series for $M_{1}$ for the period 1854-1998 is from Table 5 of Mata and Valerio (2011). Annual series for real and nominal GDP for the period 1868-2008 are from Table 4 of Mata and Valerio (2011). A series for the official discount rate of the Banco de Portugal (the Portuguese central bank), available for the period 1930-1989, is from Table 74 of Homer and Sylla (2005). Series for the consumer price index, $M_{0}$, and $M_{2}$ for the period 1932-1989 are from the Rolnick-Weber data set.

\section{A.25 South Africa}

All of the data for South Africa are from the website of its central bank, the South African Reserve Bank (SARB). Specifically, a series for the "Bank rate" ("Lowest rediscount rate at $S A R B$ "; code is KBP1401M) is available since 1923. A series for $M_{1}$ ("Monetary aggregates / Money supply: M1, R millions"; code is KBP1371J) is available since 1967. A series for nominal GDP ("Gross domestic product at market prices, R millions"; code is KBP6006J) is available since 1946.

\section{A.26 Spain}

Annual series for $M_{0}$ and $M_{2}$ for the period 1874-1980 are from the RW data set (the years 1936-1940 are missing). An annual series for $M_{1}$ for the period 1865-1998 is from Cuadro 9.16 "Agregados Monetarios, 1865-1998" of Barciela-López, Carreras, and Tafunell (2005), pp. 697-699 (the series is labeled as "M1, datos a fin de ano, en millones de pesetas"; the years 1936-1940 are missing). An annual series for nominal GDP for the period 1850-2000 is from Cuadro 17.7 of Barciela-López, Carreras, and Tafunell (2005), pp. 1338-1340 (the series is labeled as "El PIB a precios corrientes, 1850-2000, millones de pesetas"; PIB is the Spanish acronym of GDP). An annual series for the "Descuento comercial" of the Banco de Espana (Spain's central bank, henceforth, BdE) is from Cuadro 9.17 of Barciela-López, Carreras, and Tafunell (2005), pp. 699-701. The series is available for the periods 1874-1914, 1920-1935, and 1942-1985. An annual series for the official discount rate of the BdE, available for the period 1930-1989, is from Table 74, pp. 541-542, of Homer and Sylla (2005). A monthly series for the three-month Treasury bill rate available since March 1988 ("Tipo de interese hasta 3 meses. Conjunto del mercado. Op. simples al contado. Letras del Tesoro."), is from the BdE's website, and it has been converted to the 
annual frequency by taking annual averages (the data for 1988 have been ignored, since the series starts in March of that year).

\section{A.27 Switzerland}

Annual series for the consumer price index, $M_{0}, M_{1}$ (based on the 1995 definition), $M_{3}$ (based on the 1995 definition), and the Swiss National Bank's (henceforth, SNB) official discount rate, all available at least since 1929, are from the SNB's website. Specifically, the series for $M_{0}, M_{1}$, and $M_{3}$ from the SNB's Historical Statistics, which are available up until 2006, have been extended up to 2014 by applying the annual growth rates of the corresponding monetary aggregate from the SNB's Monthly Statistical Bulletin of July 2015 (see section "Monetary base and liquidity, B2 Monetary aggregates M1, M2 and M3, Level (annually)". The series for the discount rate is available up until 2007. An annual series for nominal GDP available for the period 1948-2005 is from the website of the project Economic history of Switzerland during the 20th century - see at http://www.fsw.uzh.ch/histstat/main.php. (Q.16b Gross domestic product (expenditure approach) in real 1990 prices and nominal, 1948-2005 in Million Swiss Francs).

\section{A.28 Taiwan}

All of the data are from the Central Bank of the Republic of China (Taiwan), that is, Taiwan's central bank (henceforth CBRCT). An annual series for nominal GDP ("GDP by expenditures at current prices") is available for the period 1951-2013. An annual series for the CBRCT's discount rate is available for the period 19622014. Two annual series for $M_{1}$ ("M1A (End of Period), M1A = Currency in circulation(currency held by the public)+Checking accounts and passbook deposits of enterprises, individuals and non-profit organizations held in banks and community financial institutions" and "M1B (End of Period), M1B = M1A + Passbook savings deposits of Individuals and non-profit organizations in banks and community financial institutions") are both available for the period 1962-2014. In order to be sure that the series we use in this paper does not include components that go beyond a transaction purpose, we used the first one, M1A.

\section{A.29 Turkey}

A monthly series for $M_{1}$, available since January 1964, is from the website of Turkey's central bank, Turkiye Cumhuriyet Merkez Bankasi (henceforth, TCMB). The annual series used in the paper has been constructed by taking simple annual averages of the original monthly data. A series for the central bank's discount rate is from Homer and Sylla's (2005) Table 74, pages 541-542, until 1990. After that, it is from TCMB. Specifically, TCMB's website reports the dates in which the discount rate 
was changed, together with the new values taken by the discount rate at each date. Based on this information, for each year since 1990 we have calculated the number of days in the year for which each value of the discount rate has been in effect, and based on this we have computed, for every year, a simple weighted average of the individual values of the discount rate. A series for the gross domestic product in current prices, available since 1967, is from the website of TurkStat (Turkey's statistical office).

\section{A.30 United Kingdom}

All of the U.K. data are from version 2.2 of the Bank of England's data set of long-run historical statistics, which is available from the Bank of England's website. The Excel spreadsheet, called threecenturies_v2.2.xlsx (henceforth, TC), was downloaded on August 5, 2015. The first version of the data set was discussed in detail in Hills and Dimsdale (2010). A series for $M_{0}$ for the period 1870 to the present is from column $\mathrm{N}$ of sheet 12 of TC. A series for $M_{3}$ for the period 1870-1969 is from column $\mathrm{S}$ of sheet 12 of TC (the series is originally from Capie and Webber (1985)). A series for $M_{4}$ for the period 1963 to the present is from column Z of sheet 12 of TC. A series for $M_{1}$ for the period 1922 to the present has been constructed in the following way. For the period 1922-1969, we take annual averages of Capie and Webber's (1985) monthly $M_{1}$ series, which is in column G of sheet 29 of TC. As for the period 1969 to the present, we take annual averages of the quarterly aggregate "Non-interest bearing $M_{1}$ " from column F of sheet 30 of TC. Finally, we link the resulting two annual series by splicing. A series for the Bank of England's monetary policy rate (known as the "Bank Rate") available since 1694 is from column B of sheet 15 of TC. A series for a long-term interest rate (the "Consol yield") is from sheet 15 of TC. A series for real GDP ("Chained composite measure of GDP at market prices. Chained volume measure £mn, reference year 2011") available since 1700 is from column D of sheet 2 of TC, and the corresponding series for nominal GDP ("Composite estimate of UK nominal GDP at market prices £mn") is from column D of sheet 3. A series for real consumption ("Real consumption, Chained Volume measure, £mn, 2011 prices") is from sheet 2 of TC.

\section{A.31 United States}

The series for the three-month Treasury bill rate, nominal GDP, and both the "standard" $M_{1}$ aggregate and the "New $M_{1}$ " one, all available for the period 1915-2008, are from Lucas and Nicolini (2015). All series have been updated based on either series' updated original data sources. The original source for the three-month Treasury bill rate is the Economic Report of the President (henceforth, ERP), whereas the ones for nominal GDP are Kuznets and Kendrick's Table Ca184-191 before 1929, and Table 1.1.5 of the National Income and Product Accounts (henceforth, NIPA) after that. The series for the St. Louis adjusted monetary base (the acronym is $A M B S L$ ), 
available since 1918, is from FRED II, at the website of the Federal Reserve Bank of St. Louis. A series for $M_{2}$, and a discontinued series for $M_{3}$, available since 1959, and for the period 1959-2005, respectively, are from FRED II (acronyms are M2SL and M3SL, respectively). A series for $M_{2}$ available for the period 1878-2003 is from the RW data set. Annual series for nominal GDP at current prices, real GDP in millions of 2009 dollars, and the GDP deflator (Index: 2009=100) are from Officer and Williamson (2015).

\section{A.32 Venezuela}

Annual data for nominal GDP ("Producto Interno Bruto, Millones de Bolívares a Precios Corrientes"), $M_{1}$ ("Circulante, (M1), I.1, Circulante, Liquidez Monetaria y Liquidez Ampliada, Saldos al final de cada período en millones de bolívares"), and a short-term rate ("Tasas de Interes Activas Anuales Nominales Promedio, Ponderadas de los Bancos Comerciales y Universales, Porcentajes") are from the Banco Central de Venezuela. GDP is available for the period 1957-2007. $M_{1}$ is available for the period 1940-2014. The interest rate is available for the period 1962-1999. An alternative monthly interest series, available since July 1997 ("Tasa de Interés Aplicable al Cálculo de los Intereses Sobre Prestaciones Sociales (Porcentajes)") has been converted to the annual frequency by taking averages within the year. It has been used for the scatterplot in Figure 1, but it cannot be linked to the other interest rate series because, over the period of overlapping, the two series are different.

\section{B Mathematical Derivations}

\section{B.1 Interest rate rules and money rules}

Note that (6) and (7) in the text imply

$$
\beta E\left[\frac{V^{\prime}\left(\omega^{\prime}\right)}{\pi\left(s^{\prime}\right)}\right]=\frac{\varepsilon}{R}
$$

and

$$
\delta=\frac{\varepsilon}{n}\left[1-\frac{R^{m}}{R}\right] .
$$

Substituting this in equation (4) we obtain

or

$$
U^{\prime}(x)=\frac{\varepsilon}{R}+\frac{\varepsilon}{n}\left[1-\frac{R^{m}}{R}\right]
$$

$$
\begin{aligned}
\varepsilon & =\frac{U^{\prime}(x)}{\left[\frac{1}{n}+\frac{1}{R}\left(1-\frac{1}{n} R^{m}\right)\right]} \\
& =\frac{n U^{\prime}(x)}{\left[1+\frac{1}{R}\left(n-R^{m}\right)\right]} .
\end{aligned}
$$


Now, combining (7) and (9), we obtain

$$
\beta E\left[\frac{\varepsilon^{\prime}\left(s^{\prime}\right)}{\pi\left(s^{\prime}\right)}\right] R=\varepsilon
$$

or, using the result above and noting that $x=z(1-\theta(n))$,

$$
\beta E\left[\frac{n\left(s^{\prime}\right) U^{\prime}\left[\left(z\left(s^{\prime}\right)\left(1-\theta\left(n\left(s^{\prime}\right)\right)\right)\right]\right.}{\left[1+\frac{1}{R\left(s^{\prime}\right)}\left(n\left(s^{\prime}\right)-R^{m}\left(s^{\prime}\right)\right)\right]} \frac{1}{\pi\left(s^{\prime}\right)}\right] R=\frac{n U^{\prime}(z(1-\theta(n)))}{\left[1+\frac{1}{R}\left(n-R^{m}\right)\right]} .
$$

But replacing the inflation rate $\pi\left(s^{\prime}\right)=\frac{M\left(s^{\prime}\right) x\left(s^{\prime}\right)}{M x} \frac{n}{n\left(s^{\prime}\right)}$, we obtain

$$
\beta E\left[\frac{U^{\prime}\left[\left(z\left(s^{\prime}\right)\left(1-\theta\left(n\left(s^{\prime}\right)\right)\right)\right]\right.}{\left[1+\frac{1}{R\left(s^{\prime}\right)}\left(n\left(s^{\prime}\right)-R^{m}\left(s^{\prime}\right)\right)\right]} \frac{M}{M\left(s^{\prime}\right)}\right] R=\frac{z(1-\theta(n)) U^{\prime}(z(1-\theta(n)))}{\left[1+\frac{1}{R}\left(n-R^{m}\right)\right]} .
$$

Now, if we let

$$
\Omega=\frac{U^{\prime}(z(1-\theta(n))) z(1-\theta(n))}{\left[1+\frac{1}{R}\left(n-R^{m}\right)\right]},
$$

we can write the expression above as

$$
\beta E\left[\Omega\left(s^{\prime}\right) \frac{M}{M^{\prime}}\right] R=\Omega .
$$

But

$$
M\left(s^{\prime}\right)=M+\mu\left(s^{\prime}\right) P,
$$

so

$$
\frac{M}{M\left(s^{\prime}\right)}=1-\frac{\mu\left(s^{\prime}\right)}{\pi\left(s^{\prime}\right) m\left(s^{\prime}\right)}=\left(1-\frac{\mu\left(s^{\prime}\right) n\left(s^{\prime}\right)}{\pi\left(s^{\prime}\right) z\left(s^{\prime}\right)\left(1-\theta\left(n\left(s^{\prime}\right)\right)\right)}\right) .
$$

Replacing the above,

or

$$
\beta E\left[\Omega\left(s^{\prime}\right)\left(1-\frac{\mu\left(s^{\prime}\right) n\left(s^{\prime}\right)}{\pi\left(s^{\prime}\right) z\left(s^{\prime}\right)\left(1-\theta\left(n\left(s^{\prime}\right)\right)\right)}\right)\right] R=\Omega
$$

$$
\beta E\left(\frac{\Omega\left(s^{\prime}\right)}{\Omega}\right)-\beta E\left(\frac{\Omega\left(s^{\prime}\right)}{\Omega} \frac{\mu\left(s^{\prime}\right) n\left(s^{\prime}\right)}{\pi\left(s^{\prime}\right) z\left(s^{\prime}\right)\left(1-\theta\left(n\left(s^{\prime}\right)\right)\right)}\right)=\frac{1}{R} .
$$

In general, there are many solutions for the growth rate of money stochastic sequence $\mu\left(s^{\prime}\right)$ that are consistent with a given interest rate. This is so because the nominal interest rate pins down (weighted) expected inflation, but there are many distributions of future price levels that are consistent with the same expected value of inflation. Notice, however, that there exists a unique growth rate of money that is consistent with the interest rate sequence, and that is predetermined the period before, the solution, $\mu^{*}$, satisfying

$$
E\left(\frac{\beta \Omega\left(s^{\prime}\right)}{\Omega}\right)-\mu^{*} E\left(\frac{\beta \Omega\left(s^{\prime}\right)}{\Omega} \frac{n\left(s^{\prime}\right)}{\pi\left(s^{\prime}\right) z\left(s^{\prime}\right)\left(1-\theta\left(n\left(s^{\prime}\right)\right)\right)}\right)=\frac{1}{R} .
$$




\section{B.2 The Bellman equation describing the decision problem}

The Bellman equation describing the decision problem is

$$
\begin{aligned}
V(\omega)= & \max _{x, n, m, b, q\left(s^{\prime}\right)} U(x)-\varepsilon\left[m+b+E\left[q\left(s^{\prime}\right) \pi\left(s^{\prime}\right) \widetilde{P}^{Q}\left(s^{\prime}\right)\right]-\omega\right]-\delta[x-m n] \\
& +\beta E\left[V\left(\frac{m R^{m}+b R+[1-\theta(n)] z-x}{\pi\left(s^{\prime}\right)}+\tau\left(s^{\prime}\right)+q\left(s^{\prime}\right)\right)\right]
\end{aligned}
$$

where, for simplicity, we omitted the dependence of current variables on the state, and where $s^{\prime}$ denotes the future state.

The first order conditions are

$$
\begin{gathered}
x: \quad U^{\prime}(x)=\beta E\left[\frac{V^{\prime}\left(\omega^{\prime}\right)}{\pi\left(s^{\prime}\right)}\right]+\delta \\
n: \quad \delta m=\beta E\left[\frac{V^{\prime}\left(\omega^{\prime}\right)}{\pi\left(s^{\prime}\right)}\right] \theta_{n}(n) z \\
m: \quad \delta n+\beta E\left[\frac{V^{\prime}\left(\omega^{\prime}\right)}{\pi\left(s^{\prime}\right)}\right] R^{m}=\varepsilon \\
b: \quad \beta E\left[\frac{V^{\prime}\left(\omega^{\prime}\right)}{\pi\left(s^{\prime}\right)}\right] R=\varepsilon \\
q\left(s^{\prime}\right): \quad \beta V^{\prime}\left(\omega^{\prime}\right)=\varepsilon \pi\left(s^{\prime}\right) P^{Q}\left(s^{\prime}\right),
\end{gathered}
$$

and the envelope condition is

$$
V^{\prime}(\omega)=\varepsilon
$$

Note that (3) and (4) imply

$$
\beta E\left[\frac{V^{\prime}\left(\omega^{\prime}\right)}{\pi\left(s^{\prime}\right)}\right]\left(R-R^{m}\right)=\delta n,
$$

which in turn implies

$$
\frac{m}{\theta_{n}(n) z}\left(R-R^{m}\right)=n
$$

In equilibrium,

$$
m=\frac{x}{n}=\frac{z(1-\theta(n))}{n},
$$

so if we replace the value of $m$ in the previous equation and let $r^{*} \equiv\left(R-R^{m}\right)$, we obtain

$$
r^{*} \equiv\left(R-R^{m}\right)=n^{2} \frac{\theta_{n}(n)}{1-\theta(n)} .
$$




\section{Integration Properties of the Data}

Tables C.1a-C.1c report, for the series in our data set, bootstrapped $p$-values for Elliot et al.'s (1996) tests (for technical details, see Section 5 in the text).

\section{C.1 $M_{1}$ velocity and the short rate}

Evidence of a unit root in $M_{1}$ velocity and the short rate is typically strong, with the bootstrapped $p$-values being almost uniformly greater than the $10 \%$ significance level we take as our benchmark throughout the entire paper, and often significantly so. The following exceptions ought to be briefly discussed.

First, and least important, in a few cases, results based on the two alternative lag orders we consider produce contrasting evidence. This is the case, for example, for the logarithms of velocity and the short rate for Israel; for log velocity for Chile for the period 1940-1995; and for the short rate for West Germany. In these cases, we regard the null of a unit root as not having been convincingly rejected, and in what follows we therefore proceed under the assumption that these series are I(1). For Israel and Chile, there are two main reasons for doing so:

(i) Even if the tests performed perfectly, as a simple matter of probability, they would still incorrectly reject the null at the $x \%$ level $x \%$ of the time. This means that a small fraction of fluke rejections of the null of a unit root should be expected even if all of the series we are dealing with are indeed $\mathrm{I}(1)$.

(ii) The visual evidence from Figure 2 in the online appendix indeed provides support to the notion that these results are simply part of the "unavoidable flukes" associated with statistical testing. This is clearly the case for Israel, with the logarithms of both velocity and the short rate exhibiting an obvious I(1) behavior (keep in mind that, as discussed in Section 5, these series should not exhibit a trend, which on the contrary they do). Evidence for Chile's velocity is just slightly less strong, but still it suggests that the series can be regarded as $\mathrm{I}(1)$.

Finally, for Chile a unit root in log velocity is not rejected for the longer sample period (1941-2012), which suggests that ambiguity of the results for the shorter period may just be a small-sample issue.

Ambiguity of the results for West Germany's short rate, on the other hand, cannot be explained along the same lines. On the one hand, the visual evidence from Figure 6 in the online appendix by no means suggests that the series may be I(1); on the contrary, if anything it suggests the opposite. Further, we do indeed have reasons for entertaining the possibility that post-WWII West German short rates might be $\mathrm{I}(0)$. By the Fisher effect, short-term rates should be equal to the Wicksellian (or 'natural') rate of interest plus expected inflation. Given the Bundesbank's strong counter-inflationary stance, we might logically expect post-WWII German inflation to be I(0). In turn, absent a significant extent of permanent variation in Germany's 
natural rate of interest, ${ }^{1}$ this would imply that German short-term rates should be stationary, too. Evidence on the integration properties of post-WWII German inflation is mixed. For the period considered herein, a unit root in CPI inflation cannot be rejected, with bootstrapped p-values for Elliot et al.'s tests without a time trend being equal to 0.374 and 0.131 . For the longer sample 1948-1998, however, rejection is strong, with the $p$-values equal to 0.016 and 0.001 . So the bottom line is that although we regard a unit root in West Germany's short rate as not having been convincingly rejected, and in what follows we therefore proceed under the assumption that the short rate is $\mathrm{I}(1)$, it has to be kept in mind that this may not be the case.

Second - and more important - under the gold standard, a unit root in both the level and the logarithm of the short rate (either with, or without the $1 \%$ correction) is rejected for Canada, Finland, France, and Spain, and it is rejected for Switzerland based on the logarithm of the short rate with the $1 \%$ correction. In all of these cases, stationarity of the short rate precludes it from being entered in any cointegrated system or cointegrating regression. ${ }^{2}$ On the other hand, it is not rejected for Italy and Portugal, whereas for Japan, results based on the two alternative lag orders we consider produce contrasting evidence, and therefore, as we did before, we regard the null of a unit root as not having been convincingly rejected, and we therefore treat Japan's short rate for the period 1885-1913 as being I(1). By the same token, a unit root in velocity under the gold standard is strongly rejected for Finland and Italy, whereas it is not rejected for Canada, Japan, and Spain. As for Italy's velocity for the period 1861-1913, visual evidence from Figure 6 in the online appendix clearly suggests that rejection of the null of a unit root should be regarded as one of those fluke results which, as previously mentioned, are all but unavoidable when performing a large number of statistical tests, such as in the present case. We therefore proceed under the assumption that Italy's velocity under the gold standard was I(1).

Third, by the same token, a unit root in the level of the short rate is rejected for Argentina, Brazil for the period 1934-2012, and Chile for the period 1941-2012, whereas in none of those cases it is rejected based on the logarithms. For these three cases, we will therefore eschew the Selden-Latané specification. Under the gold standard, a unit root in either the level or the logarithm of velocity is rejected for Italy. In this case, we will therefore uniquely consider unrestricted specifications for GDP, $M_{1}$, and the short rate.

Fourth, for Taiwan a unit root in velocity is rejected based on the level, but not based on the logarithm. In this case, we will eschew the Selden-Latané specification.

\footnotetext{
${ }^{1}$ Labor productivity data from the Ohanian and Raffo (2011) data set, however, point toward a significant slowdown in post-WWII German labor productivity growth. Evidence for real GDP growth is qualitatively the same. (All of these results are available upon request.) As discussed in Laubach and Williams (2003), for example, under very general conditions this should be expected to map (although not one-for-one) into a corresponding decrease in the natural rate of interest. (Specifically, this mapping holds within the Ramsey and Solow growth models, for example.)

${ }^{2}$ See footnote 12 .
} 


\section{C.2 GDP and $M_{1}$}

Evidence of a unit root in the logarithms of nominal GDP and nominal $M_{1}$ is, likewise, typically strong. ${ }^{3}$ For GDP, a unit root is rejected only for Bolivia and for France under the gold standard (the latter rejection is ultimately irrelevant, since, as previously mentioned, for France the interest rate is stationary, so that it is not possible to analyze cointegrated systems). As for $M_{1}$, it is rejected only for Israel, Canada (1967-2013), and Finland (1914-1985). For Bolivia, Israel, Canada (1967-2013), and Finland (1914-1985), we will therefore eschew unrestricted specifications for GDP, $M_{1}$, and the short rate, and we will uniquely focus on bivariate systems with velocity and the short rate.

\section{C.3 Are the series under investigation $\mathrm{I}(2)$ ?}

A necessary condition for performing either Johansen's or Shin's cointegration tests is that the series under investigation must contain a unit root, and that their order of integration is not greater than one. Tables C. $2 a-$ C. $2 b$ report bootstrapped $p$-values for Elliot et al.'s (1996) unit root tests with an intercept, but no time trend, for either the log- or the first-differences of $M_{1}$ velocity and the short rate, and for the log-differences of nominal $M_{1}$ and nominal GDP.

For Morocco and for Portugal under the gold standard, it is not possible to reject the null of a unit root in either the log-differences or the first-differences of $M_{1}$ velocity and the short rate. By the same token, for Hong Kong a unit root can be rejected only for either the log- or the first-difference of the short rate. This implies that for these three cases, it is not possible to run any cointegration test, and in what follows we will therefore ignore them.

For Italy over the post-WWII period and for Turkey, a unit root can be rejected only for the first-differences of $M_{1}$ velocity and the short rate and for the log-difference of velocity. In these two cases, we will therefore only run cointegration tests based on the semi-log and the Selden-Latané specifications. On the other hand, for West Germany we cannot run cointegration tests based on the Selden-Latané specification because the null of a unit root cannot be rejected for the level of $M_{1}$ velocity.

Finally, there are several countries for which it is not possible to reject the null of a unit root in the log-differences of nominal GDP and/or nominal $M_{1}$. In all of these cases, we will eschew unrestricted specifications for GDP, $M_{1}$, and the short rate, and we will uniquely focus on bivariate systems featuring (the logarithms of) velocity and the short rate.

\footnotetext{
${ }^{3}$ Again, in those few cases in which results based on the two alternative lag orders produce contrasting evidence, we regard the null of a unit root as not having been convincingly rejected, and we proceed under the assumption that the series is $\mathrm{I}(1)$.
} 


\section{Why Not Use Shin's (1994) Asymptotic Crit- ical Values in Performing Tests of the Null of Cointegration?}

As discussed in the text, all cointegration tests in this paper have been performed based on bootstrapped $p$-values. As for Johansen's tests of the null of no cointegration, the rationale for doing so was provided by Johansen (2002) himself, who showed how, in small samples, trace and maximum eigenvalue tests based on asymptotic critical values typically tend to perform poorly. Since this is a small-sample issue, as a matter of simple logic we should expect Shin's (1994) tests of the null of cointegration to suffer from an analogous poor performance, thus justifying the use of a bootstrapping procedure to compute critical and $p$-values.

In this appendix we provide an additional rationale for bootstrapping Shin's tests. As we show, even in very large samples (in the following experiments, we use samples of length $T=100,000$ ), the Monte Carlo distributions of Shin's test statistics coincide with the asymptotic distribution of the critical values reported in Shin's (1994) Table 1 only if the cointegration residual has no persistence (specifically, it is white noise). This holds for either of the four kernels we use for computing Shin's test statistics. Further, the greater the persistence of the cointegration residual, the more the Monte Carlo distributions of Shin's test statistics in very large samples deviate from the asymptotic distribution reported in Shin (1994). Since, as we discuss in the text, the "candidate cointegration residuals" produced by either Shin's or Johansen's procedure based on the actual data typically exhibit very high persistence, this logically implies that, if cointegration is truly there, performing Shin's tests based on his asymptotic critical values would automatically bias such tests toward rejection of the null of cointegration. This provides a further rationale for bootstrapping Shin's tests.

The model we use for the Monte Carlo experiments is given by

$$
\begin{gathered}
y_{i, t}=y_{i, t-1}+\epsilon_{i, t}, i=1,2, \text { with } \epsilon_{i, t} \sim \text { i.i.d. } N(0,1) \\
x_{t}=\frac{y_{1, t}+y_{2, t}}{2}+u_{t} \\
u_{t}=\rho u_{t-1}+v_{t}, \text { with } 0 \leq \rho<1, v_{t} \sim \text { i.i.d. } N(0,1) .
\end{gathered}
$$

As for $\rho$, we consider six possible values, corresponding to alternative ranges of persistence of the cointegration residual between the three series, that is, $\rho=0,0.25$, $0.5,0.75,0.9,0.95$. There are two reasons for using this specific data generation process (henceforth, DGP). First, it captures the essence of the problem at hand. Here we tipically ${ }^{4}$ have three I(1) series - GDP, $M_{1}$, and a short term nominal ratewhose long-run dynamics might obey a long-run equilibrium relationship (that is,

\footnotetext{
${ }^{4}$ We say "typically" because, as reported in Tables C.1a-C.1c, in a few cases (most of the time, under the gold standard), the null of a unit root can be rejected for $M_{1}$ velocity and/or the short term nominal rate.
} 
they might be cointegrated). Second, by parameterizing the extent of persistence of the deviation from the long-run equilibrium relationship, we can effectively explore how the performance of Shin's (1994) test depends on such persistence, even in very large samples. This is key because, as already pointed out, real-world ('candidate') cointegration residuals from long-run money demand relationships are indeed very highly persistent. Intuitively, for the reasons discussed by Engle and Granger (1987), we would expect that, ceteris paribus, the higher the persistence of the cointegration residual, the more difficult it is for any statistical test to detect cointegration. As we will see, this is indeed the case.

Details of the Monte Carlo simulations are as follows. For each value of $\rho$, we perform $N=100,000$ Monte Carlo simulations of samples of length $T=100,000$. For each individual simulation, we run a pre-sample of length 10,000 , which we then discard in order to eliminate dependence on initial conditions (which we set to $y_{1,0}=$ $\left.y_{2,0}=x_{0}=0\right)$. Following Shin (1994, Section 5, pp. 103-105), we set the number of leads and lags used in the dynamic OLS estimation of Shin's regression to $K=$ $\left[T^{1 / 3}\right]$, where $[x]$ stands for "the largest integer of $x "{ }^{5}$ In computing Shin's test statistic - which we do based on Shin's (1994) equation (2), page 93, that is, for a model with an intercept but no time trend - we consider the following four kernels, which are described, for example, in Andrews (1991, expressions (2.7), page 821): Bartlett, Parzen, Tukey-Hanning, and "Quadratic Spectral" (which, for the reasons we discuss below, is our kernel of choice in the entire paper). We select the spectral bandwidth parameter (in Shin's notation, $\ell$ ) via the "plug-in" method discussed in Andrews (1991) (see his Section 6, "Automatic Bandwidth Estimators").

The results are reported in Table D.1. Several key facts are immediately apparent from the table. Specifically, they are as follows.

First, a comparison between the second column and the columns from the third to the sixth shows that the critical values reported in Shin's (1994) Table 1 are valid only in the case of a cointegrated DGP in which the cointegration residual is white noise. This holds true for either of the four kernels we consider. Since in most real-world applications, cointegration residuals are typically very highly persistent, this implies that Shin's critical values are essentially irrelevant for practical purposes. ${ }^{6}$

Second - and crucially - as the persistence of the cointegration residual increases, the Monte Carlo distributions of Shin's test statistic get systematically 'shifted upwards' for each individual fractile. Once again, this holds, albeit with some differences

\footnotetext{
${ }^{5}$ We have experimented with alternative values of $K$, either larger or smaller than $\left[T^{1 / 3}\right]$, and the results reported below are robust to using such alternative values, as long as they are not 'too small' (e.g., $K=1$ ) or 'too large'.

${ }^{6}$ To be precise: For a few fractiles (specifically, the 1, 70, 90, 95, 97.5, and 99\% ones), our Monte Carlo critical values for the case in which $\rho=0$ are slightly different from Shin's (1994) asymptotic critical values. For the $90 \%$ fractile, for example, our critical value is 0.161 based on either kernel, whereas the value reported by Shin is 0.163 . Since Shin generated his critical values "using a sample size of 2000" (see Shin (1994, page 99)), rather than 100,000 as we did, we believe our critical values should regarded as more reliable.
} 
(see the third point below), for either of the four kernels we consider. At the $10 \%$ level we use in the paper, for example, the critical value is equal to 0.161 for $\rho=0$ for either of the four kernels, but it ranges between 0.311 and 0.429 for $\rho=0.5$; it ranges between 0.622 and 0.940 for $\rho=0.75$; and it ranges between 2.866 and 4.471 for $\rho=0.95$ (which is, in many cases, an empirically plausible value). This implies that, even asymptotically, relying on Shin's (1994, Table 1) critical values would induce a researcher to incorrectly reject the null hypothesis of cointegration too often in any situation in which the cointegration residual is characterized by at least some moderate extent of persistence. The practical implication is that if in real-world situations - in which we do not even have the advantage of using samples of length $T=100,000$ - we were to perform Shin's tests based on his asymptotic critical values, we would most likely end up rejecting cointegration at the $x \%$ level much more than $x \%$ of the times.

Third, among the four kernels we consider, there is a clear "ranking" in terms of how much the fractiles of the associated Monte Carlo distributions deviate from Shin's asymptotic critical values. Specifically, for each individual fractile, the lowest extent of upward deviation is associated with the quadratic spectral kernel, whereas the largest pertains to the Bartlett kernel. This is why all of our empirical work based on Shin's tests is based on the quadratic spectral kernel. ${ }^{7}$

\section{E Methodological Issues Pertaining to Bootstrap- ping Cointegrated Processes}

\section{E.1 Why bootstrapping critical and $p$-values}

As for Johansen's tests, the rationale for bootstrapping critical and $p$-values was provided by Johansen (2002) himself, who showed how, in small samples, trace and maximum eigenvalue tests based on asymptotic critical values typically tend to perform poorly. ${ }^{8}$ Since this is a small-sample issue, as a matter of logic we should expect Shin's (1994) tests to suffer from an analogous poor performance, thus justifiying the use of a bootstrapping procedure.

Appendix D provides an additional rationale for bootstrapping Shin's tests. As we show there, even in very large samples, the distributions of Shin's test statistics coincide with the asymptotic distribution reported in Shin's (1994) Table 1 only if the

\footnotetext{
${ }^{7}$ To be precise, this does not represent a very strong rationale for preferring this kernel to either of the other three. Since we are going to bootstrap all of the tests, it is reasonable to expect that either of the other three kernels will produce both larger test statistics based on the actual data and more upward-shifted bootstrapped distributions, but in the end, the resulting bootstrapped $p$-values should be the same. However, since at the end of the day we ought to choose one kernel, our choice still appears as logical to us.

${ }^{8}$ This indeed provided the motivation behind the boostrapping procedures proposed by Swensen (2006), and then by Cavaliere, Rahbek, and Taylor (2012), which improves upon Swensen's (and will be used in what follows).
} 
cointegration residual has no persistence. Further, the greater the persistence of the cointegration residual, the more the Monte Carlo distributions of Shin's test statistics in very large samples is shifted upward compared to the asymptotic distribution reported in Shin (1994). Since, as we document in the text (see Section 7.1), the "candidate cointegration residuals" produced by either Shin's or Johansen's procedure based on the actual data typically exhibit very high persistence, this logically implies that, if cointegration is truly there, performing Shin's tests based on his asymptotic critical values would automatically bias such tests toward rejection of the null of cointegration.

\section{E.2 Details of the bootstrapping procedures}

As for Johansen's tests, we bootstrap trace and maximum eigenvalue statistics via the procedure proposed by Cavaliere et al. (2012; henceforth, CRT). In a nutshell, CRT's procedure is based on the notion of computing critical and $p$-values by bootstrapping the model that is relevant under the null hypothesis. This means that for tests of the null of no cointegration against the alternative of one or more cointegrating vectors, the model that is being bootstrapped is a simple, noncointegrated VAR in differences. For the maximum eigenvalue tests of $h$ versus $h+1$ cointegrating vectors, on the other hand, the model that ought to be bootstrapped is the VECM estimated under the null of $h$ cointegrating vectors. All of the technical details can be found in CRT, to which the reader is referred. We select the VAR lag order as the maximum ${ }^{9}$ between the lag orders chosen by the Schwartz and the Hannan-Quinn criteria ${ }^{10}$ for the VAR in levels.

As for Shin's tests, to the very best of our knowledge, no one has yet provided anything comparable to what CRT did for Johansen's procedure (in fact, we were not able to find a single paper discussing how to bootstrap Shin's test statistic). The bootstrap procedure we propose is based on exactly the same idea underlying CRT, that is, computing critical and $p$-values by bootstrapping the process that is relevant under the null hypothesis. Within the present context, this implies that the process to be bootstrapped is the VECM estimated under the null of one cointegration vector.

\footnotetext{
${ }^{9}$ We consider the maximum between the lag orders chosen by the SIC and HQ criteria because the risk associated with selecting a lag order smaller than the true one (model misspecification) is more serious than the one resulting from choosing a lag order greater than the true one (overfitting).

${ }^{10} \mathrm{On}$ the other hand, we do not consider the Akaike Information Criterion since, as discussed by Luetkepohl (1991), for example, for systems featuring I(1) series, the AIC is an inconsistent lag selection criterion, in the sense of not choosing the correct lag order asymptotically.
} 


\section{E.3 Monte Carlo evidence on the performance of the two bootstrapping procedures}

Table 1 in the text reports Monte Carlo evidence on the performance of the bootstrapping procedure for Johansen's trace tests ${ }^{11}$ proposed by Cavaliere, Rahbek, and Taylor (2012), ${ }^{12}$ whereas Table E.2 in appendix E reports evidence for the bootstrapping procedure for Shin's tests proposed herein. In either case, we perform the Monte Carlo simulations based on two types of DGP, featuring no cointegration and cointegration, respectively. The rationale for doing this is that, first, Johansen's and Shin's tests are based on different null hypotheses (no cointegration for the former and cointegration for the latter); and second, in order to properly interpret the results from either test based on the actual data, it is necessary to see how the two bootstrapping procedures perform conditional on the two possible alternative states of the world.

As for the DGP featuring no cointegration, we simply consider three independent random walks. As for the one featuring cointegration, we consider the one discussed in Appendix D, which allows us to explore how the two procedures perform conditional on alternative ranges of persistence of the cointegration residuals (this is conceptually in line with some of the evidence reported by Engle and Granger (1987)). For either DGP, we consider five alternative sample lengths, $T=50,100,200,500$, and 1,000. The results reported in either table are based on 1,000 Monte Carlo simulations. For each simulation we generate a sample of length $T+100$, and we then discard the first 100 observations in order to eliminate dependence on initial conditions (which we set to 0 for either series). For each individual simulation, we perform bootstrapping based on 5,000 replications.

\section{E.3.1 Evidence for Johansen's test of the null of no cointegration}

Table 1 reports evidence for Johansen's trace test of the null of no cointegration against the alternative of one or more cointegration vectors. Specifically, the table reports, for either DGP, sample length, and (for the DGP featuring cointegration) value of $\rho$, the fraction of replications for which no cointegration is rejected at the $10 \%$ level. The following main findings clearly emerge from the table.

First, in line with the evidence reported by both CRT and Benati (2015), the procedure performs remarkably well conditional on DGPs featuring no cointegration. A key point that ought to be stressed is that the specific sample length used in the simulations does not appear to make any material difference for the final results, with the

\footnotetext{
${ }^{11}$ Numerically near-identical evidence for Johansen's maximum eigenvalue tests is not reported for reasons of space, but it is available upon request.

${ }^{12}$ Extensive Monte Carlo evidence on the good performance of Cavaliere et al.'s (2012) procedure was already provided by Cavaliere et al. themselves in their original paper. Benati (2015) also provided some (much more limited) evidence conditional on the specific DGPs he was interested in. The rationale for providing additional evidence here is the same as Benati (2015), that is, looking at how the procedure performs conditional on the DGPs we are interested in here.
} 
fractions of rejections ranging between 0.098 and 0.119 (with the ideal one being 0.1 ). This is testimony to the power of bootstrapping, which is capable of automatically controlling for the specific characteristics of the DGP under investigation.

Second, when the DGP does feature cointegration, ideally we would like the test to reject as much as possible. As the lower part of the table shows, the procedure indeed performs very well if $\rho$ is small. If $\rho=0$, for example, cointegration is already detected $100 \%$ of the time for $T=100$, whereas if $\rho=0.5$, it is detected $88.2 \%$ of the time for $T=100$, and a sample length of $T=200$ is already sufficient to detect cointegration $100 \%$ of the time. As $\rho$ increases, however, the performance deteriorates. The intuition for this is straightforward: as the cointegration residual becomes more and more persistent, it gets closer and closer to a random walk (in which case there would be no cointegration), and the procedure therefore needs larger and larges samples to detect the truth (that the residual is highly persistent but ultimately stationary). In particular, as $\rho$ increases, the fraction of rejections tends to converge, for each sample size, to the fraction of rejections under the DGP featuring no cointegration. This is especially apparent for $T=50$ or 100 , with the fractions being equal to 0.114 and 0.120 , respectively. In the limit, for $\rho \rightarrow 1$, the procedure will tend to reject $10 \%$ of the time.

Comparison with the Monte Carlo evidence of Cavaliere et al. (2012) This evidence is qualitatively and also quantitatively in line with the Monte Carlo evidence reported in CRT's Tables I and II, pp. 1731-1732. Although the DGPs they used (either noncointegrated VARs or cointegrated VECMs featuring one cointegration vector) were different from the DGPs used herein, their results and ours turn out to be very close. Specifically, the results are as follows:

- The results in panel $(b)$ of their Table I illustrate the excellent performance of their bootstrapping procedure for tests of the null of no cointegration when the true DGP features no cointegration. In line with the evidence reported in the first row of our Table E.1, their results illustrate how, at the $5 \%$ level, the empirical rejection frequencies (henceforth, ERF) are quite close to $5 \%$ irrespective of the sample size.

- Panel $(a)$ in the same table reports qualitatively and quantitatively similar evidence for the maximum eigenvalue test of 1 versus 2 cointegrating vectors, conditional on DGPs featuring one cointegrating vector.

- Finally, Table II reports evidence on the ability of the sequential bootstrapped procedure to select the correct cointegration rank, which in their experiments is one (see the columns under the heading 'Bootstrap (CRT)'). Those results are in line with the ones reported in our Table 1 conditional on DGPs featuring one cointegration vector. In either case, the larger the sample size, the more frequently CRT's procedure detects the truth, with ERFs converging toward 
1 for sufficiently large samples. In comparatively small samples (e.g., for $T=$ $50)$, ERFs are typically much below one - as we show, the more so, the more persistent is the cointegration residual. ${ }^{13}$

The bottom line is that our Monte Carlo evidence, although based on a set of DGPs that have been specifically tailored to the problem at hand, is in fact exactly in line, both qualitatively and quantitatively, with the evidence reported in CRT.

Summing up There are two things to take away from all this and to keep in mind in order to correctly interpret the results from Johansen's bootstrapped tests performed on the actual data:

- If the true DGP features no cointegration, Cavaliere et al.'s (2012) procedure performs remarkably well irrespective of the sample size.

- If, however, the true DGP does feature cointegration, Johansen's test - even bootstrapped as in Cavaliere et al. (2012)-performs well only if the persistence of the cointegration residual is sufficiently low, and/or the sample size is sufficiently large. ${ }^{14}$ If, on the other hand, the cointegration residual is persistent and the sample size is small, the procedure will fail to detect cointegration a nonnegligible fraction of the time. For example, with $T=100$, cointegration will be detected $43.3 \%$ of the time if $\rho=0.75$ and just $12.0 \%$ of the time if $\rho=$ 0.95 .

All of this means that if Johansen's tests do detect cointegration, we should have a reasonable presumption that cointegration is indeed there. If, on the other hand, they do not detect it, a possible explanation is that the sample period is too short, and/or the cointegration residual is highly persistent.

\section{E.3.2 Evidence for Shin's (1994) test of the null of cointegration}

Before delving into the Monte Carlo evidence reported in Table E.1, we spend some time discussing two technical issues.

\footnotetext{
${ }^{13}$ Different from the present work, CRT do not explore how the persistence of the cointegration residual affects the performance of their procedure. The results reported in their Table II, however, are quantitatively in line with ours. We found out this in the following way. We simulated their VECM conditional on one cointegration vector 10,000 times for samples of length $T=10,000$, and for each simulation we computed the implied cointegration residual, and based on it we estimated an $\mathrm{AR}(4)$ process (in fact, given the nature of their DGP, an $\mathrm{AR}(2)$ would have been enough). The sum of the AR coefficients is our measure of persistence. For their benchmark case of $\delta=0.1$, both the mean and the median of the distribution were equal to 0.61 . From their Table II, we can see that for $\delta=0.1$ and $T=50$, the ERF is $49.0 \%$. In Table 1 we report, for $T=50$ and $\rho=0.5$, an ERF of $35 \%$.

${ }^{14}$ Since cointegration is a property of a system pertaining, in principle, to the infinite long run, Faust and Leeper (1997)'s point about the intrinsic difficulty of identifying such features of the data based on finite samples directly applies.
} 
Two technical issues A first strictly technical issue pertains to how to estimate the VECM that is going to be bootstrapped conditional on one cointegration vector. Here there are (at least) two possibilities. A first one is to simply use Johansen's estimator of the VECM, as detailed in Hamilton (1994), for example. ${ }^{15}$ A second possibility is to follow the two-step procedure discussed in Luetkepohl (1991) ${ }^{16}$ which calls for (i) getting the residual from the cointegrating regression (which Shin's procedure produces automatically) and then (ii) estimating the VECM via OLS conditional on such cointegration residual.

A key difference between the two procedures is that, as discussed by Luetkepohl (1991), whereas Johansen's estimator is valid for any number of cointegration vectors in the system, this second approach is only valid in the case in which there is just one cointegration vector. This is not an issue when we test for cointegration between (log) $M_{1}$ velocity and (the log of) a short rate: clearly, within such a system there can be at most one cointegration vector. It is potentially an issue, however, when we consider trivariate, "unrestricted" systems with a short rate and nominal GDP and nominal $M_{1}$. In these cases, we preliminarily perform Johansen's tests for the null of no cointegration between the short rate and nominal GDP. The rationale for preliminarily performing Johansen's is that, for the short rate and nominal GDP, we regard no cointegration as the "natural null hypothesis".

Evidence Table E.1 reports evidence for the proposed bootstrapping procedure. Details of the Monte Carlo simulations are exactly as before under all respects (types of DGP considered, sample lengths, etc.). Once again, the table reports, for either DGP, sample length, and (for the DGP featuring cointegration) value of $\rho$, the fraction of replications for which no cointegration is rejected at the $10 \%$ level. For the DGP featuring cointegration - that is, under the null hypothesis for which the test was designed - the following main findings emerge from the table.

First, the proposed bootstrapping procedure improves upon Shin's asymptotic critical values as long as the cointegration residual exhibits some mild extent of persistence. If $\rho$ is equal to either 0 or 0.25 , the performance of tests based on our proposed procedure and on Shin's asymptotic critical values is essentially equivalent. For larger values of $\rho$, however, the two performances diverge, with the proposed bootstrapping procedure outperforming tests based on Shin's asymptotic critical values the more, the larger the value of $\rho$. Focusing, just to fix ideas, on the comparative performance of tests based on samples of length $T=100$, the two procedures are still essentially equivalent when $\rho=0.5$, with the fraction of simulations for which the null hypothesis is incorrectly rejected being equal to 0.143 and 0.136 . For $\rho=0.75$, however, the two performances already start to significantly diverge, with tests based on asymptotic critical values incorrectly rejecting the null $33.6 \%$ of the time, and our procedure only rejecting $17.2 \%$ of the time. For very highly persistent cointegration

\footnotetext{
${ }^{15}$ See Hamilton (1994, chap. 20).

${ }^{16}$ See Luetkepohl (1991, pp. 370-371).
} 
residuals, the difference becomes large: for $\rho=0.95$, in particular, asymptotic critical values would lead a researcher to reject the null of cointegration $72.1 \%$ of the time, whereas the bootstrap-based procedure only rejects $25.1 \%$ of the time.

Second - and counterintuitively - increasing the sample size does not improve the comparative performance of tests based on asymptotic critical values. On the contrary, the larger the sample size, the worse the comparative performance of tests based on asymptotic critical values becomes. This is uniformly the case for all values of $\rho$. For $\rho=0.95$, for example, tests based on Shin's asymptotic critical values incorrectly reject cointegration $72.1 \%$ of the time for $T=100,93.2 \%$ of the time for $T=$ 200, and $100.0 \%$ of the time for $T=1,000$. The corresponding fractions of rejections based on the bootstrap procedure, on the other hand, are equal to 25.1, 23.3, and $15.1 \%$, respectively. The reason for this counterintuitive phenomenon is straightforward, and it has to do with the results reported in Table D.1 of Appendix D. Even in very large samples (there we worked with samples of length $T=100,000$ ), the Monte Carlo distribution of Shin's test statistic gets "shifted upward", compared to the asymptotic distribution whose fractiles are reported in Shin's (1994) Table 1, the more the larger the value of $\rho$. For the present purposes, this implies that, the larger $\rho$, the more tests based on asymptotic critical values will reflect such very-large-samples distortion. As a result, the larger $T$, the worse tests based on asymptotic critical values will become. On the other hand, the performance of the proposed bootstrapping procedure, although not as good as that of Cavaliere et al.'s procedure for Johansen's tests, is uniformly superior to that of tests based on asymptotic critical values.

Third, the performance of the bootstrap procedure follows a hump-shaped pattern as a function of the sample size. For each value of $\rho$, the fraction of rejections reaches a maximum (among the sample sizes considered herein) for $T=100$, and it then declines monotonically, reaching the minimum for $T=1,000$. We do not have a clear intuition for why this may be the case, but the pattern is a robust one, so it ought to be the case that some deep underlying cause is at work here. In particular, it is reassuring that, for $T=1,000$ - that is, under the circumstances in which Shin's asymptotical critical values perform worse - the bootstrap procedure works best, with the fractions of false rejections ranging between 0.111 and 0.115 for $\rho$ smaller than or equal to 0.75 , and increasing to 0.13 and 0.151 for $\rho$ equal to 0.9 and 0.95 , respectively.

Turning to the DGP featuring no cointegration, here, ideally, we would want the tests to reject as much as possible. At first blush, it would appear that, conditional on this DGP, Shin's asymptotic critical values perform uniformly much better than our bootstrapping procedure. Upon a moment's reflection, however, it clearly appears that such apparently superior performance is nothing but a fluke, and it simply originates from the fact that - as we just discussed - the higher the persistence of the cointegration residual, the more the Monte Carlo distribution of Shin's test statistic gets shifted upward compared to the asymptotic distribution reported by Shin, with the result that, based on Shin's asymptotic critical values, you reject more and more frequently. Another way of putting this is that the results reported in the next to the 
last row of Table E.1 are nothing but the limit of what is reported in the previous part of the table, based on Shin's asymptotic critical values, as $\rho$ progressively increased. The bottom line is that such apparently superior performance is just a fluke. As for the proposed bootstrapped procedure, even in very large samples, the ERFs it produces by no means approach the ideal one of $100 \%$. For $T=1,000$, for example, cointegration is rejected only about $38 \%$ of the time, and based on smaller sample lengths, much less than that.

Overall, the Monte Carlo evidence reported in Table E.1 clearly shows how the bootstrapping procedure we are here proposing significantly improves upon tests based on Shin's asymptotic critical values. At the same time, however, the performance is far from perfect: conditional on the DGP featuring cointegration, for example, if $\rho=0.95$ and $T=200$, we incorrectly reject the null of about $23 \%$ of the time.

Summing up There are two things to take away from all this and to keep in mind in order to correctly interpret the results from Shin's bootstrapped tests performed on the actual data:

- If the true DGP features no cointegration, our procedure rejects the null of cointegration much less than it should.

- If, on the other hand, the true DGP does feature cointegration, the procedure although it represents an improvement upon using Shin's asymptotic critical values - still does not perform optimally, the more so the more persistent the cointegration residual is.

Key implications from all this are as follows:

First, Shin's asymptotic critical values should not be used.

Second, lack of rejection of the null of cointegration based on Shin's tests and our bootstrapping procedure does not represent strong evidence that cointegration is truly there. As the last row of Table E.1 shows, if the true DGP does not feature cointegration, our procedure will capture the truth between 17.5 and $37.8 \%$ of the time.

Third, rejection of the null of cointegration does not appear to be especially informative about the true nature of the DGP, as the ERFs are not significantly different conditional on the two possible states of the world.

Another way to put all this is that results from Shin's tests appear, overall, as less informative than the corresponding results produced by Johansen's tests bootstrapped as in CRT. 


\section{F Are GDP and Short-Term Nominal Interest Rates Cointegrated?}

As discussed by Shin (1994), when the number of I(1) regressors in his cointegrating regressions is greater than one, a necessary condition for his approach to be valid is that they are not cointegrated. This means that for either of the unrestricted cointegrating regressions we run in Appendix G, that is

$$
\ln \left(M_{1, t}\right)=\beta_{0}+\beta_{1} \ln \left(N G D P_{t}\right)+\beta_{2} R_{t}+\varepsilon_{t},
$$

or

$$
\ln \left(M_{1, t}\right)=\beta_{0}+\beta_{1} \ln \left(N G D P_{t}\right)+\beta_{2} \ln \left(R_{t}\right)+\varepsilon_{t},
$$

where the notation is obvious, with $N G D P_{t}$ and $R_{t}$ being nominal GDP and the short rate, the two right-hand-side variables ought not to share a common stochastic trend.

Tables F.1.a-F.1.c report results from Johansen ${ }^{17}$ cointegration tests for (the log of) the short rate and the logarithm of nominal GDP. Out of 34 tests, we fail to reject the null in 25 cases. Taken at face value, these results would imply that either (F.1) or (F.2) can indeed be run in those cases, whereas in the remaining nine cases, Shin's approach cannot be applied. In fact, we regard those nine rejections as (quite obvious) flukes, which is why in Tables G.1a-G.1c in Appendix G we report results from either (F.1) or (F.2) for all 34 samples. The reason for this is that, based on economic logic, the notion that the short-term rate might share a common stochastic trend with nominal GDP is manifestly absurd. Further, as we discuss in the next paragraph, it is not uncommon for Johansen's tests to "detect" cointegration among variables which, based on either economic logic - or just simple, plain logic - cannot possibly be cointegrated.

Most (or all) economists would likely think that the long-run evolution of the price level has nothing to do with global warming. Whereas the latter is driven by $\mathrm{CO}_{2}$ emissions, the former depends on the nature of the monetary regime. This is not, however, what Johansen's cointegration tests - taken at face value - would seem to suggest. As Table F.1 shows, for two countries (Bolivia and Brazil) out of the four we consider, the very same Johansen tests we use to explore the presence of a long-run money demand "detect" cointegration between the logarithm of the price level and either the ocean or the land "global temperature anomaly", the two most commonly used indicators of the strength of global warming. ${ }^{18}$ These results are much more common than might be thought: the very first draft of Benati (2015), which was

\footnotetext{
${ }^{17}$ We only consider Johansen tests because, as we will discuss shortly, no cointegration between GDP and the short rate is the "natural null hypothesis".

${ }^{18}$ The "global temperature anomaly" - either for the earth's landmass or for its oceans - is defined as the temperature's deviation from a reference level, which is essentially an average since January 1880. Monthly, seasonally unadjusted series for the earth's global land and ocean temperature anomalies are from the U.S. National Oceanic and Atmospheric Administration's website. The
} 
presented at a conference at the Swiss National Bank and is still available from the SNB's website, documented how the very same Johansen tests used herein "detect" cointegration between Canada's unemployment rate and the concentration of $\mathrm{CO}_{2}$ in the atmosphere, and between the ocean "global temperature anomaly" and the unemployment rate in the Euro area, the United Kingdom, and Canada. All of this is to bring home the point that (economic) logic should take precedence over results from statistical tests, and when the two collide, the former should prevail.

\section{G Searching for a Long-Run Money Demand}

Tables SELA.2, SL.2, LL.2, and LLCO.2 in the online appendix report results from either Johansen or Shin tests for cointegration between (log) velocity and (the log of) the short rate based on the four specifications considered herein: Selden-Latané, semi-log, log-log, and log-log with the $1 \%$ correction to the short rate along the lines of Alvarez and Lippi (2009).

Figures SELA.1-SELA.6, SL.1-SL.6, LL.1-LL.6, and LLCO.1-LLCO.6 in the online appendix report, in the top rows, the candidate cointegration residuals produced by either Johansen's or Stock and Watson's (1993) estimators, and, in the bottom rows, the bootstrapped distributions ${ }^{19}$ of the corresponding estimates of the coefficient on (the log of) the short rate (so, to be clear, what Figures LL.1-LL.6 and LLCO.1-LLCO.6 show, for example, are the bootstrapped distributions of the estimated elasticities). For each bootstrapped distribution we also report the mean, the median, and the 5th and 95th percentiles. For the reasons discussed in Sections 6 and 7, and especially in Section 7.2, we report both candidate cointegration residuals and estimates of the coefficients on the short rate for all countries rather than only for those for which statistical tests detect evidence of cointegration.

Tables LL.3 and LLCO.3 report bootstrapped $p$-values for testing the null hypothesis that the elasticity of money demand is equal to the Baumol-Tobin benchmark value, -0.5 , based on bivariate systems featuring the logarithms of velocity and the short rate. Table SL.3 reports $p$-values for testing the null hypothesis that the semielasticity is equal to -0.1 based on bivariate systems featuring the short rate and the logarithm of velocity. As for the Selden-Latané specification, since, before us, no one has estimated it since 1960, we do not have any benchmark value that we can use in order to perform statistical tests. In Table SELA.3 we therefore report bootstrapped $p$-values for testing the null hypothesis that the coefficient on the short rate should be equal to -0.4 , which is roughly equal to the median (or modal) estimate we obtain for the United States based on the Lucas-Nicolini aggregate (see Figure SELA.6).

series are available since January 1880 and have been converted to the annual frequency by taking simple annual averages.

${ }^{19}$ Bootstrapping has been implemented as in Cavaliere et al. (2012) based on the estimated VECM conditional on one cointegration vector. 
Tables SL.4, LL.4, and LLCO.4 report results from Johansen's cointegration tests based on unrestricted specifications featuring (the log of) the short rate, and the logarithms of nominal GDP and $M_{1}$, and Tables SL.5, LL.5, and LLCO.5 report the corresponding results from Shin's tests.

Finally, Tables SL.6, LL.6, and LLCO.6 report bootstrapped $p$-values for testing the null hypothesis that the income elasticity of money demand is equal to 1 , based on the same unrestricted specifications of Tables SL.4, LL.4, and LLCO.4, and Tables SL.5, LL.5, and LLCO.5. ${ }^{20}$

\section{G.1 Unrestricted tests of the null of cointegration}

Although this paper mostly focuses on the results produced by bivariate systems, let us start by briefly discussing those produced by Shin's tests applied to unrestricted specifications featuring (the logarithm of) the short rate and the logarithms of either nominal or real GDP and $M_{1}$. The reason for doing so is that they represent one "extreme end" of the spectrum within the full set of our results. As Tables SL.5, LL.5, and LLCO.5 show, based on unrestricted three-variables systems it is extremely difficult to reject the null of cointegration. At the $10 \%$ level, we obtain just four rejections of the null out of 32 tests (that is, $12.5 \%$ of the total) based on the semi$\log$ specification, whereas based on the log-log specification with the $1 \%$ correction to the short rate, we obtain only one rejection out of 31 tests (3.2\% of the total). These figures are in line with the number of 'fluke rejections' we should expect from the tests even in the best of circumstances, and in fact, for the log-log specification with the $1 \%$ correction, they are much smaller. ${ }^{21}$ This means that, in principle, these rejections could well be "explained away" as flukes.

This is, however, not the position we want to take here. Rather, we want to downplay these results. The reasons for this have already been discussed in Sections 6.2.2 and 6.2.3 in the text and Section E.3.2 in Appendix E. As we stressed there, lack of rejection of the null of cointegration based on Shin's tests and our bootstrapping procedure does not represent strong evidence that cointegration is truly there. This means that the results reported in Tables SL.5, LL.5, and LLCO.5 do not truly represent strong evidence in favor of cointegration, and we should not read too much into them.

\footnotetext{
${ }^{20}$ We do not consider specifications featuring the levels of either GDP or $M_{1}$. For the reasons discussed in Section 3, it is not possible to meaningfully test for a unit root based on the level of either series, and, as a consequence, it is not possible to run cointegration tests based on them.

${ }^{21}$ To fix ideas for the less econometrically inclined readers, under ideal circumstances, any statistical test should incorrectly reject the null hypothesis at the $x \%$ level $x \%$ of the time.
} 


\section{G.2 Testing for cointegration between velocity and the short rate}

Turning to the set of results based on bivariate systems, the evidence reported in Tables SELA.2, SL.2, LL.2, and LLCO.2 can be usefully classified as follows.

\section{G.2.1 Cases in which evidence of cointegration is strong}

United States We start with the United States, which has been the focus of the most intensive investigation and for which researchers such as Friedman and Kuttner (1992; henceforth, FK) have documented the disappearance, starting from the 1980s, of any previously identified stable relationship between monetary aggregates, GDP, and interest rates. As the results based on the standard $M_{1}$ aggregate show, based on (log) velocity and (the $\log$ of) the short rate FK's results for $M_{1}{ }^{22}$ are still valid, with Johansen's test not rejecting the null of no cointegration, and Shin's test strongly rejecting the null of cointegration, and based on either specification.

Things are very different, however, based on Lucas and Nicolini's (2015) "New $M_{1}$ " aggregate. (For the sake of simplicity, from now on, when we refer to the United States, " $M_{1}$ " will mean "Lucas and Nicolini's New $M_{1}$ aggregate", whereas the traditional aggregate will be explicitly referred to as the "standard $M_{1}$ aggregate".) In line with the visual evidence in the second panel of Figure 1 in the online appendix, both Johansen and Shin tests in Table SELA.2 point toward the presence of cointegration between the two series, with $p$-values for the trace and maximum eigenvalue tests equal to 0.038 and 0.048 , and the $p$-value for Shin's test equal to 0.121. These results provide statistical backing to Lucas and Nicolini's (2015) point that, once money market deposit accounts (MMDAs) are properly classified, on the basis of the economic function they perform, as part of $M_{1}$, the puzzle highlighted by FK, for example, of the lack of a stable demand for $M_{1}$ simply disappears.

Further, a comparison between the results based on the Selden-Latané specification and those based on the semi-log and log-log ones confirms the visual impression from Figure 1 in the online appendix, with the null of no cointegration not being rejected based on the log-log specification, and with the semi-log specification producing weak and inconclusive evidence (with the corresponding $p$-values being equal to 0.101 and 0.081 ). This suggests that for the United States, the data would seem to prefer the Selden-Latané specification, as opposed to the semi-log and log-log, which have dominated the literature on money demand. As we will see, this appears to be the case for several other low-inflation countries, notably the United Kingdom and Canada.

Other countries Moving to other countries, because of the sheer size of the overall set of results reported in the online appendix, in what follows we will mostly focus

\footnotetext{
${ }^{22} \mathrm{FK}$ considered several monetary and even credit aggregates.
} 
on the Selden-Latané specification and on the log-log one with the $1 \%$ correction to the short rate, which the data seem to favor compared to the semi-log one.

Among the very high-inflation countries, evidence of cointegration is strong for Argentina, Brazil, Chile, Israel, and Mexico. Further, for Chile it is important to keep in mind that, as shown in Figure 2 in the online appendix, Chilean log velocity had exhibited, in the early 1970s, a dramatic temporary fall at a time when the short rate was spiking upward, which distorts any attempt-based on cointegration or otherwise - to detect a positive relationship between the two series. Although we do not have any solid, comprehensive explanation for this phenomenon, it is worth recalling that those years (the fall in velocity was especially marked between 1971 and 1974) had been characterized by the economic and political turmoil that culminated with Augusto Pinochet's military coup d'etat of September 1973. Although we have no hard proof of this, it is therefore highly likely that the fall in velocity of the early 1970s had been mostly unrelated to interest rates fluctuations, and it had been instead caused by the turmoil that was ravaging the country.

Among other countries, evidence of cointegration is strong for Canada, Korea, New Zealand, Norway, and Portugal (1914-1965) based on the Selden-Latané specification; and for Canada (1967-2012), New Zealand, Norway, Portugal, South Africa, and Switzerland based on the log-log specification with the $1 \%$ correction to the short rate (based on the semi-log specification, on the other hand, evidence of cointegration is strong only for Canada and Portugal (1914-1965)).

Let us now turn to the symmetric case in which both Johansen's and Shin's tests produce weak or nonexistent evidence of cointegration.

\section{G.2.2 Cases in which evidence of cointegration is weak or nonexistent}

This is the case for Finland (1914-1985) and Japan under the gold standard based on either specification, for Portugal (1966-1998) based on either the Selden-Latané specification or the semi-log, and for West Germany based on the log-log.

The main issue that is worth exploring here is to which extent these results might reasonably be regarded as flukes that are due to a short sample period and/or a highly persistent cointegration residual. For Portugal the sample period is indeed very short, but the CCRs shown in Figures SELA.5 and SL.5 appear as hardly stationary. For Finland the CCR in Figures SELA.3 and LLCO.3 also looks hardly stationary, whereas the length of the sample period (72 years) cannot be invoked as an explanation for not having detected a long-run relationship between the series. Finally, for Japan evidence is mixed. On the one hand, the sample period is just 28 years long, and the CCRs produced by Johansen's procedure mostly appear as stationary and are moderately persistent (see Tables SELA.1, ..., LLCO.1). On the other hand, the CCRs produced by Stock and Watson's estimator appear as all but stationary, and in fact the point estimate of $\hat{\rho}_{M U B}$ in Tables SELA.1, ..., LLCO.1 are borderline explosive. 
Let us now turn to the case in which Johansen's and Shin's tests give conflicting signals, thus producing ambiguous results.

\section{G.2.3 Cases in which evidence is ambiguous}

An important point to keep in mind here is that, as discussed in Section 6 and Appendix E, Johansen's tests exhibit an overall better performance and appear as more informative than Shin's.

Johansen: Cointegration, Shin: No cointegration Nowhere this is better illustrated than in the case of the United Kingdom. Whereas the visual evidence in Figure 3 in the online appendix points towards a strong relationship between velocity and the short rate, and Johansen's tests detect cointegration based on the SeldenLatané specification at a very high confidence level (with both $p$-values smaller than 0.02 ), the $p$-value for Shin's test is equal to 0.046, thus strongly rejecting the null of cointegration. (Qualitatively similar evidence is produced by the semi-log specification, whereas the results based on the log-log specification are uniformly weak.) This result is most likely a fluke: Although the sample period is quite long (91 years), the estimates of the persistence of the CCRs reported in Table SELA.1 are quite high (at 0.64 and 0.69). The results from Monte Carlo simulations reported in Table E.1 show that, with $T=100$ and $\rho=0.75$, Shin's test incorrectly rejects cointegration $17.2 \%$ of the time. This position is reinforced by the strong evidence of stationarity exhibited by the CCRs in Figure SELA.6. Taking into account the fact that Shin's tests are less informative than Johansen's, it can be reasonably concluded that, overall, evidence does indeed point toward cointegration.

The same holds - to an even greater extent - for Switzerland for the period 19482005. Based on either specification, Johansen's tests detect very strong evidence of cointegration, whereas Shin's tests consistently reject the null. In this case, too, cointegration residuals uniformly look stationary, and they are moderately persistent. Taking into account that the sample period, at 58 years, is not especially long, it is fair to conclude that evidence points quite strongly toward cointegration.

Turning to Norway, on the other hand, although the statistical evidence is qualitatively in line with that for the United Kingdom, here we want to downplay it and to argue that some skepticism is instead in order. The main reason for this is that the CCR appears as very highly persistent and possibly nonstationary, which is conceptually related to the visual evidence in the last panel of Figure 4 in the online appendix.

Johansen: No cointegration, Shin: Cointegration Turning to the opposite case, in the main text we already discussed the case of Turkey. As we argued there, a possible explanation for the failure on the part of Johansen's procedure to detect 
evidence of cointegration based on either the Selden-Latané or the semi-log specifications is the high persistence of the CCR, coupled with the comparatively short sample length. The same argument holds for Colombia, Germany (1876-1913), Japan (1955-2013), Italy, the Netherlands, Spain, and Switzerland (1851-1906) based on the Selden-Latané specification; and for Australia, Canada (1934-2006), Colombia, Germany (1876-1913), Japan (1955-2013), Korea, the Netherlands, Spain, and Taiwan based on the log-log specification with the $1 \%$ correction to the short rate. In most of these cases, sample periods are quite short, and estimates of the persistence of the CCRs in Tables SELA.1 and LLCO.1 are moderate to high, thus suggesting that failure to detect cointegration based on Johansen's tests may simply originate from the problem discussed by Engle and Granger (1987), which we discussed in Sections 6 and 7 in the main text and in Appendix E.

Let us now turn to the evidence produced by Johansen's procedure applied to unrestricted specifications for $M_{1}$, GDP, and the short rate.

\section{G.3 Unrestricted tests of the null of no cointegration}

Tables SL.4, LL.4, and LLCO.4 report results from Johansen's tests of the null hypothesis of no cointegration based on unrestricted specifications for the logarithms of GDP and $M_{1}$ and (the logarithm of) the short rate.

Based on the semi-log specification, at the $10 \%$ level, cointegration is detected based on both the trace and the maximum eigenvalue tests for Argentina, Bolivia, Brazil (1934-2012), Chile, Israel, Mexico, the Netherlands, Norway, Switzerland (19482005), Taiwan, and the United Kingdom, whereas the two tests produce opposite results for Australia, Brazil (1974-2012), Canada, Germany (1876-2013), Japan (19552013), Korea, Portugal (1914-1965), South Africa, and Spain. Only for the remaining few cases do Johansen tests clearly not reject the null of no cointegration, although, as previously discussed, in a number of instances a plausible explanation is the short sample period and/or the persistence of the cointegration residual.

Based on the log-log specification with the $1 \%$ correction to the short rate, cointegration is detected based on both the trace and the maximum eigenvalue tests for Argentina, Brazil (1974-2012), Canada (1967-2013), Japan (1955-2013), Korea, Israel, Mexico, the Netherlands, Norway, Portugal (1914-1965), and Switzerland (1948-2005), whereas the two tests produce opposite results for Bolivia, Germany (1876-2013), New Zealand, and South Africa.

\section{G.3.1 Is the income elasticity of money demand equal to 1?}

Tables SL.6, LL.6, and LLCO.6. report bootstrapped p-values for testing the null hypothesis that the income elasticity of money demand should be equal to one, based on unrestricted specifications for the logarithms of GDP and $M_{1}$ and (the logarithm of) the short rate. Overall, results are mixed. Based on the semi-log specification, a unitary income elasticity is rejected in 13 cases out of 31 (i.e., $43.3 \%$ of the time) 
based on Johansen's estimator of the cointegration vector and in 21 cases $(70.0 \%$ of the time) based on Stock and Watson's estimator. The corresponding figures based on the log-log specification with the $1 \%$ correction on the short rate are 11 cases (36.7\% of the time) based on Johansen's estimator, and 19 cases (63.3\% of the time) based on Stock and Watson's.

\section{G.4 Two cases in which the short rate is stationary}

Finally, for two cases - Canada and Spain under the gold standard - it is not possible to find any evidence pointing toward cointegration. Since in either case the short rate is $\mathrm{I}(0)$ - see Table C.1b - cointegration tests can only be applied to the bivariate system comprising the logarithms of nominal GDP and nominal $M_{1}$. For Canada, Johansen's trace statistic is equal to 10.932 with a bootstrapped $p$-value equal to 0.398 , whereas the maximum eigenvalue statistic is equal to 8.647 , with a bootstrapped $p$-value of 0.484 . For Spain, the corresponding figures are the following (bootstrapped $p$-values in parentheses): for the trace test, $5.192(0.895)$, and for the maximum eigenvalue test, 4.214 (0.914). As for Shin's tests, they are equal to 0.218 (0.074) for Canada and to 0.486 (0.049) for Spain. 


\section{References}

Alvarez, F., And F. Lippi (2009): "Financial Innovation and the Transactions Demand for Cash," Econometrica, 77(2), 363-402.

Andrews, D. W. K. (1991): "Heteroskedasticity and Autocorrelation-Consistent Covariance Matrix Estimation," Econometrica, 59(3), 817-858.

BAffigi, A. (2011): "Italian National Accounts: A Project of Banca d'Italia, ISTAT and University of Rome Tor Vergata," Economic History Working Papers, Banca d'Italia, n. 18.

Bancaditalia (2013): "Tavole Storiche, Indicatori Monetari e Finanziari," Dicembre 2013.

Barciela-López, C., A. Carreras, and X. Tafunell (2005): Estadísticas Históricas de España: Siglos XIX-XX, Vol. 3. Fundacion BBVA.

Barkai, H., and N. Liviatan (2007): The Bank of Israel Volume 1: A Monetary History. New York, Oxford University Press.

Benati, L. (2015): "The Long-Run Phillips Curve: A Structural VAR Investigation," Journal of Monetary Economics, 76(November), 15-28.

Bernanke, B. S., M. Gertler, and M. Watson (1997): "Systematic Monetary Policy and the Effects of Oil Price Shocks," Brookings Papers on Economic Activity, 1997(1), 91-157.

Boeschoten, W. (1992): Hoofdlijnen van de economische geschiedenis van Nederland 1900-1990. Amsterdam: NIBE.

Braun-Llona, J., M. Braun-Llona, I. Briones, J. Diaz, R. Luders, and G. Wagner (1998): "Economia Chilena 1810-1995. Estadisticas Historicas," Pontificia Universidad Catolica de Chile, documento de trabajo.

Bundesbank (1976): Deutsches Geld- und Bankwesen in Zahlen 1876-1975. Deutsche Bundesbank.

Capie, F., And A. Webber (1985): A Monetary History of the United Kingdom, 1870-1982. London: Allen and Unwin.

Cavaliere, G., A. Rahbek, and A. M. R. Taylor (2012): "Bootstrap Determination of the Cointegration Rank in Vector Autoregressive Models," Econometrica, 80(4), 1721-1740.

DeJong, A. (1967): "Geschiedenis van de Nederlandsche Bank," Vol. 3, pp. 644-645. 
Elliot, G., T. J. Rothenberg, and J. H. Stock (1996): "Efficient Tests for an Autoregressive Unit Root," Econometrica, 64(4), 813-836.

Engle, R. F., and C. W. J. Granger (1987): "Cointegration and Error Correction: Representation, Estimation, and Testing," Econometrica, 55(2), 251-276.

Faust, J., And E. Leeper (1997): "When Do Long-Run Identifying Restrictions Give Reliable Results?," Journal of Business and Economic Statistics, 15(3), 345353.

Fratianni, M., And F. Spinelli (1997): A Monetary History of Italy. Cambridge University Press.

Friedman, B. M., And K. N. Kuttner (1992): "Money, Income, Prices, and Interest Rates," American Economic Review, 82(3), 472-492.

Furlong, K. (2001): “The Montreal Gazette Call Loan Rate, 1871-1907,” Canadian Journal of Economics, 34(1), 165-173.

HaAvisto, T. (1992): Money and Economic Activity in Finland, 1866-1985. Lund Economic Studies.

Hamilton, J. (1994): Time Series Analysis. Princeton, NJ, Princeton University Press.

Hansen, B. E. (1999): "The Grid Bootstrap and the Autoregressive Model," Review of Economics and Statistics, 81(4), 594-607.

Hills, S., And R. T. N. Dimsdale (2010): "The UK Recession in Context: What Do Three Centuries of Data Tell Us?," Bank of England Quarterly Bulletin, (2010 Q4), 277-291.

Homer, S., And R. Sylla (2005): A History of Interest Rates. John Wiley and Sons.

Johansen, S. (2002): "A Small Sample Correction for the Test of Cointegrating Rank in the Vector Autoregressive Model," Econometrica, 70(5), 1929-1961.

Junguito, R., And H. Rincón (2007): "La política fiscal en el siglo XX en Colombia," in J. Robinson and M. Urrutia (eds.), Economía Colombiana del Siglo XX: Un Análisis Cuantitativo, Banco de la República y Fondo de Cultura Económica, Colombia, pp. - .

Klovland, J. T. (2004): "Monetary aggregates in Norway 1819-2003," in Øyvind Eitrheim, Jan T. Klovland and Jan F. Qvigstad, eds., Historical Monetary Statistics for Norway 1819Ü2003, Norges Bank, Occasional Paper N. 35/2004. 
Laubach, T., and J. Williams (2003): "Measuring the Natural Rate of Interest," The Review of Economics and Statistics, 85(4), 1063-1070.

LuchsJr., R. E. (1988): "Money Demand in the United States: A Quantitative Review," Carnegie-Rochester Conference Series on Public Policy, 29, 137-168.

LucasJr., R. E., And J.-P. Nicolini (2015): "On the Stability of Money Demand," Journal of Monetary Economics, 73, 48-65.

Luetkepohl, H. (1991): Introduction to Multiple Time Series Analysis, 2nd edition. Springer-Verlag.

Mata, E., And N. Valerio (2011): The Concise Economic History of Portugal: A Comprehensive Guide.

Meltzer, A. H. (1963): "The Demand for Money: The Evidence from the Time Series," Journal of Political Economy, 71(3), 219-246.

Metcalf, C., A. Redish, and R. Shearer (1996): "New Estimates of the Canadian Money Stock: 1871-1967," University of British Columbia Discussion Paper No. 96-17, July 1996.

Muscatelli, A., And F. Spinelli (2000): "The Long-Run Stability of the Demand for Money: Italy 1861-1996," Journal of Monetary Economics, 45(3), 717-739.

Officer, L. H., And S. H. Williamson (2015): "The Annual Consumer Price Index for the United States, 1774-2014," available at: http://www.measuringworth.com/uscpi/.

Ohanian, L. E., And A. Raffo (2011): "Aggregate Hours Worked in OECD Countries: New Measurement and Implications for Business Cycles," Journal of Monetary Economics, 59(1), 40-56.

SaintMarc, M. (1983): Histoire Monetarie de la France, 1880-1980. Paris, Presses Universitaires de la France.

Shearer, R. A., and C. Clark (1984): "Canada and the Interwar Gold Standard, 1920-35: Monetary Policy without a Central Bank," in M. D. Bordo and A. J. Schwartz, eds., A Retrospective on the Classical Gold Standard, 1821-1931, University of Chicago Press, pp. 277-310.

SHIN, Y. (1994): "A Residual-Based Test of the Null of Cointegration against the Alternative of No Cointegration," Econometric Theory, 10(1), 91-115.

Smits, J.-P., P. WoltJer, and D. Ma (2009): "A Dataset on Comparative Historical National Accounts, ca. 1870-1950: A Time-Series Perspective," pp. University of Groningen, mimeo. 
Stock, J. H., And M. W. Watson (1993): "A Simple Estimator of Cointegrating Vectors in Higher Order Integrated Systems," Econometrica, 61(4), 783-820.

Swensen, A. R. (2006): "Bootstrap Algorithms for Testing and Determining the Cointegration Rank in VAR Models," Econometrica, 74(6), 1699-1714.

TAmaki, N. (1995): Japanese Banking: A History (1859-1959). New York: Cambridge University Press. 


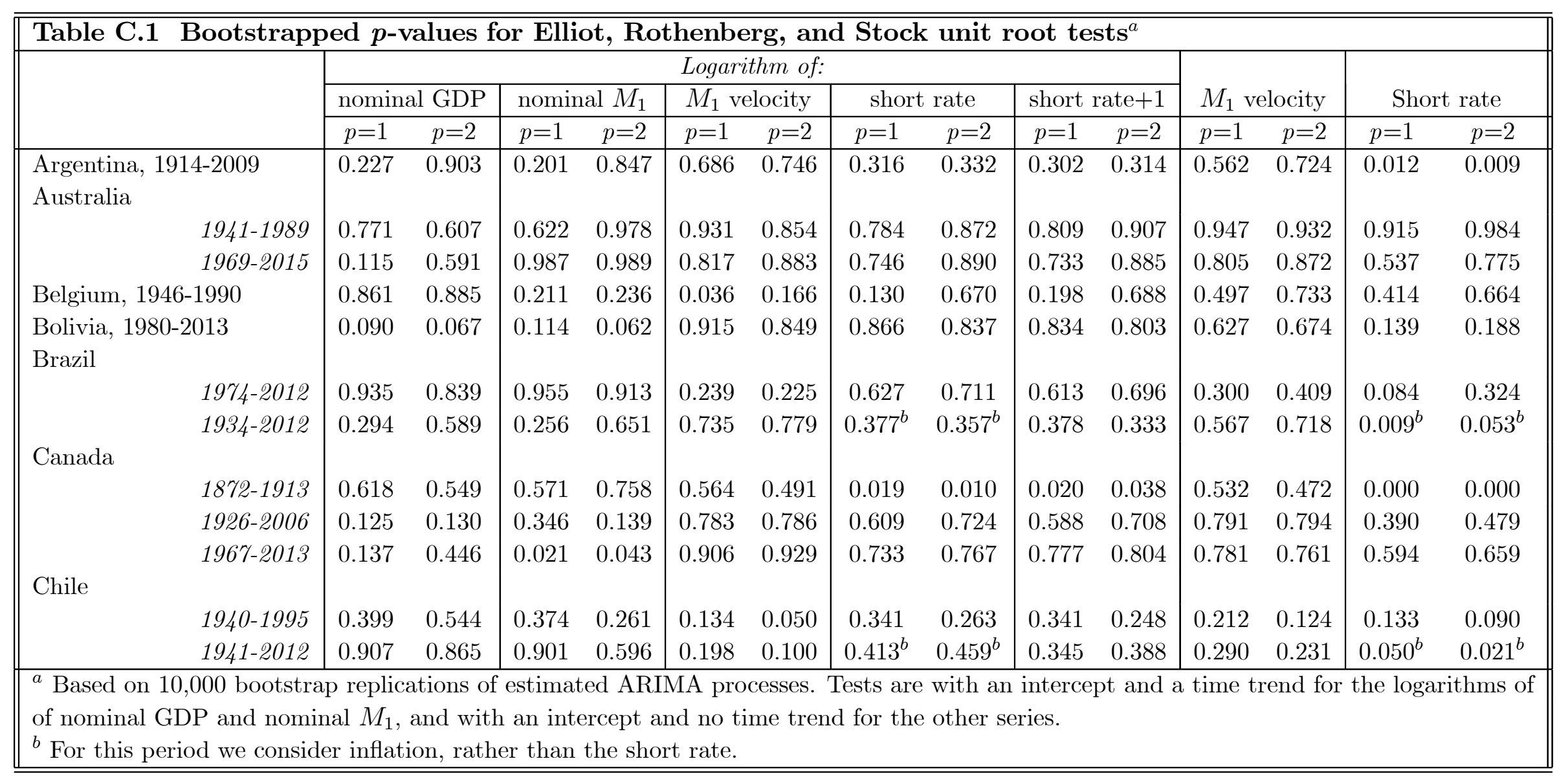




\begin{tabular}{|c|c|c|c|c|c|c|c|c|c|c|c|c|c|c|}
\hline \multicolumn{11}{|c|}{\begin{tabular}{r|r} 
Table C.1 (continued) Bootstrapped $\boldsymbol{p}$-values for Elliot, $\mathbf{R}$ \\
Logarithm of:
\end{tabular}} & \multirow{2}{*}{\multicolumn{2}{|c|}{$M_{1}$ velocity }} & \multirow{2}{*}{\multicolumn{2}{|c|}{ Short rate }} \\
\hline & \multicolumn{2}{|c|}{ nominal GDP } & \multicolumn{2}{|c|}{ nominal $M_{1}$} & \multicolumn{2}{|c|}{$M_{1}$ velocity } & \multicolumn{2}{|c|}{ short rate } & \multicolumn{2}{|c|}{ short rate +1} & & & & \\
\hline & $p=1$ & $p=2$ & $p=1$ & $p=2$ & $p=1$ & $p=2$ & $p=1$ & $p=2$ & $p=1$ & $p=2$ & $p=1$ & $p=2$ & $p=1$ & $p=2$ \\
\hline $\begin{array}{l}\text { Colombia, 1959-2011 } \\
\text { Finland }\end{array}$ & 0.990 & 0.838 & 0.995 & 0.993 & 0.719 & 0.794 & 0.440 & 0.473 & 0.449 & 0.468 & 0.671 & 0.741 & 0.416 & 0.268 \\
\hline $1867-1913$ & 0.790 & 0.840 & 0.071 & 0.364 & 0.008 & 0.039 & 0.094 & 0.043 & 0.095 & 0.042 & 0.004 & 0.038 & 0.074 & 0.042 \\
\hline $1914-1985$ & 0.277 & 0.099 & 0.056 & 0.078 & 0.765 & 0.574 & 0.538 & 0.513 & 0.373 & 0.519 & 0.904 & 0.886 & 0.504 & 0.520 \\
\hline France, 1852-1913 & 0.001 & 0.001 & 0.896 & 0.891 & 0.642 & 0.803 & 0.051 & 0.037 & 0.047 & 0.041 & 0.522 & 0.743 & 0.027 & 0.040 \\
\hline Germany, 1876-1913 & 0.111 & 0.896 & 0.008 & 0.433 & 0.021 & 0.185 & 0.126 & 0.236 & 0.125 & 0.228 & 0.043 & 0.230 & 0.144 & 0.257 \\
\hline Guatemala, 1980-2012 & 0.959 & 0.967 & 0.976 & 0.987 & 0.726 & 0.660 & 0.630 & 0.584 & 0.631 & 0.576 & 0.675 & 0.582 & 0.597 & 0.580 \\
\hline $\begin{array}{l}\text { Hong Kong, 1985-2012 } \\
\text { Japan }\end{array}$ & 0.052 & 0.263 & 0.517 & 0.731 & 0.938 & 0.958 & 0.754 & 0.716 & 0.662 & 0.546 & 0.812 & 0.888 & 0.505 & 0.464 \\
\hline $1885-1913$ & 0.637 & 0.817 & 0.452 & 0.596 & 0.761 & 0.864 & 0.034 & 0.230 & 0.034 & 0.235 & 0.792 & 0.874 & 0.035 & 0.251 \\
\hline $1955-2013$ & 0.217 & 0.716 & 0.131 & 0.438 & 0.946 & 0.928 & 0.726 & 0.752 & 0.757 & 0.766 & 0.791 & 0.770 & 0.598 & 0.571 \\
\hline Korea, 1970-2014 & 0.107 & 0.322 & 0.182 & 0.548 & 0.567 & 0.539 & 0.546 & 0.654 & 0.424 & 0.565 & 0.387 & 0.317 & 0.084 & 0.301 \\
\hline $\begin{array}{l}\text { Israel, 1983-2014 } \\
\text { Italy }\end{array}$ & 0.000 & 0.172 & 0.000 & 0.000 & 0.623 & 0.010 & 0.243 & 0.017 & 0.177 & 0.006 & 0.320 & 0.000 & 0.117 & 0.000 \\
\hline 1861-1913 & 0.955 & 0.995 & 0.116 & 0.723 & 0.016 & 0.007 & 0.767 & 0.802 & 0.766 & 0.798 & 0.006 & 0.005 & 0.756 & 0.780 \\
\hline $1949-1996$ & 0.794 & 0.889 & 0.993 & 0.945 & 0.333 & 0.648 & 0.857 & 0.899 & 0.861 & 0.897 & 0.234 & 0.643 & 0.805 & 0.848 \\
\hline
\end{tabular}




\begin{tabular}{|c|c|c|c|c|c|c|c|c|c|c|c|c|c|c|}
\hline \multicolumn{15}{|l|}{ "Table C.1 (continued) } \\
\hline & \multicolumn{10}{|c|}{ Logarithm of: } & \multirow{2}{*}{\multicolumn{2}{|c|}{$M_{1}$ velocity }} & \multirow{2}{*}{\multicolumn{2}{|c|}{ Short rate }} \\
\hline & \multicolumn{2}{|c|}{ nominal GDP } & \multicolumn{2}{|c|}{ nominal $M_{1}$} & \multicolumn{2}{|c|}{$M_{1}$ velocity } & \multicolumn{2}{|c|}{ short rate } & \multicolumn{2}{|c|}{ short rate +1} & & & & \\
\hline & $p=1$ & $p=2$ & $p=1$ & $p=2$ & $p=1$ & $p=2$ & $p=1$ & $p=2$ & $p=1$ & $p=2$ & $p=1$ & $p=2$ & $p=1$ & $p=2$ \\
\hline Mexico, 1985-2014 & 0.013 & 0.021 & 0.066 & 0.016 & 0.767 & 0.100 & 0.629 & 0.289 & 0.603 & 0.238 & 0.679 & 0.027 & 0.346 & 0.023 \\
\hline Morocco, 1985-2008 & 0.298 & 0.255 & 0.797 & 0.869 & 0.904 & 0.761 & 0.859 & 0.747 & 0.867 & 0.752 & 0.434 & 0.267 & 0.896 & 0.755 \\
\hline Netherlands, 1950-1992 & 0.985 & 0.996 & 0.703 & 0.783 & 0.100 & 0.194 & 0.194 & 0.450 & 0.211 & 0.438 & 0.232 & 0.297 & 0.243 & 0.347 \\
\hline New Zealand, 1934-2014 & 0.971 & 0.983 & 0.437 & 0.490 & 0.801 & 0.801 & 0.562 & 0.531 & 0.553 & 0.519 & 0.776 & 0.766 & 0.334 & 0.301 \\
\hline Norway, 1946-2013 & 0.969 & 0.990 & 0.099 & 0.118 & 0.883 & 0.868 & 0.511 & 0.545 & 0.538 & 0.575 & 0.826 & 0.820 & 0.601 & 0.605 \\
\hline Portugal & & & & & & & & & & & & & & \\
\hline 1891-1913 & 0.621 & 0.764 & 0.255 & 0.941 & 0.015 & 0.503 & 0.392 & 0.336 & 0.384 & 0.321 & 0.010 & 0.492 & 0.503 & 0.330 \\
\hline $1914-1998$ & 0.634 & 0.614 & 0.209 & 0.145 & 0.594 & 0.407 & 0.716 & 0.714 & 0.704 & 0.693 & 0.607 & 0.430 & 0.596 & 0.469 \\
\hline $\begin{array}{l}\text { South Africa, 1967-2014 } \\
\text { Spain }\end{array}$ & 0.985 & 0.987 & 0.875 & 0.863 & 0.884 & 0.919 & 0.367 & 0.457 & 0.369 & 0.464 & 0.853 & 0.887 & 0.316 & 0.332 \\
\hline $1874-1913$ & 0.953 & 0.951 & 0.462 & 0.318 & 0.601 & 0.569 & 0.056 & 0.019 & 0.061 & 0.020 & 0.649 & 0.598 & 0.059 & 0.020 \\
\hline 1941-1989 & 0.632 & 0.504 & 0.154 & 0.505 & 0.187 & 0.440 & 0.828 & 0.878 & 0.822 & 0.871 & 0.363 & 0.512 & 0.589 & 0.720 \\
\hline Switzerland & 0.152 & 0.497 & 0.851 & 0.863 & 0.838 & 0.560 & 0.069 & 0.103 & 0.023 & 0.067 & 0.796 & 0.433 & 0.062 & 0.104 \\
\hline 1948-2005 & 0.949 & 0.930 & 0.498 & 0.712 & 0.425 & 0.359 & 0.156 & 0.177 & 0.242 & 0.165 & 0.453 & 0.417 & 0.186 & 0.120 \\
\hline Taiwan, 1962-2013 & 0.502 & 0.844 & 0.216 & 0.645 & 0.264 & 0.229 & 0.609 & 0.671 & 0.606 & 0.667 & 0.053 & 0.033 & 0.427 & 0.524 \\
\hline Turkey, 1968-2014 & 0.869 & 0.826 & 0.412 & 0.639 & 0.839 & 0.766 & 0.643 & 0.666 & 0.662 & 0.683 & 0.776 & 0.753 & 0.735 & 0.764 \\
\hline United Kingdom, 1922-2014 & 0.076 & 0.679 & 0.082 & 0.571 & 0.925 & 0.842 & 0.814 & 0.851 & 0.707 & 0.816 & 0.837 & 0.768 & 0.333 & 0.572 \\
\hline United States, 1915-2014 & 0.642 & 0.315 & $0.609^{b}$ & $0.380^{b}$ & $0.657^{b}$ & $0.572^{b}$ & 0.639 & 0.598 & 0.569 & 0.498 & $0.737^{b}$ & $0.551^{b}$ & 0.296 & 0.317 \\
\hline Venezuela, 1962-1999 & 0.521 & 0.752 & 0.738 & 0.817 & 0.574 & 0.729 & 0.744 & 0.730 & 0.749 & 0.721 & 0.543 & 0.786 & 0.691 & 0.706 \\
\hline West Germany, 1960-1989 & 0.844 & 0.963 & 0.662 & 0.840 & 0.752 & 0.739 & 0.067 & 0.137 & 0.068 & 0.142 & 0.721 & 0.719 & 0.069 & 0.138 \\
\hline
\end{tabular}




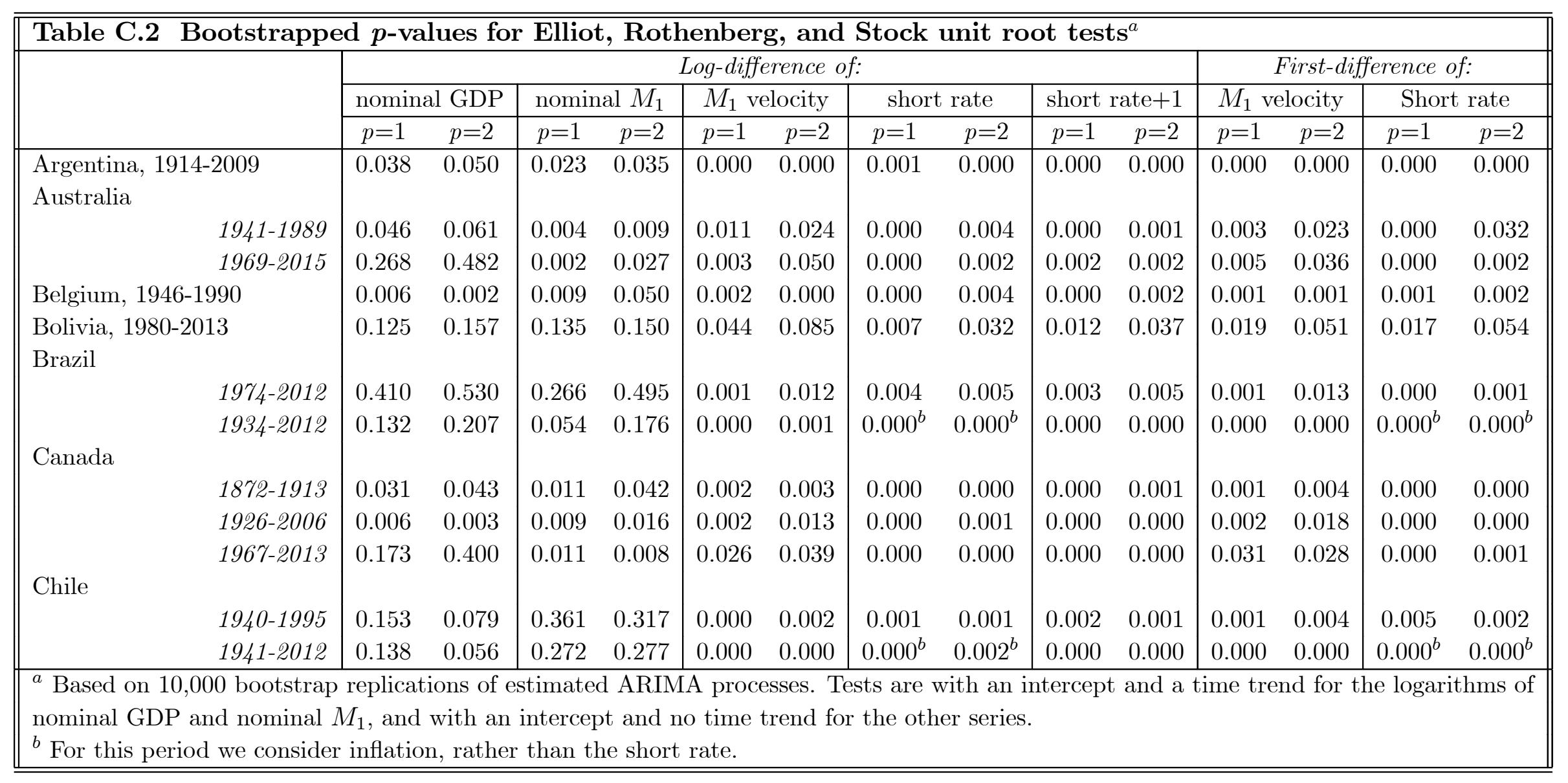




\begin{tabular}{|c|c|c|c|c|c|c|c|c|c|c|c|c|c|c|}
\hline \multicolumn{15}{|l|}{ Table C.2 (continuec } \\
\hline & \multicolumn{10}{|c|}{ Log-difference of: } & \multicolumn{4}{|c|}{ First-difference of: } \\
\hline & \multicolumn{2}{|c|}{ nominal GDP } & \multicolumn{2}{|c|}{ nominal $M_{1}$} & \multicolumn{2}{|c|}{$M_{1}$ velocity } & \multicolumn{2}{|c|}{ short rate } & \multicolumn{2}{|c|}{ short rate +1} & \multicolumn{2}{|c|}{$M_{1}$ velocity } & \multicolumn{2}{|c|}{ Short rate } \\
\hline & $p=1$ & $p=2$ & $p=1$ & $p=2$ & $p=1$ & $p=2$ & $p=1$ & $p=2$ & $p=1$ & $p=2$ & $p=1$ & $p=2$ & $p=1$ & $p=2$ \\
\hline $\begin{array}{l}\text { Colombia, 1959-2011 } \\
\text { Finland }\end{array}$ & 0.479 & 0.711 & 0.021 & 0.276 & 0.001 & 0.008 & 0.001 & 0.005 & 0.001 & 0.004 & 0.001 & 0.005 & 0.005 & 0.012 \\
\hline $1867-1913$ & 0.003 & 0.016 & 0.001 & 0.032 & 0.000 & 0.013 & 0.006 & 0.028 & 0.006 & 0.027 & 0.001 & 0.025 & 0.006 & 0.027 \\
\hline $1914-1985$ & 0.012 & 0.049 & 0.010 & 0.006 & 0.001 & 0.001 & 0.000 & 0.003 & 0.005 & 0.006 & 0.000 & 0.003 & 0.000 & 0.002 \\
\hline Germany, 1876-1913 & 0.132 & 0.148 & 0.003 & 0.071 & 0.001 & 0.043 & 0.000 & 0.013 & 0.002 & 0.001 & 0.002 & 0.051 & 0.001 & 0.015 \\
\hline Guatemala, 1980-2012 & 0.070 & 0.129 & 0.013 & 0.041 & 0.007 & 0.032 & 0.003 & 0.060 & 0.003 & 0.058 & 0.011 & 0.032 & 0.002 & 0.099 \\
\hline $\begin{array}{l}\text { Hong Kong, 1985-2012 } \\
\text { Japan }\end{array}$ & 0.340 & 0.375 & 0.044 & 0.158 & 0.082 & 0.237 & 0.012 & 0.024 & 0.016 & 0.014 & 0.084 & 0.197 & 0.009 & 0.013 \\
\hline $1885-1913$ & 0.012 & 0.039 & 0.015 & 0.025 & 0.002 & 0.014 & 0.003 & 0.025 & 0.002 & 0.001 & 0.003 & 0.020 & 0.002 & 0.026 \\
\hline 1955-2013 & 0.513 & 0.748 & 0.164 & 0.389 & 0.012 & 0.064 & 0.000 & 0.003 & 0.000 & 0.000 & 0.005 & 0.015 & 0.000 & 0.000 \\
\hline Korea, 1970-2014 & 0.696 & 0.755 & 0.101 & 0.296 & 0.001 & 0.009 & 0.001 & 0.001 & 0.001 & 0.001 & 0.001 & 0.002 & 0.004 & 0.001 \\
\hline $\begin{array}{l}\text { Israel, 1983-2014 } \\
\text { Italy }\end{array}$ & 0.012 & 0.000 & 0.060 & 0.000 & 0.003 & 0.037 & 0.004 & 0.035 & 0.004 & 0.025 & 0.008 & 0.017 & 0.014 & 0.0565 \\
\hline $1861-1913$ & 0.000 & 0.001 & 0.001 & 0.007 & 0.000 & 0.010 & 0.001 & 0.001 & 0.000 & 0.000 & 0.000 & 0.020 & 0.001 & 0.001 \\
\hline $1949-1996$ & 0.205 & 0.565 & 0.152 & 0.394 & 0.002 & 0.031 & 0.002 & 0.120 & 0.001 & 0.104 & 0.001 & 0.057 & 0.000 & 0.031 \\
\hline
\end{tabular}




\begin{tabular}{|c|c|c|c|c|c|c|c|c|c|c|c|c|c|c|}
\hline \multirow[t]{4}{*}{ Table C.2 (continued) I } & $\overline{\text { Boots }}$ & $\overline{\mathrm{appe}}$ & $\overline{p-v a l u}$ & es for 1 & Elliot, 1 & $\overline{\text { Rothen }}$ & perg, a & $\overline{\mathrm{ad} \mathrm{St}}$ & "ck un & root & tests $^{a}$ & & & \\
\hline & \multicolumn{10}{|c|}{ Log-difference of: } & \multicolumn{4}{|c|}{ First-difference of: } \\
\hline & \multicolumn{2}{|c|}{ nominal GDP } & \multicolumn{2}{|c|}{ nominal $M_{1}$} & \multicolumn{2}{|c|}{$M_{1}$ velocity } & \multicolumn{2}{|c|}{ short rate } & \multicolumn{2}{|c|}{ short rate +1} & \multicolumn{2}{|c|}{$M_{1}$ velocity } & \multicolumn{2}{|c|}{ Short rate } \\
\hline & $p=1$ & $p=2$ & $p=1$ & $p=2$ & $p=1$ & $p=2$ & $p=1$ & $p=2$ & $p=1$ & $p=2$ & $p=1$ & $p=2$ & $p=1$ & $p=2$ \\
\hline Mexico, 1985-2014 & 0.239 & 0.002 & 0.100 & 0.129 & 0.009 & 0.029 & 0.009 & 0.036 & 0.007 & 0.033 & 0.013 & 0.019 & 0.006 & 0.009 \\
\hline Morocco, 1985-2008 & 0.016 & 0.389 & 0.141 & 0.336 & 0.056 & 0.455 & 0.164 & 0.431 & 0.150 & 0.418 & 0.015 & 0.192 & 0.096 & 0.316 \\
\hline Netherlands, 1950-1992 & 0.068 & 0.437 & 0.007 & 0.099 & 0.001 & 0.057 & 0.000 & 0.000 & 0.000 & 0.000 & 0.001 & 0.042 & 0.000 & 0.000 \\
\hline New Zealand, 1934-2014 & 0.002 & 0.017 & 0.001 & 0.027 & 0.001 & 0.009 & 0.000 & 0.000 & 0.000 & 0.000 & 0.001 & 0.001 & 0.000 & 0.000 \\
\hline Norway, 1946-2013 & 0.001 & 0.019 & 0.004 & 0.040 & 0.002 & 0.026 & 0.000 & 0.000 & 0.000 & 0.000 & 0.001 & 0.027 & 0.000 & 0.000 \\
\hline \multicolumn{15}{|l|}{ Portugal } \\
\hline 1891-1913 & 0.030 & 0.100 & 0.000 & 0.368 & 0.000 & 0.172 & 0.092 & 0.235 & 0.000 & 0.000 & 0.000 & 0.196 & 0.100 & 0.238 \\
\hline $1914-1998$ & 0.026 & 0.039 & 0.006 & 0.010 & 0.000 & 0.000 & 0.003 & 0.089 & 0.003 & 0.075 & 0.000 & 0.000 & 0.001 & 0.003 \\
\hline \multicolumn{15}{|l|}{ Spain } \\
\hline $\begin{array}{l}1014-1910 \\
1941-1989\end{array}$ & 0.001 & 0.006 & 0.011 & 0.011 & 0.011 & 0.051 & 0.000 & 0.000 & 0.000 & 0.000 & 0.027 & 0.095 & 0.000 & 0.002 \\
\hline \multicolumn{15}{|l|}{ Switzerland } \\
\hline $1851-1906$ & 0.001 & 0.018 & 0.002 & 0.049 & 0.001 & 0.005 & 0.000 & 0.000 & 0.001 & 0.002 & 0.000 & 0.001 & 0.000 & 0.000 \\
\hline $1948-2005$ & 0.028 & 0.087 & 0.000 & 0.005 & 0.000 & 0.009 & 0.000 & 0.000 & 0.000 & 0.000 & 0.000 & 0.007 & 0.000 & 0.001 \\
\hline Taiwan, 1962-2013 & 0.222 & 0.556 & 0.020 & 0.032 & 0.003 & 0.003 & 0.000 & 0.000 & 0.000 & 0.000 & 0.001 & 0.001 & 0.000 & 0.000 \\
\hline Turkey, 1968-2014 & 0.494 & 0.598 & 0.297 & 0.518 & 0.008 & 0.081 & 0.006 & 0.114 & 0.006 & 0.116 & 0.003 & 0.029 & 0.002 & 0.060 \\
\hline United Kingdom, 1922-2014 & 0.006 & 0.052 & 0.017 & 0.053 & 0.007 & 0.024 & 0.000 & 0.000 & 0.000 & 0.000 & 0.002 & 0.032 & 0.000 & 0.000 \\
\hline United States, 1915-2014 & 0.000 & 0.000 & $0.000^{b}$ & $0.000^{b}$ & $0.000^{b}$ & $0.000^{b}$ & 0.000 & 0.000 & 0.000 & 0.000 & $0.000^{b}$ & $0.001^{b}$ & 0.000 & 0.000 \\
\hline Venezuela, 1962-1999 & 0.171 & 0.305 & 0.035 & 0.344 & 0.001 & 0.051 & 0.031 & 0.037 & 0.037 & 0.040 & 0.000 & 0.064 & 0.061 & 0.039 \\
\hline West Germany, 1960-1989 & 0.106 & 0.243 & 0.011 & 0.175 & 0.007 & 0.090 & 0.007 & 0.077 & 0.006 & 0.072 & 0.005 & 0.114 & 0.005 & 0.054 \\
\hline
\end{tabular}




\begin{tabular}{|c|c|c|c|c|c|c|c|c|c|c|c|c|c|}
\hline \multicolumn{14}{|c|}{$\begin{array}{l}\text { Table D.1 Simulated fractiles of the distribution in very large samples of Shin's (1994) tests of the } \\
\text { null hypothesis of cointegration, }{ }^{a} \text { based on alternative kernels, and for alternative values of the } \\
\text { persistence of the cointegration residual }\end{array}$} \\
\hline \multirow[b]{3}{*}{ Fractile } & \multirow{3}{*}{$\begin{array}{c}\text { Asymptotic } \\
\text { critical } \\
\text { values from } \\
\text { Shin's (1994) } \\
\text { Table } 1\end{array}$} & \multicolumn{12}{|c|}{ Persistence of the cointegration residual: } \\
\hline & & \multicolumn{4}{|c|}{$\rho=0^{b}$} & \multicolumn{4}{|c|}{$\rho=0.25^{b}$} & \multicolumn{4}{|c|}{$\rho=0.5^{b}$} \\
\hline & & BAR & PAR & $\mathrm{TH}$ & QS & BAR & PAR & $\mathrm{TH}$ & QS & BAR & PAR & $\mathrm{TH}$ & QS \\
\hline 0.01 & 0.017 & 0.018 & 0.018 & 0.018 & 0.018 & 0.027 & 0.026 & 0.026 & 0.022 & 0.047 & 0.045 & 0.044 & 0.034 \\
\hline 0.025 & 0.021 & 0.021 & 0.021 & 0.021 & 0.021 & 0.032 & 0.031 & 0.031 & 0.026 & 0.055 & 0.053 & 0.052 & 0.040 \\
\hline 0.05 & 0.024 & 0.024 & 0.024 & 0.024 & 0.024 & 0.037 & 0.037 & 0.036 & 0.031 & 0.065 & 0.062 & 0.061 & 0.047 \\
\hline 0.1 & 0.029 & 0.029 & 0.029 & 0.029 & 0.029 & 0.046 & 0.044 & 0.044 & 0.037 & 0.078 & 0.075 & 0.074 & 0.057 \\
\hline 0.2 & 0.037 & 0.037 & 0.037 & 0.037 & 0.037 & 0.058 & 0.057 & 0.056 & 0.048 & 0.100 & 0.096 & 0.094 & 0.072 \\
\hline 0.3 & 0.045 & 0.045 & 0.045 & 0.045 & 0.045 & 0.070 & 0.068 & 0.067 & 0.057 & 0.110 & 0.115 & 0.113 & 0.087 \\
\hline 0.4 & 0.053 & 0.053 & 0.053 & 0.053 & 0.053 & 0.082 & 0.080 & 0.079 & 0.067 & 0.142 & 0.136 & 0.134 & 0.103 \\
\hline 0.5 & 0.063 & 0.063 & 0.063 & 0.063 & 0.063 & 0.100 & 0.095 & 0.094 & 0.080 & 0.168 & 0.162 & 0.158 & 0.122 \\
\hline 0.6 & 0.074 & 0.074 & 0.075 & 0.075 & 0.075 & 0.116 & 0.113 & 0.112 & 0.095 & 0.199 & 0.191 & 0.188 & 0.144 \\
\hline 0.7 & 0.090 & 0.091 & 0.091 & 0.091 & 0.091 & 0.141 & 0.137 & 0.136 & 0.115 & 0.242 & 0.233 & 0.228 & 0.175 \\
\hline 0.8 & 0.115 & 0.115 & 0.115 & 0.115 & 0.115 & 0.178 & 0.174 & 0.172 & 0.146 & 0.306 & 0.294 & 0.288 & 0.222 \\
\hline 0.9 & 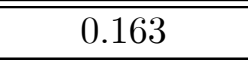 & $\begin{array}{c}0.161 \\
\end{array}$ & 0.161 & $\begin{array}{c}0.161 \\
\end{array}$ & $\begin{array}{l}0.161 \\
\end{array}$ & 0.249 & 0.243 & 0.240 & 0.205 & 0.429 & 0.412 & 0.404 & 0.311 \\
\hline "0.95 & 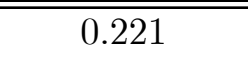 & 0.215 & "0.215 & 0.215 & 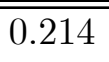 & 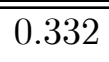 & 0.325 & 0.321 & 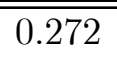 & 0.573 & 0.550 & 0.538 & 0.415 \\
\hline 0.975 & 0.285 & 0.280 & 0.280 & 0.280 & 0.282 & 0.434 & 0.423 & 0.418 & 0.355 & 0.747 & 0.718 & 0.703 & 0.538 \\
\hline 0.99 & 0.38 & 0.395 & 0.395 & 0.396 & 0.390 & 0.611 & 0.597 & 0.592 & 0.501 & 1.048 & 1.006 & 0.987 & 0.765 \\
\hline \multicolumn{14}{|c|}{$\begin{array}{l}{ }^{a} \text { Tests are based on Shin's (1994) equation (2), page } 93 \text {, i.e. for a model with an intercept, but no time trend. For detail } \\
\text { on the data generation process used in the Monte Carlo simulations, see Appendix B. }{ }^{b} K=\left[T^{1 / 3}\right] ; \ell \text { is selected via } \\
\text { Andrews' (1991) 'plug-in' method. BAR = Bartlett kernel; PAR = Parzen kernel; TH = Tukey-Hanning kernel; } \\
\text { QS = quadratic spectral kernel }\end{array}$} \\
\hline
\end{tabular}




\begin{tabular}{|c|c|c|c|c|c|c|c|c|c|c|c|c|c|}
\hline \multicolumn{14}{|c|}{$\begin{array}{l}\text { Table D.1 (continued) Simulated fractiles of the distribution in very large samples of Shin's (1994) } \\
\text { tests of the null hypothesis of cointegration, }{ }^{a} \text { based on alternative kernels, and for alternative } \\
\text { values of the persistence of the cointegration residual }\end{array}$} \\
\hline \multirow[b]{3}{*}{ Fractile } & \multirow{3}{*}{$\begin{array}{c}\text { Asymptotic } \\
\text { critical } \\
\text { values from } \\
\text { Shin's (1994) } \\
\text { Table } 1\end{array}$} & \multicolumn{12}{|c|}{ Persistence of the cointegration residual: } \\
\hline & & \multicolumn{4}{|c|}{$\rho=0.75^{b}$} & \multicolumn{4}{|c|}{$\rho=0.9^{b}$} & \multicolumn{4}{|c|}{$\rho=0.95^{b}$} \\
\hline & & BAR & PAR & $\mathrm{TH}$ & QS & BAR & PAR & $\mathrm{TH}$ & QS & BAR & PAR & $\mathrm{TH}$ & QS \\
\hline 0.01 & 0.017 & 0.103 & 0.098 & 0.095 & 0.067 & 0.259 & 0.251 & 0.242 & 0.164 & 0.504 & 0.496 & 0.478 & 0.318 \\
\hline 0.025 & 0.021 & 0.121 & 0.116 & 0.112 & 0.080 & 0.307 & 0.296 & 0.286 & 0.193 & 0.594 & 0.585 & 0.560 & 0.371 \\
\hline 0.05 & 0.024 & 0.142 & 0.136 & 0.132 & 0.094 & 0.357 & 0.346 & 0.334 & 0.227 & 0.695 & 0.682 & 0.654 & 0.436 \\
\hline 0.1 & 0.029 & 0.171 & 0.163 & 0.159 & 0.113 & 0.429 & 0.415 & 0.401 & 0.272 & 0.833 & 0.821 & 0.789 & 0.526 \\
\hline 0.2 & 0.037 & 0.218 & 0.208 & 0.202 & 0.144 & 0.548 & 0.530 & 0.512 & 0.348 & 1.063 & 1.045 & 1.004 & 0.672 \\
\hline 0.3 & 0.045 & 0.263 & 0.251 & 0.244 & 0.174 & 0.663 & 0.641 & 0.620 & 0.422 & 1.282 & 1.262 & 1.214 & 0.815 \\
\hline 0.4 & 0.053 & 0.310 & 0.296 & 0.289 & 0.205 & 0.779 & 0.754 & 0.728 & 0.497 & 1.504 & 1.482 & 1.426 & 0.960 \\
\hline 0.5 & 0.063 & 0.369 & 0.352 & 0.343 & 0.244 & 0.927 & 0.898 & 0.867 & 0.591 & 1.783 & 1.758 & 1.691 & 1.142 \\
\hline 0.6 & 0.074 & 0.436 & 0.417 & 0.405 & 0.289 & 1.093 & 1.058 & 1.022 & 0.700 & 2.104 & 2.073 & 1.994 & 1.349 \\
\hline 0.7 & 0.090 & 0.531 & 0.508 & 0.493 & 0.352 & 1.331 & 1.289 & 1.246 & 0.852 & 2.565 & 2.528 & 2.432 & 1.648 \\
\hline 0.8 & 0.115 & 0.668 & 0.639 & 0.621 & 0.444 & 1.661 & 1.613 & 1.558 & 1.066 & 3.211 & 3.166 & 3.048 & 2.070 \\
\hline 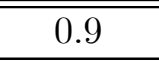 & $\begin{array}{c}0.163 \\
\end{array}$ & 0.940 & 0.898 & $\begin{array}{c}0.873 \\
\end{array}$ & 0.622 & 2.335 & 2.263 & 2.191 & 1.505 & 4.471 & 4.408 & 4.244 & 2.886 \\
\hline$\overline{c 0.95}$ & $\bar{~} 0.221$ & " 1.252 & " 1.198 & $\bar{~} 1.166$ & 0.831 & $\bar{~} 3.139$ & ב3.032 & 2.929 & 2.021 & $\begin{array}{c}5.983 \\
\end{array}$ & "5.893 & 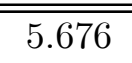 & ב 3.862 \\
\hline 0.975 & 0.285 & 1.620 & 1.559 & 1.520 & 1.087 & 4.111 & 3.987 & 3.850 & 2.625 & 7.873 & 7.745 & 7.499 & 5.069 \\
\hline 0.99 & 0.38 & 2.288 & 2.190 & 2.127 & 1.517 & 5.761 & 5.568 & 5.360 & 3.673 & 11.064 & 10.931 & 10.498 & 7.096 \\
\hline
\end{tabular}




\begin{tabular}{|c|c|c|c|c|c|}
\hline \multicolumn{6}{|c|}{ 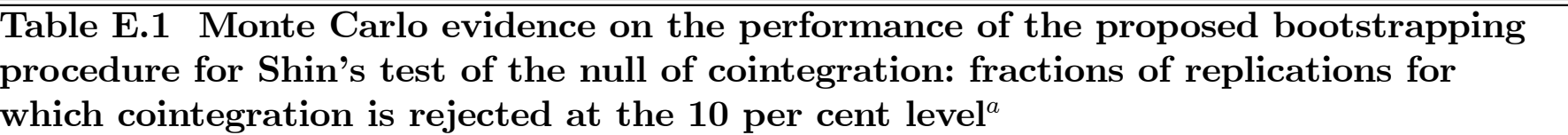 } \\
\hline & \multicolumn{5}{|c|}{ Sample length: } \\
\hline & $T=50$ & $\bar{T}=100$ & $\bar{T}=200$ & $\bar{T}=50$ & $T=1000$ \\
\hline Persistence of the cointegration residual: & \multicolumn{5}{|c|}{ True data-generation process: cointegration } \\
\hline$\rho=0$ & & & & & \\
\hline based on Shin's asymptotic critical values & 0.092 & 0.087 & 0.082 & 0.096 & 0.091 \\
\hline $\begin{array}{l}\text { based on the bootstrapped p-values } \\
\qquad \rho=0.25\end{array}$ & 0.093 & 0.113 & 0.131 & 0.130 & 0.114 \\
\hline based on Shin's asymptotic critical values & 0.056 & 0.082 & 0.110 & 0.125 & 0.117 \\
\hline $\begin{array}{l}\text { based on the bootstrapped p-values } \\
\qquad \rho=0.5\end{array}$ & 0.080 & 0.121 & 0.134 & 0.131 & 0.111 \\
\hline based on Shin's asymptotic critical values & 0.066 & 0.143 & 0.193 & 0.236 & 0.253 \\
\hline $\begin{array}{l}\text { based on the bootstrapped p-values } \\
\qquad \rho=0.75\end{array}$ & 0.094 & 0.136 & 0.135 & 0.137 & 0.113 \\
\hline based on Shin's asymptotic critical values & 0.132 & 0.336 & 0.491 & 0.574 & 0.613 \\
\hline $\begin{array}{l}\text { based on the bootstrapped p-values } \\
\qquad \rho=0.9\end{array}$ & 0.133 & 0.172 & 0.153 & 0.138 & 0.115 \\
\hline based on Shin's asymptotic critical values & 0.198 & 0.618 & 0.835 & 0.952 & 0.967 \\
\hline $\begin{array}{l}\text { based on the bootstrapped p-values } \\
\qquad \rho=0.95\end{array}$ & 0.154 & 0.227 & 0.193 & 0.150 & 0.133 \\
\hline based on Shin's asymptotic critical values & 0.232 & 0.721 & 0.932 & 0.994 & 1.000 \\
\hline \multirow[t]{2}{*}{ based on the bootstrapped p-values } & 0.177 & 0.251 & 0.233 & 0.176 & 0.151 \\
\hline & \multicolumn{5}{|c|}{ True data-generation process: no cointegration } \\
\hline Based on Shin's asymptotic critical values & 0.274 & 0.819 & 0.985 & 1.000 & 1.000 \\
\hline Based on the bootstrapped p-values & 0.175 & 0.308 & 0.372 & 0.342 & 0.378 \\
\hline
\end{tabular}




\begin{tabular}{|c|c|c|}
\hline \multicolumn{3}{|c|}{$\begin{array}{l}\text { Table F.1a Results from Johansen's cointegration tests between the } \\
\text { logarithms of nominal GDP and of a short-term rate } \text { rat }^{a}\end{array}$} \\
\hline & $\begin{array}{c}\text { Trace tests of the null of no } \\
\text { cointegration against the } \\
\text { alternative of } 1 \text { or more } \\
\text { cointegrating vectors: }\end{array}$ & $\begin{array}{l}\text { Maximum eigenvalue } \\
\text { tests of } 0 \text { versus } 1 \\
\text { cointegrating vectors: }\end{array}$ \\
\hline Argentina, 1914-2004 & $38.246(0.001)$ & $37.348(0.000)$ \\
\hline Bolivia, 1980-2013 & $25.248(0.032)$ & $25.145(0.019)$ \\
\hline Brazil & & \\
\hline 1974-2012 & $19.461(0.142)$ & $14.1757(0.231)$ \\
\hline 1934-2012 & $20.974(0.037)$ & $18.993(0.030)$ \\
\hline \multicolumn{3}{|l|}{ Chile } \\
\hline $1940-1995$ & $19.854(0.062)$ & $19.833(0.033)$ \\
\hline 1941-2012 & $11.096(0.380)$ & $9.328(0.416)$ \\
\hline Israel, 1983-2014 & $11.678(0.605)$ & $9.845(0.620)$ \\
\hline
\end{tabular}




\begin{tabular}{|c|c|c|}
\hline $\begin{array}{l}\text { Table F.1b Result } \\
\text { GDP and a short-t }\end{array}$ & $\begin{array}{l}\text { from Johansen's cointe } \\
\text { m rate }\end{array}$ & etween the logarit \\
\hline & $\begin{array}{l}\text { Trace tests of the null of no } \\
\text { cointegration against the } \\
\text { alternative of } 1 \text { or more } \\
\text { cointegration vectors: }\end{array}$ & $\begin{array}{l}\text { Maximum eigenvalue } \\
\text { tests of } 0 \text { versus } 1 \\
\text { cointegration vectors: }\end{array}$ \\
\hline Canada, 1926-2006 & $3.765(0.953)$ & $3.671(0.930)$ \\
\hline Colombia, 1959-2011 & $16.117(0.213)$ & $13.102(0.253)$ \\
\hline Finland, 1914-1985 & $6.299(0.773)$ & $4.663(0.863)$ \\
\hline Hong Kong, 1985-2012 & $20.509(0.114)$ & $18.521(0.096)$ \\
\hline Japan & & \\
\hline $1885-1913$ & $12.058(0.318)$ & $11.475(0.268)$ \\
\hline 1955-2013 & $22.656(0.048)$ & $17.674(0.069)$ \\
\hline Korea, 1970-2014 & $43.262(0.001)$ & $27.120(0.010)$ \\
\hline Italy & & \\
\hline 1861-1913 & $6.650(0.737)$ & $5.377(0.781)$ \\
\hline $1949-1966$ & $13.751(0.253)$ & $13.496(0.182)$ \\
\hline
\end{tabular}




\begin{tabular}{||l|c|c||}
\hline \hline $\begin{array}{l}\text { Table F.1b (continued) } \\
\text { between the logarithm of nominal GDP and a short-term } \text { rate }^{a}\end{array}$ \\
\hline & $\begin{array}{c}\text { Results from Johansen's of the null of no } \\
\text { cointegration against the } \\
\text { alternative of 1 or more } \\
\text { cointegration vectors: }\end{array}$ & $\begin{array}{c}\text { Maximum eigenvalue } \\
\text { tests of 0 versus } 1 \\
\text { cointegration vectors: }\end{array}$ \\
\hline Morocco, 1985-2008 & $9.589(0.673)$ & $9.012(0.614)$ \\
Netherlands, 1950-1992 & $21.231(0.049)$ & $17.593(0.066)$ \\
Norway, 1946-2013 & $4.789(0.881)$ & $2.962(0.970)$ \\
Portugal & & $11.138(0.324)$ \\
& $16.733(0.132)$ & $9.122(0.638)$ \\
South Africa, 1967-2014 & $12.740(0.482)$ & $8.671(0.493)$ \\
Spain, 1941-1989 & $13.547(0.236)$ & $14.566(0.076)$ \\
Switzerland, 1851-1906 & $14.726(0.108)$ & $9.838(0.286)$ \\
Taiwan, 1962-2013 & $10.084(0.358)$ & $26.519(0.006)$ \\
Turkey, 1968-2014 & $33.729(0.003)$ & $10.935(0.400)$ \\
United Kingdom, 1922-2014 & $16.251(0.205)$ & $7.593(0.544)$ \\
United States, 1915-2014 & $8.134(0.591)$ & $3.749(0.923)$ \\
West Germany, 1960-1989 & $3.885(0.947)$ & $7.730(0.709)$ \\
\hline${ }^{a}$ Bootstrapped $p$-values (in parentheses) are based on 10,000 bootstrap replications. \\
\hline \hline
\end{tabular}




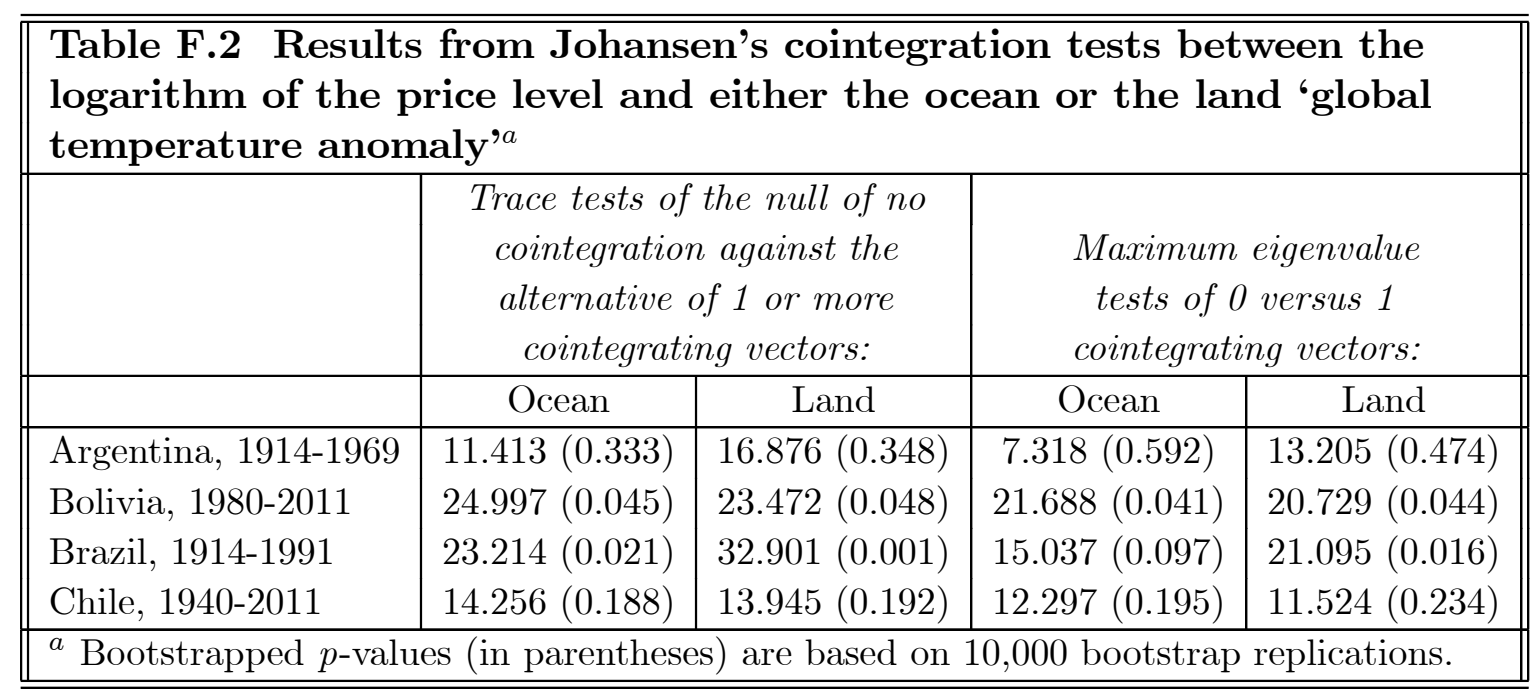




\section{Tables for the online appendix}




\section{I: Full set of results based on the Selden-Latané specification}




\begin{tabular}{|c|c|c|c|}
\hline \multicolumn{4}{|c|}{$\begin{array}{l}\text { Table SELA.1 Assessing the persistence of candidate cointegration } \\
\text { residuals: Hansen (1999) 'grid bootstrap' estimates of the sum of the } \\
\text { autoregressive coefficients based on AR(2) models (median, and } 90 \\
\text { per cent bootstrapped confidence interval) }\end{array}$} \\
\hline \multicolumn{4}{|c|}{ I: Based on Johansen's estimator of the cointegration vector } \\
\hline Australia, 1969-2015 & $0.30[0.01 ; 0.59]$ & Mexico, 1985-2014 & $0.46[0.26 ; 0.68]$ \\
\hline Bolivia, 1980-2013 & $0.44[0.17 ; 0.76]$ & Netherlands, 1950-1992 & $0.61[0.37 ; 0.89]$ \\
\hline Brazil, 1974-2012 & $0.59[0.36 ; 0.84]$ & New Zealand, 1934-2004 & $0.75[0.62 ; 0.89]$ \\
\hline Canada & & Norway, 1946-2013 & $0.97[0.89 ; 1.02]$ \\
\hline 1926-2006 & $0.77[0.64 ; 0.91]$ & Portugal & \\
\hline $1967-2013$ & $0.33[0.13 ; 0.54]$ & $1914-1965$ & $0.67[0.48 ; 0.90]$ \\
\hline Chile, 1940-1995 & $0.87[0.72 ; 1.02]$ & $1966-1998$ & $1.00[0.90 ; 1.02]$ \\
\hline Colombia, 1959-2011 & $0.85[0.68 ; 1.02]$ & South Africa, 1967-2014 & $0.86[0.73 ; 1.01]$ \\
\hline Finland, 1914-1985 & $0.93[0.83 ; 1.01]$ & Spain, 1941-1989 & $0.59[0.39 ; 0.80]$ \\
\hline Germany, 1876-1913 & $0.59[0.32 ; 0.95]$ & Switzerland, 1948-2005 & $0.74[0.56 ; 0.95]$ \\
\hline Guatemala, 1980-2012 & $0.63[0.34 ; 1.02]$ & Turkey, 1968-2014 & $0.92[0.75 ; 1.03]$ \\
\hline Japan & & United Kingdom, 1922-2014 & $0.64[0.49 ; 0.81]$ \\
\hline $1885-1913$ & $0.45[0.08 ; 0.89]$ & United States, 1915-2014 & \\
\hline $1955-2013$ & $0.81[0.68 ; 0.97]$ & standard $M_{1}$ & $0.92[0.84 ; 1.01]$ \\
\hline Korea, 1970-2014 & $0.56[0.32 ; 0.81]$ & Lucas-Nicolini 'New $M_{1}$ ' & $0.61[0.47 ; 0.75]$ \\
\hline Israel, 1983-2013 & $0.36[0.32 ; 0.40]$ & Venezuela, 1962-1999 & $0.91[0.74 ; 1.03]$ \\
\hline Italy, 1949-1996 & $0.98[0.80 ; 1.03]$ & & \\
\hline \multicolumn{4}{|c|}{$\begin{array}{l}{ }^{a} \text { Based on } 2,000 \text { bootstrap replications for each value of } \rho \text { in the grid. Candidate cointe- } \\
\text { gration residuals have been computed based on the bivariate model for velocity and the } \\
\text { short rate, and Johansen's estimator. }\end{array}$} \\
\hline
\end{tabular}




\begin{tabular}{|c|c|c|c|}
\hline \multicolumn{4}{|c|}{$\begin{array}{l}\text { Table SELA.1 (continued) Assessing the persistence of candidate } \\
\text { cointegration residuals: Hansen (1999) 'grid bootstrap' estimates } \\
\text { of the sum of the autoregressive coefficients based on } \operatorname{AR}(2) \\
\text { models (median, and } 90 \text { per cent bootstrapped confidence interval) }{ }^{a}\end{array}$} \\
\hline \multicolumn{4}{|c|}{ II: Based on Stock and Watson's estimator of the cointegration vector } \\
\hline Australia, 1969-2015 & $0.31[0.03 ; 0.61]$ & Mexico, 1985-2014 & $0.52[0.31 ; 0.72]$ \\
\hline Bolivia, 1980-2013 & $0.57[0.28 ; 0.95]$ & Netherlands, 1950-1992 & $0.71[0.48 ; 1.01]$ \\
\hline Brazil, 1974-2012 & $0.79[0.62 ; 1.01]$ & New Zealand, 1934-2004 & $0.81[0.68 ; 0.95]$ \\
\hline Canada & & Norway, 1946-2013 & $1.00[0.96 ; 1.02]$ \\
\hline 1926-2006 & $0.82[0.70 ; 0.96]$ & Portugal & \\
\hline $1967-2013$ & $0.34[0.13 ; 0.56]$ & $1914-1965$ & $0.67[0.47 ; 0.91]$ \\
\hline Chile, 1940-1995 & $0.85[0.71 ; 1.02]$ & $1966-1998$ & $1.02[0.99 ; 1.10]$ \\
\hline Colombia, 1959-2011 & $0.87[0.70 ; 1.02]$ & South Africa, 1967-2014 & $1.01[0.96 ; 1.03]$ \\
\hline Finland, 1914-1985 & $0.97[0.91 ; 1.01]$ & Spain, 1941-1989 & $0.61[0.41 ; 0.82]$ \\
\hline Germany, 1876-1913 & $0.99[0.87 ; 1.03]$ & Turkey, 1968-2014 & $0.94[0.76 ; 1.03]$ \\
\hline Guatemala, 1980-2012 & $0.65[0.34 ; 1.02]$ & Switzerland, 1948-2005 & $0.84[0.67 ; 1.02]$ \\
\hline Japan & & United Kingdom, 1922-2014 & $0.69[0.54 ; 0.84]$ \\
\hline $1885-1913$ & $1.01[0.87 ; 1.06]$ & United States, 1915-2014 & \\
\hline 1955-2013 & $0.87[0.74 ; 1.01]$ & standard $M_{1}$ & $1.00[0.96 ; 1.02]$ \\
\hline Korea, 1970-2014 & $0.57[0.34 ; 0.82]$ & Lucas-Nicolini 'New $M_{1}$ ' & $0.64[0.51 ; 0.79]$ \\
\hline Israel, 1983-2013 & $0.35[0.32 ; 0.39]$ & Venezuela, 1962-1999 & $0.89[0.69 ; 1.03]$ \\
\hline Italy, 1949-1996 & $0.98[0.85 ; 1.03]$ & & \\
\hline \multicolumn{4}{|c|}{$\begin{array}{l}{ }^{a} \text { Based on } 2,000 \text { bootstrap replications for each value of } \rho \text { in the grid. Candidate cointe- } \\
\text { gration residuals have been computed based on the bivariate model for velocity and the } \\
\text { short rate, and Johansen's estimator. }\end{array}$} \\
\hline
\end{tabular}




\begin{tabular}{|c|c|c|c|c|}
\hline \multicolumn{5}{|c|}{ Table SELA.2 Cointegration tests between $M_{1}$ velocity and a short rate } \\
\hline \multirow[b]{2}{*}{ Country } & \multirow[b]{2}{*}{ Period } & \multicolumn{2}{|c|}{ I: Johansen's tests } & \multirow[b]{2}{*}{ II: Shin's tests } \\
\hline & & $\operatorname{Trace}^{b}$ & $\begin{array}{l}\text { Maximum } \\
\text { eigenvalue }^{c}\end{array}$ & \\
\hline \multirow[t]{2}{*}{ Australia } & 1941-1989 & $6.699(0.735)$ & $6.613(0.642)$ & $0.434(0.103)$ \\
\hline & $1969-2015$ & $16.903(0.116)$ & $15.890(0.063)$ & $0.278(0.227)$ \\
\hline Belgium & 1946-1990 & $12.892(0.339)$ & $10.528(0.361)$ & $0.099(0.906)$ \\
\hline Bolivia & $1980-2013$ & $19.339(0.089)$ & $18.519(0.053)$ & $0.090(0.976)$ \\
\hline Brazil & 1974-2012 & $30.987(0.005)$ & $25.024(0.008)$ & $0.640(0.018)$ \\
\hline \multirow[t]{2}{*}{ Canada } & 1926-2006 & $23.244(0.017)$ & $21.714(0.007)$ & $0.800(0.197)$ \\
\hline & $1967-2013$ & $26.139(0.016)$ & $25.195(0.007)$ & $0.090(0.558)$ \\
\hline \multirow[t]{2}{*}{ Chile } & 1940-1995 & $24.191(0.024)$ & $14.026(0.133)$ & $0.696(0.024)$ \\
\hline & 1941-2012 & $23.304(0.020)$ & $18.084(0.035)$ & $0.411(0.307)$ \\
\hline Colombia & $1959-2011$ & $8.435(0.673)$ & $6.439(0.717)$ & $0.251(0.433)$ \\
\hline Finland & 1914-1985 & $6.825(0.742)$ & $6.765(0.622)$ & $1.391(0.071)$ \\
\hline Germany & $1876-1913$ & $9.882(0.571)$ & $8.996(0.503)$ & $0.490(0.197)$ \\
\hline Guatemala & $1980-2012$ & $20.282(0.058)$ & $18.014(0.049)$ & $0.053(0.872)$ \\
\hline \multirow[t]{2}{*}{ Japan } & $1885-1913$ & $11.870(0.408)$ & $10.834(0.333)$ & $0.455(0.094)$ \\
\hline & $1955-2013$ & $9.846(0.511)$ & $9.240(0.427)$ & $0.141(0.888)$ \\
\hline Korea & $1970-2014$ & $18.407(0.074)$ & $16.909(0.060)$ & $0.175(0.351)$ \\
\hline Israel & $1983-2014$ & $154.166(0.000)$ & $154.098(0.000)$ & $0.137(0.282)$ \\
\hline Italy & 1949-1996 & $15.767(0.145)$ & $12.474(0.171)$ & $0.457(0.230)$ \\
\hline Mexico & $1985-2014$ & $47.085(0.000)$ & $29.609(0.007)$ & $0.110(0.312)$ \\
\hline Netherlands & 1950-1992 & $14.491(0.211)$ & $10.052(0.349)$ & $0.253(0.381)$ \\
\hline New Zealand & $1934-2014$ & $15.384(0.155)$ & $14.282(0.093)$ & $0.965(0.175)$ \\
\hline Norway & 1946-2013 & $22.770(0.021)$ & $17.992(0.031)$ & $0.932(0.084)$ \\
\hline \multirow[t]{2}{*}{ Portugal } & 1914-1965 & $26.827(0.012)$ & $25.749(0.004)$ & $0.086(0.495)$ \\
\hline & 1966-1998 & $11.733(0.422)$ & $8.818(0.511)$ & $0.278(0.004)$ \\
\hline South Africa & $1967-2014$ & $17.877(0.117)$ & $16.635(0.068)$ & $0.489(0.109)$ \\
\hline Spain & 1941-1989 & $14.260(0.183)$ & $13.569(0.120)$ & $0.272(0.272)$ \\
\hline \multirow[t]{2}{*}{ Switzerland } & $1851-1906$ & $15.883(0.109)$ & $12.625(0.158)$ & $0.635(0.225)$ \\
\hline & 1948-2005 & $38.892(0.000)$ & $35.289(0.000)$ & $0.985(0.033)$ \\
\hline Turkey & $1968-2014$ & $6.817(0.814)$ & $4.614(0.896)$ & $0.164(0.523)$ \\
\hline United Kingdom & $1922-2014$ & $23.261(0.019)$ & $21.680(0.011)$ & $0.900(0.046)$ \\
\hline \multicolumn{5}{|l|}{ United States } \\
\hline standard $M_{1}$ & $1915-2014$ & $7.152(0.767)$ & $4.822(0.870)$ & $3.507(0.007)$ \\
\hline Lucas-Nicolini $M_{1}$ & $1915-2014$ & $20.769(0.038)$ & $16.557(0.048)$ & $0.554(0.121)$ \\
\hline Venezuela & 1962-1999 & $7.635(0.724)$ & $5.836(0.776)$ & $0.412(0.112)$ \\
\hline
\end{tabular}




\begin{tabular}{|c|c|c|c|}
\hline \multicolumn{4}{|c|}{$\begin{array}{l}\text { Table SELA.3 Bootstrapped } p \text {-values }{ }^{a} \text { for testing the null hy } \\
\text { that the coefficient on the short rate is equal to }-0.4 \text {, based } \\
\text { te systems featuring velocity and the short rate }\end{array}$} \\
\hline \multicolumn{4}{|c|}{ I: Based on Johansen's estimator of the cointegration vector } \\
\hline Argentina, 1914-2009 & 0.002 & Israel, 1983-2013 & 0.007 \\
\hline Australia, 1969-2015 & 0.120 & Italy, 1949-1996 & 0.021 \\
\hline Bolivia, 1980-2013 & 0.426 & Mexico, 1985-2014 & 0.001 \\
\hline Brazil & & Netherlands, 1950-1992 & 0.344 \\
\hline $1974-2012$ & $3.0 \mathrm{e}-4$ & New Zealand, 1934-2004 & 0.141 \\
\hline 1934-2012 & 0.002 & Norway, 1946-2013 & 0.084 \\
\hline Canada & & Portugal & \\
\hline 1926-2006 & 0.001 & $1914-1965$ & 0.006 \\
\hline $1967-2013$ & 0.005 & $1966-1998$ & 0.028 \\
\hline Chile & & South Africa, 1967-2014 & 0.323 \\
\hline $1940-1995$ & $1.0 \mathrm{e}-3$ & Spain, 1941-1989 & 0.010 \\
\hline 1941-2012 & 0.014 & Switzerland, 1948-2005 & 0.001 \\
\hline Colombia, 1959-2011 & 0.435 & Taiwan, 1962-2013 & 0.214 \\
\hline Finland, 1914-1985 & 0.268 & Turkey, 1968-2014 & 0.433 \\
\hline Germany, 1876-1913 & 0.136 & United Kingdom, 1922-2014 & 0.101 \\
\hline Guatemala, 1980-2012 & 0.030 & United States, 1915-2014 & \\
\hline Japan & & standard $M_{1}$ & 0.331 \\
\hline $1885-1913$ & 0.445 & Venezuela, 1962-1999 & 0.039 \\
\hline 1955-2013 & 0.185 & West Germany, 1960-1989 & 0.446 \\
\hline Korea, 1970-2014 & 0.011 & & \\
\hline
\end{tabular}




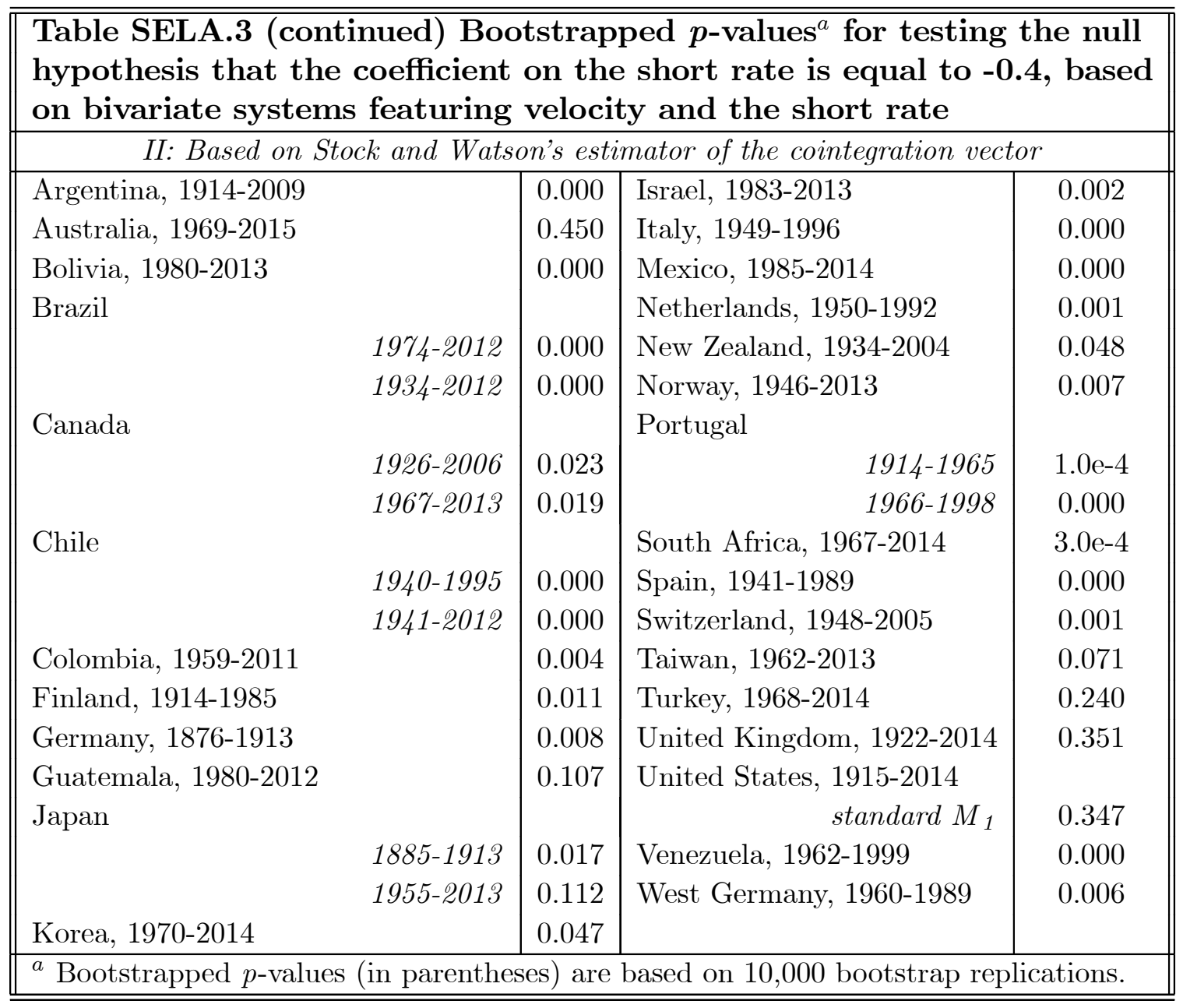




\section{II: Full set of results based on the semi-log specification}




\begin{tabular}{|c|c|c|c|}
\hline \multicolumn{4}{|c|}{$\begin{array}{l}\text { Table SL.1 Assessing the persistence of candidate cointegration residuals: } \\
\text { Hansen (1999) 'grid bootstrap' estimates of the sum of the autoregressive } \\
\text { coefficients based on AR(2) models (median, and } 90 \text { per cent bootstrapped } \\
\text { confidence interval) }\end{array}$} \\
\hline \multicolumn{4}{|c|}{ I: Based on Johansen's estimator of the cointegration vector } \\
\hline Argentina, 1914-2009 & $0.42[0.29 ; 0.54]$ & Israel, 1983-2013 & $0.37[0.33 ; 0.41]$ \\
\hline Australia, 1969-2015 & $0.41[0.13 ; 0.69]$ & Italy, 1949-1966 & $0.95[0.78 ; 1.03]$ \\
\hline Bolivia, 1980-2013 & $0.50[0.23 ; 0.82]$ & Mexico, 1985-2014 & $0.58[0.40 ; 0.79]$ \\
\hline Brazil & & Netherlands, 1950-1992 & $0.61[0.39 ; 0.89]$ \\
\hline $1974-2012$ & $0.64[0.42 ; 0.91]$ & New Zealand, 1934-2004 & $0.78[0.65 ; 0.90]$ \\
\hline 1934-2012 & $0.54[0.36 ; 0.73]$ & Norway, 1946-2013 & $0.97[0.89 ; 1.02]$ \\
\hline Canada & & Portugal & \\
\hline 1926-2006 & $0.76[0.63 ; 0.91]$ & $1914-1965$ & $0.76[0.61 ; 1.00]$ \\
\hline $1967-2013$ & $0.75[0.61 ; 0.90]$ & $1966-1998$ & $1.00[0.91 ; 1.02]$ \\
\hline Chile & & South Africa, 1967-2014 & $0.86[0.73 ; 1.01]$ \\
\hline $1940-1995$ & $0.77[0.63 ; 0.91]$ & Spain, 1941-1989 & $0.67[0.47 ; 0.89]$ \\
\hline 1941-2012 & $0.74[0.64 ; 0.85]$ & Switzerland, 1948-2005 & $0.74[0.55 ; 0.94]$ \\
\hline Colombia, 1959-2011 & $0.84[0.69 ; 1.02]$ & Taiwan, 1962-2013 & $0.82[0.70 ; 0.95]$ \\
\hline Finland, 1914-1985 & $0.88[0.77 ; 1.01]$ & Turkey, 1968-2014 & $0.86[0.68 ; 1.17]$ \\
\hline Germany, 1876-1913 & $0.61[0.34 ; 0.91]$ & United Kingdom, 1922-2014 & $0.69[0.54 ; 0.86]$ \\
\hline Guatemala, 1980-2012 & $0.64[0.32 ; 1.02]$ & United States, 1915-2014 & \\
\hline Japan & & standard $M_{1}$ & $0.91[0.83 ; 1.00]$ \\
\hline $1885-1913$ & $0.45[0.09 ; 0.89]$ & Lucas-Nicolini 'New $M_{1}$ ', & $0.64[0.51 ; 0.77]$ \\
\hline 1955-2013 & $0.86[0.75 ; 1.01]$ & Venezuela, 1962-1999 & $0.93[0.75 ; 1.03]$ \\
\hline Korea, 1970-2014 & $0.60[0.40 ; 0.82]$ & West Germany, 1960-1989 & $0.39[0.07 ; 0.72]$ \\
\hline
\end{tabular}




\begin{tabular}{|c|c|c|c|}
\hline \multicolumn{4}{|c|}{$\begin{array}{l}\text { Table SL.1 (continued) Assessing the persistence of candidate cointegration } \\
\text { residuals: Hansen (1999) 'grid bootstrap' estimates of the sum of the auto- } \\
\text { regressive coefficients based on } \operatorname{AR}(2) \text { models (median, and } 90 \text { per cent } \\
\text { bootstrapped confidence interval) }{ }^{a}\end{array}$} \\
\hline \multicolumn{4}{|c|}{ II: Based on Stock and Watson's estimator of the cointegration vector } \\
\hline Argentina, 1914-2009 & $0.62[0.50 ; 0.75]$ & Israel, 1983-2013 & $0.36[0.32 ; 0.40]$ \\
\hline Australia, 1969-2015 & $0.42[0.15 ; 0.69]$ & Italy, 1949-1996 & $0.98[0.85 ; 1.13]$ \\
\hline Bolivia, 1980-2013 & $0.66[0.37 ; 1.02]$ & Mexico, 1985-2014 & $0.58[0.36 ; 0.82]$ \\
\hline Brazil & & Netherlands, 1950-1992 & $0.71[0.50 ; 1.13]$ \\
\hline $1974-2012$ & $0.84[0.69 ; 1.02]$ & New Zealand, 1934-2004 & $0.83[0.72 ; 0.97]$ \\
\hline 1934-2012 & $0.85[0.73 ; 1.01]$ & Norway, 1946-2013 & $1.01[0.97 ; 1.02]$ \\
\hline Canada & & Portugal & \\
\hline 1926-2006 & $0.81[0.69 ; 0.96]$ & $1914-1965$ & $0.76[0.59 ; 0.98]$ \\
\hline $1967-2013$ & $0.44[0.22 ; 0.67]$ & $1966-1998$ & $1.03[0.99 ; 1.13]$ \\
\hline Chile & & South Africa, 1967-2014 & $1.01[0.97 ; 1.04]$ \\
\hline $1940-1995$ & $0.83[0.68 ; 1.01]$ & Spain, 1941-1989 & $0.69[0.50 ; 0.89]$ \\
\hline 1941-2012 & $0.84[0.71 ; 1.01]$ & Switzerland, 1948-2005 & $0.82[0.67 ; 1.01]$ \\
\hline Colombia, 1959-2011 & $0.89[0.72 ; 1.16]$ & Taiwan, 1962-2013 & $0.83[0.73 ; 0.95]$ \\
\hline Finland, 1914-1985 & $0.93[0.83 ; 1.01]$ & Turkey, 1968-2014 & $0.88[0.70 ; 1.03]$ \\
\hline Germany, 1876-1913 & $0.99[0.87 ; 1.03]$ & United Kingdom, 1922-2014 & $0.75[0.61 ; 0.90]$ \\
\hline Guatemala, 1980-2012 & $0.67[0.35 ; 1.02]$ & United States, 1915-2014 & \\
\hline Japan & & standard $M_{1}$ & $1.00[0.94 ; 1.02]$ \\
\hline $1885-1913$ & $1.01[0.85 ; 1.05]$ & Lucas-Nicolini 'New $M_{1}$ ', & $0.68[0.55 ; 0.82]$ \\
\hline $1955-2013$ & $0.91[0.79 ; 1.01]$ & Venezuela, 1962-1999 & $0.92[0.72 ; 1.03]$ \\
\hline Korea, 1970-2014 & $0.63[0.42 ; 0.86]$ & West Germany, 1960-1989 & $1.01[0.82 ; 1.03]$ \\
\hline
\end{tabular}




\begin{tabular}{|c|c|c|c|}
\hline \multicolumn{4}{|c|}{$\begin{array}{l}\text { Table SL.2 Results from cointegration tests between the logarithm of } M_{1} \\
\text { velocity and a short-term rate }{ }^{a}\end{array}$} \\
\hline & \multicolumn{2}{|c|}{ I: Johansen's tests of the null of no cointegration } & \multirow[b]{2}{*}{$\begin{array}{l}\text { II: Shin's tests } \\
\text { of the null of } \\
\text { cointegration }\end{array}$} \\
\hline & $\begin{array}{l}\text { Trace tests of the null of no } \\
\text { cointegration against the } \\
\text { alternative of } 1 \text { or more } \\
\text { cointegration vectors: }\end{array}$ & $\begin{array}{l}\text { Maximum eigenvalue } \\
\text { tests of } 0 \text { versus } 1 \\
\text { cointegration vectors: }\end{array}$ & \\
\hline \multicolumn{4}{|l|}{ Australia } \\
\hline 1941-1989 & $3.145(0.982)$ & $3.051(0.973)$ & $0.479(0.196)$ \\
\hline 1969-2015 & $15.445(0.168)$ & $14.513(0.099)$ & $0.341(0.188)$ \\
\hline Argentina, 1914-2009 & $26.061(0.014)$ & $24.401(0.010)$ & $1.145(0.138)$ \\
\hline Belgium, 1946-1990 & $21.978(0.018)$ & $20.165(0.016)$ & $0.166(0.519)$ \\
\hline Bolivia, 1980-2013 & $11.373(0.526)$ & $10.630(0.423)$ & $0.098(0.984)$ \\
\hline \multicolumn{4}{|l|}{ Brazil } \\
\hline 1974-2012 & $24.126(0.026)$ & $18.618(0.042)$ & $0.710(0.015)$ \\
\hline 1934-2012 & $30.346(0.005)$ & $29.179(0.004)$ & $2.041(0.012)$ \\
\hline Canada, 1934-2006 & $19.801(0.064)$ & $17.675(0.042)$ & $0.550(0.184)$ \\
\hline \multicolumn{4}{|l|}{ Chile } \\
\hline $1940-1995$ & $24.654(0.021)$ & $16.839(0.065)$ & $0.712(0.019)$ \\
\hline 1941-2012 & $17.068(0.110)$ & $13.001(0.151)$ & $0.386(0.401)$ \\
\hline Colombia, 1959-2011 & $8.275(0.683)$ & $6.601(0.692)$ & $0.275(0.429)$ \\
\hline Finland, 1914-1985 & $8.331(0.642)$ & $6.771(0.659)$ & $1.317(0.029)$ \\
\hline Germany, 1876-1913 & $9.839(0.572)$ & $8.794(0.534)$ & $0.498(0.195)$ \\
\hline Guatemala, 1980-2012 & $20.076(0.055)$ & $18.069(0.043)$ & $0.070(0.779)$ \\
\hline \multicolumn{4}{|l|}{ Japan } \\
\hline $1885-1913$ & $11.681(0.425)$ & $10.425(0.365)$ & $0.462(0.082)$ \\
\hline 1955-2013 & $12.868(0.237)$ & $12.710(0.154)$ & $0.172(0.882)$ \\
\hline Korea, 1970-2014 & $17.188(0.106)$ & $16.609(0.070)$ & $0.152(0.491)$ \\
\hline Israel, 1983-2014 & $162.338(0.000)$ & $161.736(0.000)$ & $0.155(0.231)$ \\
\hline Italy, 1949-1996 & $15.265(0.163)$ & $12.130(0.182)$ & $0.441(0.233)$ \\
\hline
\end{tabular}




\begin{tabular}{|c|c|c|c|}
\hline \multicolumn{4}{|c|}{$\begin{array}{l}\text { Table SL.2 (continued) Results from cointegration tests between the logarithm } \\
\text { of } M_{1} \text { velocity and a short-term rate }{ }^{a}\end{array}$} \\
\hline & \multicolumn{2}{|c|}{ I: Johansen's tests of the null of no cointegration } & \multirow[b]{2}{*}{$\begin{array}{l}\text { II: Shin's tests } \\
\text { of the null of } \\
\text { cointegration }\end{array}$} \\
\hline & $\begin{array}{l}\text { Trace tests of the null of no } \\
\text { cointegration against the } \\
\text { alternative of } 1 \text { or more } \\
\text { cointegration vectors: }\end{array}$ & $\begin{array}{l}\text { Maximum eigenvalue } \\
\text { tests of } 0 \text { versus } 1 \\
\text { cointegration vectors: }\end{array}$ & \\
\hline Mexico, 1985-2014 & $44.438(0.000)$ & $35.513(0.002)$ & $0.110(0.333)$ \\
\hline Netherlands, 1950-1992 & $15.988(0.143)$ & $10.743(0.286)$ & $0.257(0.360)$ \\
\hline New Zealand, 1934-2014 & $14.828(0.183)$ & $13.801(0.109)$ & $1.117(0.166)$ \\
\hline Norway, 1946-2013 & $23.540(0.021)$ & $19.644(0.021)$ & $1.102(0.058)$ \\
\hline \multicolumn{4}{|l|}{ Portugal } \\
\hline $1914-1965$ & $20.171(0.073)$ & $19.072(0.038)$ & $0.117(0.383)$ \\
\hline $1966-1998$ & $9.385(0.580)$ & $6.676(0.722)$ & $0.267(0.004)$ \\
\hline South Africa, 1967-2014 & $18.114(0.108)$ & $17.183(0.060)$ & $0.535(0.071)$ \\
\hline Spain, 1941-1989 & $12.394(0.279)$ & $11.458(0.215)$ & $0.300(0.274)$ \\
\hline \multicolumn{4}{|l|}{ Switzerland } \\
\hline $1851-1906$ & $13.641(0.162)$ & $13.071(0.115)$ & $0.630(0.239)$ \\
\hline $1948-2005$ & $35.641(0.001)$ & $32.258(0.000)$ & $1.048(0.023)$ \\
\hline Taiwan, 1962-2013 & $7.561(0.690)$ & $6.064(0.742)$ & $0.325(0.222)$ \\
\hline Turkey, 1968-2014 & $11.058(0.450)$ & $9.009(0.444)$ & $0.167(0.508)$ \\
\hline United Kingdom, 1922-2014 & $20.169(0.051)$ & $19.443(0.021)$ & $1.208(0.022)$ \\
\hline \multicolumn{4}{|l|}{ United States, 1915-2014 } \\
\hline standard $M_{1}$ & $7.214(0.747)$ & $5.637(0.777)$ & $3.658(0.005)$ \\
\hline Lucas-Nicolini's 'New $M_{1}$ ' & $16.867(0.101)$ & $14.791(0.081)$ & $0.612(0.116)$ \\
\hline Venezuela, 1962-1999 & $6.917(0.785)$ & $5.128(0.844)$ & $0.399(0.150)$ \\
\hline West Germany, 1960-1989 & $7.118(0.879)$ & $6.316(0.857)$ & $0.409(0.141)$ \\
\hline
\end{tabular}




\begin{tabular}{|c|c|c|c|}
\hline \multicolumn{4}{|c|}{$\begin{array}{l}\text { Table SL.3 Bootstrapped } p \text {-values }{ }^{a} \text { for testing the null hypothesis } \\
\text { that the semi-elasticity is equal to }-0.1 \text {, based on bivariate systems } \\
\text { featuring the short rate and the logarithm of velocity }\end{array}$} \\
\hline \multicolumn{4}{|c|}{ I: Based on Johansen's estimator of the cointegration vector } \\
\hline Argentina, 1914-2009 & 0.005 & Israel, 1983-2013 & 0.490 \\
\hline Australia, 1969-2015 & 0.058 & Italy, 1949-1996 & 0.019 \\
\hline Bolivia, 1980-2013 & 0.114 & Mexico, 1985-2014 & 0.002 \\
\hline Brazil & & Netherlands, 1950-1992 & 0.270 \\
\hline $1974-2012$ & $1.0 \mathrm{e}-4$ & New Zealand, 1934-2004 & 0.336 \\
\hline 1934-2012 & 0.003 & Norway, 1946-2013 & 0.095 \\
\hline Canada & & Portugal & \\
\hline 1926-2006 & 0.104 & $1914-1965$ & 0.015 \\
\hline $1967-2013$ & 0.227 & $1966-1998$ & 0.035 \\
\hline Chile & & South Africa, 1967-2014 & 0.438 \\
\hline $1940-1995$ & $1.0 \mathrm{e}-4$ & Spain, 1941-1989 & 0.028 \\
\hline 1941-2012 & 0.006 & Switzerland, 1948-2005 & $8.0 \mathrm{e}-4$ \\
\hline Colombia, 1959-2011 & 0.084 & Taiwan, 1962-2013 & 0.167 \\
\hline Finland, 1914-1985 & 0.062 & Turkey, 1968-2014 & 0.011 \\
\hline Germany, 1876-1913 & 0.180 & United Kingdom, 1922-2014 & 0.090 \\
\hline Guatemala, 1980-2012 & 0.072 & United States, 1915-2014 & \\
\hline Japan & & standard $M_{1}$ & 0.320 \\
\hline $1885-1913$ & 0.408 & Lucas-Nicolini 'New $M_{1}$ ' & 0.146 \\
\hline 1955-2013 & 0.019 & Venezuela, 1962-1999 & 0.021 \\
\hline Korea, 1970-2014 & 0.409 & West Germany, 1960-1989 & 0.447 \\
\hline
\end{tabular}




\begin{tabular}{|c|c|c|c|}
\hline \multicolumn{4}{|c|}{$\begin{array}{l}\text { Table SL.3 (continued) Bootstrapped } p \text {-values }{ }^{a} \text { for testing the null } \\
\text { hypothesis that the semi-elasticity is equal to }-0.1 \text {, based on biva- } \\
\text { riate systems featuring the short rate and the logarithm of velocity }\end{array}$} \\
\hline \multicolumn{4}{|c|}{ II: Based on Stock and Watson's estimator of the cointegration vector } \\
\hline Argentina, 1914-2009 & 0.000 & Israel, 1983-2013 & 0.000 \\
\hline Australia, 1969-2015 & 0.000 & Italy, 1949-1996 & 0.000 \\
\hline Bolivia, 1980-2013 & 0.000 & Mexico, 1985-2014 & 0.000 \\
\hline Brazil & & Netherlands, 1950-1992 & 0.029 \\
\hline $1974-2012$ & 0.000 & New Zealand, 1934-2004 & 0.001 \\
\hline 1934-2012 & 0.000 & Norway, 1946-2013 & 0.010 \\
\hline Canada & & Portugal & \\
\hline 1926-2006 & 0.084 & $1914-1965$ & 0.003 \\
\hline $1967-2013$ & 0.003 & $1966-1998$ & 0.000 \\
\hline Chile & & South Africa, 1967-2014 & 0.000 \\
\hline $1940-1995$ & 0.000 & Spain, 1941-1989 & 0.000 \\
\hline 1941-2012 & 0.000 & Switzerland, 1948-2005 & 0.385 \\
\hline Colombia, 1959-2011 & 0.000 & Taiwan, 1962-2013 & 0.004 \\
\hline Finland, 1914-1985 & 0.149 & Turkey, 1968-2014 & 0.000 \\
\hline Germany, 1876-1913 & 0.000 & United Kingdom, 1922-2014 & 0.267 \\
\hline Guatemala, 1980-2012 & 0.001 & United States, 1915-2014 & \\
\hline Japan & & standard $M_{1}$ & 0.115 \\
\hline $1885-1913$ & 0.040 & Lucas-Nicolini 'New $M_{1}$ ' & 0.109 \\
\hline $1955-2013$ & 0.340 & Venezuela, 1962-1999 & 0.000 \\
\hline Korea, 1970-2014 & 0.123 & West Germany, 1960-1989 & 0.001 \\
\hline
\end{tabular}




\begin{tabular}{|c|c|c|}
\hline \multicolumn{3}{|c|}{$\begin{array}{l}\text { Table SL.4 Results from Johansen's tests of the null hypothesis of no cointegration based on } \\
\text { unrestricted specifications: test statistics and bootstrapped } p \text {-values }{ }^{a} \text { (in parentheses) }\end{array}$} \\
\hline & $\begin{array}{c}\text { Trace tests of the null of no } \\
\text { cointegration against the } \\
\text { alternative of } 1 \text { or more } \\
\text { cointegration vectors: }\end{array}$ & $\begin{array}{l}\text { Maximum eigenvalue } \\
\text { tests of } 0 \text { versus } 1 \\
\text { cointegration vectors: }\end{array}$ \\
\hline Argentina, 1914-2009 & $36.376(0.056)$ & $22.701(0.098)$ \\
\hline Australia, 1969-2015 & $35.978(0.074)$ & $16.929(0.411)$ \\
\hline Bolivia, 1980-2013 & $62.673(0.004)$ & $47.797(0.002)$ \\
\hline \multicolumn{3}{|l|}{ Brazil } \\
\hline 1934-2012 & $46.869(0.012)$ & $33.021(0.015)$ \\
\hline $1974-2012$ & $48.543(0.031)$ & $25.648(0.140)$ \\
\hline \multicolumn{3}{|l|}{ Canada } \\
\hline 1926-2006 & $24.879(0.420)$ & $22.109(0.126)$ \\
\hline $1967-2013$ & $43.774(0.018)$ & $21.241(0.186)$ \\
\hline \multicolumn{3}{|l|}{ Chile } \\
\hline $1940-1995$ & $56.195(0.002)$ & $41.492(0.002)$ \\
\hline 1941-2012 & $41.229(0.026)$ & $33.379(0.009)$ \\
\hline Colombia, 1959-2011 & $32.154(0.281)$ & $20.063(0.326)$ \\
\hline Finland, 1914-1985 & $22.329(0.543)$ & $15.485(0.468)$ \\
\hline Germany, 1876-1913 & $43.838(0.060)$ & $25.442(0.153)$ \\
\hline \multicolumn{3}{|l|}{ Japan } \\
\hline $1885-1913$ & $28.025(0.352)$ & $15.520(0.567)$ \\
\hline $1955-2013$ & $39.105(0.106)$ & $27.673(0.074)$ \\
\hline Korea, 1970-2014 & $61.329(0.004)$ & $25.450(0.153)$ \\
\hline Israel, 1983-2013 & $178.839(0.000)$ & $161.626(0.000)$ \\
\hline
\end{tabular}




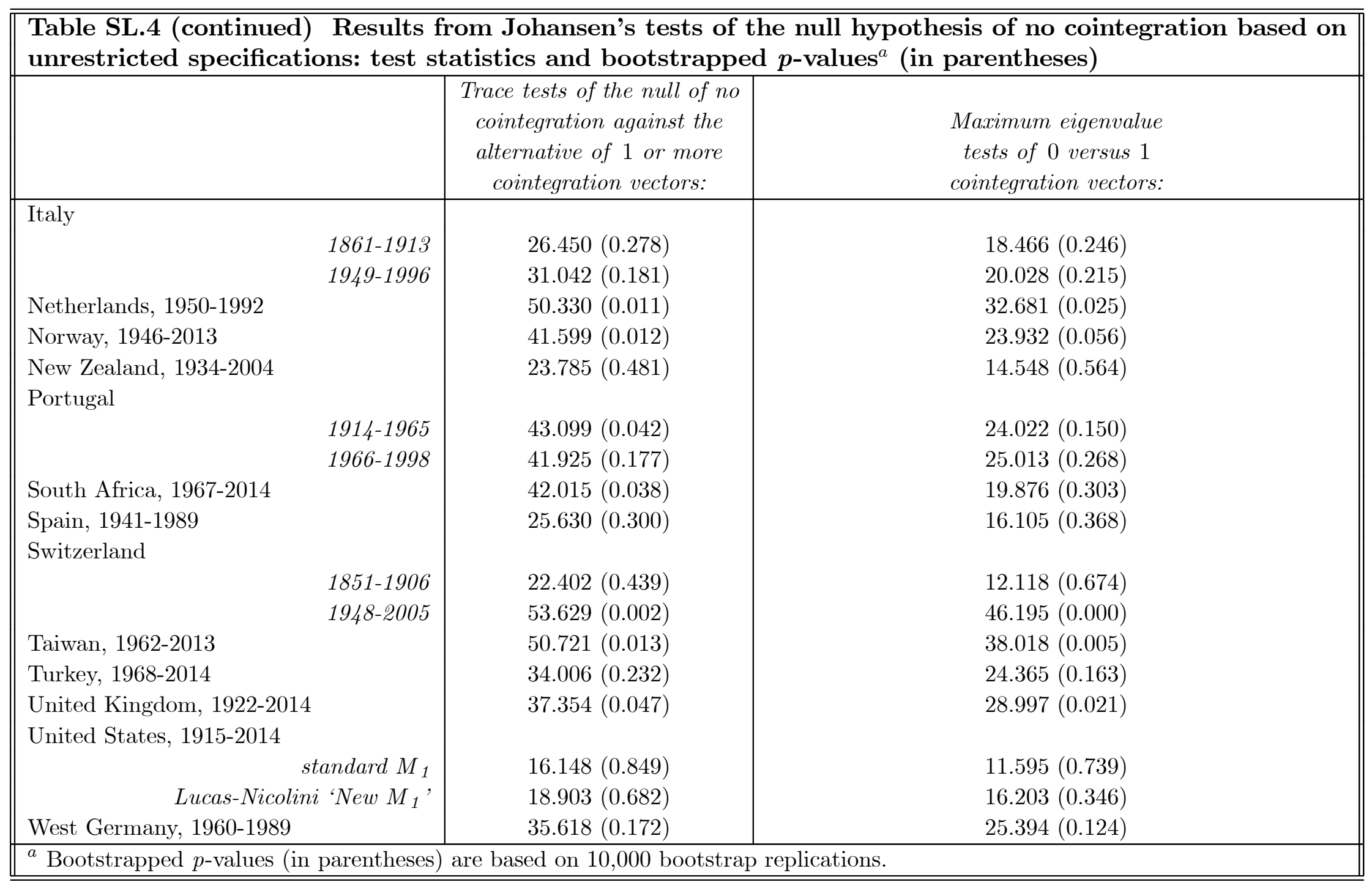




\begin{tabular}{|c|c|c|c|}
\hline \multicolumn{4}{|c|}{$\begin{array}{l}\text { Table SL.5 Results from Shin's (1994) tests of the null hypothesis of cointegration: } \\
\text { test statistics and bootstrapped } p \text {-values }^{a} \text { (in parentheses) based on unrestricted } \\
\text { specifications }^{a}\end{array}$} \\
\hline Argentina, 1914-2009 & $0.233(0.216)$ & Italy & \\
\hline Australia, 1969-2015 & $0.057(0.406)$ & $1861-1913$ & $0.096(0.494)$ \\
\hline Bolivia, 1980-2013 & $0.056(0.804)$ & $1949-1996$ & $0.092(0.188)$ \\
\hline Brazil & & Norway, 1946-2013 & $0.090(0.639)$ \\
\hline 1934-2012 & $0.037(0.853)$ & New Zealand, 1934-2004 & $0.115(0.497)$ \\
\hline $1974-2012$ & $0.126(0.056)$ & Portugal & \\
\hline Canada & & $1914-1965$ & $0.069(0.284)$ \\
\hline 1926-2006 & $0.090(0.743)$ & $1966-1998$ & $0.046(0.957)$ \\
\hline $1967-2013$ & $0.061(0.518)$ & South Africa, 1967-2014 & $0.039(0.792)$ \\
\hline Chile & & Spain, 1941-1989 & $0.104(0.287)$ \\
\hline $1940-1995$ & $0.119(0.126)$ & Switzerland & \\
\hline 1941-2012 & $0.125(0.368)$ & 1851-1906 & $0.065(0.827)$ \\
\hline Colombia, 1959-2011 & $0.115(0.076)$ & $1948-2005$ & $0.090(0.243)$ \\
\hline Finland, 1914-1985 & $0.085(0.609)$ & Taiwan, 1962-2013 & $0.158(0.081)$ \\
\hline Germany, 1876-1913 & $0.062(0.538)$ & Turkey, 1968-2014 & $0.030(0.894)$ \\
\hline Japan & & United Kingdom, 1922-2014 & $0.134(0.476)$ \\
\hline $1885-1913$ & $0.051(0.555)$ & United States, 1915-2014 & \\
\hline 1955-2013 & $0.116(0.476)$ & standard $M_{1}$ & $0.310(0.149)$ \\
\hline Korea, 1970-2014 & $0.071(0.225)$ & Lucas-Nicolini 'New $M_{1}$ ', & $0.125(0.511)$ \\
\hline Israel, 1983-2013 & $0.038(0.755)$ & West Germany, 1960-1989 & $0.115(0.084)$ \\
\hline Netherlands, 1950-1992 & $0.062(0.524)$ & & \\
\hline $\begin{array}{r}{ }^{a} \text { Bootstrapped } p \text {-values are based } \\
\text { null hypothesis of one cointegratio } \\
\ln (M \\
M_{1, t}=\text { nominal } M_{1} ; N G D P_{t}=\mathrm{n}\end{array}$ & $\begin{array}{l}10,000 \text { boots } \\
\text { ector. The est } \\
=\beta_{0}+\beta_{1} \ln ( \\
\text { aal } G D P ; R_{t}\end{array}$ & $\begin{array}{l}\text { ap replications of the VECM esti } \\
\text { nated regression is } \\
\left.G D P_{t}\right)+\beta_{2} R_{t}+u_{t} \\
\text { short rate. }\end{array}$ & under the \\
\hline
\end{tabular}




\begin{tabular}{|c|c|c|c|c|}
\hline \multicolumn{5}{|c|}{$\begin{array}{l}\text { Table SL.6 Bootstrapped } p \text {-values }{ }^{a} \text { for testing the null hypothesis } \\
\text { that the income elasticity is equal to } 1\end{array}$} \\
\hline \multicolumn{5}{|c|}{ I: Based on Johansen's estimator of the cointegration vector } \\
\hline Argentina, 1914-2009 & & 0.315 & Korea, 1970-2014 & 0.453 \\
\hline Australia, 1969-2015 & & 0.094 & Israel, 1983-2013 & 0.389 \\
\hline Bolivia, 1980-2013 & & 0.210 & Netherlands, 1950-1992 & 0.253 \\
\hline Brazil & & & New Zealand, 1934-2004 & 0.440 \\
\hline & $1974-2012$ & 0.097 & Norway, 1946-2013 & 0.164 \\
\hline & 1934-2012 & 0.005 & Portugal & \\
\hline \multirow[t]{3}{*}{ Canada } & & & $1914-1965$ & 0.196 \\
\hline & 1926-2006 & 0.060 & $1966-1998$ & 0.021 \\
\hline & $1967-2013$ & 0.186 & South Africa, 1967-2014 & 0.393 \\
\hline \multirow[t]{3}{*}{ Chile } & & & Spain, 1941-1989 & 0.215 \\
\hline & $1940-1995$ & 0.032 & Switzerland, 1948-2005 & 0.052 \\
\hline & 1941-2012 & 0.097 & Taiwan, 1962-2013 & 0.265 \\
\hline \multirow{6}{*}{$\begin{array}{l}\text { Colombia, 1959-2011 } \\
\text { Finland, 1914-1985 } \\
\text { Germany, 1876-1913 } \\
\text { Japan }\end{array}$} & & 0.409 & United Kingdom, 1922-2014 & 0.064 \\
\hline & & 0.037 & United States, 1915-2014 & \\
\hline & & 0.046 & standard $M_{1}$ & 0.056 \\
\hline & & & Lucas-Nicolini 'New $M_{1}$ ', & 0.325 \\
\hline & $1885-1913$ & 0.055 & West Germany, 1960-1989 & 0.175 \\
\hline & $1955-2013$ & 0.489 & & \\
\hline
\end{tabular}




\begin{tabular}{|c|c|c|c|c|}
\hline \multicolumn{5}{|c|}{$\begin{array}{l}\text { Table SL.6 (continued) Bootstrapped } p \text {-values }{ }^{a} \text { for testing the null } \\
\text { hypothesis that the income elasticity is equal to } 1\end{array}$} \\
\hline \multicolumn{5}{|c|}{ II: Based on Stock and Watson's estimator of the cointegration vector } \\
\hline Argentina, 1914-2009 & & 0.043 & Korea, 1970-2014 & 0.026 \\
\hline Australia, 1969-2015 & & 0.053 & Israel, 1983-2013 & 0.019 \\
\hline Bolivia, 1980-2013 & & 0.145 & Netherlands, 1950-1992 & 0.099 \\
\hline Brazil & & & New Zealand, 1934-2004 & 0.023 \\
\hline & $1974-2012$ & 0.023 & Norway, 1946-2013 & 0.085 \\
\hline & 1934-2012 & $6.0 \mathrm{e}-4$ & Portugal & \\
\hline \multirow[t]{3}{*}{ Canada } & & & $1914-1965$ & 0.038 \\
\hline & 1926-2006 & 0.044 & $1966-1998$ & 0.013 \\
\hline & $1967-2013$ & 0.426 & South Africa, 1967-2014 & 0.032 \\
\hline \multirow[t]{3}{*}{ Chile } & & & Spain, 1941-1989 & 0.009 \\
\hline & $1940-1995$ & 0.048 & Switzerland, 1948-2005 & 0.053 \\
\hline & 1941-2012 & 0.213 & Taiwan, 1962-2013 & 0.161 \\
\hline \multirow{6}{*}{$\begin{array}{l}\text { Colombia, 1959-2011 } \\
\text { Finland, 1914-1985 } \\
\text { Germany, 1876-1913 } \\
\text { Japan }\end{array}$} & & 0.229 & United Kingdom, 1922-2014 & 0.046 \\
\hline & & 0.001 & United States, 1915-2014 & \\
\hline & & 0.006 & standard $M_{1}$ & 0.006 \\
\hline & & & Lucas-Nicolini 'New M $M_{1}$ ' & 0.364 \\
\hline & $1885-1913$ & 0.003 & West Germany, 1960-1989 & 0.239 \\
\hline & 1955-2013 & 0.454 & & \\
\hline
\end{tabular}




\section{III: Full set of results based on the log-log specification}




\begin{tabular}{|c|c|c|c|}
\hline \multicolumn{4}{|c|}{$\begin{array}{l}\text { Table LL.1 Assessing the persistence of candidate cointegration residuals: } \\
\text { Hansen (1999) 'grid bootstrap' estimates of the sum of the autoregressive } \\
\text { coefficients based on } \operatorname{AR}(2) \text { models (median, and } 90 \text { per cent bootstrapped } \\
\text { confidence interval) }\end{array}$} \\
\hline \multicolumn{4}{|c|}{ I: Based on Johansen's estimator of the cointegration vector } \\
\hline Argentina, 1914-2009 & $0.82[0.72 ; 0.93]$ & Korea, 1970-2014 & $0.82[0.61 ; 1.02]$ \\
\hline Australia, 1969-2015 & $0.57[0.30 ; 0.93]$ & Israel, 1983-2013 & $0.66[0.49 ; 0.83]$ \\
\hline Bolivia, 1980-2013 & $0.73[0.53 ; 0.96]$ & Mexico, 1985-2014 & $1.00[0.61 ; 1.04]$ \\
\hline Brazil & & Netherlands, 1950-1992 & $0.64[0.38 ; 0.98]$ \\
\hline \multirow[b]{3}{*}{ Canada } & $0.93[0.79 ; 1.02]$ & New Zealand, 1934-2004 & $0.85[0.74 ; 1.01]$ \\
\hline & $0.93[0.83 ; 1.02]$ & Norway, 1946-2013 & $0.94[0.86 ; 1.01]$ \\
\hline & & Portugal & \\
\hline \multirow[b]{3}{*}{ Chile } & $0.79[0.64 ; 0.97]$ & $1914-1965$ & $0.82[0.67 ; 1.01]$ \\
\hline & $0.42[0.23 ; 0.61]$ & $1966-1998$ & $1.01[0.95 ; 1.06]$ \\
\hline & & South Africa, 1967-2014 & $0.90[0.78 ; 1.01]$ \\
\hline \multirow{7}{*}{$\begin{array}{l}\text { Colombia, 1959-2011 } \\
\text { Finland, 1914-1985 } \\
\text { Germany, 1876-1913 } \\
\text { Guatemala, 1980-2012 } \\
\text { Japan }\end{array}$} & $0.78[0.63 ; 1.00]$ & Spain, 1941-1989 & $0.84[0.68 ; 1.01]$ \\
\hline & $0.83[0.71 ; 0.97]$ & Switzerland, 1948-2005 & $0.76[0.58 ; 0.96]$ \\
\hline & $0.88[0.70 ; 1.02]$ & Taiwan, 1962-2013 & $0.85[0.74 ; 0.97]$ \\
\hline & $0.89[0.79 ; 1.01]$ & United Kingdom, 1922-2014 & $0.84[0.72 ; 0.98]$ \\
\hline & $0.63[0.35 ; 0.99]$ & United States, 1915-2014 & \\
\hline & $0.57[0.27 ; 0.99]$ & standard $M_{1}$ & $0.96[0.88 ; 1.01]$ \\
\hline & & Lucas-Nicolini 'New $M_{1}$ ', & $0.84[0.74 ; 0.95]$ \\
\hline $1885-1913$ & $0.44[0.10 ; 0.85]$ & Venezuela, 1962-1999 & $0.95[0.80 ; 1.03]$ \\
\hline 1955-2013 & $0.91[0.82 ; 1.01]$ & West Germany, 1960-1989 & $0.39[0.08 ; 0.71]$ \\
\hline
\end{tabular}




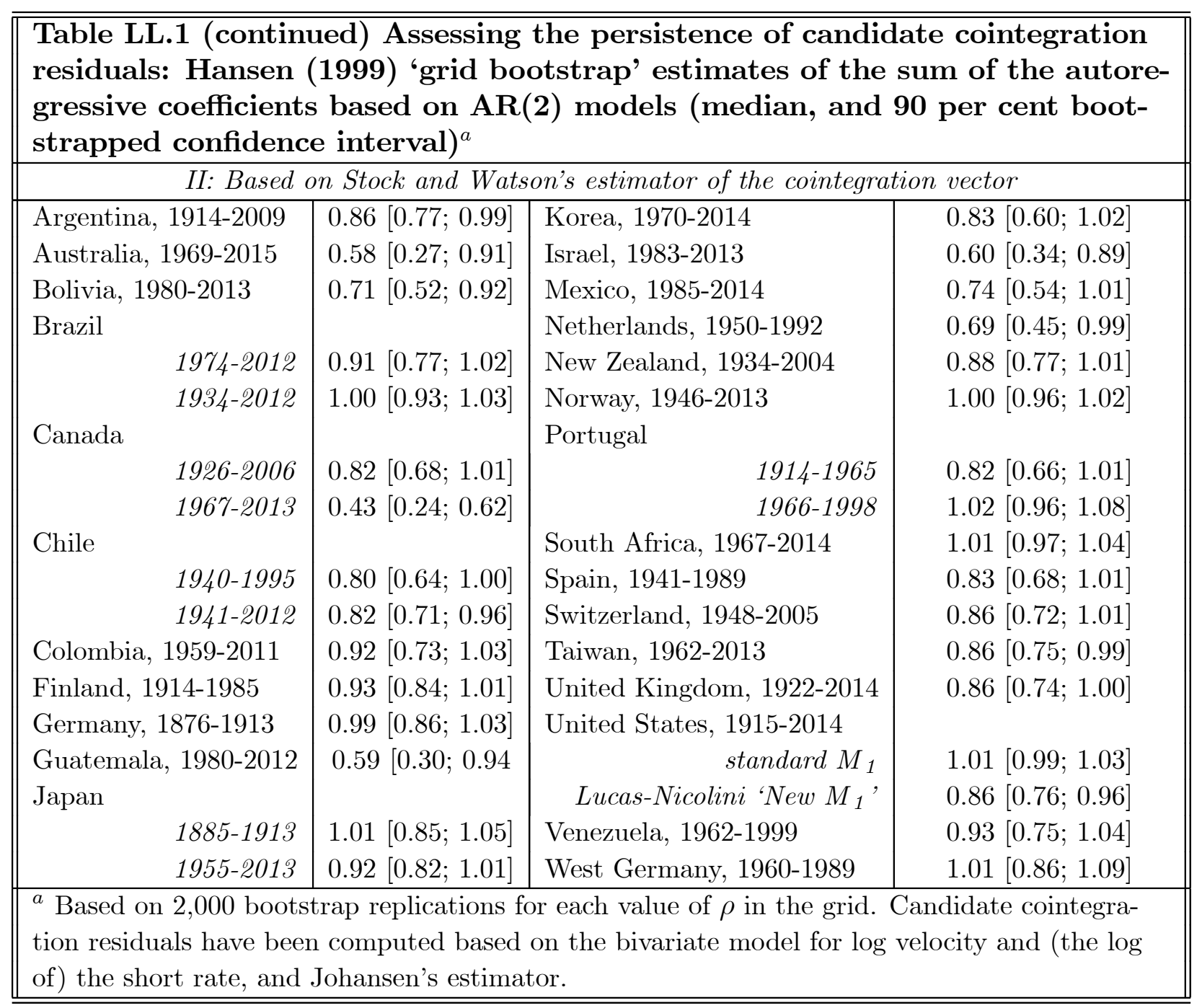




\begin{tabular}{|c|c|c|c|}
\hline \multicolumn{4}{|c|}{$\begin{array}{l}\text { Table LL.2 Results from cointegration tests between the logarithm of } M_{1} \\
\text { velocity and of a short-term rate }{ }^{a}\end{array}$} \\
\hline & \multicolumn{2}{|c|}{ I: Johansen's tests of the null of no cointegration } & \multirow[b]{2}{*}{$\begin{array}{l}\text { II: Shin's tests } \\
\text { of the null of } \\
\text { cointegration }\end{array}$} \\
\hline & $\begin{array}{c}\text { Trace tests of the null of no } \\
\text { cointegration against the } \\
\text { alternative of } 1 \text { or more } \\
\text { cointegration vectors: }\end{array}$ & $\begin{array}{l}\text { Maximum eigenvalue } \\
\text { tests of } 0 \text { versus } 1 \\
\text { cointegration vectors: }\end{array}$ & \\
\hline \multicolumn{4}{|l|}{ Australia } \\
\hline $1941-1989$ & $8.426(0.583)$ & $8.414(0.459)$ & $0.331(0.110)$ \\
\hline 1969-2015 & $9.268(0.594)$ & $8.387(0.503)$ & $0.240(0.436)$ \\
\hline Argentina, 1914-2009 & $21.471(0.027)$ & $18.988(0.020)$ & $0.549(0.301)$ \\
\hline Belgium, 1946-1990 & $20.900(0.028)$ & $20.106(0.019)$ & $0.127(0.721)$ \\
\hline Bolivia, 1980-2013 & $12.745(0.410)$ & $12.509(0.279)$ & $0.179(0.192)$ \\
\hline \multicolumn{4}{|l|}{ Brazil } \\
\hline $1974-2012$ & $20.760(0.052)$ & $15.175(0.095)$ & $0.319(0.108)$ \\
\hline $1934-2012$ & $20.165(0.032)$ & $16.607(0.037)$ & $2.014(0.013)$ \\
\hline Canada, 1934-2006 & $11.260(0.438)$ & $8.582(0.496)$ & $0.402(0.267)$ \\
\hline \multicolumn{4}{|l|}{ Chile } \\
\hline $1940-1995$ & $26.274(0.011)$ & $19.076(0.030)$ & $0.165(0.274)$ \\
\hline 1941-2012 & $16.822(0.096)$ & $12.958(0.136)$ & $0.122(0.758)$ \\
\hline Colombia, 1959-2011 & $6.558(0.824)$ & $4.852(0.871)$ & $0.226(0.507)$ \\
\hline Finland, 1914-1985 & $9.003(0.586)$ & $7.299(0.611)$ & $1.382(0.027)$ \\
\hline Germany, 1876-1913 & $9.959(0.560)$ & $8.653(0.544)$ & $0.528(0.171)$ \\
\hline Guatemala, 1980-2012 & $18.851(0.079)$ & $17.208(0.054)$ & $0.073(0.724)$ \\
\hline \multicolumn{4}{|l|}{ Japan } \\
\hline $1885-1913$ & $11.980(0.403)$ & $10.787(0.336)$ & $0.433(0.098)$ \\
\hline 1955-2013 & $16.010(0.148)$ & $14.415(0.121)$ & $0.145(0.874)$ \\
\hline Korea, 1970-2014 & $4.769(0.908)$ & $4.011(0.914)$ & $0.345(0.252)$ \\
\hline Israel, 1983-2014 & $27.703(0.012)$ & $26.547(0.008)$ & $0.157(0.224)$ \\
\hline
\end{tabular}




\begin{tabular}{|c|c|c|c|}
\hline \multicolumn{4}{|c|}{$\begin{array}{l}\text { Table LL.2 (continued) Results from cointegration tests between the logarithm of } \\
M_{1} \text { velocity and of a short-term rate }{ }^{a}\end{array}$} \\
\hline & \multicolumn{2}{|c|}{ I: Johansen's tests of the null of no cointegration } & \multirow[b]{2}{*}{$\begin{array}{l}\text { II: Shin's tests } \\
\text { of the null of } \\
\text { cointegration }\end{array}$} \\
\hline & $\begin{array}{c}\text { Trace tests of the null of no } \\
\text { cointegration against the } \\
\text { alternative of } 1 \text { or more } \\
\text { cointegration vectors: }\end{array}$ & $\begin{array}{l}\text { Maximum eigenvalue } \\
\text { tests of } 0 \text { versus } 1 \\
\text { cointegration vectors: }\end{array}$ & \\
\hline Mexico, 1985-2014 & $15.082(0.261)$ & $14.091(0.201)$ & $0.134(0.275)$ \\
\hline Netherlands, 1950-1992 & $15.143(0.169)$ & $9.214(0.400)$ & $0.206(0.440)$ \\
\hline New Zealand, 1934-2014 & $18.825(0.060)$ & $17.319(0.033)$ & $0.565(0.381)$ \\
\hline Norway, 1946-2013 & $24.171(0.015)$ & $21.084(0.013)$ & $0.634(0.219)$ \\
\hline \multicolumn{4}{|l|}{ Portugal } \\
\hline $1914-1965$ & $21.471(0.052)$ & $20.634(0.026)$ & $0.124(0.339)$ \\
\hline $1966-1998$ & $20.147(0.075)$ & $15.350(0.117)$ & $0.065(0.645)$ \\
\hline South Africa, 1967-2014 & $16.667(0.145)$ & $15.560(0.091)$ & $0.319(0.176)$ \\
\hline Spain, 1941-1989 & $7.606(0.670)$ & $7.429(0.563)$ & $0.253(0.256)$ \\
\hline \multicolumn{4}{|l|}{ Switzerland } \\
\hline $1851-1906$ & $13.664(0.160)$ & $13.090(0.113)$ & $0.664(0.219)$ \\
\hline $1948-2005$ & $24.175(0.017)$ & $20.705(0.015)$ & $0.928(0.107)$ \\
\hline Taiwan, 1962-2013 & $6.107(0.816)$ & $5.587(0.786)$ & $0.401(0.128)$ \\
\hline United Kingdom, 1922-2014 & $13.702(0.255)$ & $13.592(0.135)$ & $0.795(0.115)$ \\
\hline United States, 1915-2014 & & & \\
\hline standard $M_{1}$ & $12.119(0.271)$ & $10.096(0.280)$ & $2.738(0.031)$ \\
\hline Lucas-Nicolini's 'New $M_{1}$ ' & $9.626(0.514)$ & $8.926(0.409)$ & $0.571(0.237)$ \\
\hline Venezuela, 1962-1999 & $6.650(0.759)$ & $4.366(0.888)$ & $0.362(0.094)$ \\
\hline West Germany, 1960-1989 & $12.206(0.420)$ & $12.182(0.256)$ & $0.440(0.071)$ \\
\hline
\end{tabular}




\begin{tabular}{|c|c|c|c|}
\hline \multicolumn{4}{|c|}{$\begin{array}{l}\text { Table LL.3 Bootstrapped } p \text {-values }{ }^{a} \text { for testing the null hypothesis } \\
\text { that the elasticity is equal to }-0.5 \text {, based on bivariate systems featu- } \\
\text { ring the logarithms of velocity and the short rate }\end{array}$} \\
\hline \multicolumn{4}{|c|}{ I: Based on Johansen's estimator of the cointegration vector } \\
\hline Argentina, 1914-2009 & 0.442 & Korea, 1970-2014 & 0.287 \\
\hline Australia, 1969-2015 & 0.333 & Israel, 1983-2013 & 0.085 \\
\hline Bolivia, 1980-2013 & 0.099 & Mexico, $1985-2014$ & 0.012 \\
\hline Brazil & & Netherlands, 1950-1992 & 0.411 \\
\hline $1974-2012$ & 0.017 & New Zealand, 1934-2004 & 0.143 \\
\hline 1934-2012 & 0.318 & Norway, 1946-2013 & 0.079 \\
\hline Canada & & Portugal & \\
\hline 1926-2006 & 0.094 & $1914-1965$ & 0.042 \\
\hline $1967-2013$ & 0.056 & 1966-1998 & 0.009 \\
\hline Chile & & South Africa, 1967-2014 & 0.188 \\
\hline $1940-1995$ & 0.001 & Spain, 1941-1989 & 0.109 \\
\hline 1941-2012 & 0.030 & Switzerland, 1948-2005 & 0.330 \\
\hline Colombia, 1959-2011 & 0.304 & Taiwan, 1962-2013 & 0.176 \\
\hline Finland, 1914-1985 & 0.055 & United Kingdom, 1922-2014 & 0.383 \\
\hline Germany, 1876-1913 & 0.223 & United States, 1915-2014 & \\
\hline Guatemala, 1980-2012 & 0.142 & standard $M_{1}$ & 0.476 \\
\hline Japan & & Lucas-Nicolini 'New $M_{1}$ ', & 0.010 \\
\hline $1885-1913$ & 0.393 & Venezuela, 1962-1999 & 0.220 \\
\hline 1955-2013 & 0.482 & West Germany, 1960-1989 & 0.333 \\
\hline
\end{tabular}




\begin{tabular}{|c|c|c|c|}
\hline \multicolumn{4}{|c|}{$\begin{array}{l}\text { Table LL.3 (continued) Bootstrapped } p \text {-values }{ }^{a} \text { for testing the null } \\
\text { hypothesis that the elasticity is equal to }-0.5 \text {, based on bivariate sys- } \\
\text { tems featuring the logarithms of velocity and the short rate }\end{array}$} \\
\hline \multicolumn{4}{|c|}{ II: Based on Stock and Watson's estimator of the cointegration vector } \\
\hline Argentina, 1914-2009 & 0.001 & Korea, 1970-2014 & 0.484 \\
\hline Australia, 1969-2015 & 0.333 & Israel, 1983-2013 & 0.003 \\
\hline Bolivia, 1980-2013 & 0.208 & Mexico, $1985-2014$ & 0.023 \\
\hline Brazil & & Netherlands, 1950-1992 & 0.049 \\
\hline $1974-2012$ & 0.000 & New Zealand, 1934-2004 & 0.083 \\
\hline 1934-2012 & 0.000 & Norway, 1946-2013 & 0.003 \\
\hline Canada & & Portugal & \\
\hline 1926-2006 & 0.449 & $1914-1965$ & 0.007 \\
\hline $1967-2013$ & 0.000 & $1966-1998$ & 0.001 \\
\hline Chile & & South Africa, 1967-2014 & 0.002 \\
\hline $1940-1995$ & 0.000 & Spain, 1941-1989 & 0.014 \\
\hline 1941-2012 & 0.000 & Switzerland, 1948-2005 & 0.000 \\
\hline Colombia, 1959-2011 & 0.001 & Taiwan, 1962-2013 & 0.011 \\
\hline Finland, 1914-1985 & 0.116 & United Kingdom, 1922-2014 & 0.110 \\
\hline Germany, 1876-1913 & 0.000 & United States, 1915-2014 & \\
\hline Guatemala, 1980-2012 & 0.427 & standard $M_{1}$ & 0.000 \\
\hline Japan & & Lucas-Nicolini 'New $M_{1}$ ', & 0.000 \\
\hline $1885-1913$ & 0.092 & Venezuela, 1962-1999 & 0.050 \\
\hline 1955-2013 & 0.003 & West Germany, 1960-1989 & 0.000 \\
\hline
\end{tabular}




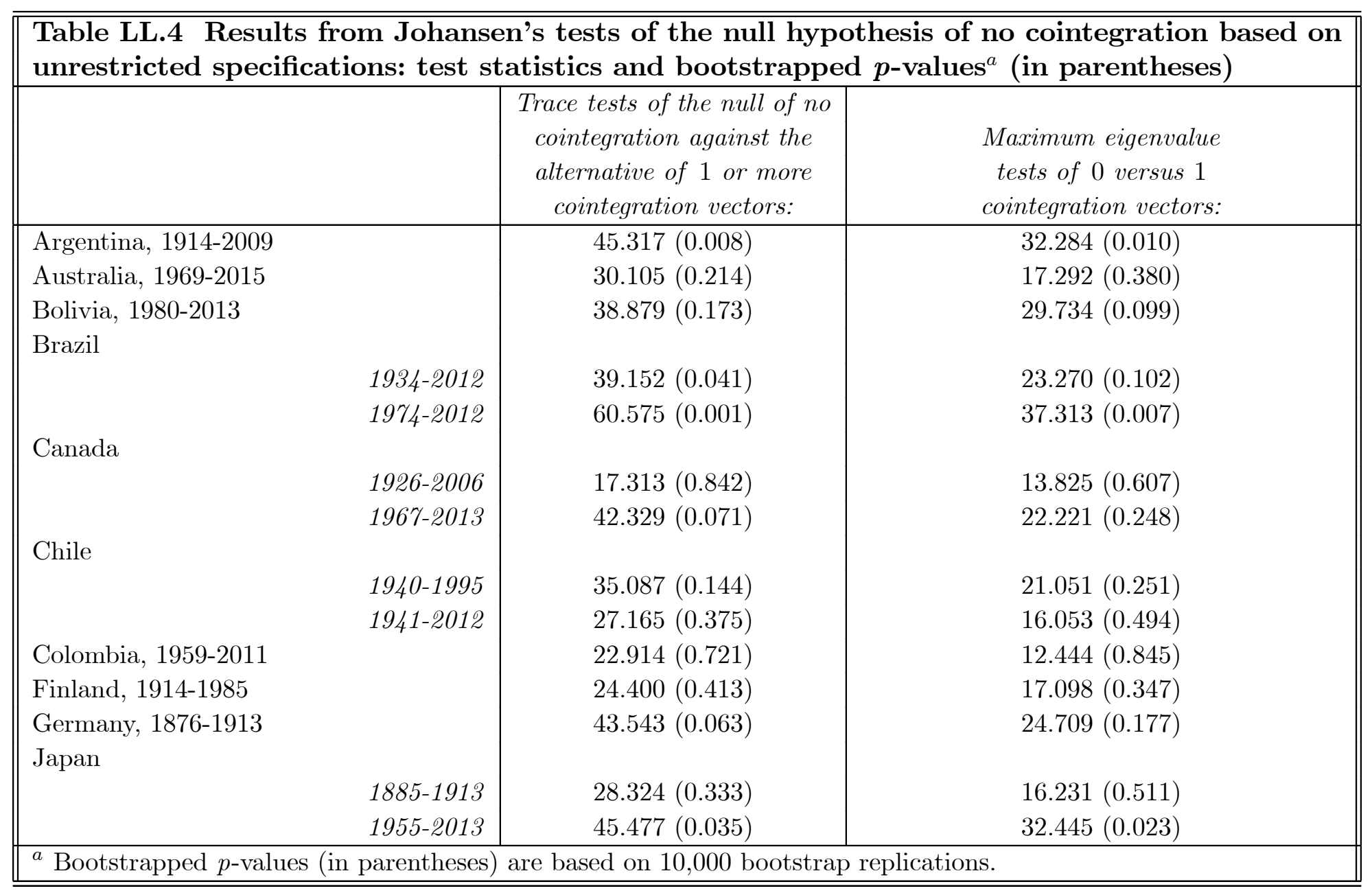




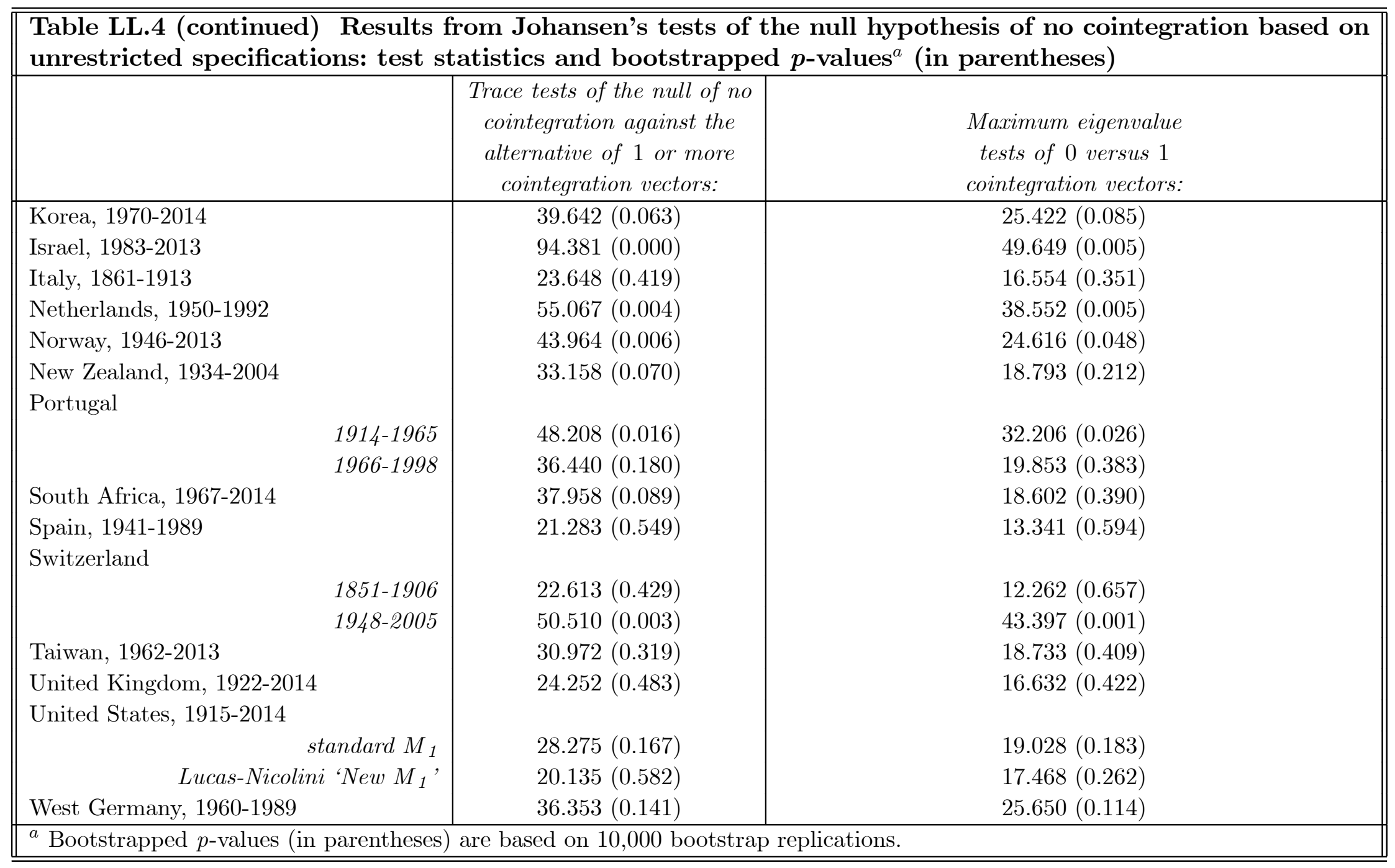




\begin{tabular}{|c|c|c|c|}
\hline \multicolumn{4}{|c|}{$\begin{array}{l}\text { Table LL.5 Results from Shin's (1994) tests of the null hypothesis of cointegration: } \\
\text { test statistics and bootstrapped } p \text {-values }^{a} \text { (in parentheses) based on unrestricted } \\
\text { specifications }^{a}\end{array}$} \\
\hline Argentina, 1914-2009 & $0.167(0.300)$ & Israel, 1983-2013 & $0.047(0.543)$ \\
\hline Australia, 1969-2015 & $0.044(0.702)$ & Italy, 1861-1913 & $0.089(0.582)$ \\
\hline Bolivia, 1980-2013 & $0.060(0.709)$ & Netherlands, 1950-1992 & $0.061(0.537)$ \\
\hline Brazil & & Norway, 1946-2013 & $0.070(0.807)$ \\
\hline 1934-2012 & $0.070(0.549)$ & New Zealand, 1934-2004 & $0.066(0.752)$ \\
\hline $1974-2012$ & $0.046(0.522)$ & Portugal & \\
\hline Canada & & $1914-1965$ & $0.064(0.179)$ \\
\hline 1926-2006 & $0.081(0.780)$ & $1966-1998$ & $0.021(0.984)$ \\
\hline $1967-2013$ & $0.050(0.660)$ & South Africa, 1967-2014 & $0.044(0.675)$ \\
\hline Chile & & Spain, 1941-1989 & $0.110(0.170)$ \\
\hline $1940-1995$ & $0.205(0.014)$ & Switzerland & \\
\hline 1941-2012 & $0.090(0.436)$ & 1851-1906 & $0.064(0.828)$ \\
\hline Colombia, 1959-2011 & $0.099(0.178)$ & $1948-2005$ & $0.127(0.062)$ \\
\hline Finland, 1914-1985 & $0.081(0.626)$ & Taiwan, 1962-2013 & $0.101(0.211)$ \\
\hline Germany, 1876-1913 & $0.072(0.417)$ & United Kingdom, 1922-2014 & $0.134(0.775)$ \\
\hline Japan & & United States, 1915-2014 & \\
\hline $1885-1913$ & $0.073(0.333)$ & standard $M_{1}$ & $0.132(0.676)$ \\
\hline 1955-2013 & $0.068(0.758)$ & Lucas-Nicolini 'New M $M_{1}^{\prime}$ & $0.066(0.948)$ \\
\hline Korea, 1970-2014 & $0.082(0.114)$ & West Germany, 1960-1989 & $0.105(0.114)$ \\
\hline $\begin{array}{r}{ }^{a} \text { Bootstrapped } p \text {-values are based } \\
\text { null hypothesis of one cointegratior } \\
\ln \left(M_{1, t}\right) \\
M_{1, t}=\text { nominal } M_{1} ; N G D P_{t}=\text { no }\end{array}$ & $\begin{array}{l}10,000 \text { boot } \\
\text { ctor. The es } \\
\beta_{0}+\beta_{1} \ln (I \\
\text { lal } G D P ; R_{t}\end{array}$ & $\begin{array}{l}\text { ap replications of the VECM estim } \\
\text { nated regression is } \\
\left.D P_{t}\right)+\beta_{2} \ln \left(R_{t}\right)+u_{t} \\
\text { short rate. }\end{array}$ & ed under the \\
\hline
\end{tabular}




\begin{tabular}{|c|c|c|c|c|}
\hline \multirow{2}{*}{\multicolumn{5}{|c|}{$\begin{array}{l}\text { Table LL.6 Bootstrapped } p \text {-values }{ }^{a} \text { for testing the null hyp } \\
\text { that the income elasticity is equal to } \mathbf{1} \\
\text { I: Based on Johansen's estimator of the cointegration vector }\end{array}$}} \\
\hline & & & & \\
\hline \multirow{4}{*}{$\begin{array}{l}\text { Argentina, 1914-2009 } \\
\text { Australia, 1969-2015 } \\
\text { Bolivia, 1980-2013 } \\
\text { Brazil }\end{array}$} & & 0.435 & Korea, 1970-2014 & 0.404 \\
\hline & & 0.447 & Israel, 1983-2013 & 0.078 \\
\hline & & 0.198 & Netherlands, 1950-1992 & 0.099 \\
\hline & & & New Zealand, 1934-2004 & 0.147 \\
\hline & $1974-2012$ & 0.003 & Norway, 1946-2013 & 0.248 \\
\hline & 1934-2012 & 0.017 & Portugal & \\
\hline \multirow[t]{3}{*}{ Canada } & & & $1914-1965$ & 0.373 \\
\hline & 1926-2006 & 0.072 & $1966-1998$ & 0.474 \\
\hline & $1967-2013$ & 0.116 & South Africa, 1967-2014 & 0.348 \\
\hline \multirow[t]{3}{*}{ Chile } & & & Spain, 1941-1989 & 0.068 \\
\hline & $1940-1995$ & 0.143 & Switzerland, 1948-2005 & 0.025 \\
\hline & 1941-2012 & 0.076 & Taiwan, 1962-2013 & 0.396 \\
\hline \multirow{6}{*}{$\begin{array}{l}\text { Colombia, 1959-2011 } \\
\text { Finland,1914-1985 } \\
\text { Germany, 1876-1913 } \\
\text { Japan }\end{array}$} & & 0.402 & United Kingdom, 1922-2014 & 0.230 \\
\hline & & 0.021 & United States, 1915-2014 & \\
\hline & & 0.044 & standard $M_{1}$ & 0.065 \\
\hline & & & Lucas-Nicolini 'New $M_{1}$ ', & 0.445 \\
\hline & $1885-1913$ & 0.059 & West Germany, 1960-1989 & 0.180 \\
\hline & $1955-2013$ & 0.344 & & \\
\hline
\end{tabular}




\begin{tabular}{|c|c|c|c|c|}
\hline \multicolumn{5}{|c|}{$\begin{array}{l}\text { Table LL.6 (continued) Bootstrapped } p \text {-values }{ }^{a} \text { for testing the null } \\
\text { hypothesis that the income elasticity is equal to } 1\end{array}$} \\
\hline \multicolumn{5}{|c|}{ II: Based on Stock and Watson's estimator of the cointegration vector } \\
\hline Argentina, 1914-2009 & & 0.017 & Korea, 1970-2014 & 0.052 \\
\hline Australia, 1969-2015 & & 0.171 & Israel, 1983-2013 & 0.392 \\
\hline Bolivia, 1980-2013 & & 0.182 & Netherlands, 1950-1992 & 0.178 \\
\hline Brazil & & & New Zealand, 1934-2004 & 0.013 \\
\hline & $1974-2012$ & $1.0 \mathrm{e}-3$ & Norway, 1946-2013 & 0.078 \\
\hline & 1934-2012 & $5.0 \mathrm{e}-4$ & Portugal & \\
\hline \multirow[t]{3}{*}{ Canada } & & & $1914-1965$ & 0.119 \\
\hline & 1926-2006 & 0.028 & $1966-1998$ & 0.091 \\
\hline & $1967-2013$ & 0.347 & South Africa, 1967-2014 & 0.031 \\
\hline \multirow[t]{3}{*}{ Chile } & & & Spain, 1941-1989 & 0.028 \\
\hline & $1940-1995$ & 0.283 & Switzerland, 1948-2005 & 0.008 \\
\hline & 1941-2012 & 0.054 & Taiwan, 1962-2013 & 0.109 \\
\hline Colombia, 1959-2011 & & 0.177 & United Kingdom, 1922-2014 & 0.091 \\
\hline Finland, 1914-1985 & & 0.002 & United States, 1915-2014 & \\
\hline Germany, 1876-1913 & & 0.007 & standard $M_{1}$ & 0.009 \\
\hline \multirow[t]{3}{*}{ Japan } & & & Lucas-Nicolini 'New M $M_{1}$ ' & 0.322 \\
\hline & $1885-1913$ & 0.003 & West Germany, 1960-1989 & 0.194 \\
\hline & 1955-2013 & 0.428 & & \\
\hline
\end{tabular}


IV: Full set of results based on the log-log specification with the correction $\ln (1+R)$ 


\begin{tabular}{|c|c|c|c|}
\hline \multirow{2}{*}{\multicolumn{4}{|c|}{$\begin{array}{l}\text { Table LLCO.1 Assessing the persistence of candidate cointegrat } \\
\text { Hansen (1999) 'grid bootstrap' estimates of the sum of the auto } \\
\text { coefficients based on } \operatorname{AR}(2) \text { models (median, and } 90 \text { per cent bo } \\
\text { confidence interval) }\end{array}$}} \\
\hline & & & \\
\hline Argentina, 1914-2009 & $0.82[0.72 ; 0.92]$ & Korea, 1970-2014 & $0.74[0.51 ; 1.01]$ \\
\hline Australia, 1969-2015 & $0.55[0.26 ; 0.87]$ & Israel, 1983-2013 & $0.69[0.57 ; 0.81]$ \\
\hline Bolivia, 1980-2013 & $0.73[0.55 ; 0.92]$ & Mexico, 1985-2014 & $0.75[0.56 ; 0.99]$ \\
\hline Brazil & & Netherlands, 1950-1992 & $0.64[0.39 ; 0.95]$ \\
\hline \multirow[b]{3}{*}{ Canada } & $0.94[0.79 ; 1.02]$ & New Zealand, 1934-2004 & $0.84[0.73 ; 0.99]$ \\
\hline & $0.92[0.82 ; 1.02]$ & Norway, 1946-2013 & $0.95[0.87 ; 1.01]$ \\
\hline & & Portugal & \\
\hline \multirow{3}{*}{$\begin{array}{l}1926-2006 \\
1967-2013\end{array}$} & $0.79[0.64 ; 0.95]$ & $1914-1965$ & $0.81[0.64 ; 1.01]$ \\
\hline & $0.39[0.20 ; 0.57]$ & $1966-1998$ & $1.01[0.95 ; 1.06]$ \\
\hline & & South Africa, 1967-2014 & $0.90[0.78 ; 1.01]$ \\
\hline \multirow{7}{*}{$\begin{array}{l}\text { Colombia, 1959-2011 } \\
\text { Finland, 1914-1985 } \\
\text { Germany, 1876-1913 } \\
\text { Guatemala, 1980-2012 } \\
\text { Japan }\end{array}$} & $0.78[0.63 ; 0.94]$ & Spain, 1941-1989 & $0.83[0.66 ; 1.01]$ \\
\hline & $0.83[0.72 ; 0.97]$ & Switzerland, 1948-2005 & $0.79[0.63 ; 1.01]$ \\
\hline & $0.88[0.71 ; 1.02]$ & Taiwan, 1962-2013 & $0.85[0.75 ; 0.97]$ \\
\hline & $0.94[0.86 ; 1.01]$ & United Kingdom, 1922-2014 & $0.81[0.68 ; 0.95]$ \\
\hline & $0.61[0.35 ; 0.98]$ & United States, 1915-2014 & \\
\hline & $0.59[0.29 ; 0.98]$ & standard $M_{1}$ & $0.96[0.89 ; 1.01]$ \\
\hline & & Lucas-Nicolini 'New $M_{1}$ ' & $0.77[0.66 ; 0.88]$ \\
\hline $1885-1913$ & $0.44[0.12 ; 0.88]$ & Venezuela, 1962-1999 & $0.95[0.80 ; 1.03$ \\
\hline $1955-2013$ & $0.93[0.85 ; 1.01]$ & West Germany, 1960-1989 & $0.39[0.07 ; 0.70]$ \\
\hline \multicolumn{4}{|c|}{$\begin{array}{l}{ }^{a} \text { Based on 2,000 bootstrap replications for each value of } \rho \text { in the grid. Candidate cointegration } \\
\text { residuals have been computed based on the bivariate model for log velocity and (the log of) the } \\
\text { short rate, and Johansen's estimator. }\end{array}$} \\
\hline
\end{tabular}




\begin{tabular}{|c|c|c|c|}
\hline \multicolumn{4}{|c|}{$\begin{array}{l}\text { Table LLCO.1 (continued) Assessing the persistence of candidate cointegration } \\
\text { residuals: Hansen (1999) 'grid bootstrap' estimates of the sum of the autore- } \\
\text { gressive coefficients based on } \operatorname{AR}(2) \text { models (median, and } 90 \text { per cent boot- } \\
\text { strapped confidence interval) }{ }^{a}\end{array}$} \\
\hline \multicolumn{4}{|c|}{ II: Based on Stock and Watson's estimator of the cointegration vector } \\
\hline Argentina, 1914-2009 & $0.86[0.77 ; 0.99]$ & Korea, 1970-2014 & $0.75[0.54 ; 1.01]$ \\
\hline Australia, 1969-2015 & $0.55[0.26 ; 0.85]$ & Israel, 1983-2013 & $0.65[0.46 ; 0.84]$ \\
\hline Bolivia, 1980-2013 & $0.72[0.55 ; 0.91]$ & Mexico, 1985-2014 & $0.73[0.51 ; 0.98]$ \\
\hline Brazil & & Netherlands, 1950-1992 & $0.70[0.46 ; 0.99]$ \\
\hline \multirow[b]{3}{*}{ Canada } & $0.91[0.77 ; 1.02]$ & New Zealand, 1934-2004 & $0.88[0.77 ; 1.01]$ \\
\hline & $1.00[0.93 ; 1.03]$ & Norway, 1946-2013 & $1.00[0.97 ; 1.02]$ \\
\hline & & Portugal & \\
\hline 1926-2006 & $0.82[0.68 ; 0.99]$ & $1914-1965$ & $0.80[0.64 ; 1.01]$ \\
\hline \multirow[b]{2}{*}{ Chile } & $0.39[0.20 ; 0.57]$ & $1966-1998$ & $1.02[0.98 ; 1.10]$ \\
\hline & & South Africa, 1967-2014 & $1.01[0.98 ; 1.04]$ \\
\hline $1940-1995$ & $0.80[0.66 ; 1.00]$ & Spain, 1941-1989 & $0.83[0.67 ; 1.01]$ \\
\hline 1941-2012 & $0.83[0.71 ; 0.98]$ & Switzerland, 1948-2005 & $0.88[0.75 ; 1.02]$ \\
\hline Colombia, 1959-2011 & $0.92[0.73 ; 1.03]$ & Taiwan, 1962-2013 & $0.86[0.76 ; 0.98]$ \\
\hline Finland, 1914-1985 & $0.97[0.90 ; 1.01]$ & United Kingdom, 1922-2014 & $0.83[0.71 ; 1.00]$ \\
\hline Guatemala, 1980-2012 & $0.60[0.31 ; 0.97]$ & United States, 1915-2014 & \\
\hline Germany, 1876-1913 & $0.99[0.86 ; 1.03]$ & standard $M_{1}$ & $1.01[0.97 ; 1.02]$ \\
\hline Japan & & Lucas-Nicolini 'New $M_{1}$ ', & $0.79[0.68 ; 0.90]$ \\
\hline $1885-1913$ & $1.01[0.86 ; 1.05]$ & Venezuela, 1962-1999 & $0.94[0.76 ; 1.03]$ \\
\hline $1955-2013$ & $0.95[0.85 ; 1.01]$ & West Germany, 1960-1989 & $1.01[0.86 ; 1.10]$ \\
\hline
\end{tabular}




\begin{tabular}{|c|c|c|c|c|}
\hline \multicolumn{5}{|c|}{$\begin{array}{l}\text { Table LLCO.2 Cointegration tests between the logarithms of } M_{1} \\
\text { velocity and of a short-term rate }{ }^{a}\end{array}$} \\
\hline \multirow[b]{2}{*}{ Country } & \multirow[b]{2}{*}{ Period } & \multicolumn{2}{|c|}{ I: Johansen's tests } & \multirow[b]{2}{*}{ II: Shin's tests } \\
\hline & & Trace $e^{b}$ & $\begin{array}{l}\text { Maximum } \\
\text { eigenvalue }\end{array}$ & \\
\hline Argentina & 1914-2009 & $21.303(0.032)$ & $18.866(0.023)$ & $0.567(0.288)$ \\
\hline \multirow[t]{2}{*}{ Australia } & 1941-1989 & $6.111(0.800)$ & $6.102(0.709)$ & $0.369(0.126)$ \\
\hline & 1969-2015 & $10.268(0.506)$ & $9.373(0.405)$ & $0.245(0.395)$ \\
\hline Belgium & 1946-1990 & $23.319(0.011)$ & $21.225(0.010)$ & $0.106(0.736)$ \\
\hline Bolivia & $1980-2013$ & $15.480(0.255)$ & $15.134(0.154)$ & $0.156(0.249)$ \\
\hline \multirow[t]{2}{*}{ Brazil } & 1974-2012 & $20.904(0.049)$ & $15.221(0.093)$ & $0.325(0.104)$ \\
\hline & 1934-2012 & $20.270(0.034)$ & $16.842(0.037)$ & $2.043(0.011)$ \\
\hline \multirow[t]{2}{*}{ Canada } & 1926-2006 & $16.019(0.127)$ & $14.698(0.077)$ & $0.854(0.158)$ \\
\hline & $1967-2012$ & $27.310(0.010)$ & $27.262(0.003)$ & $0.079(0.705)$ \\
\hline \multirow[t]{2}{*}{ Chile } & 1940-1995 & $26.453(0.013)$ & $18.953(0.033)$ & $0.178(0.244)$ \\
\hline & 1941-2012 & $18.541(0.059)$ & $13.224(0.119)$ & $0.127(0.725)$ \\
\hline Colombia & 1959-2011 & $6.603(0.830)$ & $4.896(0.872)$ & $0.225(0.502)$ \\
\hline Finland & 1914-1985 & $7.225(0.736)$ & $5.019(0.839)$ & $1.447(0.023)$ \\
\hline Germany & $1876-1913$ & $9.947(0.559)$ & $8.689(0.532)$ & $0.522(0.177)$ \\
\hline Guatemala & 1980-2012 & $18.939(0.077)$ & $17.261(0.052)$ & $0.072(0.737)$ \\
\hline \multirow[t]{2}{*}{ Japan } & $1885-1913$ & $11.938(0.408)$ & $10.737(0.331)$ & $0.435(0.099)$ \\
\hline & $1955-2013$ & $13.502(0.199)$ & $13.502(0.120)$ & $0.098(0.975)$ \\
\hline Korea & 1970-2014 & $6.698(0.746)$ & $6.075(0.715)$ & $0.282(0.269)$ \\
\hline Israel & 1983-2014 & $41.66(0.001)$ & $40.773(0.000)$ & $0.135(0.350)$ \\
\hline Mexico & 1985-2014 & $15.569(0.230)$ & $14.027(0.205)$ & $0.132(0.285)$ \\
\hline Netherlands & 1950-1992 & $15.054(0.166)$ & $9.309(0.401)$ & $0.216(0.413)$ \\
\hline New Zealand & 1934-2014 & $17.917(0.075)$ & $16.454(0.044)$ & $0.604(0.354)$ \\
\hline Norway & $1946-2013$ & $24.004(0.016)$ & $20.698(0.015)$ & $0.736(0.157)$ \\
\hline \multirow[t]{2}{*}{ Portugal } & $1914-1965$ & $20.699(0.061)$ & $19.887(0.032)$ & $0.120(0.360)$ \\
\hline & 1966-1998 & $19.392(0.086)$ & $14.975(0.125)$ & $0.074(0.546)$ \\
\hline South Africa & $1967-2014$ & $16.776(0.131)$ & $15.686(0.080)$ & $0.336(0.160)$ \\
\hline Spain & 1941-1989 & $7.850(0.642)$ & $7.632(0.537)$ & $0.261(0.256)$ \\
\hline \multirow[t]{2}{*}{ Switzerland } & 1851-1906 & $15.520(0.094)$ & $15.377(0.057)$ & $0.780(0.192)$ \\
\hline & 1948-2005 & $31.284(0.001)$ & $27.586(0.001)$ & $0.975(0.064)$ \\
\hline Taiwan & $1962-2013$ & $6.108(0.816)$ & $5.508(0.794)$ & $0.387(0.131)$ \\
\hline United Kingdom & $1922-2014$ & $15.684(0.159)$ & $15.361(0.077)$ & $0.951(0.058)$ \\
\hline \multicolumn{5}{|l|}{ United States } \\
\hline standard $M_{1}$ & $1915-2014$ & $11.224(0.342)$ & $9.563(0.320)$ & $3.021(0.015)$ \\
\hline Lucas-Nicolini $M_{1}$ & $1915-2014$ & $14.623(0.187)$ & $13.107(0.137)$ & $0.369(0.290)$ \\
\hline Venezuela & 1962-1999 & $6.616(0.771)$ & $4.389(0.888)$ & $0.364(0.094)$ \\
\hline West Germany & 1960-1989 & $12.243(0.419)$ & $12.194(0.261)$ & $0.442(0.076)$ \\
\hline \multicolumn{5}{|c|}{$\begin{array}{l}{ }^{a} \text { Bootstrapped } p \text {-values (in parentheses) are based on } 10,000 \text { bootstrap replications. } \\
{ }^{b} \text { Null of no cointegration against alternative of } 1 \text { or more cointegration vectors. } \\
{ }^{b} \text { Null of } 0 \text { versus } 1 \text { cointegration vectors. }\end{array}$} \\
\hline
\end{tabular}




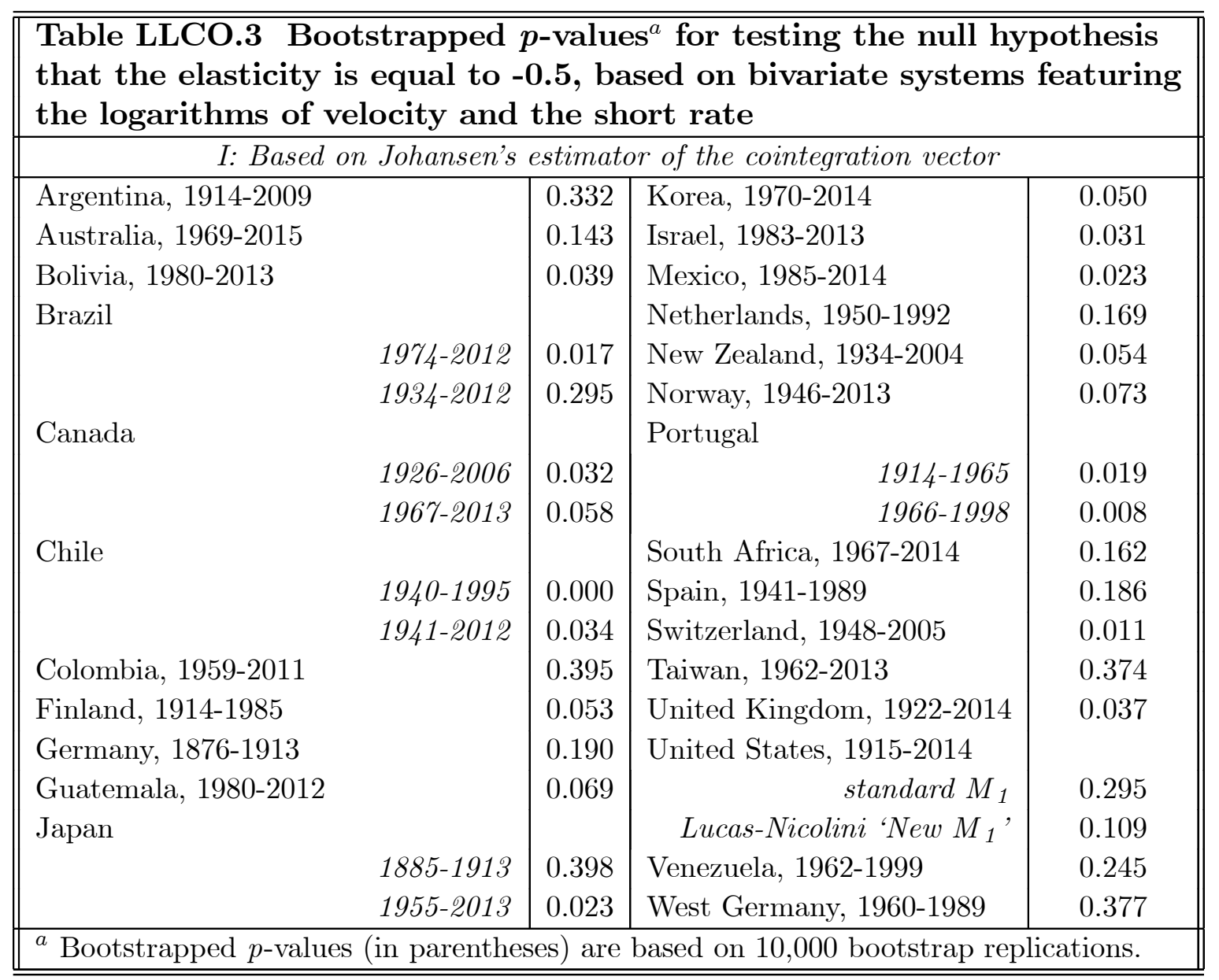




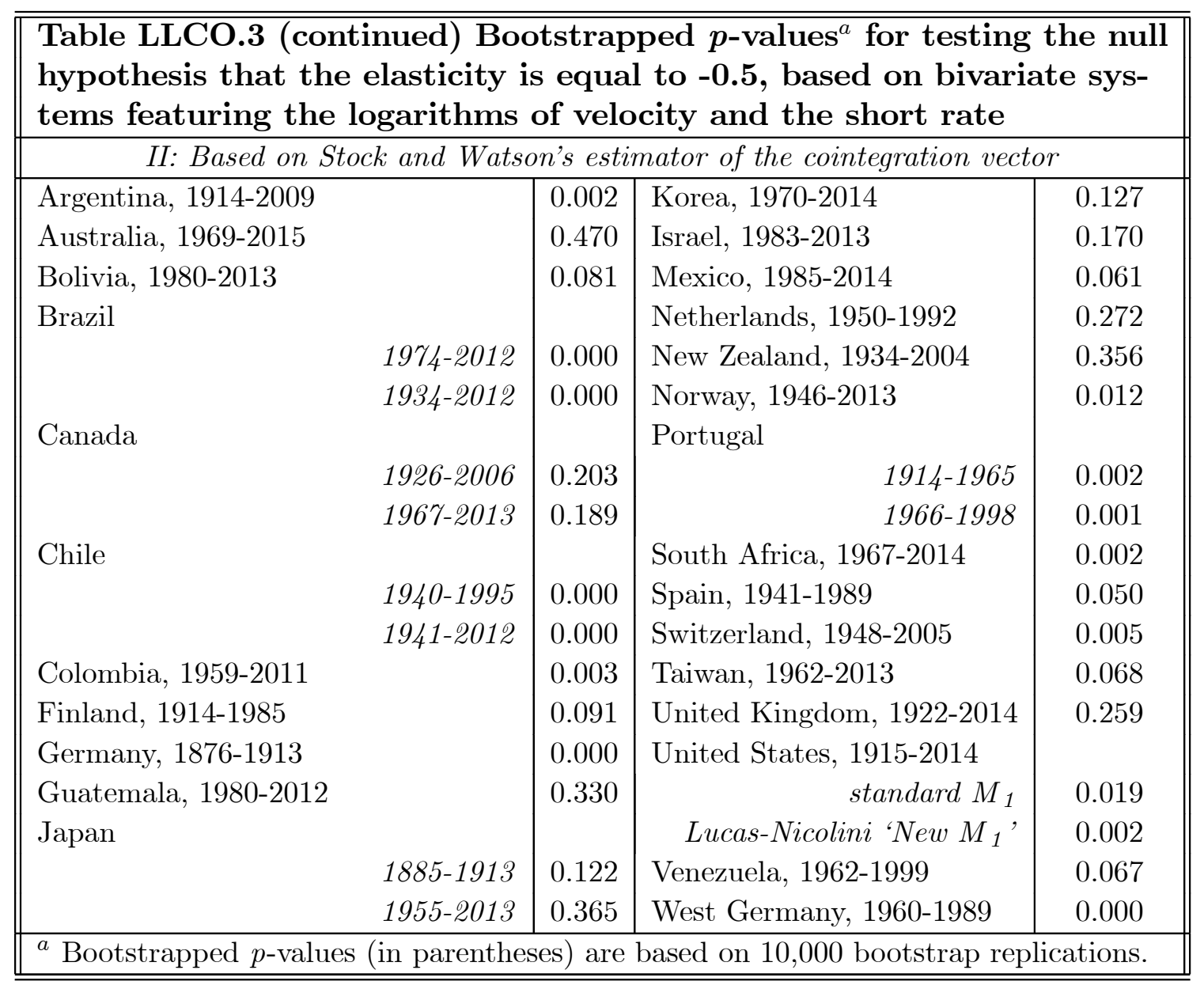




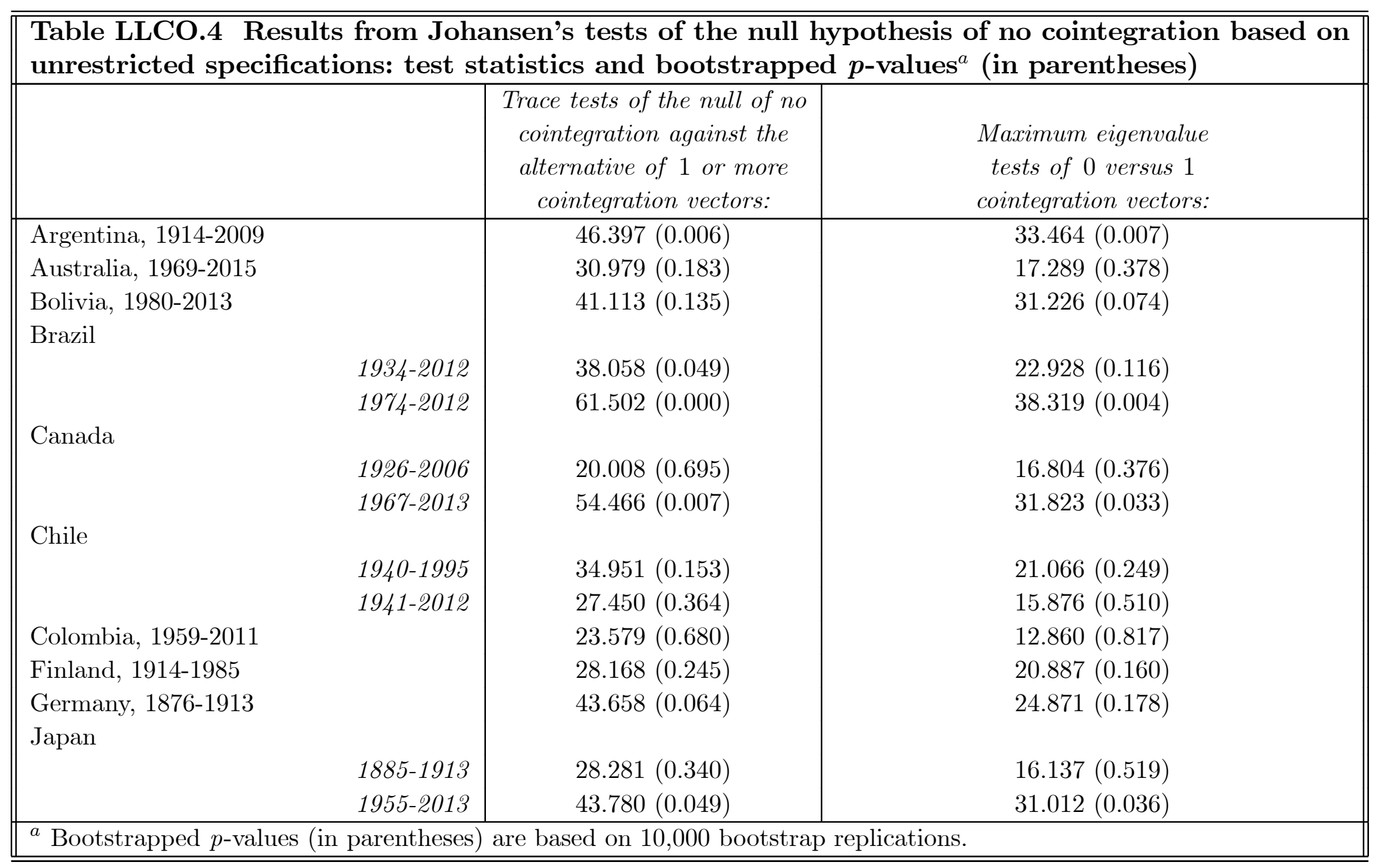




\begin{tabular}{|c|c|c|}
\hline $\begin{array}{l}\text { Table LLCO.4 (continued) Res } \\
\text { based on unrestricted specificat }\end{array}$ & $\begin{array}{l}\text { from Johansen's test } \\
\text { s: test statistics and b }\end{array}$ & $\begin{array}{l}\text { aypothesis of no c } \\
p \text {-values }^{a} \text { (in pare }\end{array}$ \\
\hline & $\begin{array}{c}\text { Trace tests of the null of no } \\
\text { cointegration against the } \\
\text { alternative of } 1 \text { or more } \\
\text { cointegration vectors: }\end{array}$ & $\begin{array}{l}\text { Maximum eigenvalue } \\
\text { tests of } 0 \text { versus } 1 \\
\text { cointegration vectors: }\end{array}$ \\
\hline Korea, 1970-2014 & $43.784(0.032)$ & $27.554(0.056)$ \\
\hline Israel, 1983-2013 & $95.473(0.000)$ & $50.929(0.000)$ \\
\hline Italy, 1861-1913 & $24.261(0.385)$ & $16.973(0.323)$ \\
\hline Netherlands, 1950-1992 & $54.319(0.005)$ & $37.561(0.008)$ \\
\hline Norway, 1946-2013 & $43.279(0.007)$ & $24.491(0.050)$ \\
\hline New Zealand, 1934-2004 & $31.801(0.094)$ & $17.733(0.261)$ \\
\hline Portugal & & \\
\hline $1914-1965$ & $47.608(0.018)$ & $31.104(0.034)$ \\
\hline $1966-1998$ & $35.621(0.206)$ & $19.491(0.416)$ \\
\hline South Africa, 1967-2014 & $38.292(0.075)$ & $18.660(0.371)$ \\
\hline Spain, 1941-1989 & $21.426(0.541)$ & $13.347(0.596)$ \\
\hline Switzerland & & \\
\hline 1851-1906 & $26.095(0.239)$ & $15.927(0.348)$ \\
\hline $1948-2005$ & $52.240(0.002)$ & $45.854(0.000)$ \\
\hline Taiwan, 1962-2013 & $33.274(0.249)$ & $21.262(0.268)$ \\
\hline United Kingdom, 1922-2014 & $27.215(0.313)$ & $19.569(0.225)$ \\
\hline United States, 1915-2014 & & \\
\hline standard $M_{1}$ & $21.101(0.539)$ & $13.896(0.532)$ \\
\hline Lucas-Nicolini 'New M ${ }_{1}$ ' & $21.1006(0.539)$ & $13.896(0.532)$ \\
\hline West Germany, 1960-1989 & $36.082(0.154)$ & $25.552(0.120)$ \\
\hline
\end{tabular}




\begin{tabular}{|c|c|c|c|}
\hline \multicolumn{4}{|c|}{$\begin{array}{l}\text { Table LLCO.5 Results from Shin's (1994) tests of the null hypothesis of cointegration: } \\
\text { test statistics and bootstrapped } p \text {-values }{ }^{a} \text { (in parentheses) based on unrestricted speci- } \\
\text { cifications }^{a}\end{array}$} \\
\hline Argentina, 1914-2009 & $0.168(0.299)$ & Israel, 1983-2013 & $0.049(0.555)$ \\
\hline Australia, 1969-2015 & $0.046(0.653)$ & Italy, 1861-1913 & $0.090(0.561)$ \\
\hline Bolivia, 1980-2013 & $0.063(0.675)$ & Netherlands, 1950-1992 & $0.062(0.527)$ \\
\hline Brazil & & Norway, 1946-2013 & $0.071(0.791)$ \\
\hline 1934-2012 & $0.071(0.529)$ & New Zealand, 1934-2004 & $0.075(0.691)$ \\
\hline $1974-2012$ & $0.047(0.520)$ & Portugal & \\
\hline \multirow[t]{2}{*}{ Canada } & & $1914-1965$ & $0.066(0.181)$ \\
\hline & $0.066(0.881)$ & $1966-1998$ & $0.013(0.983)$ \\
\hline $1967-2013$ & $0.048(0.560)$ & South Africa, 1967-2014 & $0.043(0.701)$ \\
\hline \multirow[t]{3}{*}{ Chile } & & Spain, 1941-1989 & $0.108(0.187)$ \\
\hline & $0.202(0.017)$ & Switzerland & \\
\hline & $0.093(0.430)$ & $1851-1906$ & $0.064(0.824)$ \\
\hline Colombia, 1959-2011 & $0.101(0.161)$ & 1948-2005 & $0.115(0.123)$ \\
\hline Finland, 1914-1985 & $0.082(0.617)$ & Taiwan, 1962-2013 & $0.119(0.142)$ \\
\hline Germany, 1876-1913 & $0.070(0.440)$ & United Kingdom, 1922-2014 & $0.132(0.676)$ \\
\hline Japan & & United States, 1915-2014 & \\
\hline $1885-1913$ & $0.068(0.369)$ & standard $M_{1}$ & $0.169(0.517)$ \\
\hline 1955-2013 & $0.061(0.846)$ & Lucas-Nicolini 'New $M_{1}$ ' & $0.169(0.517)$ \\
\hline Korea, 1970-2014 & $0.080(0.136)$ & West Germany, 1960-1989 & $0.109(0.109)$ \\
\hline \multicolumn{4}{|c|}{$\begin{array}{l}{ }^{a} \text { Bootstrapped } p \text {-values are based on } 10,000 \text { bootstrap replications of the VECM estimated under the } \\
\text { null hypothesis of one cointegration vector. The estimated regression is } \\
\qquad \ln \left(M_{1, t}\right)=\beta_{0}+\beta_{1} \ln \left(N G D P_{t}\right)+\beta_{2} \ln \left(1+R_{t}\right)+u_{t} \\
M_{1, t}=\text { nominal } M_{1} ; N G D P_{t}=\text { nominal } G D P ; R_{t}=\text { short rate. }\end{array}$} \\
\hline
\end{tabular}




\begin{tabular}{|c|c|c|c|c|}
\hline \multicolumn{5}{|c|}{$\begin{array}{l}\text { Table LLCO.6 Bootstrapped } p \text {-values }{ }^{a} \text { for testing the null } 1 \\
\text { that the income elasticity is equal to } 1\end{array}$} \\
\hline \\
\hline Argentina, 1914-2009 & & 0.463 & Korea, 1970-2014 & 0.456 \\
\hline Australia, 1969-2015 & & 0.477 & Israel, 1983-2013 & 0.076 \\
\hline Bolivia, 1980-2013 & & 0.166 & Netherlands, 1950-1992 & 0.117 \\
\hline Brazil & & & New Zealand, 1934-2004 & 0.162 \\
\hline & 1974-2012 & 0.003 & Norway, 1946-2013 & 0.222 \\
\hline & 1934-2012 & 0.015 & Portugal & \\
\hline \multirow[t]{3}{*}{ Canada } & & & $1914-1965$ & 0.381 \\
\hline & 1926-2006 & 0.062 & $1966-1998$ & 0.410 \\
\hline & $1967-2013$ & 0.053 & South Africa, 1967-2014 & 0.369 \\
\hline \multirow[t]{3}{*}{ Chile } & & & Spain, 1941-1989 & 0.072 \\
\hline & $1940-1995$ & 0.187 & Switzerland, 1948-2005 & 0.209 \\
\hline & 1941-2012 & 0.072 & Taiwan, 1962-2013 & 0.442 \\
\hline \multirow{6}{*}{$\begin{array}{l}\text { Colombia, 1959-2011 } \\
\text { Finland, 1914-1985 } \\
\text { Germany, 1876-1913 } \\
\text { Japan }\end{array}$} & & 0.350 & United Kingdom, 1922-2014 & 0.141 \\
\hline & & 0.026 & United States, 1915-2014 & \\
\hline & & 0.046 & standard $M_{1}$ & 0.056 \\
\hline & & & Lucas-Nicolini 'New M $M_{1}$ ' & 0.405 \\
\hline & $1885-1913$ & 0.053 & West Germany, 1960-1989 & 0.189 \\
\hline & $1955-2013$ & 0.377 & & \\
\hline
\end{tabular}




\begin{tabular}{|c|c|c|c|}
\hline \multicolumn{4}{|c|}{$\begin{array}{l}\text { Table LLCO.6 (continued) Bootstrapped } p \text {-values }{ }^{a} \text { for testing the null } \\
\text { hypothesis that the income elasticity is equal to } 1\end{array}$} \\
\hline \multicolumn{4}{|c|}{ II: Based on Stock and Watson's estimator of the cointegration vector } \\
\hline Argentina, 1914-2009 & 0.017 & Korea, 1970-2014 & 0.031 \\
\hline Australia, 1969-2015 & 0.143 & Israel, 1983-2013 & 0.438 \\
\hline Bolivia, 1980-2013 & 0.178 & Netherlands, 1950-1992 & 0.153 \\
\hline Brazil & & New Zealand, 1934-2004 & 0.014 \\
\hline $1974-2012$ & $1.0 \mathrm{e}-3$ & Norway, 1946-2013 & 0.083 \\
\hline 1934-2012 & $1.0 \mathrm{e}-4$ & Portugal & \\
\hline \multirow[t]{2}{*}{ Canada } & & $1914-1965$ & 0.092 \\
\hline & 0.026 & $1966-1998$ & 0.084 \\
\hline $1967-2013$ & 0.215 & South Africa, 1967-2014 & 0.031 \\
\hline \multirow[t]{3}{*}{ Chile } & & Spain, 1941-1989 & 0.023 \\
\hline & 0.267 & Switzerland, 1948-2005 & 0.029 \\
\hline & 0.045 & Taiwan, 1962-2013 & 0.123 \\
\hline Colombia, 1959-2011 & 0.174 & United Kingdom, 1922-2014 & 0.050 \\
\hline Finland, 1914-1985 & 0.002 & United States, 1915-2014 & \\
\hline \multirow{4}{*}{$\begin{array}{l}\text { Germany, 1876-1913 } \\
\text { Japan }\end{array}$} & 0.006 & standard $M_{1}$ & 0.006 \\
\hline & & Lucas-Nicolini 'New $M_{1}$ ' & 0.283 \\
\hline & 0.003 & West Germany, 1960-1989 & 0.207 \\
\hline & 0.396 & & \\
\hline
\end{tabular}




\section{Figures for the online appendix}


I: Selected raw series with a time dimension 
Based on the standard $M_{1}$ series

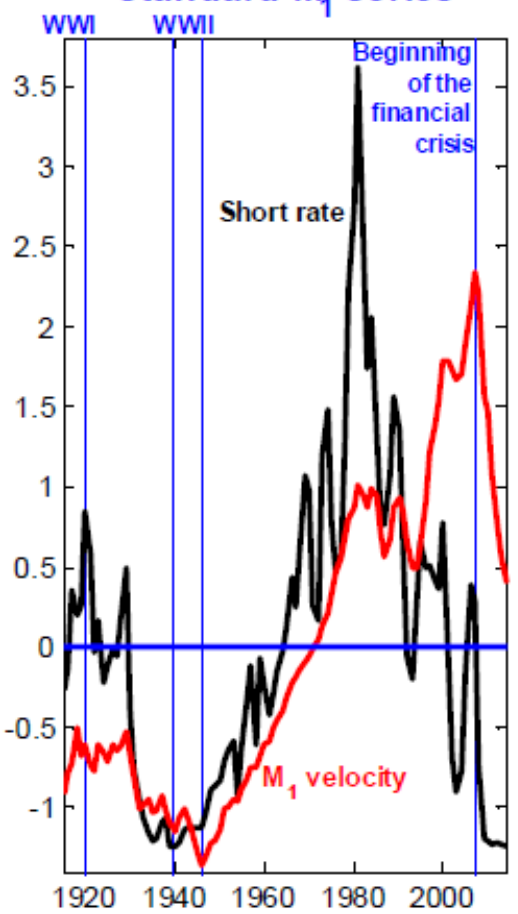

Based on Lucas and Nicolini's 'New $M_{1}$ ' series
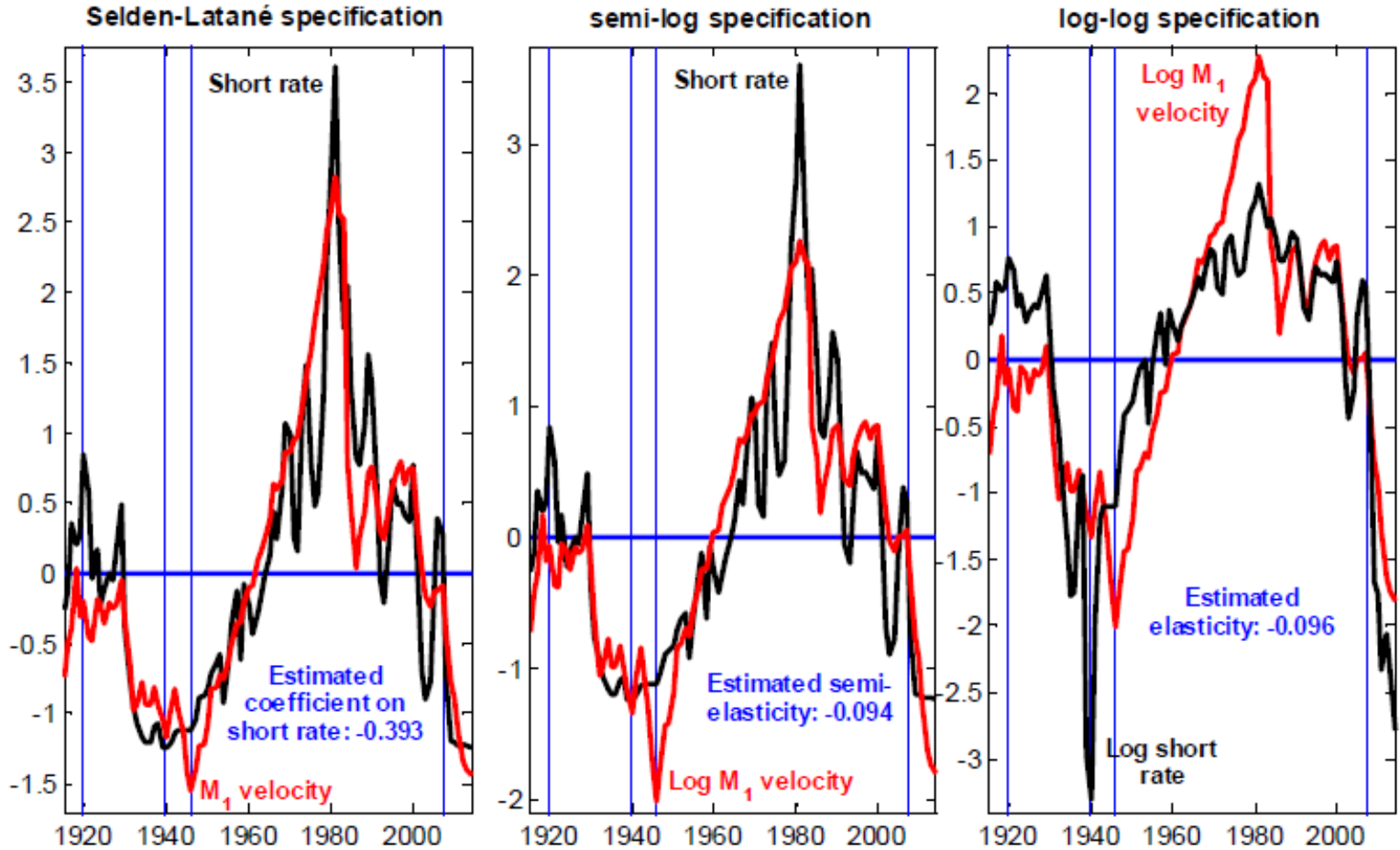

Figure 1 United States, 1915-2014: $\mathrm{M}_{1}$ velocity and the short-term nominal interest rate (de-meaned and standardized) 

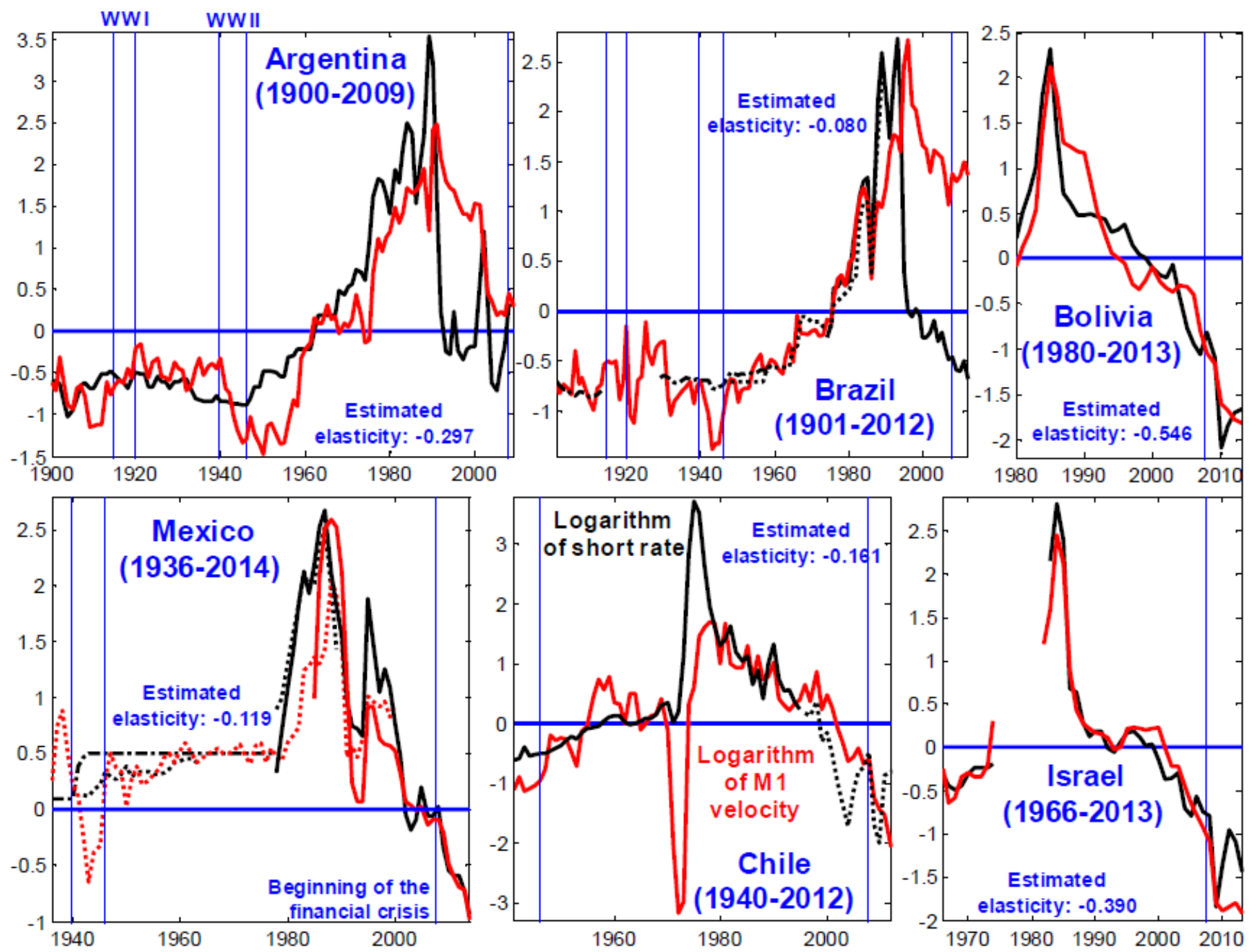

Figure 2 The logarithms of $\mathrm{M}_{1}$ velocity and the short-term nominal interest rate, de-meaned and standardized $\left(\mathrm{M}_{1}\right.$ velocity computed as the ratio between nominal GDP and nominal $\mathrm{M}_{1}$ ) 

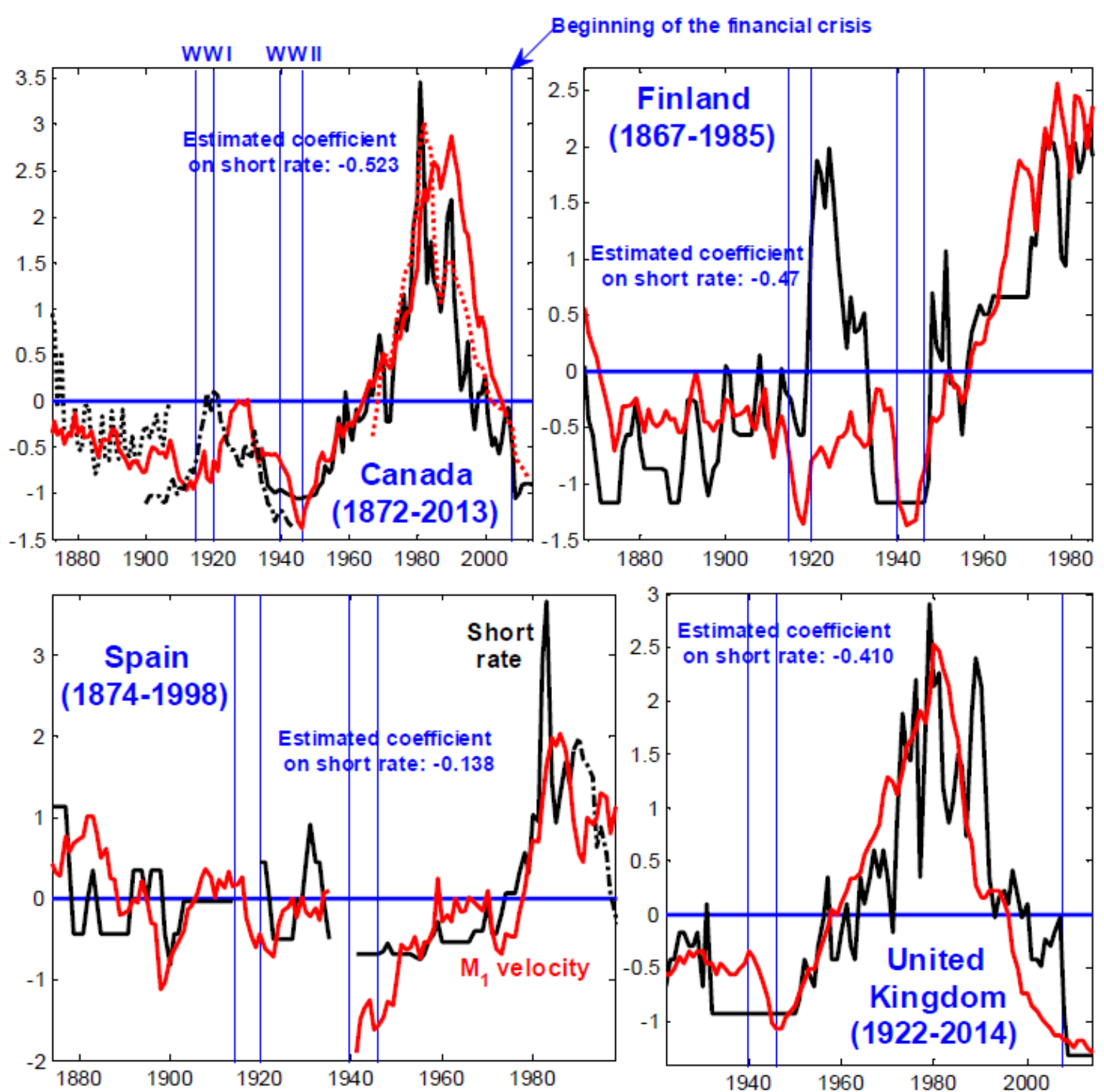

Figure $3 \quad \mathrm{M}_{1}$ velocity and the short-term nominal interest rate, de-meaned and standardized $\left(\mathrm{M}_{1}\right.$ velocity computed as the ratio between nominal GDP and nominal $\mathrm{M}_{1}$ ) 

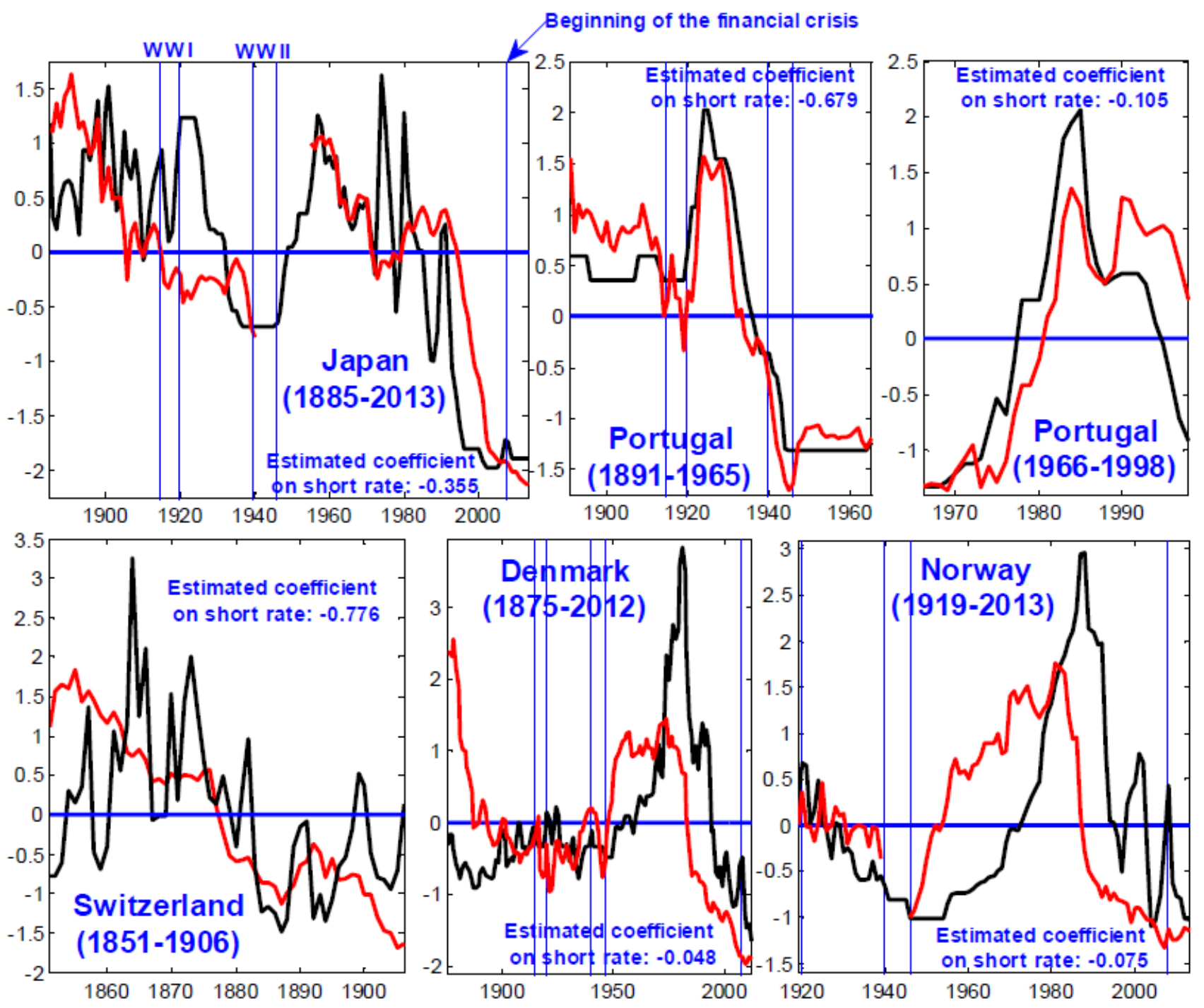

Figure $4 \mathrm{M}_{1}$ velocity and the short-term nominal interest rate, de-meaned and standardized $\left(\mathrm{M}_{1}\right.$ velocity computed as the ratio between nominal GDP and nominal $\mathrm{M}_{1}$ ) 


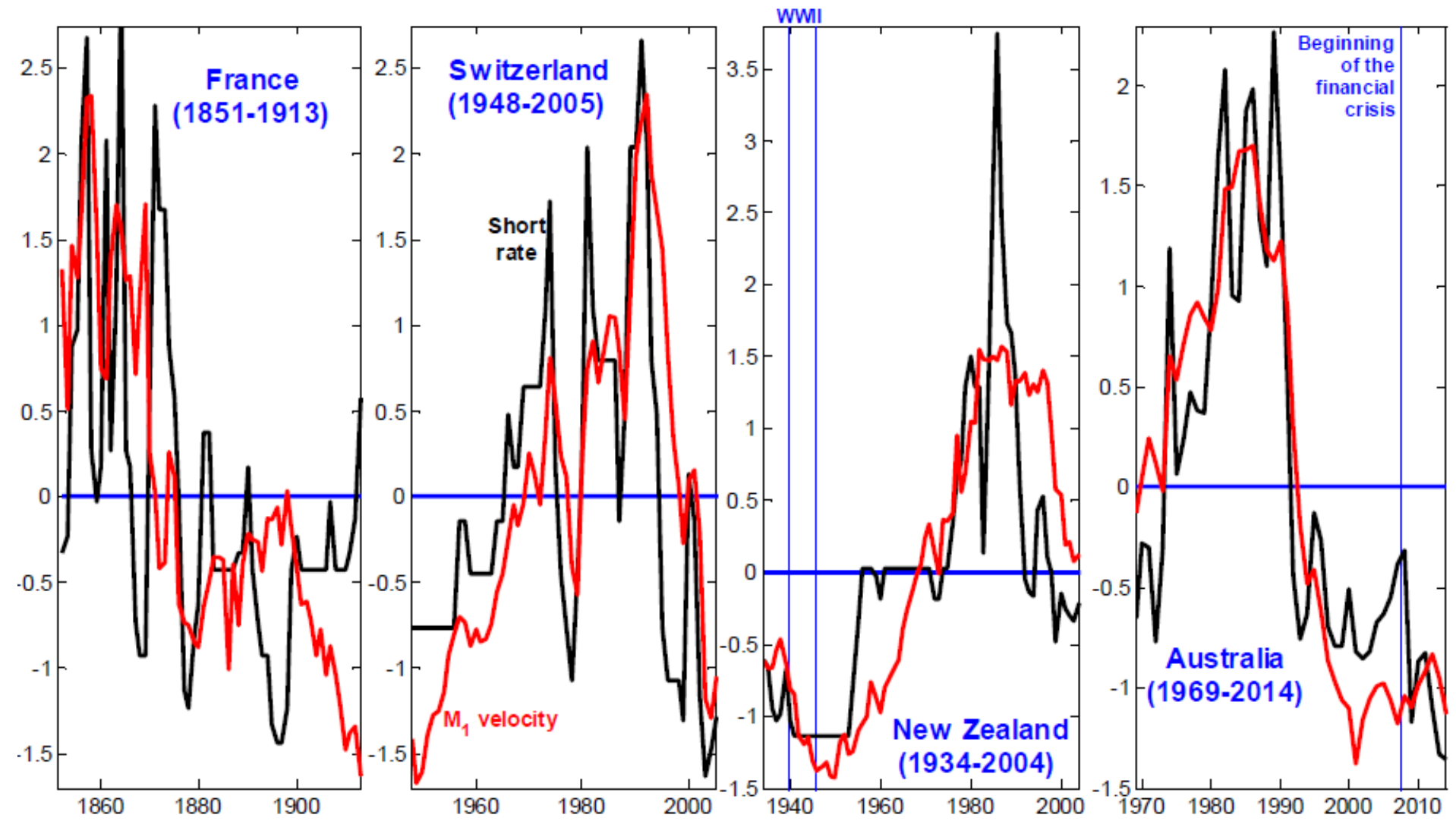

Figure $5 \quad \mathrm{M}_{1}$ velocity and the short-term nominal interest rate, de-meaned and standardized $\left(\mathrm{M}_{1}\right.$ velocity computed as the ratio between nominal GDP and nominal $\mathrm{M}_{1}$ ) 

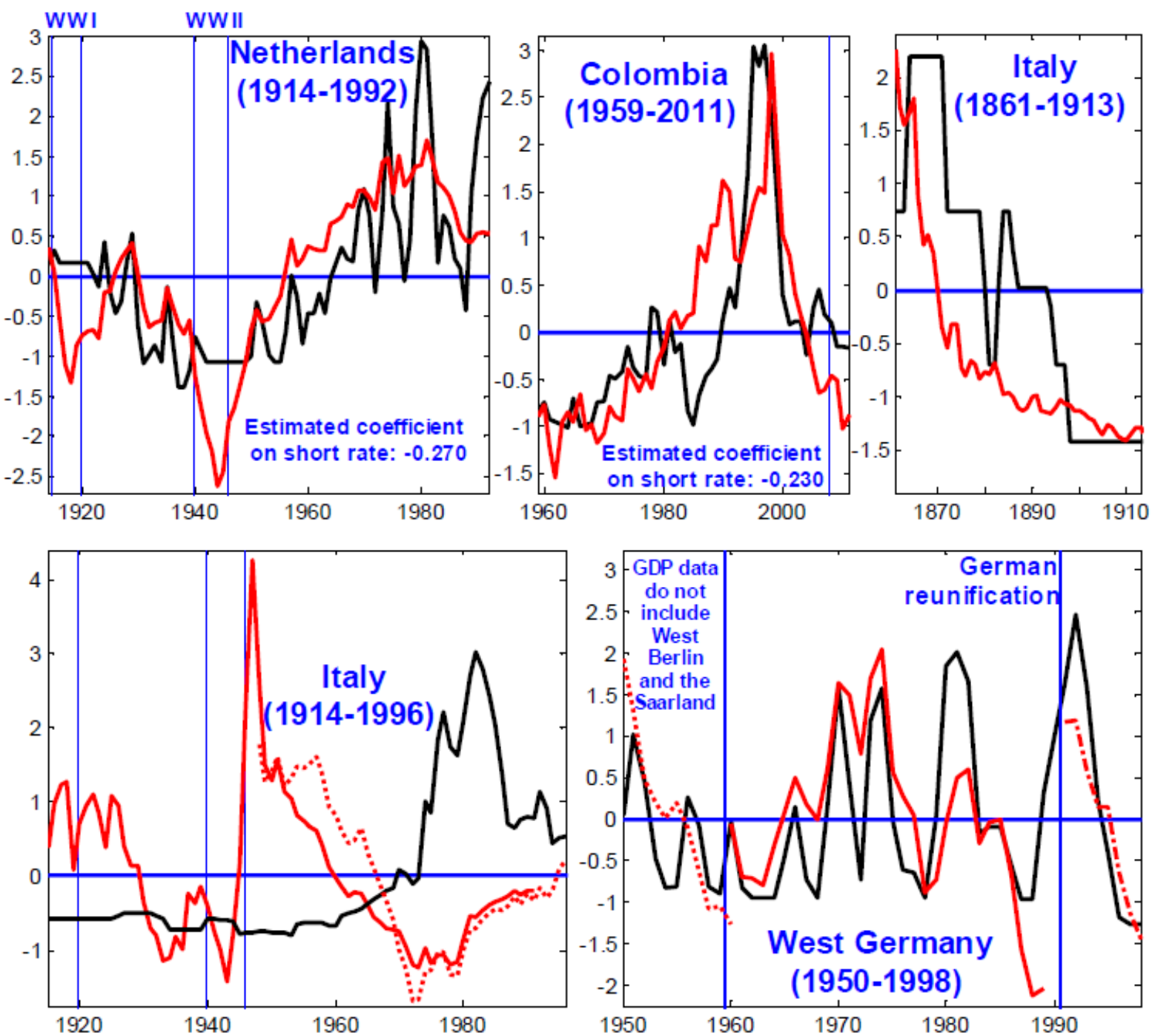

Figure $6 \quad \mathrm{M}_{1}$ velocity and the short-term nominal interest rate, de-meaned and standardized $\left(\mathrm{M}_{1}\right.$ velocity computed as the ratio between nominal GDP and nominal $\mathrm{M}_{1}$ ) 

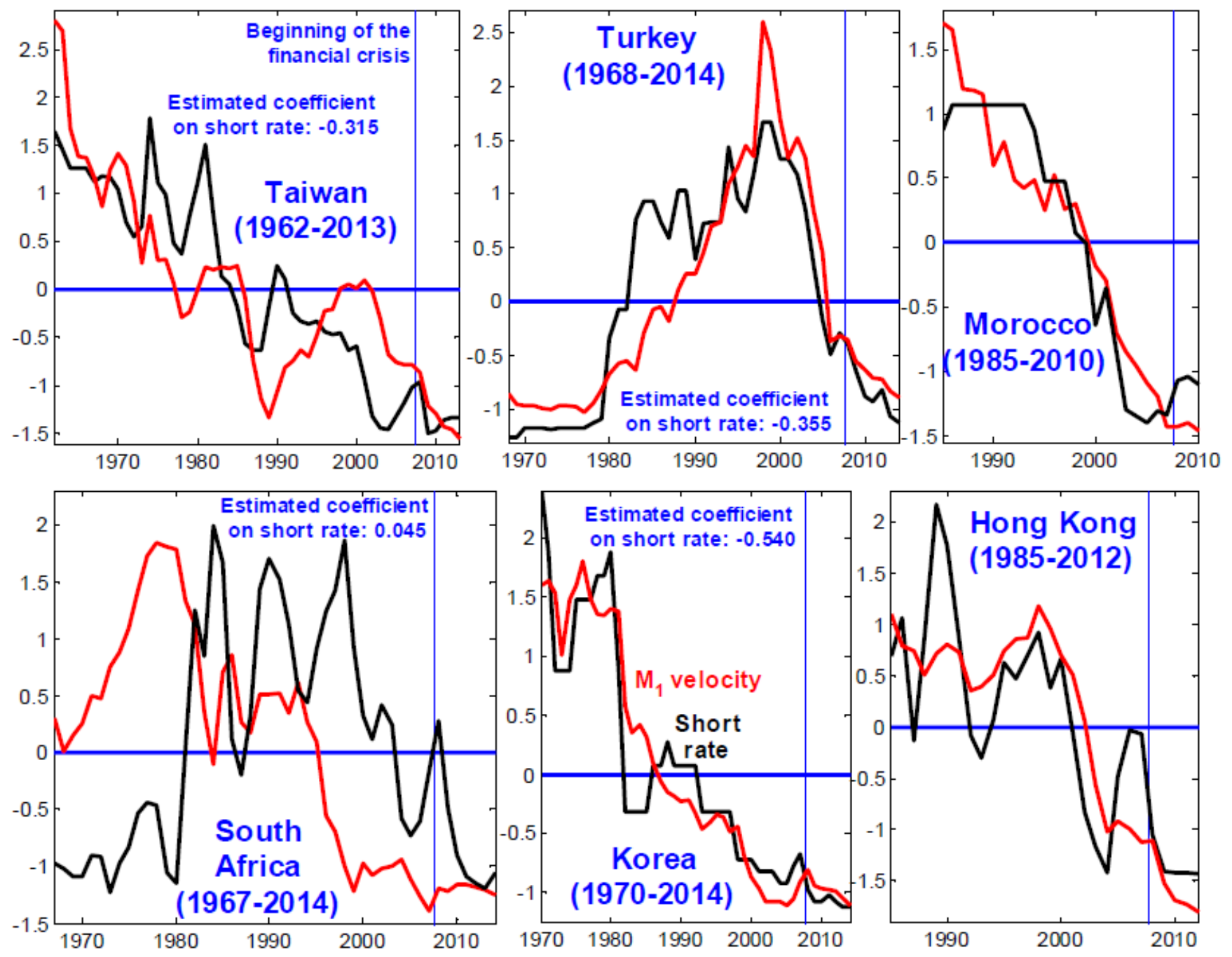

Figure $7 \quad M_{1}$ velocity and the short-term nominal interest rate, de-meaned and standardized $\left(\mathrm{M}_{1}\right.$ velocity computed as the ratio between nominal GDP and nominal $\mathrm{M}_{1}$ ) 


\section{II: Full set of results based on the Selden-Latané specification}


Candidate cointegration residuals, de-meaned and standardized
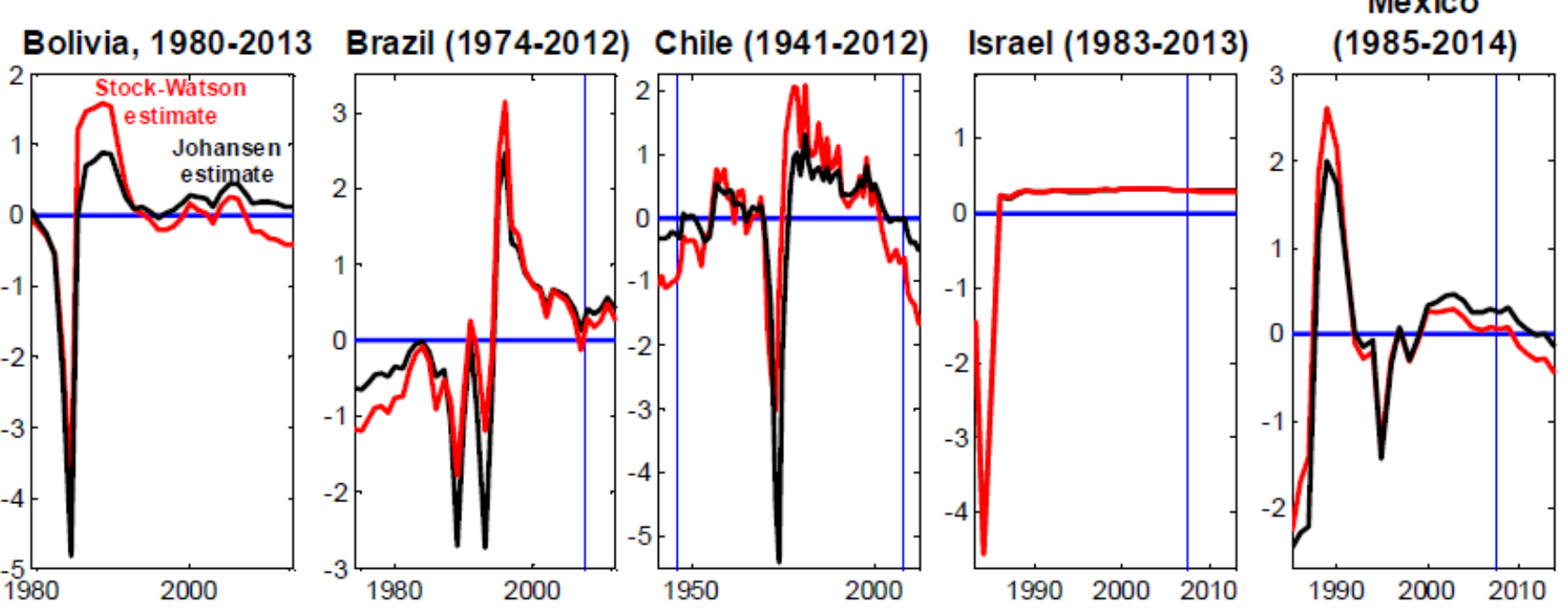

Bootstrapped distributions of the coefficient on the short rate
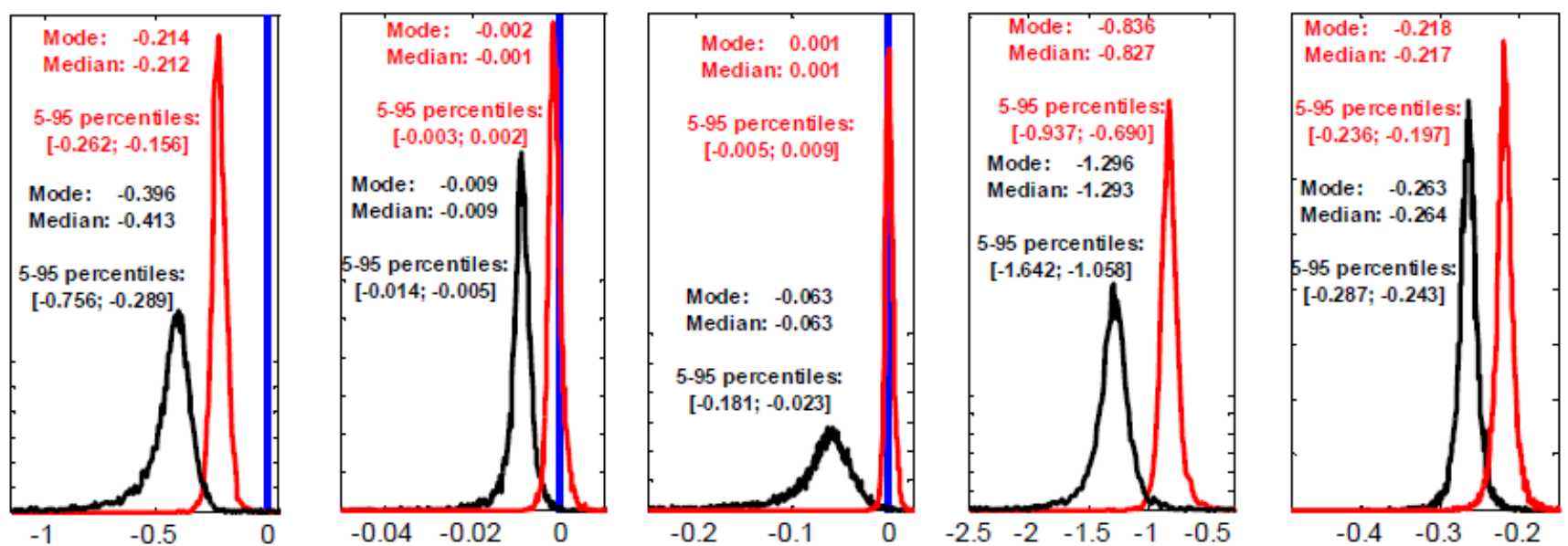

Figure SELA.1 Selden-Latané specification, imposing unitary income elasticity: cointegration residuals and bootstrapped distributions of the coefficients on the short rate 
Candidate cointegration residuals, de-meaned and standardized
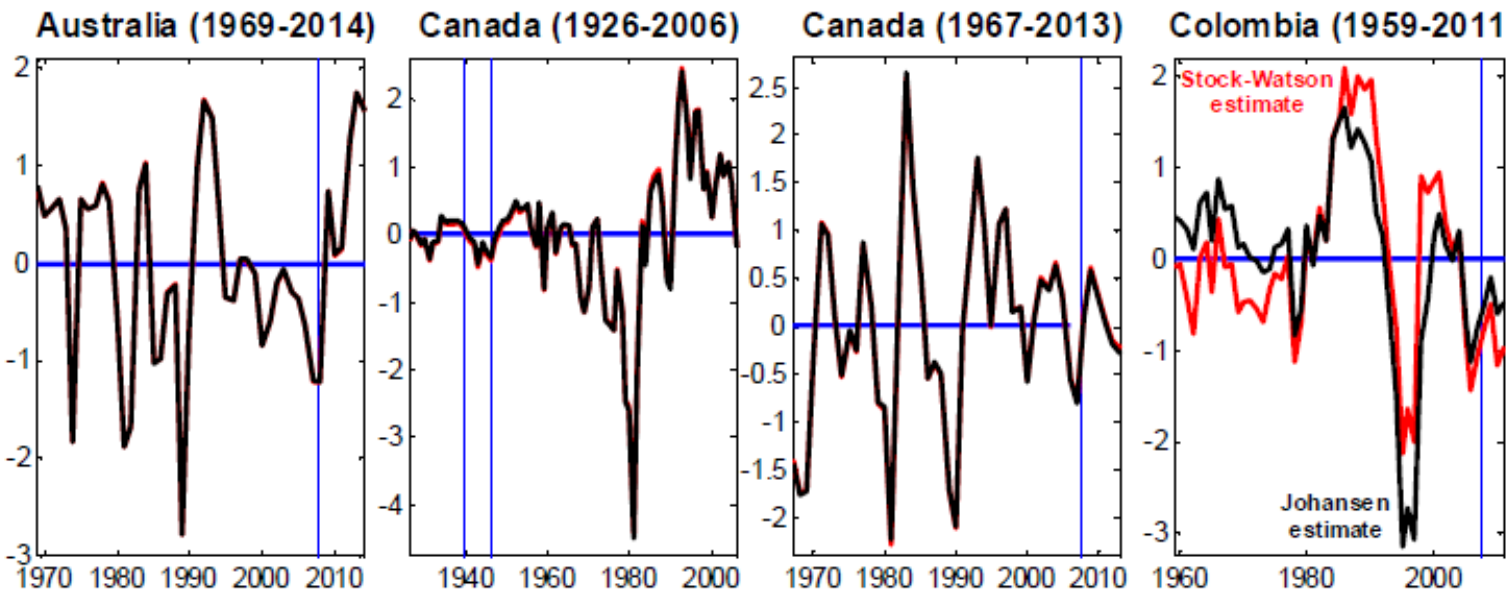

Finland (1914-1985)

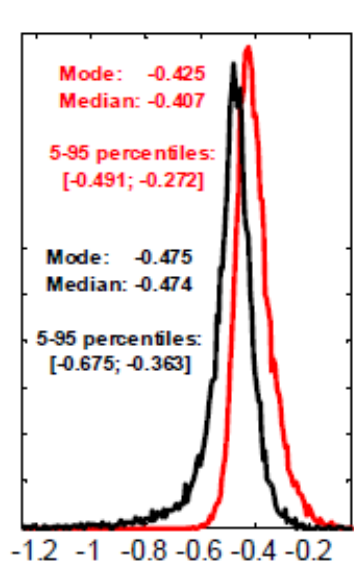

Bootstrapped distributions of the coefficient on the short rate
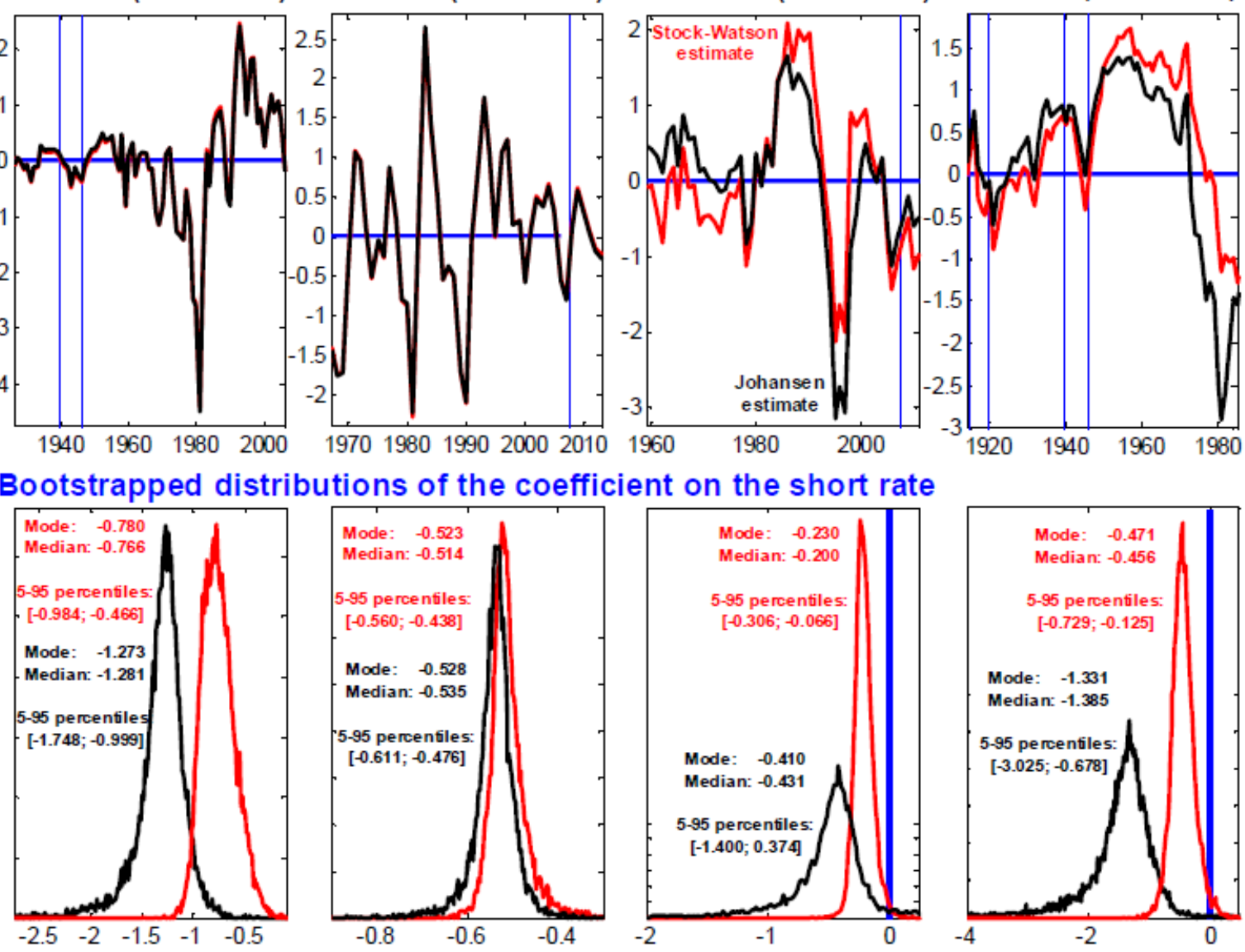

Figure SELA.2 Selden-Latané specification, imposing unitary income elasticity: cointegration residuals and bootstrapped distributions of the coefficients on the short rate 
Candidate cointegration residuals, de-meaned and standardized

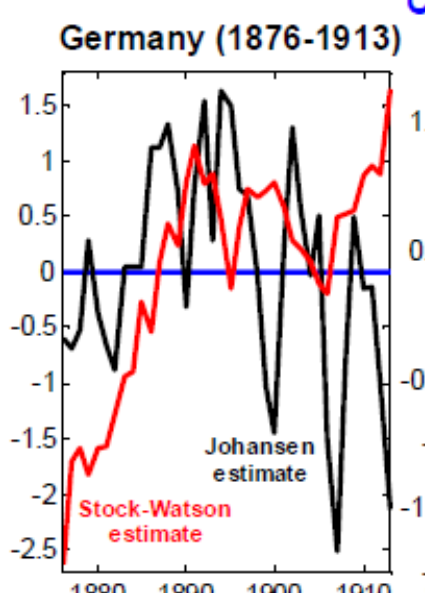

Guatemala (1980-2012) Japan (1885-1913)

Japan (1955-2013)

Korea $(1970-2014)$
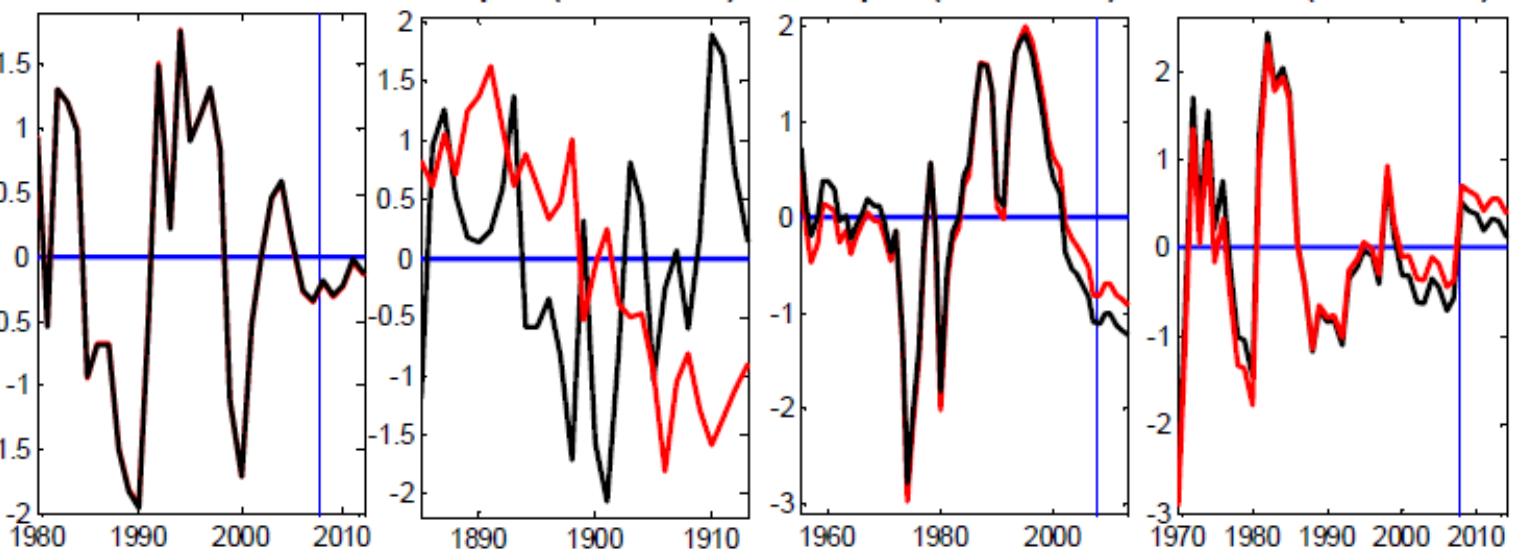

Bootstrapped distributions of the coefficient on the short rate
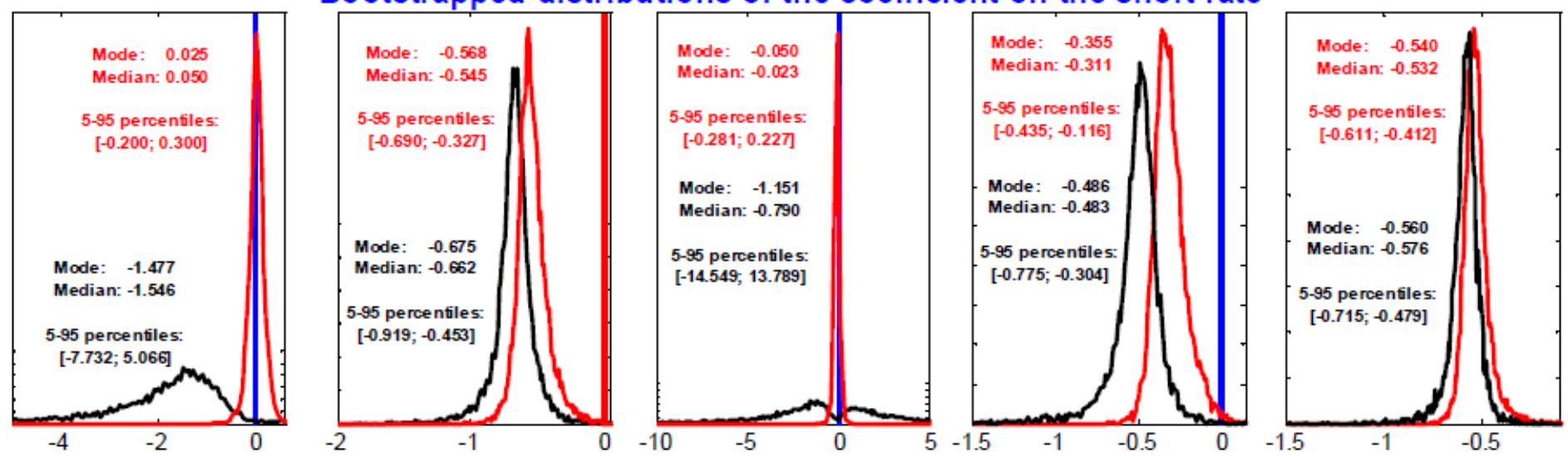

Figure SELA.3 Selden-Latané specification, imposing unitary income elasticity: cointegration residuals and bootstrapped distributions of the coefficients on the short rate 

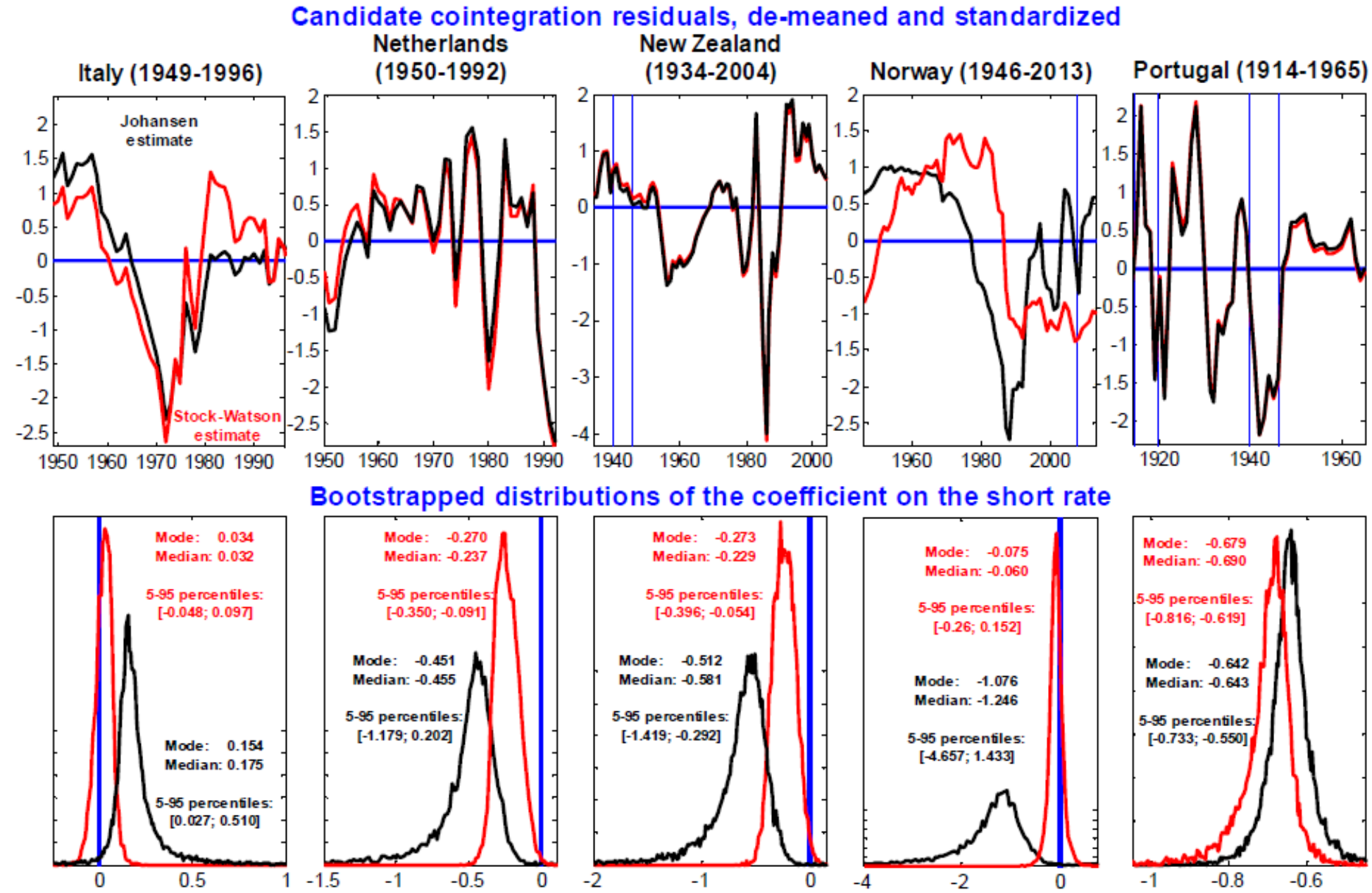

Figure SELA.4 Selden-Latané specification, imposing unitary income elasticity: cointegration residuals and bootstrapped distributions of the coefficients on the short rate 

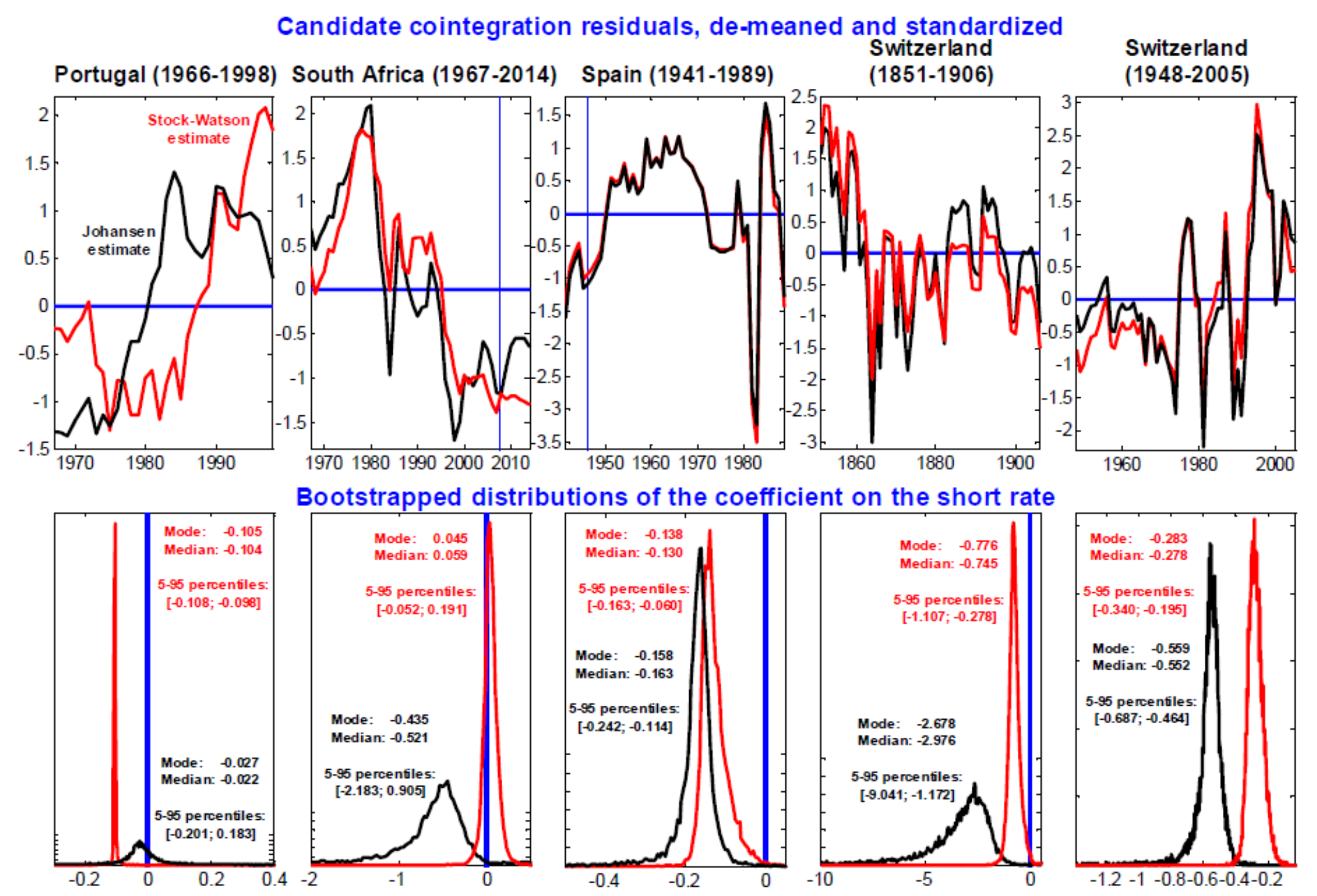

Bootstrapped distributions of the coefficient on the short rate
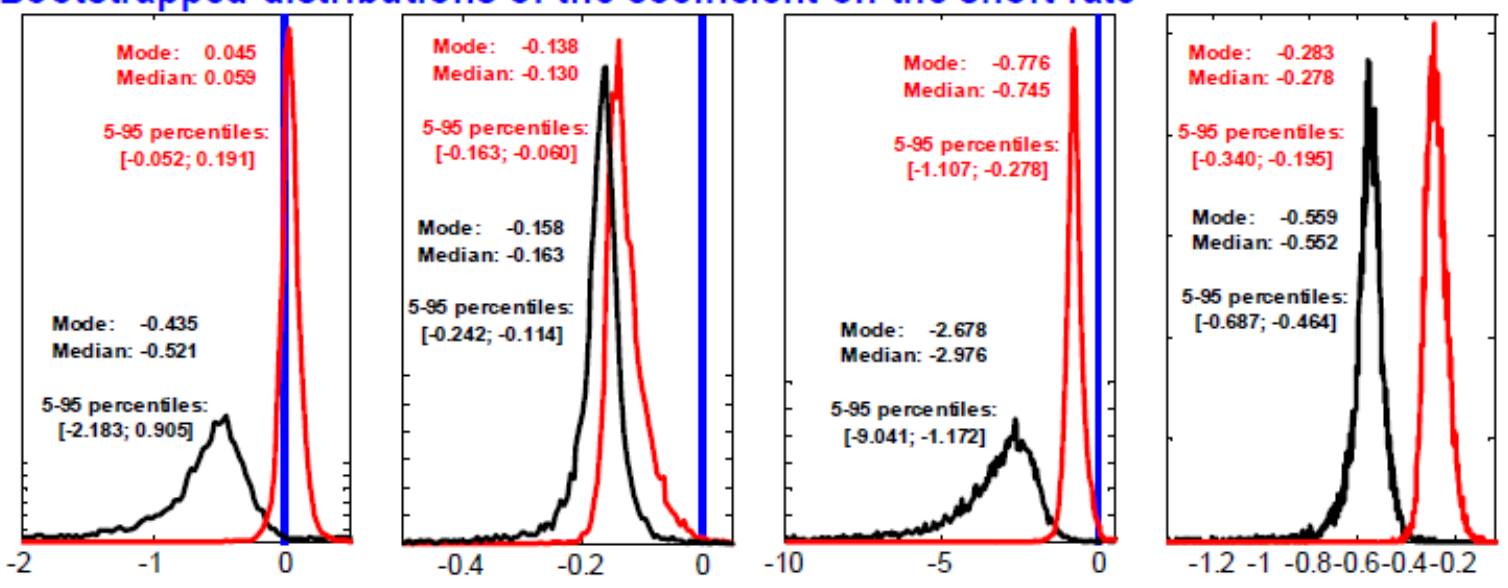

Figure SELA.5 Selden-Latané specification, imposing unitary income elasticity: cointegration residuals and bootstrapped distributions of the coefficients on the short rate 

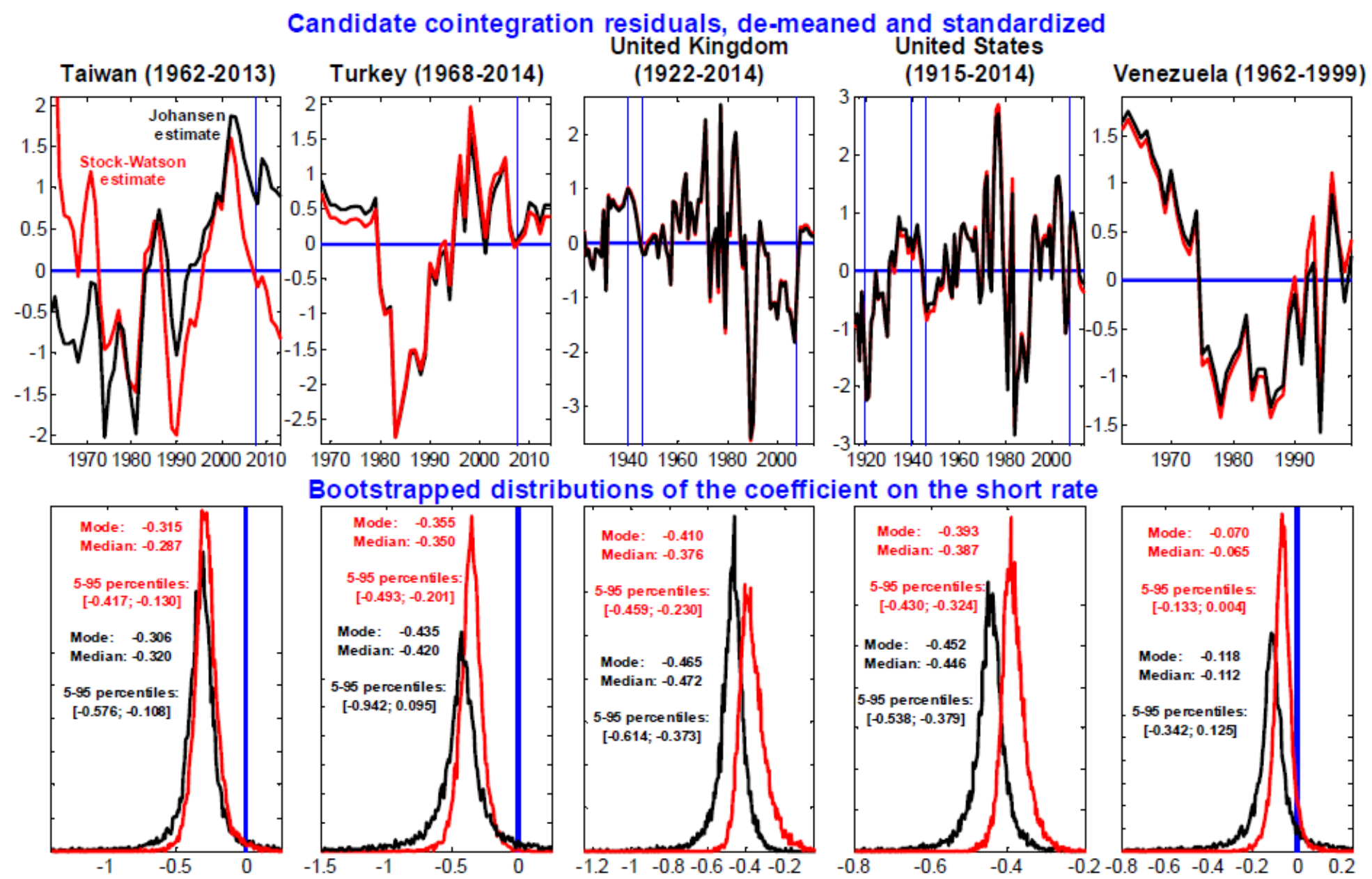

Figure SELA.6 Selden-Latané specification, imposing unitary income elasticity: cointegration residuals and bootstrapped distributions of the coefficients on the short rate 


\section{III: Full set of results based on the semi-log specification}




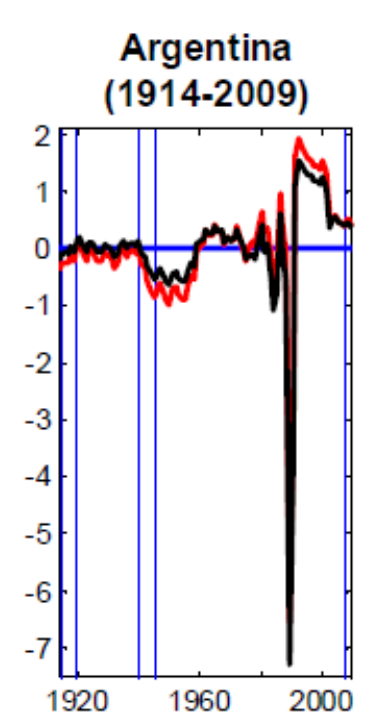

Candidate cointegration residuals, de-meaned and standardized
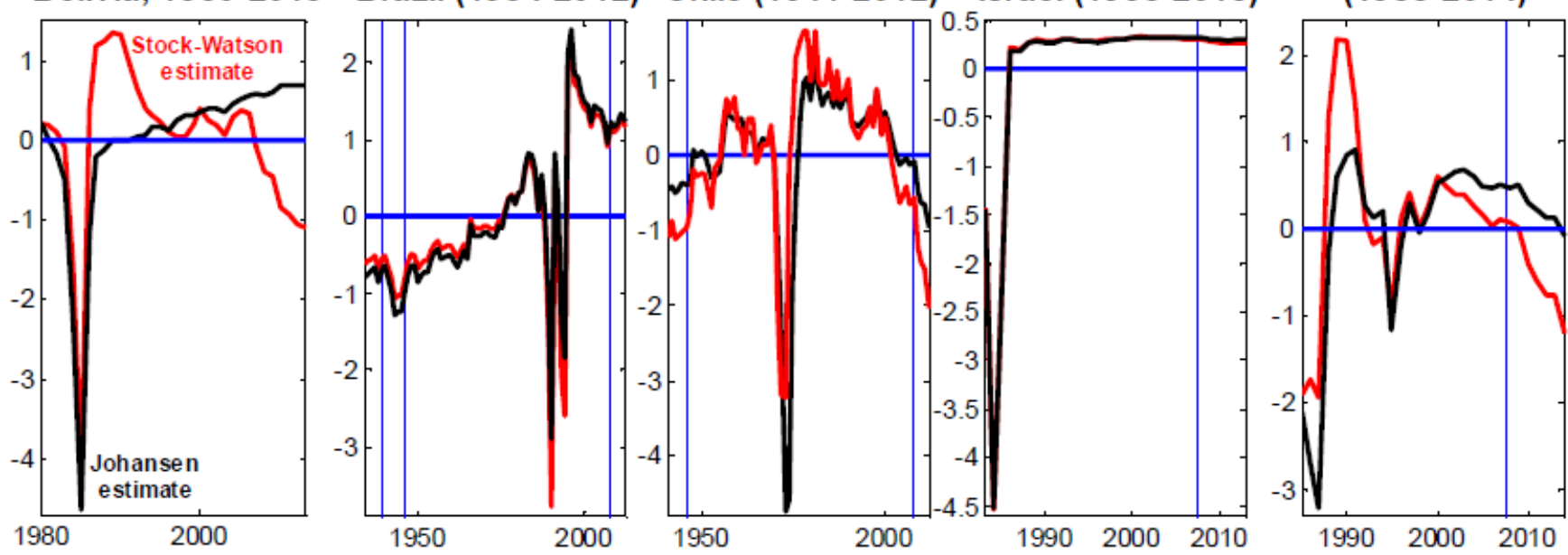

Bootstrapped distributions of the estimated semi-elasticity
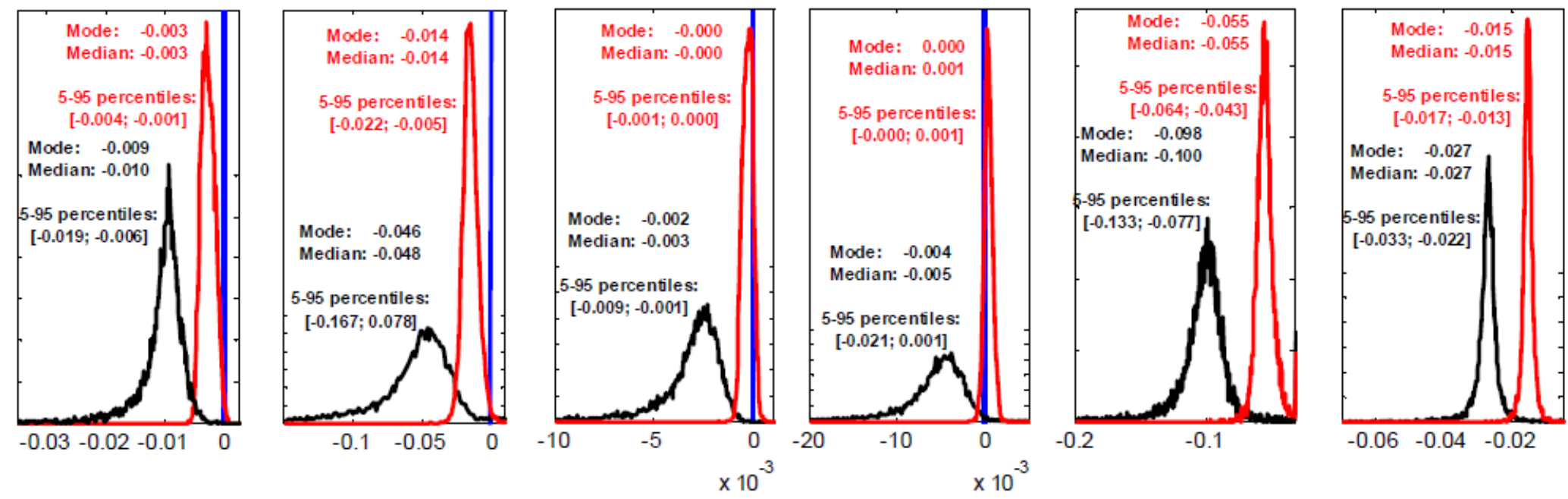

Figure SL.1 Semi-log specification, imposing unitary income elasticity: cointegration residuals and bootstrapped distributions of the coefficients on the log of the short rate 
Candidate cointegration residuals, de-meaned and standardized

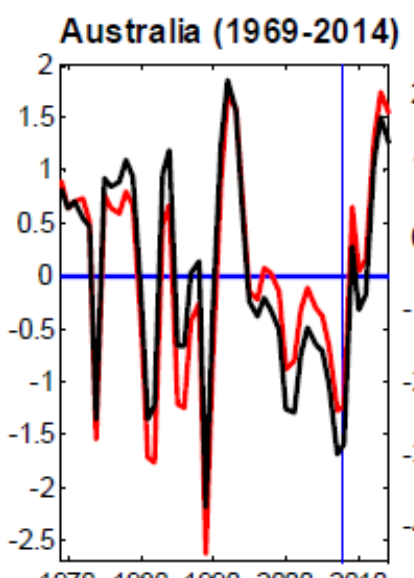

Canada (1926-2006)
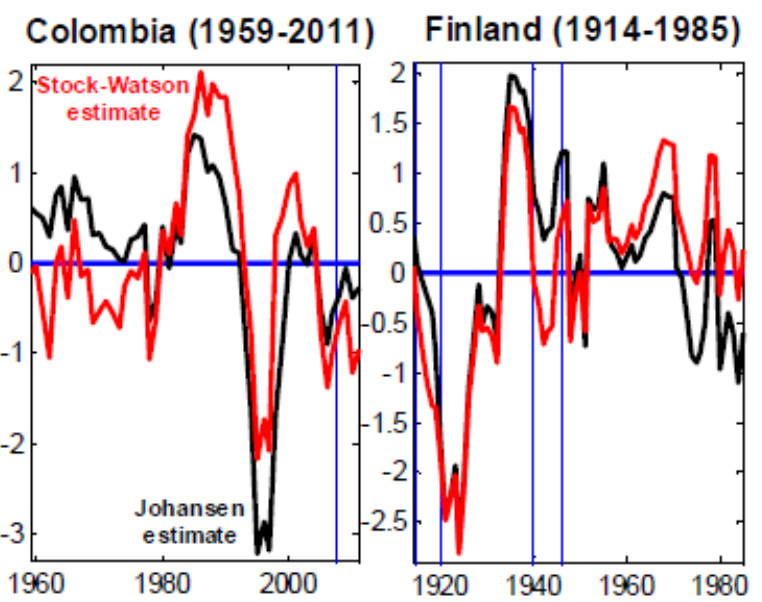

Germany (1876-1913)
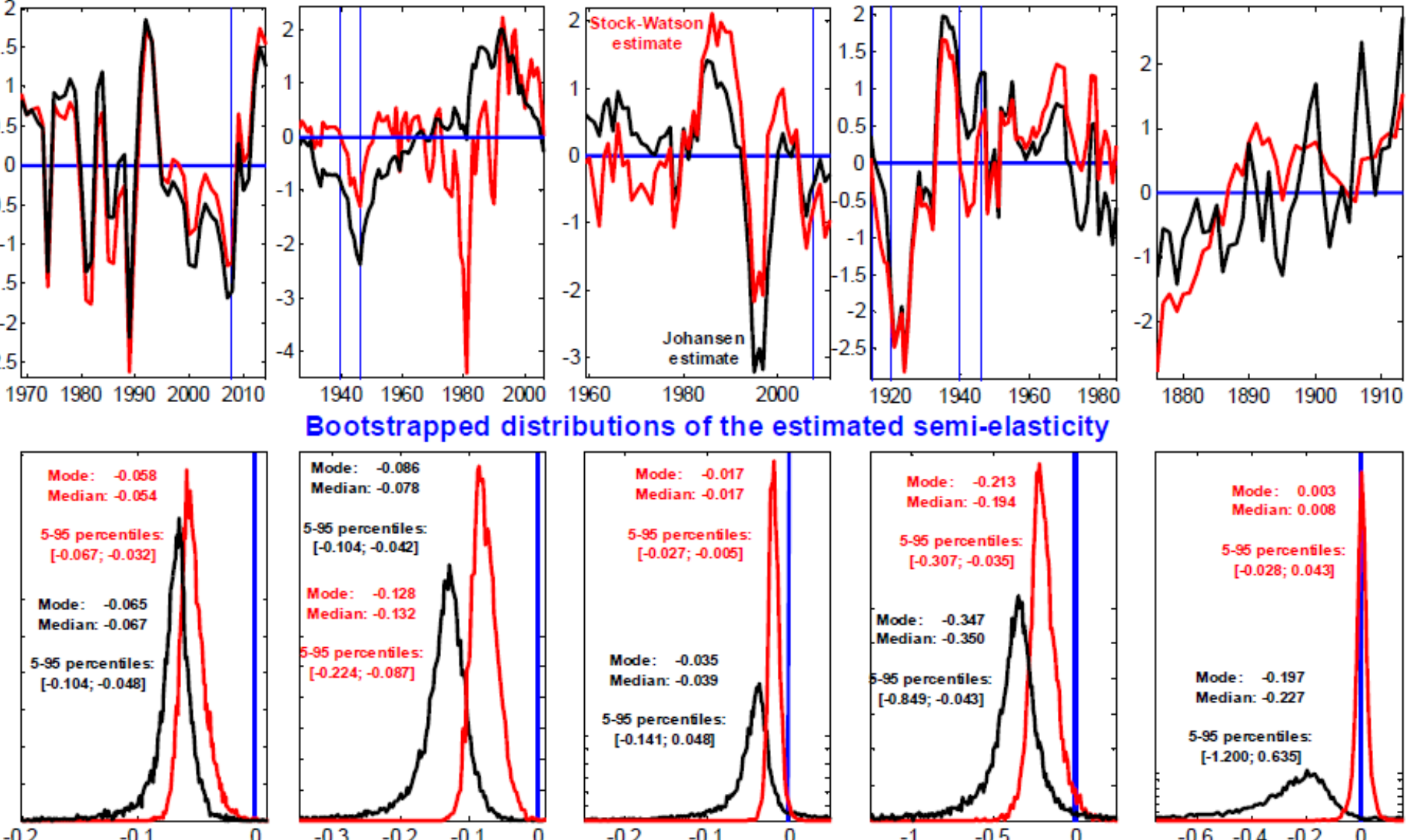

Figure SL.2 Semi-log specification, imposing unitary income elasticity: cointegration residuals and bootstrapped distributions of the coefficients on the log of the short rate 
Candidate cointegration residuals, de-meaned and standardized

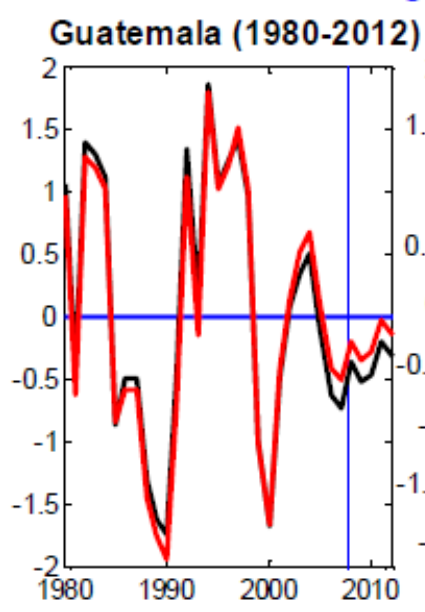

Japan (1885-1913)

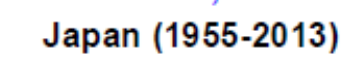

Korea (1970-2014)

Italy (1949-1996)
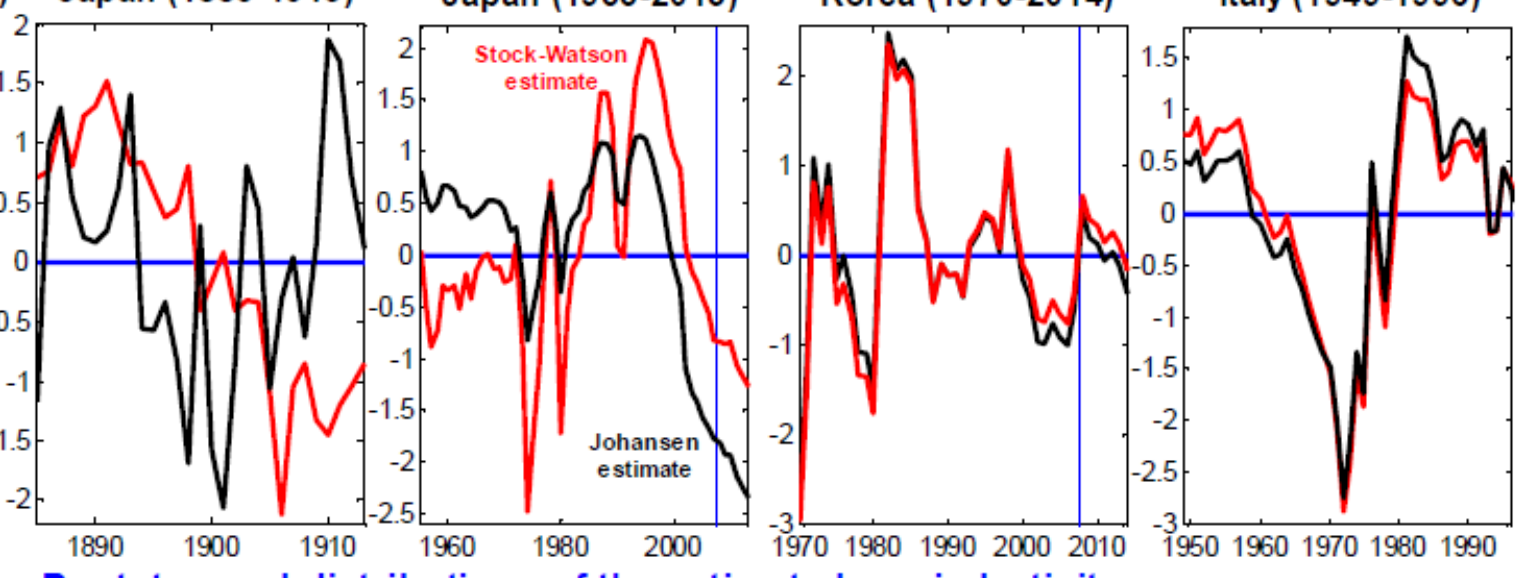

Bootstrapped distributions of the estimated semi-elasticity
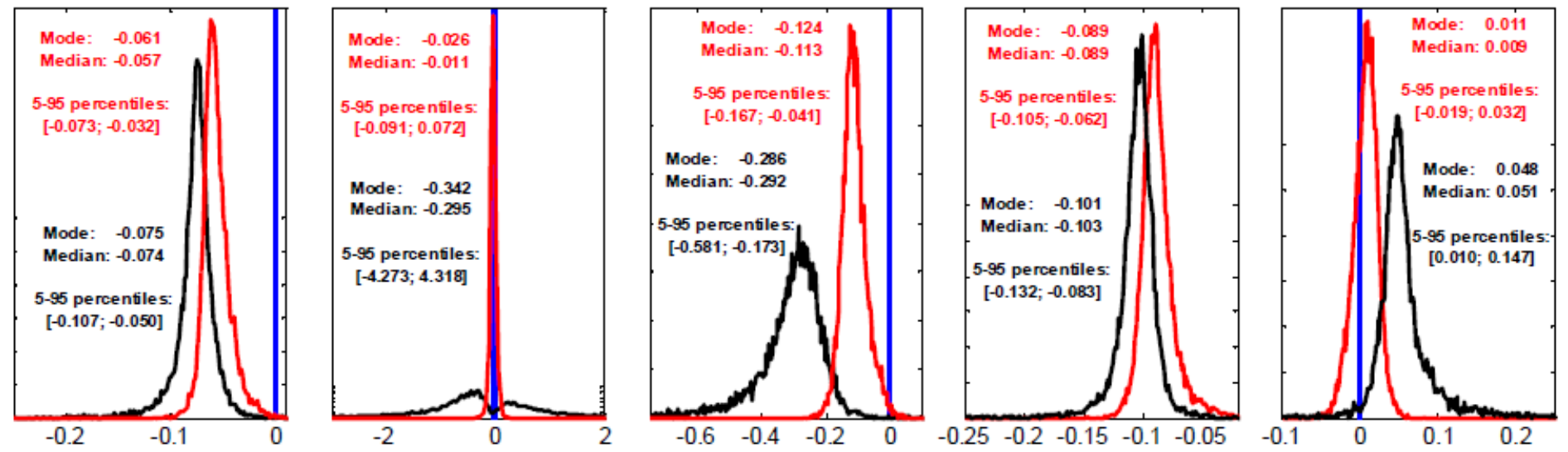

Figure SL.3 Semi-log specification, imposing unitary income elasticity: cointegration residuals and bootstrapped distributions of the coefficients on the log of the short rate 
Candidate cointegration residuals, de-meaned and standardized

Netherlands (1950-1992New Zealand (1934-2004) Norway (1946-2013) Portugal (1914-1965)
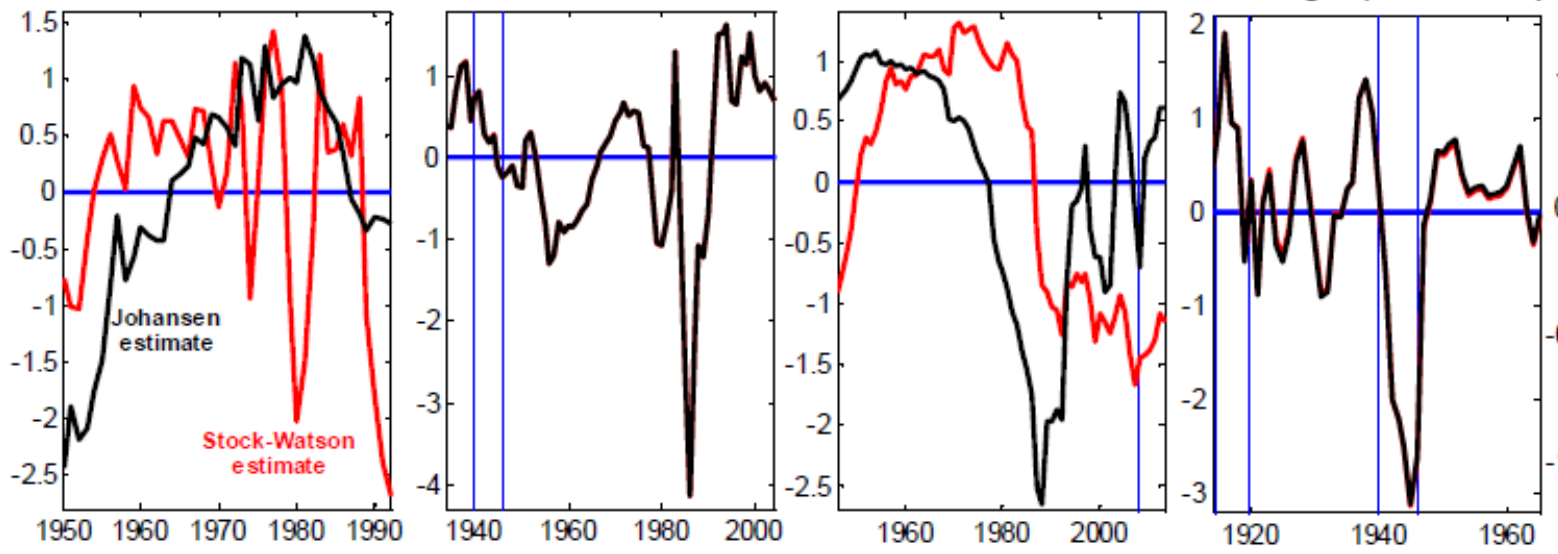

Bootstrapped distributions of the estimated semi-elasticity
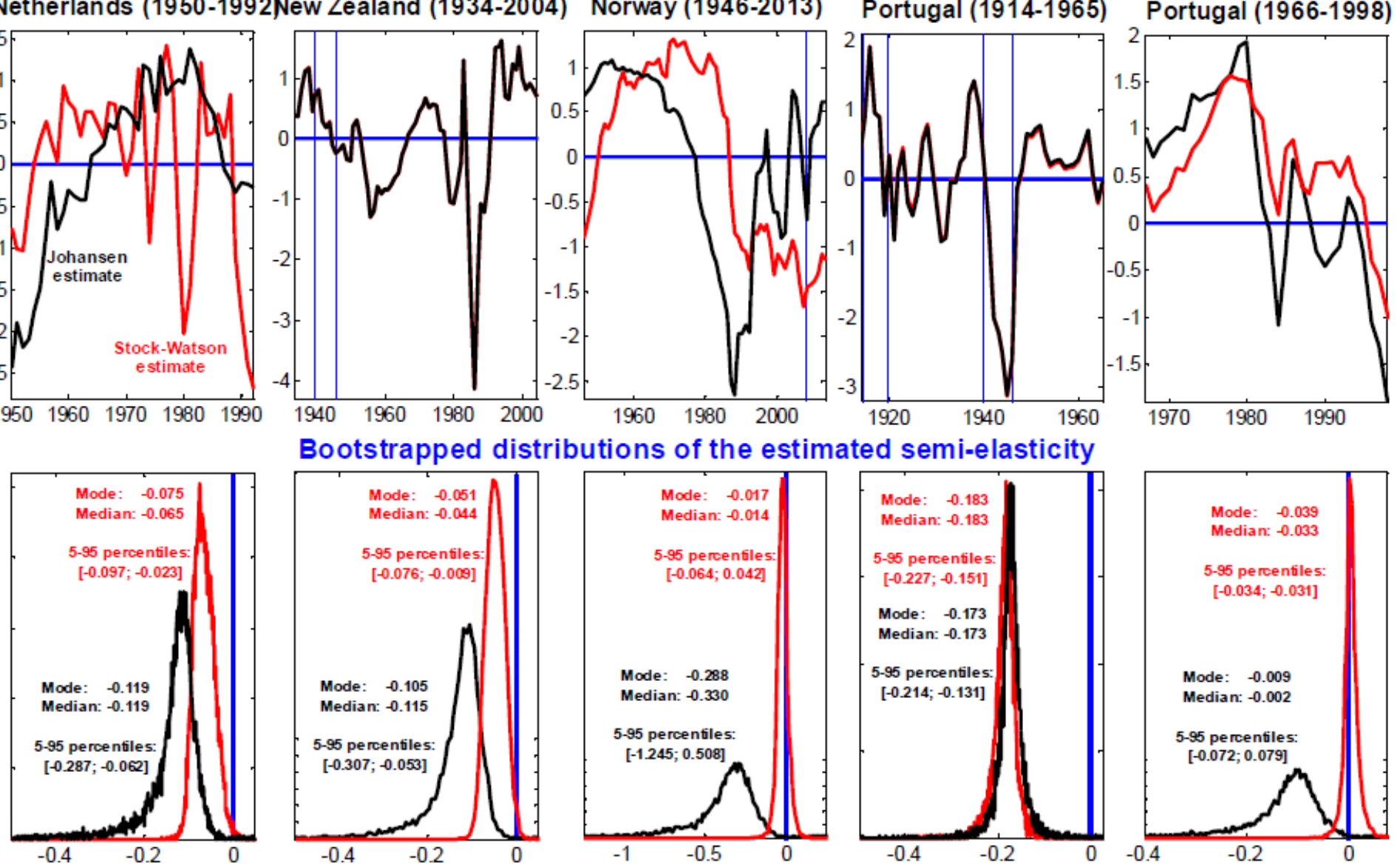

Figure SL.4 Semi-log specification, imposing unitary income elasticity: cointegration residuals and bootstrapped distributions of the coefficients on the log of the short rate 
Candidate cointegration residuals, de-meaned and standardized
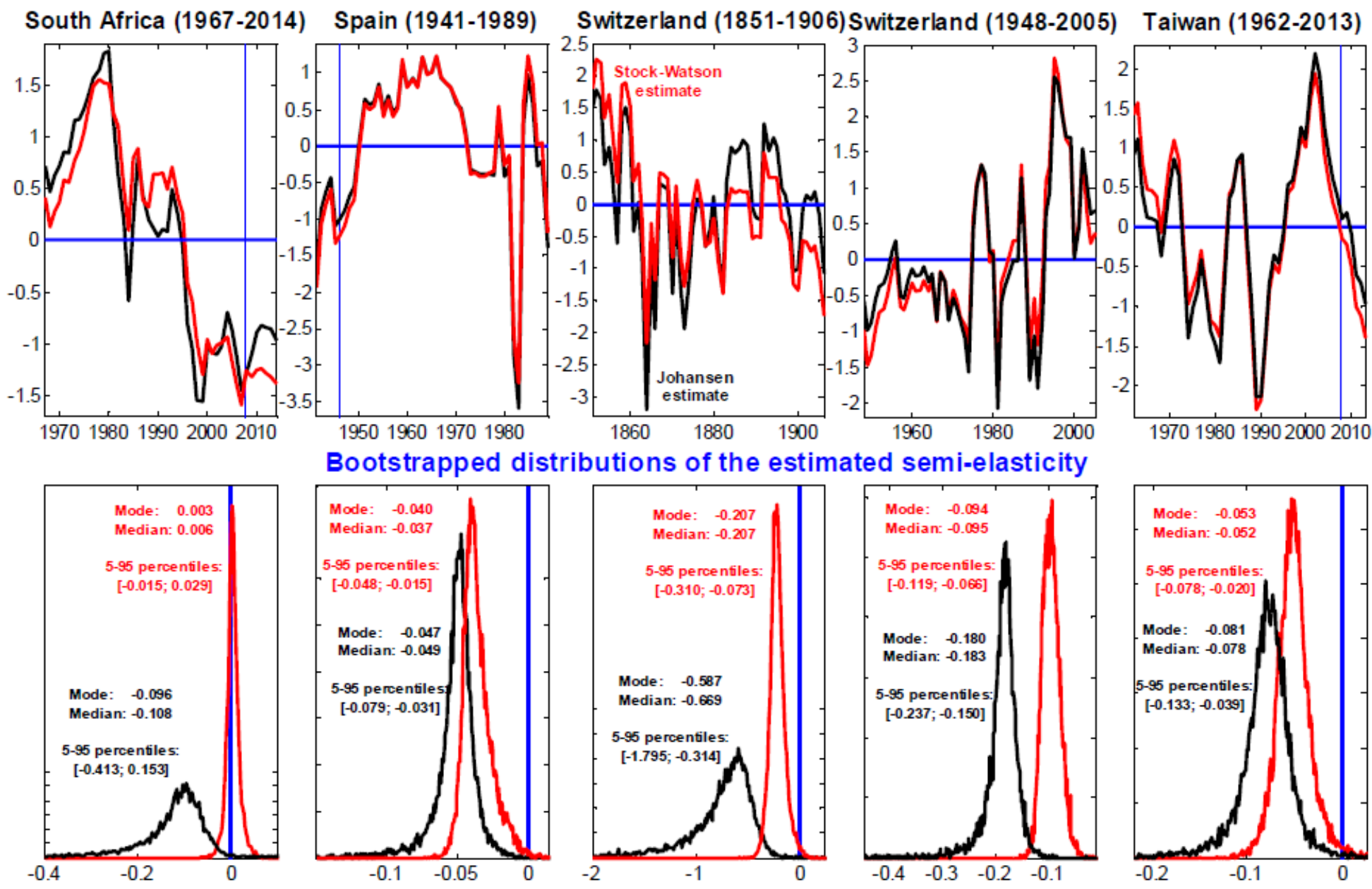

Figure SL.5 Semi-log specification, imposing unitary income elasticity: cointegration residuals and bootstrapped distributions of the coefficients on the log of the short rate 


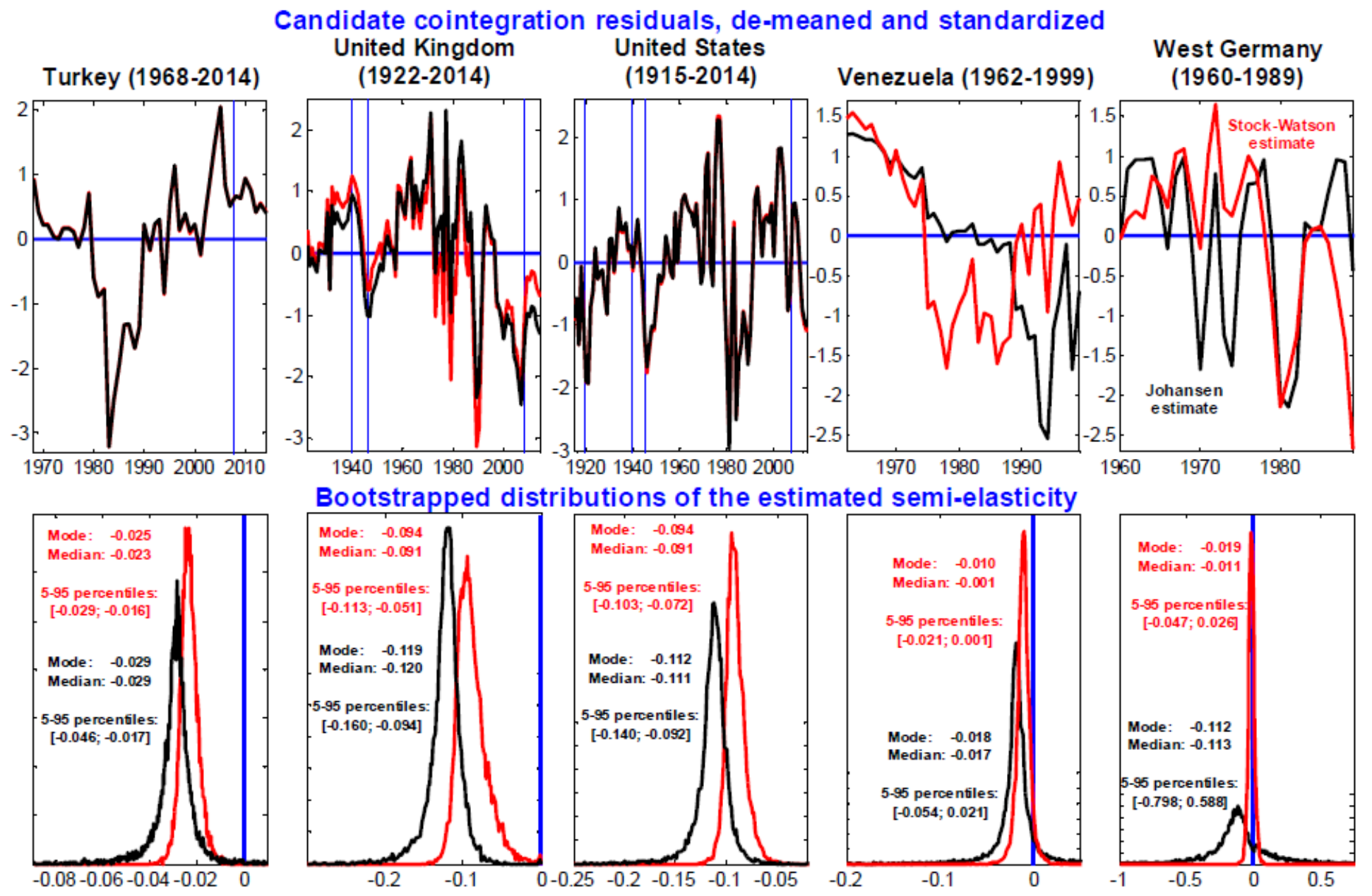

Figure SL.6 Semi-log specification, imposing unitary income elasticity: cointegration residuals and bootstrapped distributions of the coefficients on the log of the short rate 


\section{IV: Full set of results based on the log-log specification}




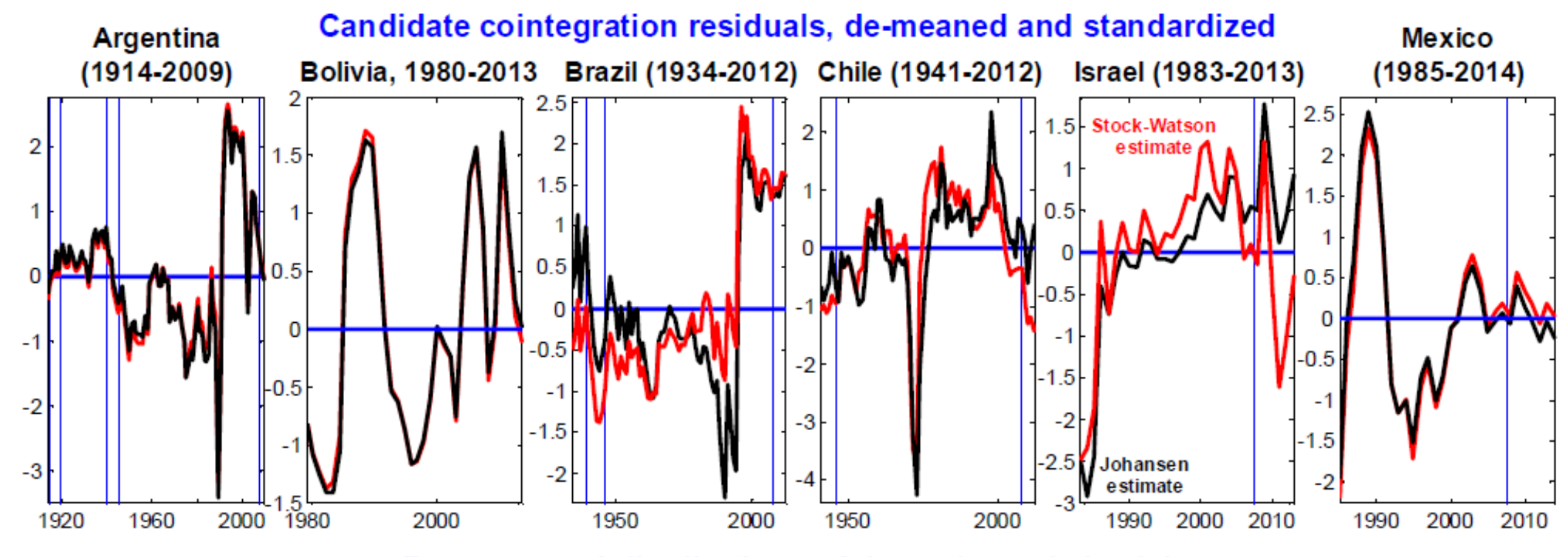

Bootstrapped distributions of the estimated elasticity
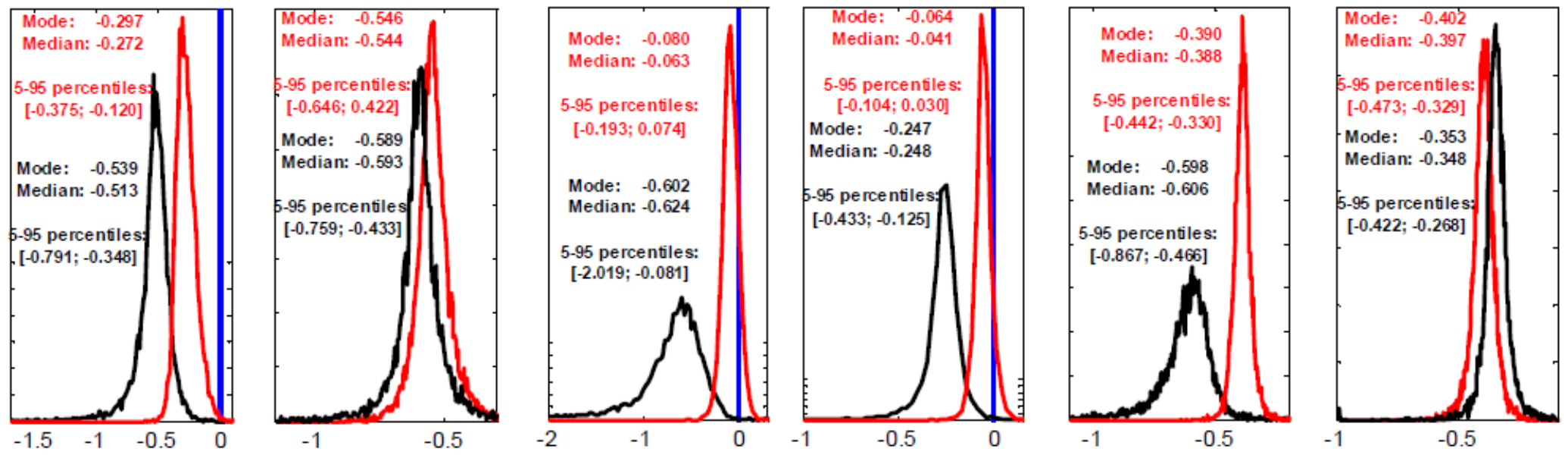

Figure LL.1 Log-log specification, imposing unitary income elasticity: cointegration residuals and bootstrapped distributions of the coefficients on the log of the short rate 
Candidate cointegration residuals, de-meaned and standardized

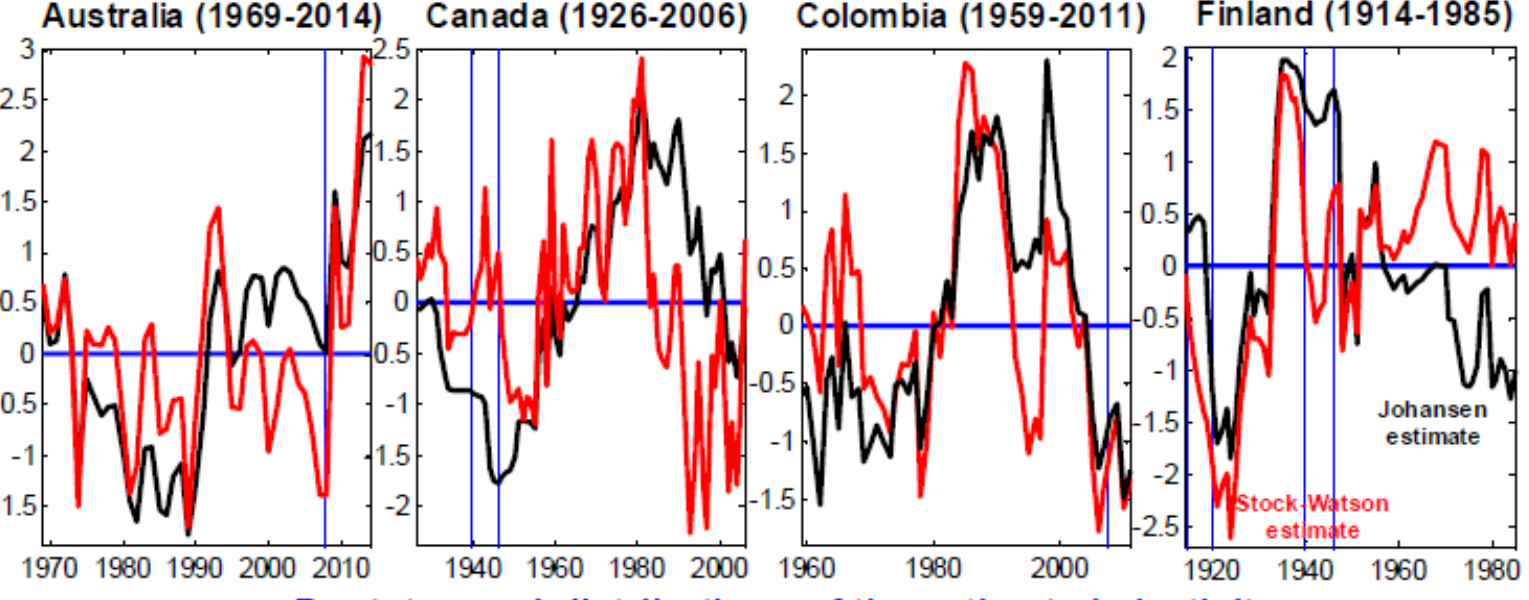

\section{Bootstrapped distributions of the estimated elasticity}
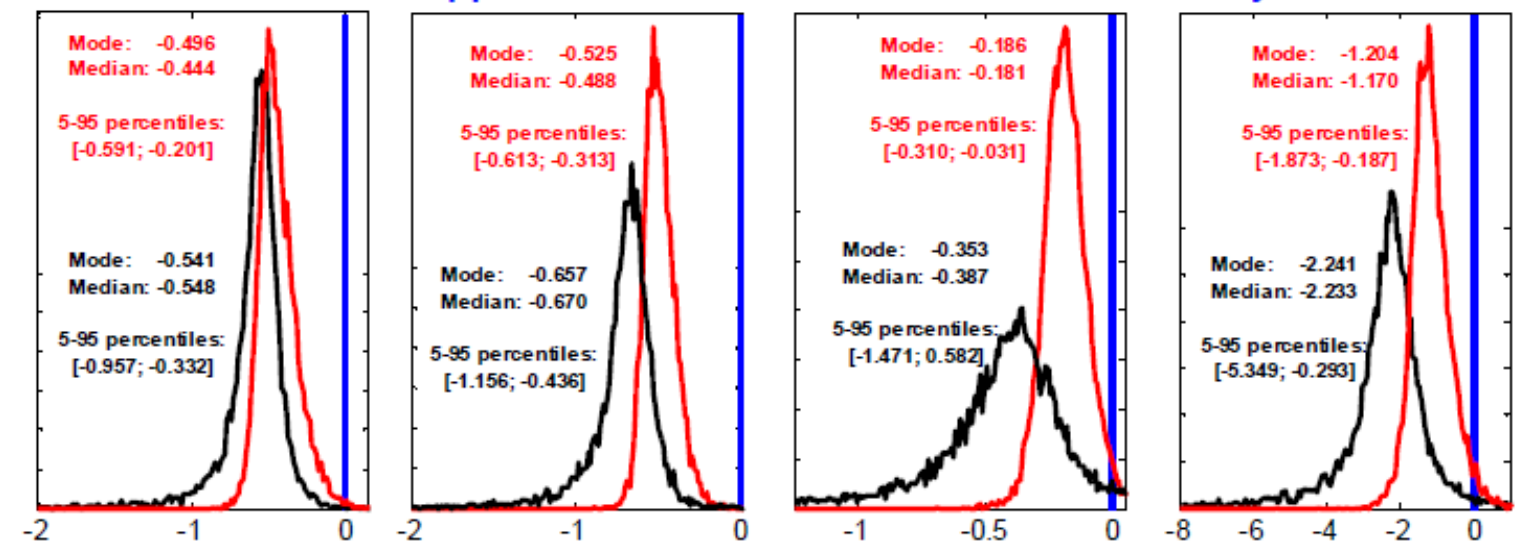

Figure LL.2 Log-log specification, imposing unitary income elasticity: cointegration residuals and bootstrapped distributions of the coefficients on the log of the short rate 
Candidate cointegration residuals, de-meaned and standardized
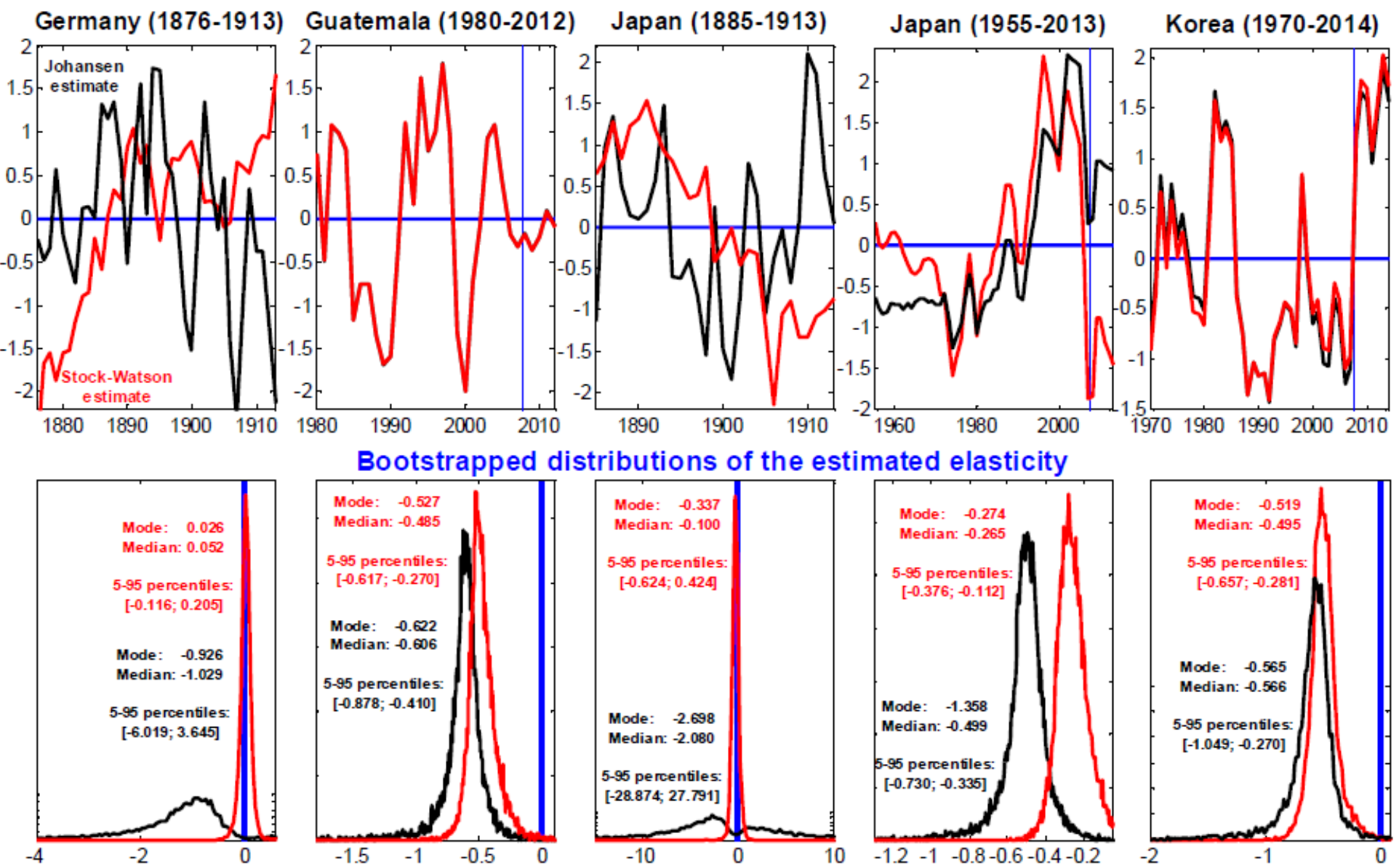

Figure LL.3 Log-log specification, imposing unitary income elasticity: cointegration residuals and bootstrapped distributions of the coefficients on the log of the short rate 

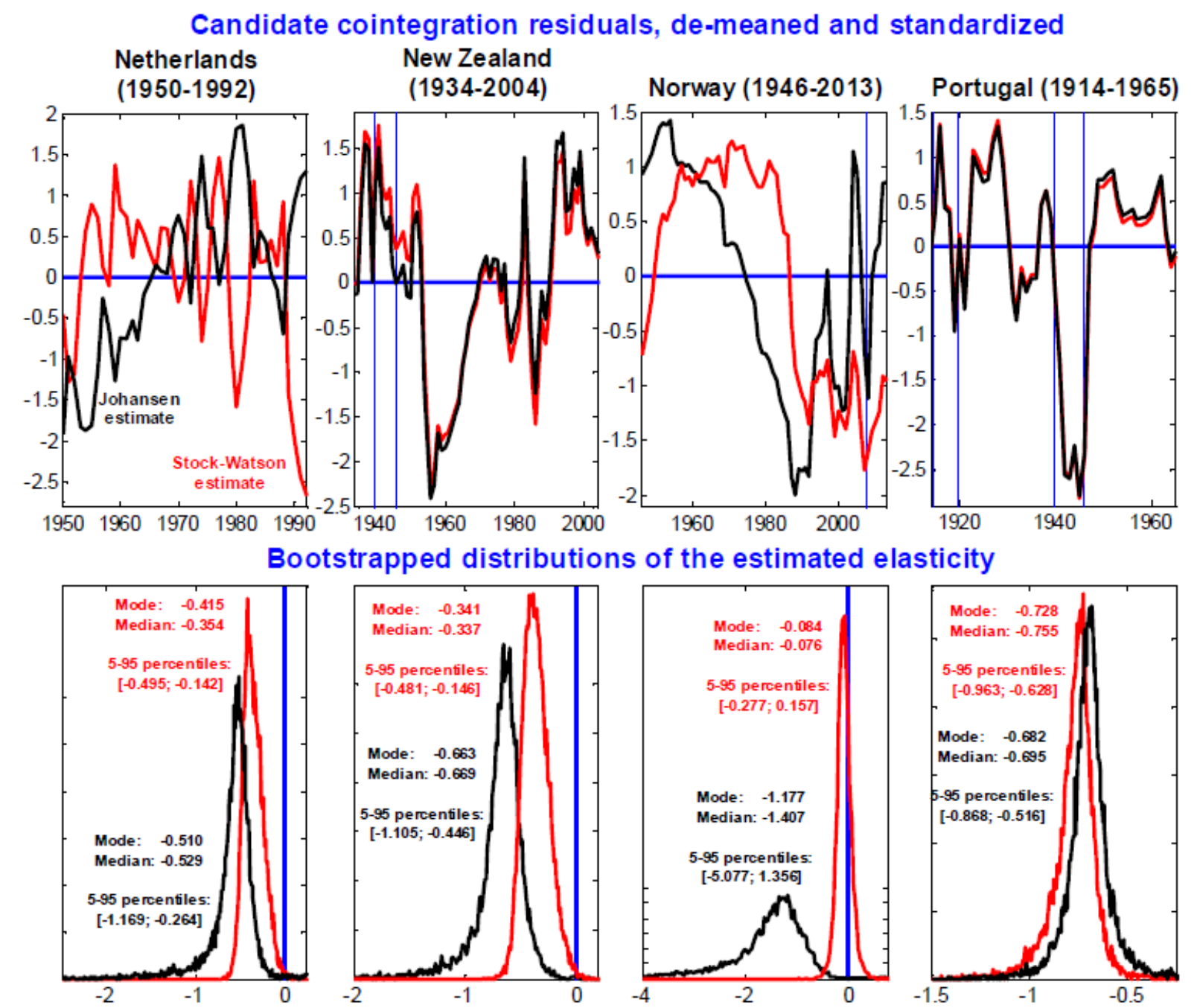

Figure LL.4 Log-log specification, imposing unitary income elasticity: cointegration residuals and bootstrapped distributions of the coefficients on the log of the short rate 
Candidate cointegration residuals, de-meaned and standardized
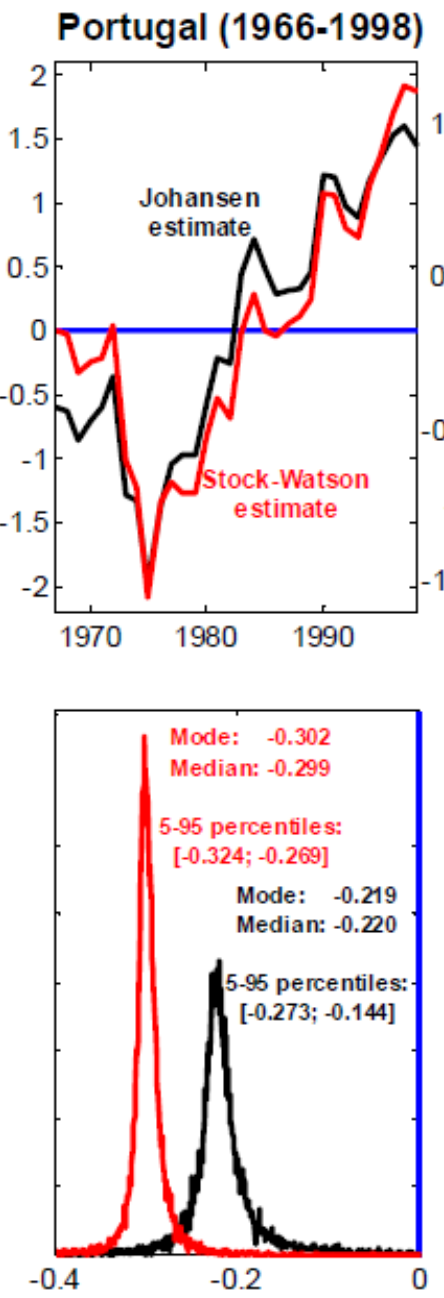

South Africa (1967-2014)

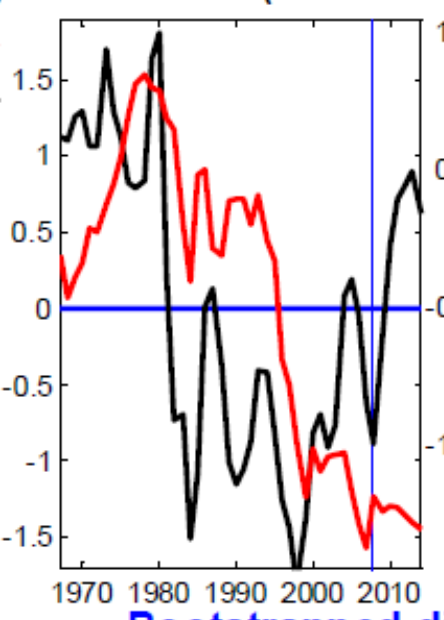

Bootstrapped distributions of the estimated elasticity

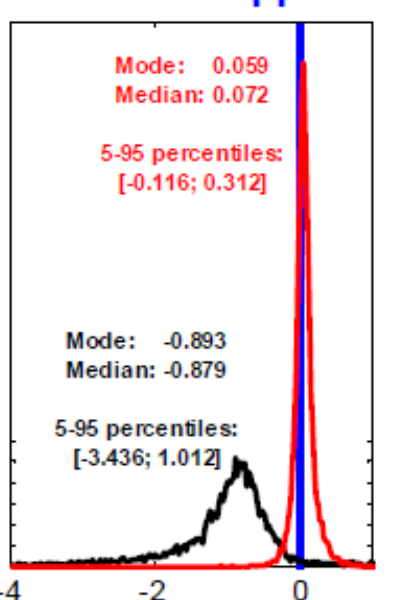

Switzerland (1851-1906)

Switzerland (1948-2005)
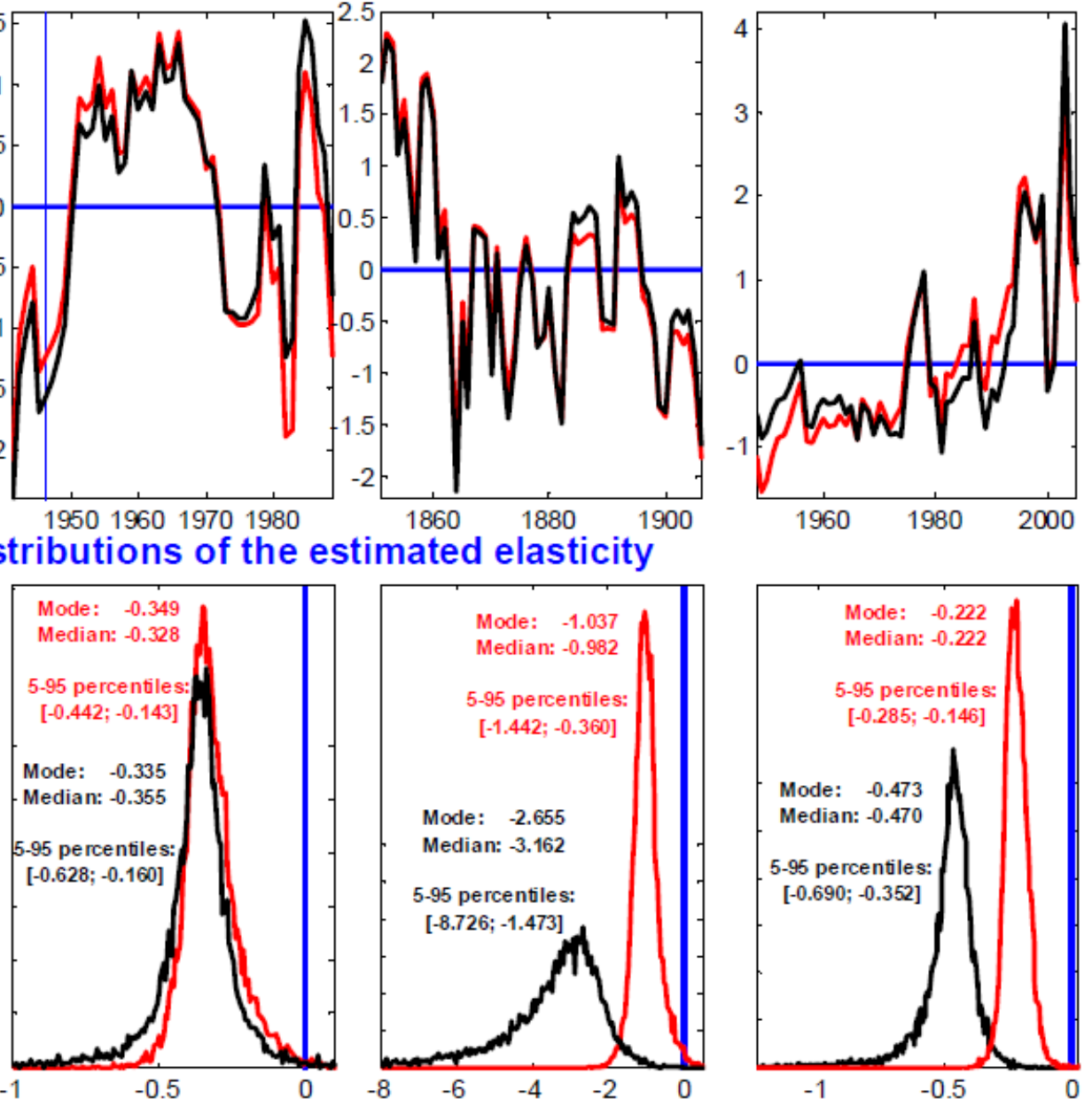

Figure LL.5 Log-log specification, imposing unitary income elasticity: cointegration residuals and bootstrapped distributions of the coefficients on the log of the short rate 
Candidate cointegration residuals, de-meaned and standardized

United Kingdom United States Venezuela (1922-2014) (1915-2014)

Venezuela
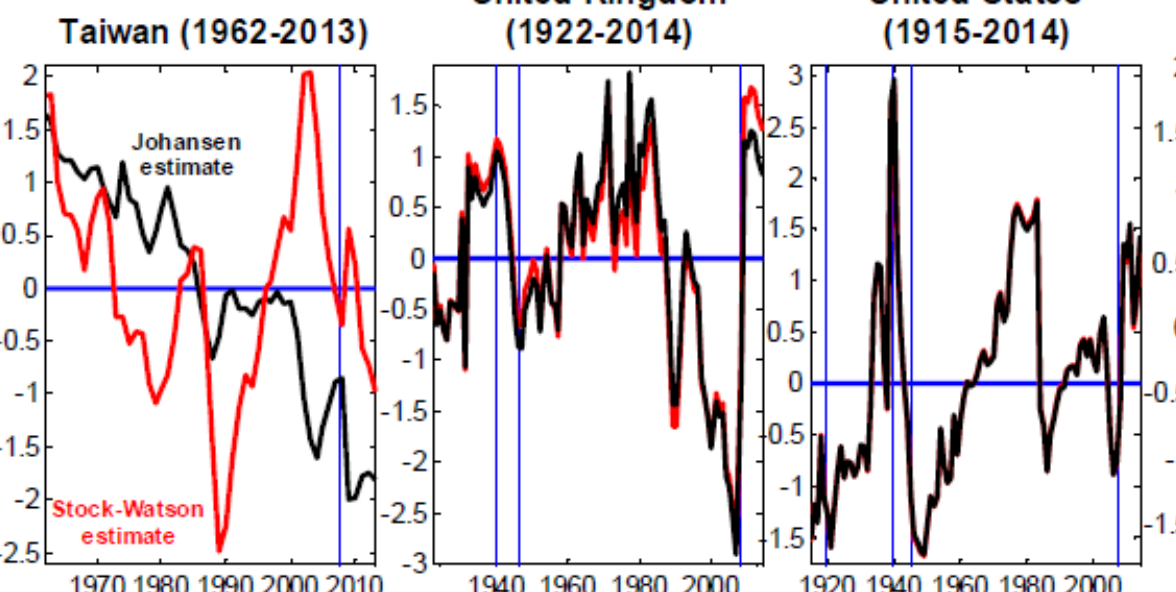

(1962-1999)

West Germany (1960-1989)

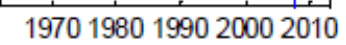

Bootstrapped distributions of the estimated elasticity

19201940196019802000
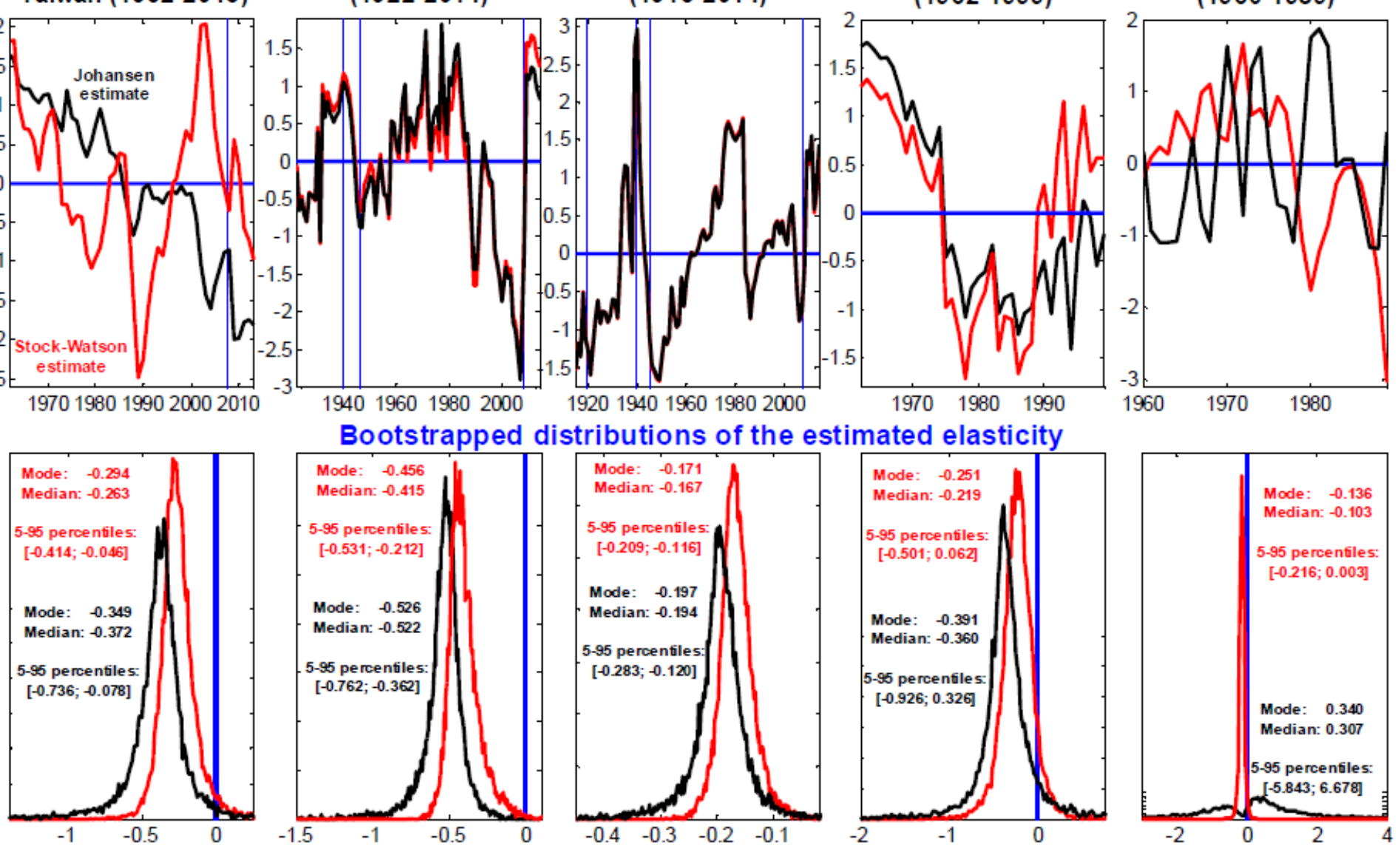

Figure LL.6 Log-log specification, imposing unitary income elasticity: cointegration residuals and bootstrapped distributions of the coefficients on the log of the short rate 
V: Full set of results based on the log-log specification with the correction $\ln (1+R)$ 

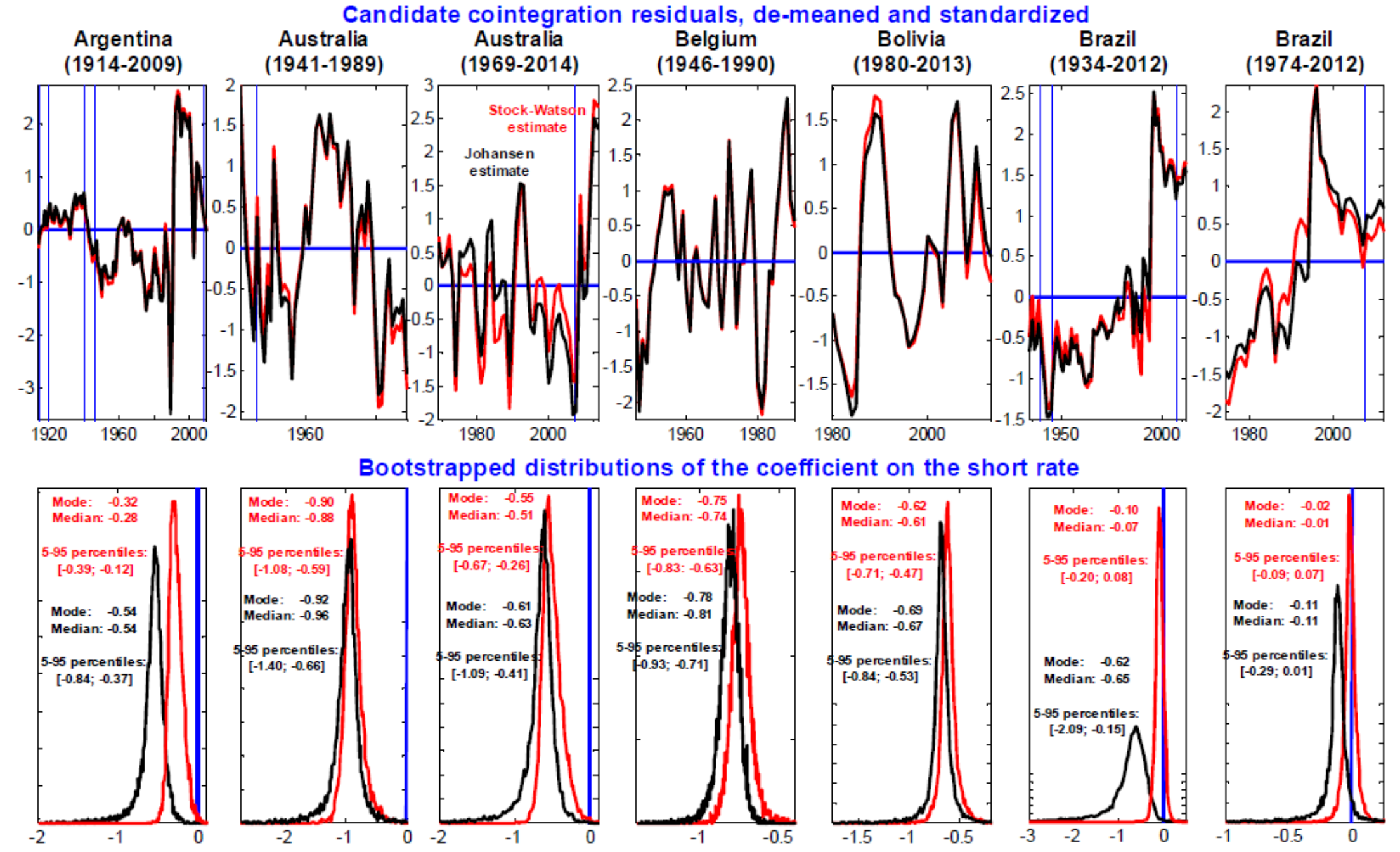

Figure LLCO.1 Log-log specification with the $1 \%$ correction to the short rate, imposing unitary income elasticity: cointegration residuals and bootstrapped distributions of the coefficients on the log of the short rate 


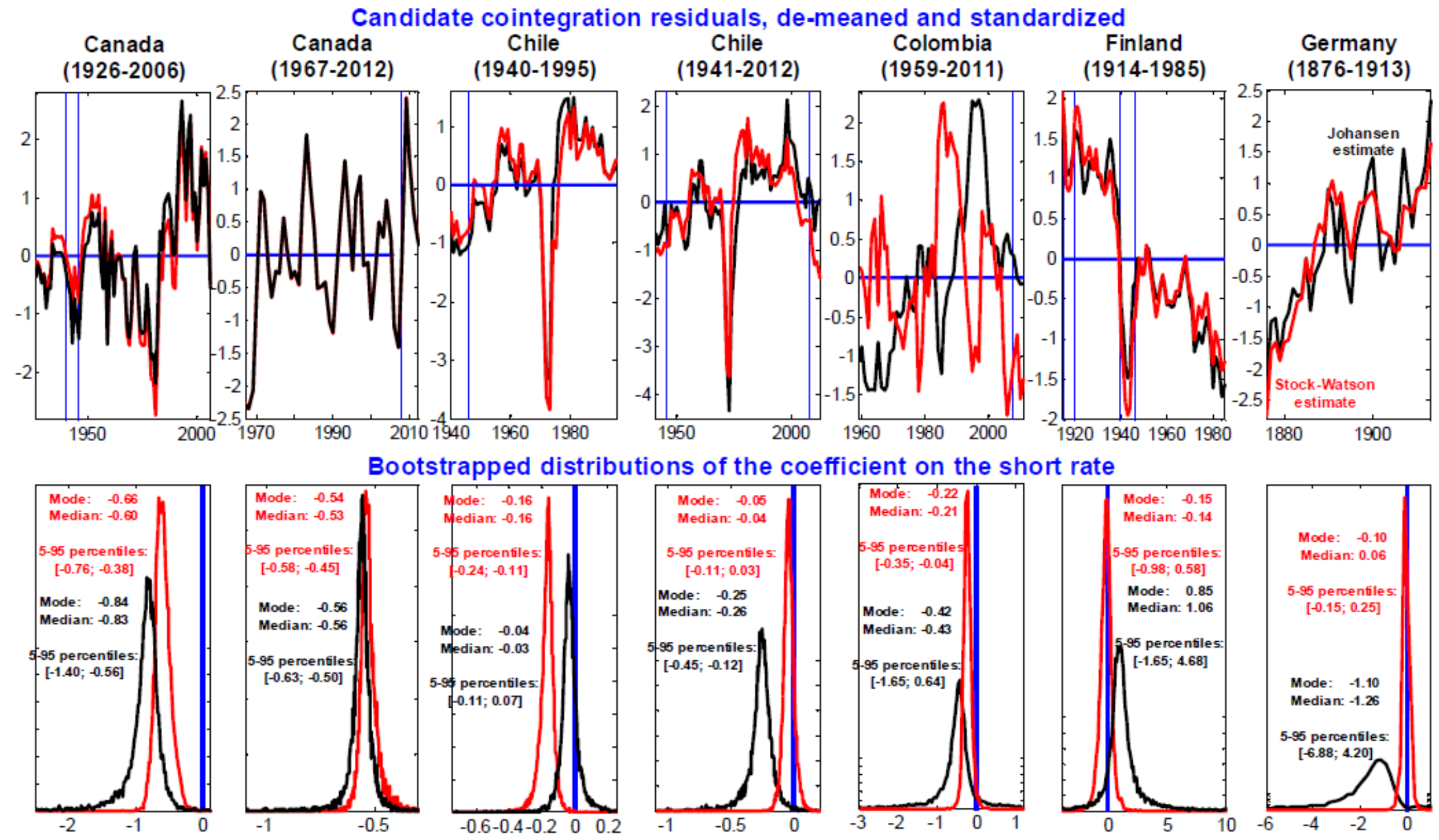

Figure LLCO.2 Log-log specification with the $1 \%$ correction to the short rate, imposing unitary income elasticity: cointegration residuals and bootstrapped distributions of the coefficients on the log of the short rate 

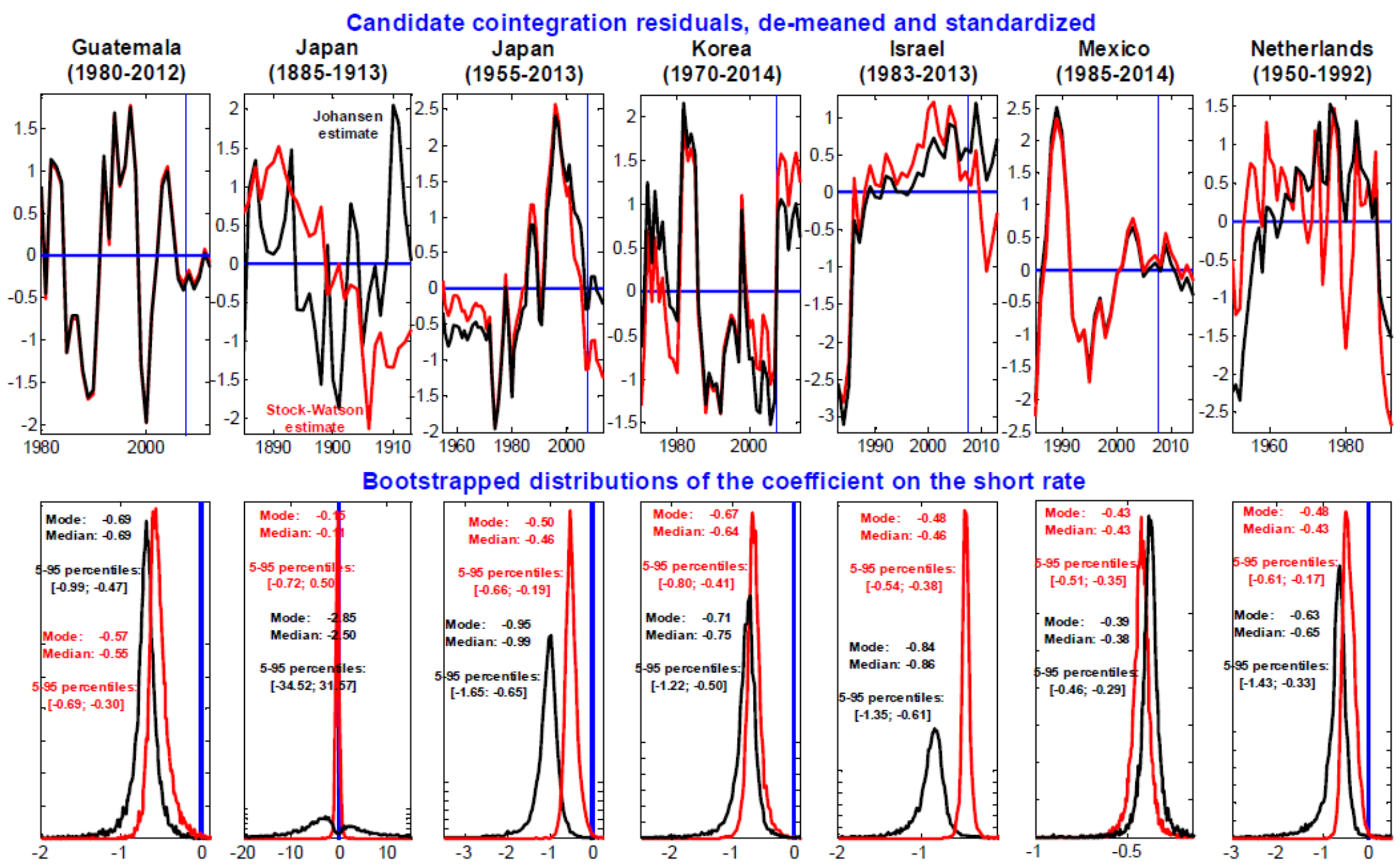

Figure LLCO.3 Log-log specification with the $1 \%$ correction to the short rate, imposing unitary income elasticity: cointegration residuals and bootstrapped distributions of the coefficients on the log of the short rate 

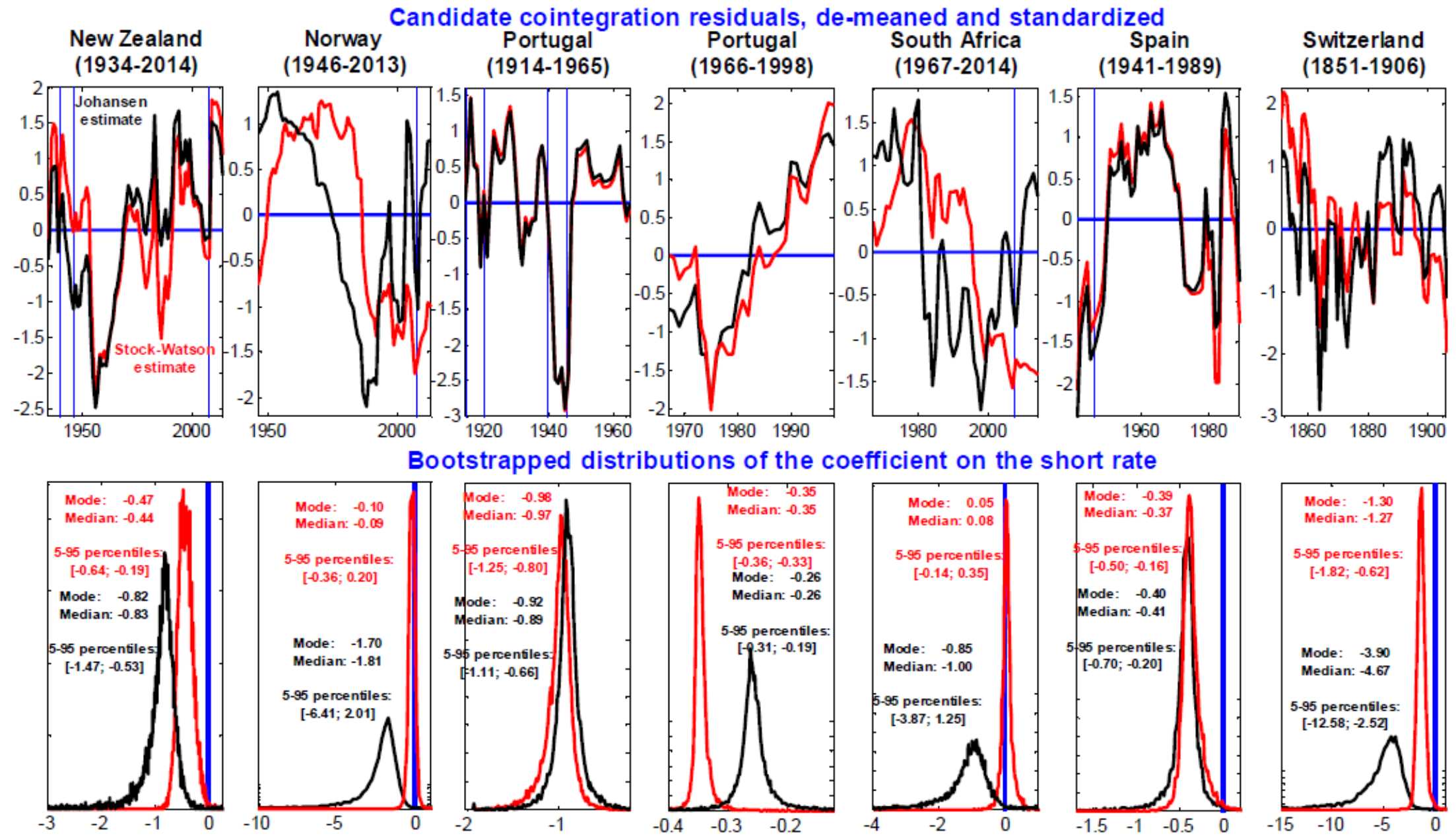

Figure LLCO.4 Log-log specification with the $1 \%$ correction to the short rate, imposing unitary income elasticity: cointegration residuals and bootstrapped distributions of the coefficients on the log of the short rate 


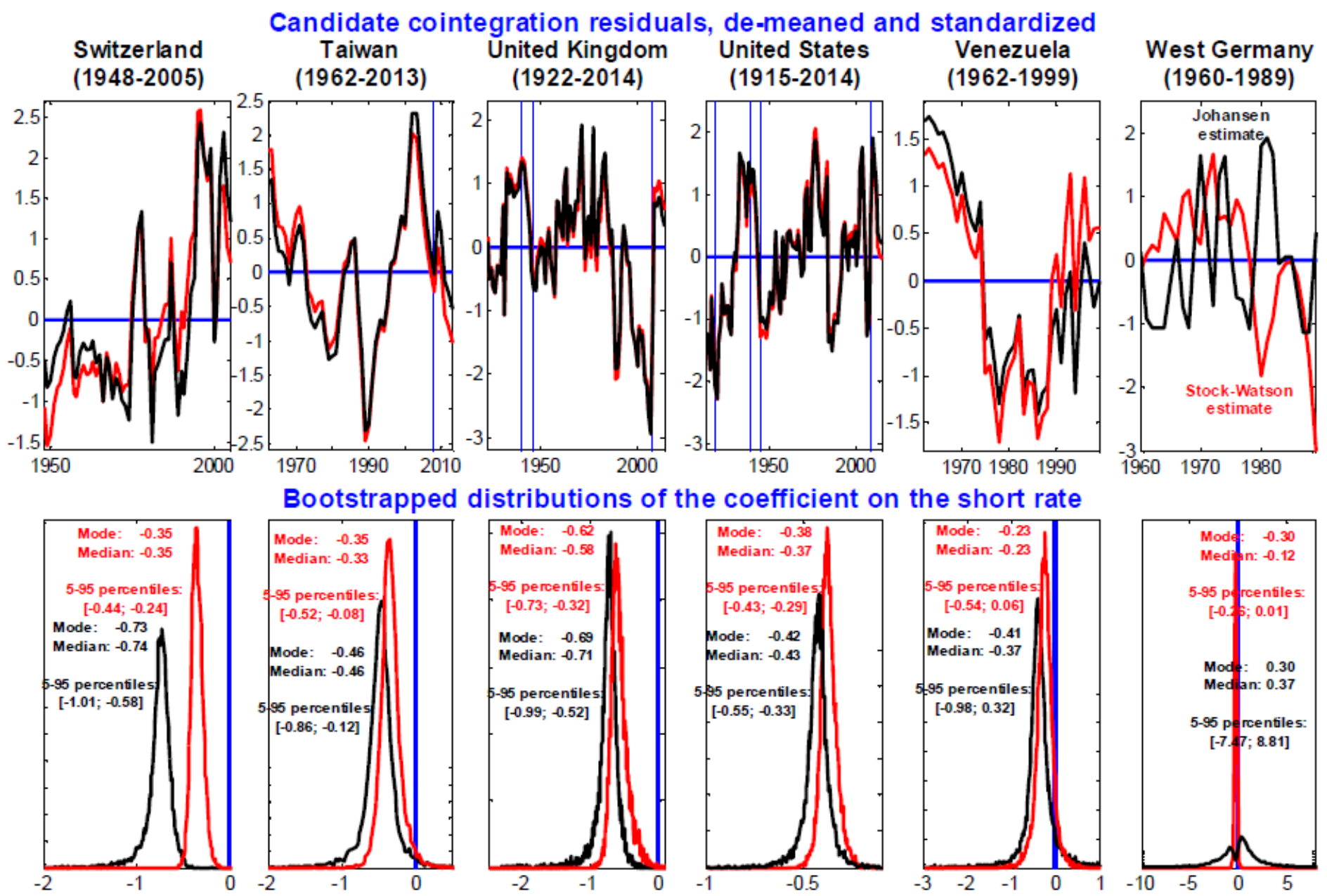

Figure LLCO.5 Log-log specification with the $1 \%$ correction to the short rate, imposing unitary income elasticity: cointegration residuals and bootstrapped distributions of the coefficients on the log of the short rate 